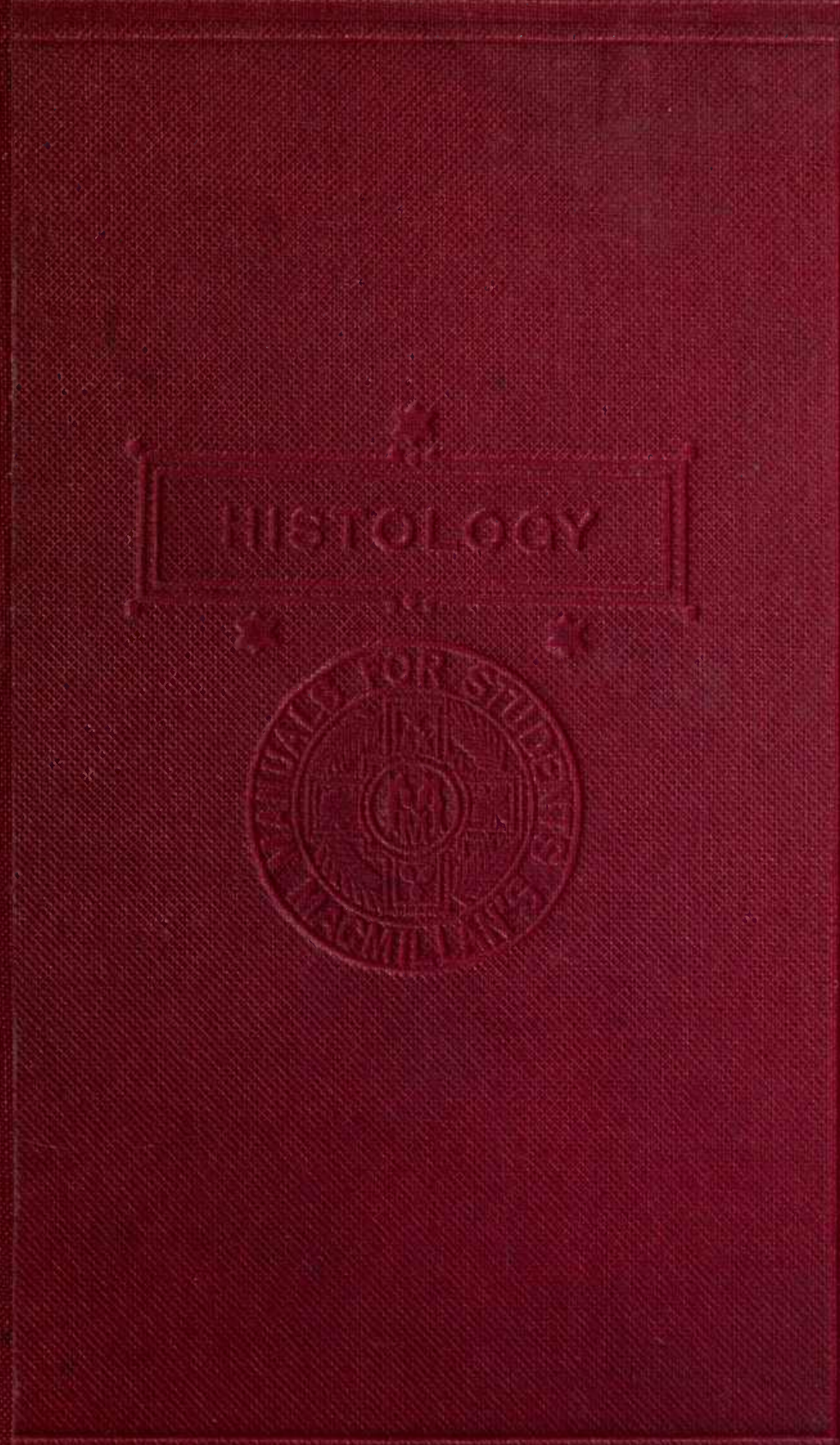




\section{LIBRARY}

OF THE

\section{UNIVERSITY OF CALIFORNIA.} BIOLOGY LIBRARY G Class

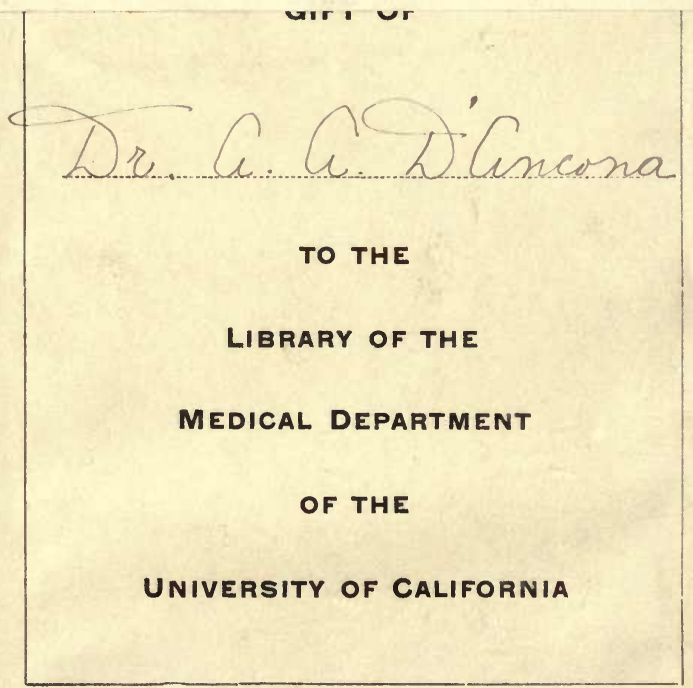




PRACTICAL HISTOLOGY 


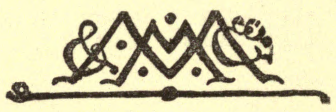

$+$ 


\section{PRACTICAL}

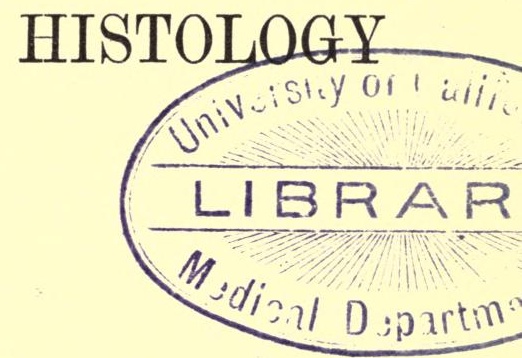

BY

\section{J. N. LAANGLEY, M.A., Sc.D., F.R.S.}

FELLOW AND LECTURER OF TRINITY COLLEGE, LECTORER ON HISTOLOGY, AND DEPUTY PROFESSOR OF PHYSIOLOGY, IN THE UNIVERSITY OF CAMBRIDGE.

I OnDon

MACMILLAN AND CO., Limited

NEW YORK: THE MACMILLAN COMPANY

1901

[All Rights reserved.] 


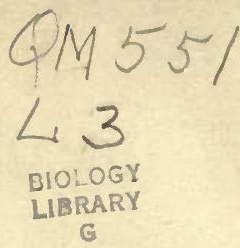

Cambriage:

PRINTED BY J. \& C. F. CLAT, AT THE UNIVERSITY PRESS. 


\section{PREFACE.}

THIS book has had its origin, on the one hand in 1 the directions for practical work which I have had printed these twenty years for the guidance of students attending my course of Practical Histology, and on the other hand, in the directions and descriptions for elementary students which I have from time to time inserted in the Practical Physiology and Histology of Professor Sir M. Foster and myself. The histological account given in the last Edition of the Practical Physiology and Histology has been, in large part, transferred to this book with such modifications as seemed necessary; and the more advanced work has been added to it.

The methods which I have tried, I have generally taken from the original sources. But I have not always done this, since in a work of this kind the Authors' names can rarely be given with advantage to the student. I wish to acknowledge my indebtedness to the Abstracts published in the Zeitschrift f. Wissenschaft- 
liche Microscopie and to the able account given by Lee in the Microtomist's Vade Mecum. I have also at times made use of Schäfer's Practical Histology and of Stirling's Outlines of Practical Histology.

It is a pleasure to thank my friend $\mathrm{Dr} \mathrm{H}$. K. Anderson for his help in testing the unending suggestions which are made for modifications in procedure.

Nearly all the methods which are given here have been tried sufficiently often to allow some confidence that the student who follows the directions will not fail of a good result. There are commonly several other methods by which a result nearly as good, and in other hands possibly better, may be obtained. Some of these are given in the Notes and in the Appendix; to have dwelt at length upon them would I think have been but a vain thing, tending to make the manipulation too much of an end in itself.

In a few cases, no method has seemed to me satisfactory, and I have been driven to choose between silence and prolixity. It will I hope be felt that I have usually chosen the former.

J. N. LANGLEY. 


\section{CONTENTS.}

LESSON

PAGE

I. Notes on the use of the Microscope. . . 1

II. Structure of the Blood and Lymph Corpuscles of the Frog . . . . . . . . 10

III. Blood Corpuscles of Man. Structure. Counting 21

IV. Measurement of Objects under the Microscope . 30

V. Staining and Mounting un-imbedded specimens . $\quad 35$

VI. Staining and Mounting Sections imbedded in Paraffin . . . . . . . . . 43

VII. Section Cutting and Imbedding. . . . $\quad$. 49

VIII. Rapid Hardening. Staining in Bulk • . 61

IX. Hyaline Cartilage . • • . . . 64

X. Connective Tissue . . . . . 70

XI. Fibro-Cartilage. Elastic Cartilage. Bone. Teeth 81

XII. Ciliated Cells. Unstriated and Cardiac Muscles 92

XIII. Striated Muscle • • • • • • • $\quad 99$

XIV. Nerve Fibres . $\quad . \quad$. $\quad . \quad$ • 107

XV. Peripheral Ganglia and Nerve Cells . • • 116

XVI. Endings of Nerve Fibres in Muscle . • . 125

XVII. Structure of Blood Vessels. Circulation. Inflammation . . . . . . . 133

XVIII. The Lymphatic System . . . . . 143

XIX. The Spleen . . . . . . . 150

XX. Salivary Glands . . . . . . . 156

XXI. Esophagus and Stomach . . . . . 165

XXII. The Intestine . . . . . . . 172

XXIII. Pancreas and Liver . . . . . . 180 
XXIV

The Lung

XXV. The Kidney . . . . . . . 193

XXVI. The Ductless Glands . . . . . 202

XXVII. Skin. Endings of Sensory Nerves . . . 207

XXVIII. Organs of Taste and Smell . . . . 216

XXIX. The Eye . . . • • • . . 221

XXX. The Internal Ear . . . . . . 229

XXXI. The Spinal Cord . . . . . . 233

XXXII. The Spinal Bulb . . . . . . 250

XXXIII. The Mid-brain and Inter-brain . • . 263

XXXIV. The Cerebellum. Cerebrum . • . . 272

XXXV. Reproductive Organs • • • • . 276

XXXVI. Cell-Division • • . . . . . 286

\section{APPENDIX.}

SEC.

PAGE

I. Observation of Fresh Tissues. Dissociation. Teasing

291

II. Methods of Hardening and of Preserving Tissues . 295

III. Imbedding and Cutting Tissues in Celloidin . 303

IV. Staining Fluids . . . • . . . 307

V. Transferring Sections. Fixatives. Fluids for Mounting . . . . . . . . 313

VI. Treatment with Silver Nitrate and Gold Chloride? 316

VII. Treatment of living Tissues with Methylene Blue. 321

VIII. Sorne Methods for Special Chemical Constituents (Iron, Phosphorus, Fat, Mucin, Chitin, Pigment, Amyloid Substance) • • • • • • . 324

IX. Injection Mass . • • • • • • 328

X. Methods of pithing. Tables . . . . . 330

INDEX 


\section{LESSON I.}

\section{THE USE OF THE MICROSCOPE.}

1. Examine the microscope. It has probably two eye-pieces or oculars, No. 2 and No. $4^{1}$, and two objectglasses or objectives $\frac{2}{3}$ rd inch and $\frac{1}{6}$ th inch ${ }^{2}$.

The tube which carries the lenses is in some microscopes moved towards or away from the stage by a rack and pinion, in others simply by twisting it up or down in a second tube. In the latter case see that the microscope tube twists easily; if it does not, clean the tube thoroughly. When the microscope tube is moved in this way, the coarse adjustment is said to be used.

The tube can also be moved up or down by turning a milled head at the top of the pillar of the microscope. Turn the milled head, and note that turning it in the direction of movement of the hands of a watch lowers the microscope tube, and turning it in the contrary direction raises the tube. When the microscope tube

1 Eye-pieces of the same magnifying power are differently named by different makers, and some name them $A, B, C$, etc.

2 In Zeiss' microscope, objectives $A$ and $D$ correspond to the $\frac{3}{4}$ th and $\frac{1}{6}$ th inch respectively.

L. 
is moved in this way, the fine adjustment is said to be used.

2. A mounted specimen. ${ }^{1}$ is given you for examination, the piece of glass on which it is placed is the slide, the thin piece of glass covering the specimen is the cover-slip.

Screw the $\frac{2}{3}$ rd inch objective on to the microscope and put the longer ocular, No. 2, into the tube. Dust the mirror, if that is necessary: use the concave mirror if there is no sub-stage condenser; use the flat mirror if there is a sub-stage condenser. Place the slide on the stage of the microscope so that the specimen is on the centre of the hole in the stage.

Lower the tube by means of the coarse adjustment, so that the lower lens of the objective is about half-aninch from the specimen; look through the ocular, and shift the mirror till the maximum amount of light is obtained; use a diaphragm beneath the stage with an aperture nearly as large as that in the stage. Look through the ocular again and slowly lower the tube until the specimen comes into view; focus with the fine adjustment till the maximum distinctness of the specimen is obtained. Note carefully the distance of the lower end of the object-glass from the specimen.

Substitute ocular No. 4 for ocular No. 2, and lower the tube with the fine adjustment, until the specimen is again distinctly seen; the magnification will be greater than with ocular No. 2.

The magnification of the $\frac{2}{3}$ rd objective with the lower ocular will probably be 60 to 70 diameters, with

${ }_{1}^{1}$ This may be a section of tissue with blood vessels injected, e.g. of kidney. 
the higher ocular 90 to 100 diameters. Examination with a magnification not greatly outside these limits is spoken of as examination under a low power of the microscope.

3. (a) Substitute the $\frac{1}{6}$ th inch object-glass for the $\frac{2}{3}$ rd inch; and the No. 2 ocular for the No. 4 . Lower the tube with the coarse adjustment until it is about $\frac{1}{8}$ inch from the cover-slip. Use a diaphragm with a small aperture, and adjust the mirror so as to obtain as much light as possible. Look through the ocular, and slowly lower the tube with the fine adjustment, until the specimen is brought into view.

It aids in catching sight of the specimen, if the slide is moved a trifle to and fro, as it is being brought into focus.

When the specimen is in focus, note carefully the distance of the object-glass from the cover-slip.

Substitute ocular No. 4 for ocular No. 2; focus with the fine adjustment, and note the increase in magnification, and the decrease in the amount of light in the field.

The magnification of the $\frac{1}{6}$ th obj. with the lower ocular will probably be 250 to 280 diameters, with the higher ocular about 400 diameters. Examination with a magnification of about 250 or more is spoken of as examination with a high power of the microscope.

(b) Raise the tube, then looking from the side, lower the tube with the coarse adjustment until the object-glass nearly touches the cover-slip. Look through the ocular, and slowly raise the tube by the fine adjustment until the specimen is focussed. 
If the specimen is transparent this method is much safer than (a).

Great care should be taken to avoid lowering the objective upon the mounted specimen, since this may force the front lens out of position. If the front lens is thus decentred, the objective should be sent back to the maker to be re-set. The high power should not be used for thick objects.

When the section is very transparent, the edge of the cover-slip-supposing this is not surrounded by a projecting rim of balsam or glycerine-may first be focussed to find the level of the cover-slip, and then the slide moved about till a faint shadow of the section is seen.

Before removing the slide from the stage, raise the microscope-tube, in order to avoid the chance of the front lens being brought into contact with mounting or cementing material at the edge of the cover-slip. In no case must a second specimen be placed under the high power without raising the microscope-tube, since the glass slides are not of constant thickness.

The microscope should never be left with the objective on, and the ocular out, or dust will settle on the upper lens of the objective.

After using the microscope put it back in the box, or cover with a bell-jar.

The student should accustom himself to keeping both eyes open when using the microscope.

4. Use of diaphragm. A diaphragm is used to cut out the peripheral rays of light which are not brought to the same focus as the central ones. 
A mounted specimen is given you which is but faintly stained. Focus it under the high power of the microscope, as in $\S 3(b)$. Take away the diaphragm, and notice that although there is more light in the field of the microscope, the outlines of cells and fibres are less sharp and distinct (especially with a sub-stage condenser). Try diaphragms with different sizes of aperture, and note which gives the best definition.

When it is desired to see chiefly or solely stained structures in the specimen no diaphragm should be used; the stained parts are then conspicuous, whilst the unstained parts are barely seen' ${ }^{1}$.

5. Sub-stage Condenser. If the microscope has a sub-stage condenser, raise this so that its upper surface is level with the stage when using a high power; when using a low power, lower the condenser till it is the same distance below the specimen as the object-glass is above it.

6. Nose-piece. Screw about two-thirds of the screw of the nose-piece into the microscope tube. (Do this on the tube withdrawn from the microscope, if it has a rack and pinion movement.) Then place the nose-piece so that the free end is opposite the rack of the tube, and screw the nose-piece home by turning the screw in the nose piece itself.

Put on the two objectives. Focus a specimen with the low objective. Turn the high objective slowly round, note whether it touches the cover-glass; if it does, raise the tube a little before turning the high

1 A teased osmic acid specimen of small medullated amongst nonmedullated nerves may be given to show this. 
objective into position, and remember to do this always when shifting from the low to the high power. In shifting from one objective to the other, see that the one in use is properly centred; focus a specimen with one objective, then move it a little way from the stop and note the difference in the appearance and illumination of the specimen.

7. When the definition of a section is not good, examine the slide and cover-slip, the upper and lower lenses of the ocular and the front surface of the objective to see that all of these are clean. Specks of dirt on the lenses of the ocular will of course move on turning round the ocular; and specks of dirt on the specimen on moving the slide.

A piece of soft chamois leather and a piece of silk should be kept in a small dust-tight box, for the purpose of cleaning the lenses; if this is not at hand, the cleaning should be left to the attendant.

Dust on the lens should be removed by lightly flicking it with silk.

Glycerine or any aqueous solution should be removed by streaming the surface with water from a wash-bottle, and then dabbing it lightly with silk or chamois leather to dry it.

Canada balsam, turpentine, clove oil, grease should be removed by placing a drop of xylol or benzine on the surface of the lens; dabbing this with silk, and repeating the process several times.

8. Thickness of cover-slip. Use of higher objectives. Objectives are generally corrected for a cover-glass of medium thickness; $(0.15$ to $0.2 \mathrm{~mm}$.), and cover-slips thicker than $0.2 \mathrm{~mm}$. should 
not be used. With $\frac{1}{8}$ th, or higher dry, or water immersion objectives the definition is much better with a cover-glass the thickness for which the lenses are corrected; this is sometimes marked on the objective. Some objectives are supplied with a correction collar, so that they can be adjusted to cover-glasses of different thicknesses. With homogeneous immersion lenses, the thickness of the cover-slip within ordinary limits makes no difference to the definition.

Before using a high objective, see not only that the cover-slip is not abnormally thick, but also that the object and the layer of balsam is thin, otherwise in focussing the deeper parts of the object, the front lens of the objective may be forced down on the slip, and put out of position.

9. Oil-immersion lenses. Place on the cover-slip and in the centre of the field, a small drop of the oil prepared for the lens. Lower the tube of the microscope slowly until the lens just touches the oil, observing this from the side. Then focus with the fine adjustment. After use, dab the surface of the lens with clean tissue paper to remove most of the oil, touch the surface with a brush dipped in xylol or benzol, and remove this gently with dust-free silk, repeat the cleaning with xylol or benzol and put away the lens.

10. Measure the thickness of half-a-dozen cover-slips with the 'cover-slip measurer.' 


\section{NOTES.}

High power objectives are adjusted either for a tube $160 \mathrm{num}$. ( $6 \frac{1}{2}$ inches) long (continental length) or for a tube 10 inches long (usually called English length; it is however now only made for special purposes). The definition of the objective suffers the more the proper length is departed from. Thus if a nose-piece is used, a correction in length is required, as by cutting down the brass mount of the objectives.

Objectives are generally named according to their equivalent focal distance, as $\frac{1}{2}$, $\frac{1}{6}$ inch : $12 \mathrm{~mm}$., $4.3 \mathrm{~mm}$. and so on: An objective consists of more than one lens; its equivalent focal distance is the focal distance of a single lens which has the same magnifying power as the objective, so that lenses of the same equivalent focal distance have the same magnifying power.

The angle of aperture is the angle which the outermost rays, passing from a point and through the outermost edge of the lens, form with one another. The greater the angle the more the object is seen from all sides.

The numerical aperture $=n \sin u$, where $n$ is the index of refraction of the medium in front of the objective (as air, water, or oil), and $u$ is the sine of half the angle of aperture. Other things being equal the brightness of the image and the definition of the object increases, the focal depth decreases, with increase of numerical aperture.

Achronatic objectives and Huyghenian eye-pieces were, till recently, the only ones ordinarily used. The achromatic objectives made with the new Jena glass are sometimes called semi-apochromatic objectives.

Apochromatic objectives and compensating eye-pieces form a more perfectly achromatic system than the foregoing. In the apochromatic len', three colours are brought to a focus instead of two, and there is cor plete colour correction for all zones instead of for one only. With any one objective and eye-piece in this system, the object is very nearly in focus with all the other eye-pieces.

Homogeneous oil-immersion objectives may be either achromatic or apochromatic, they can be made with a greater numerical aperture than the other objectives.

The initial magnifying power of an objective is the magnification which it gives at the distance of distinct vision ( $250 \mathrm{~mm}$. and 10 incheș) 
if considered as a single lens. This can be obtained by dividing 250 by the equivalent focal distance in millimetres, or 10 by the focal distance in inches. Thus if the focal distance is $4 \mathrm{~mm}$., the initial magnifying power is 62.5 , and if the focal distance is $\frac{1}{4}$ inch, the initial magnifying power is 40 . The compensating oculars of the apochromatic objectives are named $6,8,12$ etc. according to their magnifying power. Thus the magnifying power of no. 6 ocular with objective $4 \mathrm{~mm}$. is 375 .

By working distance is usually meant the distance between the front of the objective and the cover-slip, when the objective is focussed for an object on the lower surface of the cover-slip (this being of medium thickness). 


\section{LESSON II.}

\section{STRUCTURE OF THE BLOOD AND LYMPH CORPUSCLES OF THE FROG.}

1. A frog is given you the brain and spinal cord of which have been destroyed (cp. p. 330). Take the frog in one hand, and with a stout pair of scissors cut off a foot at the ankle-joint. Touch a clean slide with the cut surface, so as to leave a small drop of blood on the slide. Place on it a cover-slip.

Later, drops of fresh blood should be obtained by cutting off the other foot, the leg at the knee, the fore arm at the elbow-joint. Lastly, blood should be obtained direct from the heart; in order to do this cut through the skin in the median ventral line, cut transversely through the lower part of the sternum just above the epigastric vein, with stout scissors cut through the sternum in the middle line and so expose the heart; cut off the tip of the ventricle, and touch a slide with it. For $\$ 5,6,8$, blood which has flowed from one of the cut surfaces will serve.

Examine the mounted drop of blood under the 
microscope with a low power ${ }^{1}$ and observe the numerous corpuscles floating in the plasma.

Examine it with a high power ${ }^{1}$ and observe the red corpuscles; if a large drop of blood has been taken the corpuscles will overlap one another, in which case another preparation should be made with a smaller drop.

a. The red corpuscles are flattened ellipsoids; note their spindle shape when seen on edge as they roll over. The great majority are of the same size and tint.

b. They appear at first homogeneous, but soon a certain number show a central paler oval nucleus.

c. A single corpuscle is pale yellow; the colouring substance (hæmoglobin) is equally diffused throughout it; when several corpuscles lie over one another they together appear red.

2. Examine the colourless corpuscles in parts of the specimen where the red are not very numerous.

a. They are much fewer than the red. They are smaller than the red, but they vary in size.

$b$. They are usually spherical, when first mounted, but soon many of them put out processes and become irregular in form.

c. The majority have no distinct granules (hyaline corpuscles). Some have comparatively large and refractive granules; these are the coarsely granular corpuscles. The nucleus in these cells can seldom be made out (cp. § 15).

1 In later sections low power and high power are abbreviated to (l. p.) and (h. p.). 
d. Choosing a corpuscle, either elongated or having several processes, watch carefully its amœboid movements; make half-a-dozen drawings of its outline at intervals of about twenty seconds. As a rule the coarsely granular corpuscles put out few and rounded processes, and the finely granular corpuscles put out more numerous and more pointed processes.

e. If it is desired to watch the movements for an hour or so the drop should be protected from evaporation. (a) Melt a little glycerine jelly (cp. App. p. 314) on a warm bath, keep the cover-slip in place by gently holding a lifter against one edge, and with a small brush, brush a little glycerine jelly over the edges all round. ( $\beta$ ) If the slide is to be warmed, use melted paraffin (of low melting point) instead of glycerine jelly. Before applying the paraffin, dry the slide at the edges of the cover-slip with blotting-paper, and warm the slide. Olive oil may be used instead of glycerine jelly or paraffin.

3. a. Hanging drop. Cut out a number of pieces of blotting-paper about $3 \mathrm{~cm}$. by $2 \mathrm{~cm}$. Place them together so as to make a pad. With scissors or cork borer cut out from the centre of the pad a hole a little smaller than the cover-slip to be used. Dip the pad in salt solution 0.6 p.c. and place it on the slide. On the centre of a cover-slip place a small drop of lymph, and lower the cover-slip over the hole in the pad, so that its edges touch the blotting-paper all round, and the drop hangs in the centre and does not run off to the pad. Thus a small moist chamber is formed. The pad should be kept wet by adding a little water to one edge from time to time. Examine the movements of the white corpuscles under the microscope.

b. Lymph crowded with white corpuscles, many in active movement, may be obtained in the following way. The brain of 
a frog is destroyed, and the wound plugged with cotton-wool. A drop of curari is injected under the skin; this paralyses the lymph hearts, so that the lymph accumulates in the lymph sacs. The frog is kept in a dish containing water about $\frac{1}{4}$ inch deep, for half-a-day to a day. Lymph may be obtained from any of the lymph sacs, but, if the frog has been placed in a normal position, in especial quantity froin the ventral sacs, beneath the skin of the abdomen. Since the lymph clots quickly when withdrawn, not more should be taken up in the pipette than is required at the time.

4. a. Place on a cover-slip a small drop of lymph, with a needle take a little eulture of a large bacillus (e.g. b. filamentosus), and stir it into the drop. Examine as in $\S 3$. White corpuscles will be seen to attach themselves to the bacilli, some crawling over the bacilli, others ingesting them.

b. The white corpuscles which have ingested foreign particles will be seen, if a drop of milk or if a drop of water containing hay bacillus, or Indian ink, be injected into a lymph sac about an hour before examining the lymph.

5. Irrigation. Cut a triangular piece of blottingpaper, cut away one of the angles and apply the cut edge to the middle of one edge of the cover-slip; place a small drop of 1 p.c. acetic acid on the slide near the opposite edge of the cover-slip, and lead it with a needle to the edge taking care that the fluid does not run on to the upper surface of the cover-slip. Note the changes which take place as the acetic acid mixes with the blood.

a. In the colourless corpuscle, the cell substance becomes more transparent but shows some irregular granules; a granular nucleus comes into view. As a rule the nucleus is somewhat crescent-shaped in 
the coarsely granular cells; and is round or consists of clumps connected by thin threads in the hyaline cells.

$b$. In the red corpuscles the nucleus becomes obvious; it is when first seen nearly homogeneous, and oval in outline, later it becomes granular and usually irregularly rod-shaped.

The red corpuscles swell up owing to absorption of water, most after a time become spherical (if strong acid be used the corpuscles usually preserve their shape).

They become colourless, the hæmoglobin being dissolved from the stroma; occasionally the hæmoglobin is massed round the nucleus before complete solution takes place, and occasionally it stains the nucleus yellow.

Finally the outline of the corpuscles is seen as a faint line at some distance from the nucleus. Observe the not infrequent excentric position of the nucleus.

Some corpuscles are much more readily acted on than others.

6. Irrigate a drop of blood, first with 30 or 50 p.c. alcohol and then with a 5 p.c. solution of Spiller's purple in water or in 30 p.c. alcohol.

The red corpuscle becomes spherical and its peripheral rim, the pseudo-membrane, stains; the stain is but slight in the corpuscles which have been much exposed to the dilute alcohol. The nuclei both of the red and of the colourless corpuscles stain deeply.

7. Place several very small drops of blood two or three mm. apart on a slide and leave for a few minutes, then cover with a cover-slip, and put under a high 
power. Take a little blood from a freshly killed frog and establish a current underneath the cover-slip from one side of it to the other (cp. §5). The first small drops will have partially clotted and will serve as an imperfect barrier to the corpuscles in the current; in such places note that the shape of the red corpuscles is easily changed and recovered, and that the colourless corpuscles stick to one another and to the glass more than do the red. After the current has passed for a short time largish clumps of colourless corpuscles will be seen.

8. Evaporate to dryness on a slide a drop of a saturated solution of urea; on this place a small drop of blood, mount at once, press down the cover-slip, and observe the breaking up of the red corpuscles into spheres; sometimes a corpuscle will put out a varicose filament which breaks up later into spheres.

9. Action of boracic acid. Let a little fresh blood of a frog or newt run into about five times its volume of a 2 p.c. aqueous solution of boracic acid, and mount at once a drop of the mixture. The corpuscles, nearly normal in appearance when first mounted, rapidly become altered ; in all or nearly all cases the hæmoglobin leaves the stroma or the outer part of it, and becomes accumulated around the nucleus. As this is taking place the hæmoglobin may form a star-shaped figure in the stroma; from some corpuscles, but as a rule, from a few only, the mass formed by the nucleus with the hromoglobin is extruded.

10. Dilute a little fresh blood with twice its volume of 6 p.c. salt solution; mount a drop of the mixture and place it aside for an hour or so to clot; irrigate it with 30 p.c. alcohol and then with Spiller's purple dissolved in water or in dilute alcohol. Note the deeply stained network of fibrin fibrils and the numerous long threads of fibrin running from the broken-down colourless corpuscles. 
11. Irrigate a drop of blood with 95 p.c. alcohol; a granular precipitate will be formed in the stroma. Irrigate with Spiller's purple, the precipitate will stain deeply.

12. Preparation of a dry film of blood. In order to obtain an evenly spread film, the cover-slips must be clean ${ }^{1}$, they should be picked up with forceps; they may be held by opposite edges between finger and thumb, but not by the surfaces. Make film preparations in the following ways.

a. Have two clean cover-slips ready. Hold one with smooth-point forceps, and touch a little blood flowing fresh from the vessels so that a small drop is obtained on the centre of the glass, place on it the other cover-slip, and in two or three seconds withdraw one laterally. The cover-slips should not be pressed together, nor turned round on one another, nor should one be lifted from the other. It is not necessary that there should be blood over the whole of the surface. Wave the slips in the air so as to dry the films as quickly as possible.

b. Take a drop of blood as in (a) and with the surface of a glass rod, spread it over the cover-slip, removing any excess by using a fresh part of the glass rod. Dry, by waving the slip in the air.

The small drop of blood may be obtained from a limb, (\$1), but for this purpose the skin of the limb should be first removed, since

1 New cover-slips may be cleaned in the following way. Place for an hour or more in a mixture of 5 grams bichromate of potash, 40 c.c. water, 5 c.c. strong sulphuric acid, shake at intervals, wash in running water, place in strong spirit, remove to strong spirit (or absolute alcohol) for an hour to a day, and then in ether for an hour to a day, place on clean white paper on a smooth hard surface and rub with a dry piece of clean silk or linen. 
there is usually some lymph under it, and this will dilute the blood, besides adding small finely granular basophil and other cells to the drop. If pure blood from the heart is required the pericardial fluid should be washed away with salt solution before the heart is cut, and the salt solution sopped up with blotting-paper; the pericardial fluid contains a considerable number of small finely granular basophil cells.

The dry film should be examined (h.p.) before staining; if the outlines of the red corpuscles are indistinct, another film should be prepared.

13. Staining a film with eosin. See that 3 small wide-mouthed bottles are ready, the first containing a saturated solution of eosin in 75 p.c. alcohol, the other two containing 75 p.c. alcohol. Have ready also a pad of half-a-dozen pieces of smooth filter or blotting-paper, without fluff. Take up the cover-slip by one corner with forceps, or fasten one corner into the end of a wooden match, (this corner should not be dipped in the fluids); hold it for a minute in the eosin solution, let the excess of fluid drain off (5 seconds), hold the cover-slip for 5 seconds in the first bottle of alcohol and for 5 seconds in the second bottle of alcohol. Then place without delay between the pads of filterpaper and lightly press, shift the cover-slip at once to a fresh place, and again lightly press. Wave the coverslip in the air to dry it. When dry place a small drop of Canada balsam on the centre of the cover-slip, and lower this slowly on a glass slide.

Note the deep red stain of the granules of the coarsely granular leucocytes (the oxyphil granules). The red corpuscles should be separate, of normal shape, with distinct outlines and rather deeply stained with eosin. 
The white corpuscles and platelets will be stained a light lake red, and their outline will not be very distinct.

14. Staining a film with eosin and methylene blue. Add to the bottles used in $\S 13$, two, one containing a saturated solution of methylene blue in 75 p.c. alcohol, the other 75 p.c. alcohol. Proceed as in $\$ 13$, but after the cover-slip has been placed in the second alcohol hold it for 20 seconds in the methylene blue, dip it (half a second) in the 75 p.c. alcohol, then without delay press lightly between the blotting pads, dry and mount. The nuclei of the various cells will be stained blue. Note

a. The shape of the nuclei of the white corpuscles $(\S 5, a)$, and the bright red stain of the granules of the coarsely granular cells.

Some of the hyaline cells will probably have fragmented nuclei; the cell-substance has usually a faint brownish red stain.

b. The finely granular basophil cells; these consist of a small amount of cell-substance, containing small granules stained deep blue, and of a round feebly stained nucleus. A few only are present in blood free from lymph.

c. The swollen and partially disintegrated platelets; both cell-substance and nucleus (probably round) have a feeble blue stain, and the two may be indistinguishable. Some may be preserved in their normal form, in which case they take a fairly deep stain.

The corpuscles may be fixed before staining by one of the methods given in Lesson iII. for human blood.

15. Platelets. Mount a small drop of blood direct from the blood vessels or from the heart (cp. $§ 1$ ). 
Examine at once. Note the elongated pale cells (platelets) about $\frac{1}{3}$ the size of the red corpuscles. Some are found singly, others sticking together in groups. The nucleus can generally be made out, it is large in comparison with the amount of cell-substance. The nucleus soon becomes round and the cell-substance indistinct.

16. Examine (h. p.) a drop of fluid containing blood stained with methyl-violet. The nuclei of all the elements of the blood are stained rather deeply; the cell-substance of the white corpuscles and of the platelets takes a light stain.

The fluid is obtained as follows: Let a drop of fresh blood of a frog or newt fall into 5 c.c. of a filtered mixture containing 0.6 p.c. $\mathrm{NaCl}, 0.6$ p.c. peptone and 0.02 p.c. methyl-violet, stir at once. Place the mixture in a small glass tube and centrifugalize for a few minutes, pour off about 4 c.c. of the fluid. Shake up the rest and examine a drop. The platelets are preserved for some hours, but soon the nucleus becomes round, the cell-substance puts out hyaline blebs, and in time the cell disintegrates. In the absence of a centrifugal machine the mixture should be allowed to stand for an hour, and the lower layers taken for examination.

17. The platelets and other corpuscles of the blood are best preserved by allowing a drop of blood to run into 5 c.c. of a mixture containing 0.5 p.c. osmic acid, and 0.75 p.c. $\mathrm{NaCl}$.

The mixture is centrifugalized, most of the supernatant fluid poured off, the corpuscles shaken up in the remainder. If a little of this be examined, the platelets are seen to be elongated and the white corpuscles for the most part spherical.

A film preparation may be made by spreading a drop on a coverslip, and drying it on a warm bath. It can be stained and mounted in the usual way, but the staining of the various cells differs but little and is predominantly basic, so that the time of stay in the basic-stains must be lessened.

The cells may be stained in bulk, either with stains soluble in 
water, or with stains soluble in alcohol, by making use of the centrifugal machine ${ }^{1}$ to separate them from each fluid added.

\section{DEMONSTRATION.}

Circulation of blood in the mesentery of the newt to show the platelets sticking for a variable time to the walls of the vessels (cp. Lesson on the Circulation).

1 A convenient form of centrifugal machine is the 'High-speed Medical Centrifuge' obtainable, with a description of method of use, from most Opticians. 


\section{LESSON III.}

\section{BLOOD CORPUSCLES OF MAN. STRUCTURE. COUNTING.}

1. With a sharp needle prick the finger either at the tip, or a few millimetres from the root of the nail (the finger should be perfectly clean); touch with the centre of a cover-slip the drop of blood which issues; lower the cover-slip on a slide. Observe the red corpuscles.

a. They roll about readily when the cover-slip is lightly touched. Soon after being taken from the body they stick to one another, and, owing to their shape, usually in rouleaux.

$b$. They are biconcave discs. Note that on focussing down on the circular face a darkish centre and a light rim is first seen and then a light centre with a darkish rim: when viewed in profile and the centre focussed they appear somewhat dumb-bell shaped.

c. They appear homogeneous, their colour is like that of the red blood corpuscles of the frog (cp. Less. II. $§ 1, c)$. 
d. Towards the outside of the drop, where evaporation is going on, many of the red corpuscles are crenate.

e. They are much smaller than the red corpuscles of the frog.

2. Observe the colourless corpuscles. Most are larger than the red, they resemble in general appearance the white corpuscles of the frog; to observe their amœboid movements a drop should be protected from evaporation (Less. II. $\S 2, e$ ) and warmed to the temperature of the body.

Irrigate with ־ p.c. acetic acid (cp. Less. II. § 5 ).

a. The red corpuscles swell up and become spherical, their hæmoglobin is dissolved, leaving the hardly visible stroma. (The same effect is produced by water.)

b. No nucleus is brought into view.

c. In the white corpuscles the cell-substance becomes more transparent, and the nucleus comes into view (cp. §3).

3. Prepare two dry films of blood (cp. p. 14). Place the cover-slips film uppermost on a slide, and examine (h.p.); if there is a yellowish tinge of hæmoglobin between the corpuscles or if the outlines of the red corpuscles are indistinct, the films should be thrown away and fresh ones made. Stain one film with eosin (cp. p. 15) and the other with eosin and methylene blue (cp. p. 16). 
The film should be examined (h. p.) dry, after staining and before mounting; if the staining is too faint, it should be placed for a few seconds in the eosin or methylene blue; if the stain is too deep, it should be placed for a second in 75 p.c. alcohol.

Observe in the film stained with eosin and methylene blue the following forms of white corpuscles.

a. The finely granular cells (polynuclear corpuscles); they are larger than the red corpuscles, they have rather deeply stained irregular or fragmented nuclei; their cell-substance has small eosin stained granules. Ordinarily, about 75 p.c. of the white corpuscles are of this kind.

b. The large mononuclear cells; they also are larger than the red, the cell-substance has a faint blue stain without distinct granules, the nucleus is round and is not deeply stained.

c. The small mononuclear cells (lymphocytes); these are about the same size as the red, the cellsubstance stained a faint blue is small in amount, the nucleus is round and deeply stained.

\section{d. The coarsely granular cells, crowded with} granules stained deep red, and crescent-shaped nucleus, stained less deeply than those of the polynuclear cells. Probably one or two only will be seen.

When these corpuscles are obtained in their spherical form, the granules are less striking than when they are flattened. If the blood is exposed for a short time before the film is made, the coarsely granular cells may be the only ones obtained separately, such other colourless cells as have not disintegrated being present in clumps. 
e. Some faint blue masses arising from the platelets; these are not always seen as they quickly disintegrate.

4. Fixing corpuscles by heat before staining. The hæmoglobin is dissolved out of the red corpuscles and the white corpuscles are more or less altered in films treated with staining fluids containing less than 75 p.c. alcohol. This sometimes occurs with the 75 p.c. alcohol stains. To avoid such alteration the corpuscles may be fixed by heat, before staining, thus :-

Place a dry film of blood for 2 to $5 \mathrm{~min}$. at a temperature of $110^{\circ} \mathrm{C}$. This may be obtained by placing a Bunsen flame under one end of a long strip of copper; the part of the strip which is at a temperature of $100^{\circ} \mathrm{C}$. can be determined by noting where a small drop of water boils; the specimen should be placed a little nearer the flame than this, the filmed side undermost. (Instead of this, the cover-slip is sometimes passed two or three times through the flame of a Bunsen burner.) The corpuscles stain somewhat better after fixing, but they are apt to shrink and leave a clear space around them.

The fixation of the hæmoglobin in the corpuscles may be observed later in sections of tissues hardened in osmic acid vapour, osmic acid, mercuric chloride dissolved in salt solution, Müller's fluid, formol.

5. Platelets. Kill a rat or mouse with chloroform. Expose the heart, and cut through the pericardium. Cut through the ventricle and let one drop of blood fall into 5 c.c. of $(a)$ osmic acid and salt (II. § 16), (b) methyl-violet solution (II. § 17), (c) 1 p.c. oxalate of potassium. Stir, centrifugalize, and examine a drop for platelets. They are small, colourless, oval bodies, $\frac{1}{4}$ to $\frac{1}{3}$ the size of the red corpuscles and without nuclei.

6. Wash the tip of the finger, place on it a drop of the methyl-violet solution or of the potassium oxalate solution. Prick the finger through the drop. As soon as blood comes transfer to a slide and examine. 
7. Enumeration of the red corpuscles. Count the number of red corpuscles with a Thoma hæmacytometer (Fig. 1).

In this the capillary tube $(t)$ (Fig. 1. A), up to the mark 1 contains $\frac{1}{10}$ th of the bulb $(b)$ between the marks 1 and 101 . On the disc (d) (Fig. 1. B), 1 square millimetre is divided into 400 squares, each $\frac{1}{20}$ th $\mathrm{mm}$. The piece of glass $(e)$ around this disc is $\frac{1}{10}$ th $\mathrm{mm}$. above it. Thus when the cover-slip is put on, the space between each square and the cover-slip is

$$
\frac{1}{20} \times \frac{1}{20} \times \frac{1}{10}=\frac{1}{4000} \text { cubic } \mathrm{mm} \text {. }
$$

See that the counting cell and the pipette are clean and have ready a large cover-slip and a watch-glass containing Hayem's fluid, which consists of 1 part of sodic chloride, 5 parts of sodic sulphate, 5 parts of corrosive sublimate in 200 parts of water.

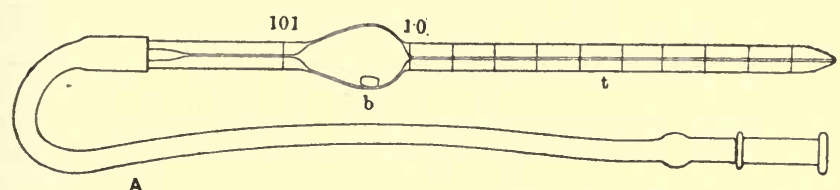

A

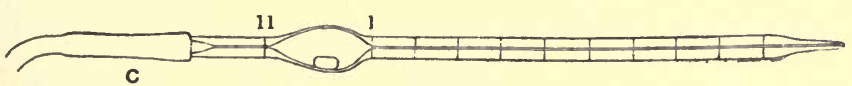

Fig. 1.

Prick the finger ${ }^{1}$ and when a sufficiently large drop of blood is obtained, gently suck blood into the pipette as far as the mark

1 The prick of a needle does not readily give sufficient blood; it is best to use the triangular needle or shielded lancet made for the purpose, and to thrust it suddenly into the finger. In obtaining blood from another person it may be obtained from the ear, as it is less sensitive than the finger but sufficiently vascular. 
1. With a cloth carefully remove any blood adhering to the point of the pipette. Slowly draw up Hayem's fluid, gently turning the pipette until the mixture is exactly at the mark 101. Put the finger on the tip of the pipette, leaving the capillary tube full of the diluting fluid, and by gently shaking thoroughly mix the blood and the fluid, taking care that the contents of the capillary tube are not drawn up into the diluting chamber. The blood is thereby diluted 1 in 100 . Allow the contents of the capillary tube, and a few drops of the diluted blood, to escape, and then at once carefully place a small drop of blood on the centre of the counting chamber. Put on the cover-slip by a sharp lateral thrust; this assures its close apposition to the wall of the chamber and Newton's colour rings should appear. Allow two or three minutes for the corpuscles to settle, then count the number of corpuscles in at least 10 adjacent squares, including in each square any corpuscles overlapping the upper and the left boundary lines but, by way of compensation, excluding those overlapping the lower and right boundary lines.

In order to facilitate the process of counting the squares are divided into groups by lines bisecting every fifth horizontal and vertical column of squares.

Determine the average number found for a square. Since the fluid on each square is $\frac{1}{4000}$ cub. mm. the average number of corpuscles found multiplied by 4000 gives the number in 1 cub. $\mathrm{mm}$. of the diluted blood, and 100 times this is the number in 1 c.mm. of the blood.

8. Enumeration of the white corpuscles. Dilute the blood 1 in 10 with the mixing pipette $C$, Fig. 1, using the same precautions as before, and taking care that a large drop of blood is collected before the point of the pipette is put into it. As diluting fluid use 5 p.c. acetic acid (coloured with methylviolet) since this renders the red corpuscles invisible. Count the number of white corpuscles lying on the large squares formed by the lines bisecting every fifth horizontal and vertical column of small squares. Count the number on ten of these large squares, using a rather low power unless the microscope is fitted with a mechanical stage. Calculate the average number for a 
large square. A large square has an area of $\frac{1}{16} \mathrm{sq}$. mm., the cubic content of the space above it is $\frac{1}{160}$ cub. mm. Hence the average number found multiplied by 160 gives the number in 1 cub. mm. of the diluted blood, and 10 times this is the number in $1 \mathrm{c.mm}$. of the blood.

9. If Gower's hæmacytometer is used proceed in the following manner.

Fill the larger pipette with Hayem's or other diluting fluid (cp. Notes) up to the mark on the stem, it then contains 995 c.mm.; empty it into the measuring glass. Fill the small pipette with freshly drawn blood up to the line marked 5 c.mm.; empty it into the measuring glass, and with the fluid in the measuring glass wash out the blood sticking to the inside of the tube; thoroughly mix the blood and diluting fluid with the glass spatula, place a small drop of the mixture in the centre of the glass cell and over it lay a cover-slip, arrange the springs on the cover-slip to keep it in position, and under a high power count the number of red corpuscles in ten of the squares which are marked at the bottom of the glass cell.

Since the depth of the cell is $\frac{1}{5} \mathrm{~mm}$. and the side of each square is $\frac{1}{10} \mathrm{~mm}$., there is beneath each square $\frac{1}{50} \mathrm{c.mm}$. of the mixture, i.e. $10 \frac{1}{10000}$ c.mm. of blood; hence the number of corpuscles in 10 squares multiplied by 10,000 gives the number of corpuscles in $1 \mathrm{c.mm}$. blood.

\section{DEMONSTRATION.}

Stage for varying temperature of hanging drop, and passing gases over it. 


\section{NOTES.}

The following solutions are used for staining films which have been fixed either by heat (cp. $\S 4$ ) or by fixing fluids (cp. below).

1. Hoematoxylin and eosin. Make Ehrlich's acid hæmatoxylin (cp. p. 307) dissolving 5 gram eosin in the water. Films stain in this in half-an-hour to two hours.

2. Chenzinsky's eosin and methylene blue.

Saturated aqueous sol. methylene blue 40 c.c. 0.5 p.c. eosin sol. in 70 p.c. alcohol Distilled water

20 "

40,

This stains slowly, requires several hours to a day; the fluid should be filtered before use.

3. Ehrlich's 'triacid' fluid. Add in order, shaking between each addition.

Saturated aqueous solution of Orange-G.

$\begin{array}{lr}\text { Distilled water } " \text { Acid Magenta } & 7 \% \\ \text { Absolute alcohol } & 15 " \\ \text { Saturated aqueous solution of methyl-green } & 25 " \\ \text { Glycerine } & 12.5 " \\ 10 "\end{array}$

This stains in about five minutes. It is chiefly used to distinguish 'neutrophil' granules staining violet, from oxyphil granules staining a brownish red.

Fixing wet films. In dry films, the white corpuscles and platelets are flattened; to avoid this the films are placed a second or so after they have been made with the film surface downwards, in a fixing agent.

The following fixing agent may be used : formol, 10 parts, 95 p.c. or absolute alcohol, 90 parts. In a little of this fluid the cover-glass is placed, film surface downwards, for 5 to 10 minutes; 
it is then washed for a second or two, stained, washed as before, then either dried, or dehydrated, and mounted in balsam.

Counting corpuscles. The following fluids are sometimes used instead of Hayem's for counting red corpuscles. (a) Sodium sulphate, sp. gr. $1025,(b)$ sodium chloride $\cdot 8$ or $\cdot 9$ p.c., (c) Pacini's fluid consisting of mercuric chloride 2 parts, sodium chloride 44 parts, glycerine 26 parts, water 226 parts. 


\section{LESSON IV.}

\section{MEASUREMENT OF OBJECTS UNDER THE MICROSCOPE.}

1. Schröder's compound camera lucida. This is perhaps one of the easiest to use if the microscope can be tilted. Set the microscope to an angle of about $45^{\circ}$. Focus with a low power the lines of a stage micrometer, i.e. a millimetre divided on glass into tenths, and one of the tenths into hundredths.

Place the drawing paper on the table in front of the microscope; put the camera over the ocular, move the point of a needle on the drawing paper, the point will be seen through the camera. Then move the camera slowly down till the lines of the stage micrometer, as well as the point of the needle, are distinct. Focus with the fine adjustment if necessary, and continue as in $\S 3$.

2. Zeiss' drawing prism (camera lucida) (Fig. 2). Place a drawing-board (made so that the drawing surface is at an angle of $25^{\circ}$ with the table) in front of the microscope, and touching its foot, or at an 
ascertained distance from it. Fix a piece of smooth paper in the middle of the drawing-board.

Slip the ring $(r)$ over the tube of the microscope $(t)$, then replace the eye-piece (o). Arrange the brass rod

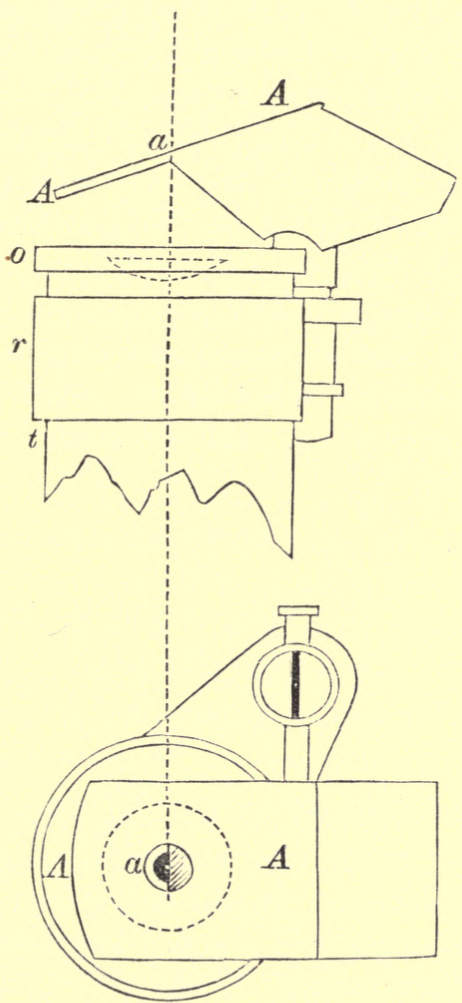

Fig. 2. The upper sketch shows the camera from the side, the lower sketch shows it from above.

carrying the prism $(A)$ on the left-hand side and shift the prism till (1) the edge $(a)$ stretches half-way over 
the lens of the eye-piece, (2) the lower angle of the prism nearly touches the edge of the eye-piece, (3) the anterior exposed surface of the prism is parallel with the drawing-paper. Then turn the prism round the vertical axis so as to uncover the eye-piece.

Focus with a low power a stage micrometer. When the lines are seen distinctly, turn the prism back again into position. On looking down the microscope with the eye close to $a$, the lines of the stage micrometer and the point of a pencil placed on the drawing-paper should be visible. If they are not, watch the lines carefully, for the appearance of the pencil point over them as the prism is turned slowly and slightly around the horizontal axis, the point of the pencil at the same time being moved; try also the effect of shading the drawing-paper.

3. Draw the $\frac{1}{10}$ th micrometer lines. Then place the drawing alongside a millimetre scale, and note the length in millimetres of the scale drawn. If it measures $80 \mathrm{~mm}$., then the scale drawn, which on the micrometer was one millimetre, has been magnified 80 times.

4. Draw similarly on another piece of paper the lines of the stage micrometer with the high eyepiece, and objective. It will be sufficient to draw the lines indicating $\frac{1}{100}$ th of a mm. Ascertain the magnification of the drawing. If the $\frac{1}{10}$ th of a mm. drawn measures $38 \mathrm{~mm}$., the magnification will obviously be 380 .

5. Substitute now a preparation of human blood for the stage micrometer, and draw some red cor- 
puscles under the high eye-piece and object-glass; taking care that the drawing-board and paper are in the same positions as in $\S 2$. Fold the scale drawn in $\S 2$ at right angles to, and through the lines; and measure with it the diameter of the corpuscles you have drawn. One division of your scale is $\frac{1}{100} \mathrm{~mm}$. i.e. $10 \mu$. ( $\mu=$ micron, $\frac{1}{1000} \mathrm{~mm}$.) The red corpuscle drawn should occupy rather less than one division of your scale since the red corpuscle is ordinarily 7 to $8 \mu$ in diameter.

6. Write on each scale drawn, the eye-piece and object-glass with which it was drawn, and the position of the drawing-board. Later, in drawing microscopic objects, draw them in the condition of one of the two scales. Thus the scale will allow the diameters of the object to be at once measured.

The phrase magnifying power of the microscope is used for the magnification of the scale, when it is drawn on a level with the stage of the microscope.

7. Measurement of size of objects by means of an ocular micrometer. The ocular micrometer consists of a dise of glass with a scale engraved on it. A ledge to receive it is placed in the eye-piece on a level with the focus of the upper lens.

Take the high eye-piece and objective, place the ocular micrometer face downwards in the ocular. Note the number of divisions of the ocular and of the stage micrometer which correspond exactly with one another. Reckon from this how many of the smaller divisions of the stage micrometer,- each of which is $10 \mu$-one division of the ocular micrometer corresponds to. Thus if 5 ocular divisions cover exactly 4 stage divisions; 1 ocular division $=\frac{4}{5} \times 10 \mu=8 \mu$, and a human red blood corpuscle would almost exactly be covered by one division of the ocular micrometer. If the microscope has a draw tube, draw it out to its full length, and redetermine the value of the ocular divisions. Determine similarly the value of one division of the ocular micrometer with the low ocular and objective. 


\section{NOTES.}

In Abbe's drawing camera (latest modification) with moderating glasses both for object and drawing paper, the light from the two sources can be readily adjusted.

Edinger's projection apparatus is very convenient for drawing the outlines of sections of brain and spinal cord, with a magnification of 10 to 30 diameters. 


\section{LESSON V.}

\section{STAINING AND MOUNTING UN-IMBEDDED SECTIONS.}

\section{Staining sections with hæmatoxylin and}

with picro-carmine. Sections are given you in water ${ }^{1}$ Place a drop or two of hæmatoxylin ${ }^{2}$ (Ehrlich's or Delafield's) in a watch-glass; dilute it with distilled water just so far that a section placed in it can be easily seen. Fill another watch-glass about $\frac{1}{3}$ rd full with picro-carmine.

Place separately on a slide a drop of each of the fluids, and examine them with a low power of the microscope. If particles are visible in either, filter it. A small filter may be taken, folded, held in forceps over a clean watch-glass; sufficient staining fluid will filter in about a minute.

Lift up a section on a glass rod 1 to $2 \mathrm{~mm}$. in diameter $^{3}$ and place in the hæmatoxylin. Transfer

${ }^{1}$ Sections of spleen hardened in potassium bichromate may be taken for $\$ \S 1$ to 8 , and the results compared.

${ }^{2}$ For the method of preparing the staining fluids see p. 307 .

${ }^{3}$ Instead of a glass rod, a glass tube finely drawn out may be used, the end being closed by fusing in a Bunsen flame. 
similarly one section to hæmatoxylin, and two to picro-carmine. The sections in hæmatoxylin will be stained in about a quarter of an hour, those in picrocarmine in half-an-hour to an hour'.

Take four watch-glasses and fill them respectively $\frac{1}{3}$ rd full with (1) tap-water, (2) 50 p.c. alcohol, (3) 75 p.c. alcohol, (4) 95 or 96 p.c. alcohol (strong methylated spirit). Cover up the 95 p.c. alcohol with a watchglass to prevent evaporation. In another watch-glass pour a few drops of clove oil.

With the fine glass rod, take a section from the hæmatoxylin and place it in tap-water for a minute, gently moving it. (The section should be a fairly deep blue; if it is not, put it back in the hæmatoxylin for a further 10 to 15 minutes.) Place it for the same time in 50 p.c. and in 75 p.c. alcohol. Leave it for 3 to 5 minutes in 95 p.c. alcohol.

Tap-water is used, since the salts in it give the section a bluer (and deeper) tint. But it causes a slight precipitate in the hæmatoxylin; this is nearly always washed off the section by the method given here. Very thin sections, those liable to break up, and those which are sticky, should be passed through all the fluids flat on a lifter instead of on a glass rod, and in this case it is best to use distilled water before tap-water so as to avoid the chance of a precipitate. Further, 30 p.c. alcohol may be used between water and 50 p.c.

If the section is folded when in 50 p.c. alcohol, it should be transferred from 50 to 75 p.c. and from 75 to

1 Delafield's hæmatoxylin (undiluted) stains sections in 1 to 2 minutes, Ehrlich's acid hæmatoxylin in 3 to 5 minutes, and Mayer's carmalum in $\frac{1}{2} \mathrm{hr}$. to 1 hour. The rate of staining varies with the agent used to fix the tissue. Tissues fixed with alcohol or mercuric chloride stain more quickly than those fixed in a fluid containing chromic acid or osmic acid. 
95 p.c. alcohol on a lifter instead of on a glass rod. Arrange the section flat on a lifter, hold it in place by touching it lightly with a needle as the lifter is raised from the fluid; wipe dry the bottom of the lifter, drain excess of fluid from it (taking care that the section does not become dry); and then lower the lifter gently into the next fluid.

Take a section from picro-carmine and treat it in the same way as the section from hæmatoxylin. If, after washing with water, it is only faintly red, put it back in the picro-carmine.

\section{Clearing the section and mounting it in} Canada balsam. Take it up on the glass rod, gently touch the edge of the watch-glass, or a piece of blottingpaper, with it to remove excess of alcohol, and place it in clove oil-the clearing agent-for 2 or 3 minutes. In the clove oil the folds in the section will usually disappear.

With a lifter transfer the sections in this case with plenty of fluid, from the clove oil to a slide, and examine them under a low power of the microscope. They should be transparent throughout. If either has any opaque spots, put it on the warm bath for a few minutes. If the opaque spots-which are caused by the presence of water-do not disappear, the section should be thrown away $^{1}$, and another passed from the staining agent through the alcohols, especial care being taken to

1 The section may be dehydrated by transferring it from the clove oil to 95 p.c. alcohol (or better, absolute alcohol) for about 10 minutes and then replacing it in clove oil; but the beginner is recommended to take a fresh section. 
remove all excess of 95 p.c. alcohol before it is placed in the clove oil.

In removing a section on a lifter from alcohol to clove oil, take care to remove all excess of alcohol.

The complete dehydration of the sections is rendered more certain by placing them in absolute alcohol after 95 p.c., but absolute alcohol is expensive and is not necessary, since clove oil will take up a small quantity of water. When xylol instead of clove oil is used as the clearing agent, greater care must be taken to dehydrate the specimen.

When the sections are transparent, tilt the slide slowly and let the clove oil run off, keeping the sections in place with the aid of a needle. Let the slide stand vertically on a piece of blotting-paper for a minute or two to drain: with the clean-cut edge of a piece of blotting-paper remove the clove oil around the specimen. Clean a cover-slip by rubbing it on a smooth, hard surface, with a piece of clean silk or linen. Let a small drop of fluid Canada balsam ${ }^{1}$ dissolved in xylol fall on the section. With the aid of a needle gently lower the cover-slip on the balsam.

The specimen may be placed on a warm bath for about halfan-hour, the cover-slip then presses out the excess of balsam, and the balsam at the edges sooner becomes firm. Injected specimens, and those containing fat globules stained with osmic acid, should not be warmed.

3. Place a section for half-an-hour in each of the following fluids, hæmatoxylin (whichever was not used in $\$ 1$ ), alum carmine, carmalum. Mount them and compare the staining.

4. Staining with methylene blue or with saffranin. With these-and a number of other reagents-it is generally best to

${ }^{1}$ If the balsam is thick, pour a little xylol into the bottle. 
overstain the sections and then to decolourize them to the required extent. Sections are left in a solution of saffranin $^{1}$ in $75 \mathrm{p}$.c. alcohol or in an aqueous solution of methylene blue for 2 to 24 hours 2 . They are then passed through the series of alcohols. In these the colour is more or less rapidly extracted and the sections must be passed through the fluids, the more quickly the more rapidly the extraction is observed to take place. Clove oil dissolves these staining agents, so that cedar wood oil or xylol, in which they are insoluble, should be used as the clearing agent, in place of clove oil. Sections of a young salamander may be stained; the changes in the nucleus during division will be seen.

\section{Staining sections and mounting them in} glycerine. Take two sections stained as in $§ 1$, remove them from the staining agent to water, stir the water with a glass rod till no more colouring matter comes from the section (a minute or two); then ( $a$ ) place one in a watch-glass with a drop of glycerine, and move it gently about till the glycerine has penetrated it; place a small drop of glycerine on a slide, to this remove the section on a needle, spread out the section, and cover with a cover-glass. Sections stained with any carmine stain may advantageously be mounted in formic glycerine (glycerine containing 1 p.c. of formic acid $1 \cdot 16$ sp. gr.).

b. Treat the other section similarly, but with dilute glycerine (equal volumes of glycerine and water) instead of with strong glycerine; use a lifter to transfer the section to the slide; remove excess of fluid and cover.

${ }^{1}$ A saturated solution of saffranin in 75 p.c. alcohol, diluted with an equal volume of 75 p.c. alcohol.

${ }^{2}$ A 1 p.c. solution diluted so that sections placed in it in a watchglass are visible. 
6. When it is desired to keep sections mounted in glycerine, they may be treated in the following way. Place the slide and a small bottle of glycerine-jelly on a warm bath. There should be no glycerine beyond the edges of the cover-slip, but if there is, remove it with blotting-paper. With a small brush, brush a little glycerine-jelly round the edges of the cover-slip. Put the slide aside for a day or more, then brush gold size (zinc white, Brunswick black, Canada balsam will also serve) over the glycerine-jelly.

7. Mounting in glycerine-jelly. Place at about $38^{\circ} \mathrm{C}$., (a) a small bottle containing glycerine-jelly, (b) the sections in water, $(c)$ a lifter, $(d)$ a clean slide and cover-slip. When the jelly is melted, place a section on the slide, run off the water, place a drop of glycerine-jelly on the section; leave in the warm for a minute, gently moving the section with a warm glass rod or lifter. Cover, and leave for another minute in the warm, gently press the cover-slip, or the layer of jelly may be too thick to allow examination under the high power. The essential point is to keep everything warm; if this is borne in mind, the details may be varied in obvious ways.

When the jelly has set, remove that at the edges of the cover-slip and surround with gold size or other cement.

\section{Double staining with hæmatoxylin and} eosin. Arrange watch-glasses as in $\S 1$, omitting that containing picro-carmine and adding one containing a saturated solution of eosin in 75 p.c. alcohol. Stain rather deeply with hæmatoxylin; after the stained section has been placed in 50 p.c. alcohol, place it in the eosin solution for one minute, then clear in 75 p.c. alcohol. Pass through 95 p.c. alcohol with 
clove oil and mount. The section when in 95 p.c. alcohol should neither be markedly blue nor markedly red; if it is blue, stain it again with eosin, passing it more quickly through the alcohols; if it is red, leave it in the alcohol till the red colour is fainter. 'The nuclei are stained with hæmatoxylin, the cell substance and most other tissue with eosin. Nearly all tissues give good results when stained in this way.

A 1 p.c. aqueous solution of eosin stains more quickly than the alcoholic solution given above; in it, a second or two will probably be sufficient to stain the section.

If the tissue has been hardened in Miiller's fluid, potassium bichromate, or by brief treatment with osmic acid, the hæmoglobin of the red corpuscles-which in these cases is usually preserved-will be stained orange with eosin.

9. After-staining with picric acid. Picric acid may be used after any other stain. It is perhaps best after carmine or hæmatoxylin ${ }^{1}$. The section is stained and treated in the usual way up to 75 p.c. alcohol (the hæmatoxylin stain should be deep, since the picric acid will much lessen it). From this it is removed to a watch-glass containing picric acid, e.g. 2 p.c. in 95 p.c. alcohol. After staying about two minutes in this, it is placed in 95 p.c. alcohol and moved about till a faint yellow tinge only is left. It is then transferred to clove oil and mounted.

Picric acid stains red corpuscles brilliantly when the hæmoglobin is preserved, it stains also elastic tissue and the horny layer of the skin; it stains muscular tissue more readily than white fibrous tissue, and striated duct cells more readily than the alveolar cells of glands. In slight excess it stains the whole section.

10. Hoematoxylin and rubin $S^{2}$ with picric acid. Stain with hæmatoxylin. After the section has been passed through alcohols

${ }^{1}$ A piece of arytenoid cartilage may be taken.

2 Rubin $S$ is the acid-magenta or säure-fuchsin made by a particular Firm, and considered by some workers to give the best stain. 
up to 75 p.c., place it for one minute in the rubin mixture. Transfer it to 95 p.c. alcohol, and treat in the usual way. If required, a little more picric tint may be given by treating it as in $\$ 7$, after it has been stained with the rubin mixture. Acid magenta stains especially the connective tissue, and is best used when a small amount only of this tissue is present (cp. App. p. 310).

11. Ehrlich-Biondi stain. This is a mixture of methylgreen 00 , orange $\mathrm{G}$, and rubin $\mathrm{S}$ (acid magenta), (cp. p. 310). The methyl-green stains nuclei, orange G stains hæmoglobin, rubin $\mathrm{S}$ stains connective tissue ; cell-substance is stained chiefly by the rubin, slightly by the orange G. Sections are placed in it from $\frac{1}{2}$ hour to a day; as a rule they must be passed rapidly through alcohols in order to preserve the nuclear stain. Xylol or cedar-wood oil should be used as the clearing agent.

The solution on keeping often loses its red tint, and gives little else than the nuclear stain; the colour may be brought back by adding a little dilute acetic acid, but if excess is added the rubin $\mathrm{S}$ only will stain. The student will probably obtain better results with the double stains given above than with this.

For iron-hæmatoxylin stain see p. 287. 


\section{- LESSON VI.}

\section{STAINING AND MOUNTING SECTIONS IMBEDDED IN PARAFFIN.}

\section{Dissolving paraffin from sections free in}

fluid ${ }^{1}$ a. Place a section in a watch-glass, and pour over it a few drops of turpentine. See that the balsam and a clean cover-slip are ready. With a lifter transfer the section to a slide, tilt the slide and wipe away the excess of turpentine, then add a drop of balsam, and cover with a cover-slip.

b. Mount another section, using xylol instead of turpentine. $\mathrm{Xylol}^{2}$ is very volatile, and the section after removal of excess of xylol will rapidly dry on the slide and become useless unless this is prevented by the addition of balsam. Xylol is preferable to turpentine for tissues that have been treated with osmic acid,

1 A compact or fairly compact structure should be taken, as a piece of liver, pancreas, ureter or bladder, hardened in potassium bichromate. The piece should be stained with hæmalum for a day before imbedding, for $\S 1$, and left unstained for $\S 2$.

2 Benzol, toluol, and a mixture of four parts of turpentine with one part of creosote, are also used to dissolve paraffin. 
since turpentine is apt to dissolve some of the stained fatty substances.

2. Staining free in fluid, sections imbedded in paraffin. Take two or three sections and dissolve the paraffin with turpentine as in $\S 1$. Take up the sections on a thin glass rod, touch blotting-paper with them to remove excess of turpentine and place in 95 p.c. (or absolute) alcohol in a watch-glass. Leave for 5 to 10 minutes, then pass through successively weaker alcohols, stain and mount as in Less. v. $§ 1$.

Note. Sections may be fixed in $\$ 3,4,5$ to the cover-slip instead of to the slide, but the beginner will find the slide easier to handle. He will also find turpentine easier to use than xylol since it evaporates less quickly and there is thus less chance of the section becoming dry; turpentine is not so good as xylol for the cover-slip method since it is apt to leave a slight film on evaporation.

3. Mounting serial stained sections. Place a small drop of collodion dissolved in clove oil, on a slide. With a small brush (or with the finger) rub the drop so that it forms a very thin film over a portion of the slide a little larger than a cover-slip. Take the ribbon of nine sections ${ }^{1}$ given you, and cut it with a scalpel into three series of three sections each. Place these on the film of collodion so that the second series of three is below the first, and the third below the second. Press a small brush lightly on the centre of each section and roll it to right and left, so as to flatten the sections and make

1 A piece of small intestine hardened in mercuric chloride may be taken; stained with hæmatoxylin for $\S \S 3,4$; unstained for $\S 5$. 
them stick to the glass. Place the collodion side uppermost, on a warm bath at a temperature just sufficient to melt the paraffin. When the paraffin is melted, dip the slide into a bottle of turpentine, for one to two minutes. Then wipe the turpentine from the lower surface of the slide, and stand the slide up to drain. Wipe away the turpentine on either side of the sections. Place a line of dilute balsam on a cover-slip near one edge; let this edge first touch the slide, and gently lower the cover-slip so that the balsam flows over the sections.

4. Flattening folded sections. a. Clean the slide by pouring on it a drop or two of strong spirit, and rubbing with a clean cloth. Place a flat basin of distilled water over a small flame, regulating the flame so that the temperature of the water is $35^{\circ}$ to $37^{\circ} \mathrm{C}$. Place the sections on the water, they will spread out and become quite flat. Dip the slide in the water obliquely, draw the sections to it with a needle, hold the upper edge of the paraffin on the slide with the needle and gently lift the slide out of water, with the sections on it. Stand it up to let the water run off, so that the sections are in contact with the glass, place between smooth pads of blotting-paper, and touch lightly to remove most of the remaining water and to make the tissue adhere to the glass. Place on a bath at about $35^{\circ} \mathrm{C}$. for half-an-hour or longer to dry without melting the paraffin. Then place on a warmer bath to melt the paraffin and mount in balsam as in $\S 3$.

b. Clean a slide; pour water on it, place the sections on the water. Place the slide on a warm bath. As the water becomes 
warm the sections will flatten. As soon as the sections are flat, remove the slide, let the water run off, and treat as after the corresponding stage in $\alpha$. With delicate sections it is better not to remove excess of water with blotting-paper, but after draining, to let the sections dry in the warm bath; in this case they should be left at $35^{\circ} \mathrm{C}$. till next day. The drying period may be shortened thus: after the slide has been at $35^{\circ} \mathrm{C}$. for half-an-hour (i) leave it in 95 p.c. alcohol for a few minutes, drain, and put on the bath for another half-an-hour, or (ii) treat similarly with absolute alcohol, drain, put in turpentine at once.

c. Proceed as in $b$, but use 50 p.c. spirit instead of water.

5. Staining serial sections on the cover-slip or slide. $a$. The several fluids required (turpentine or xylol, alcohols, staining agents) are arranged in a row in bottles without necks. (If a slide is used, the bottles should just hold the slide.)

Proceed at first as in $\$ 4$, either $a, b$, or $c$. If the cover-slip taken was clean and the process has been properly carried out, the sections will in most cases adhere to it during the subsequent staining and mounting.

After the paraffin has been dissolved in turpentine or xylol, wipe or drain off excess of fluid and place in absolute alcohol for two or three minutes; transfer for a minute to 95 p.c. alcohol, and so on through the successive alcohols to the staining agent, e.g. Delafield's hæmatoxylin. When the section is stained remove excess of staining fluid, pass back through the alcohols, removing excess of fluids at each transfer. After absolute alcohol, leave the slide in turpentine or xylol for a couple of minutes; then stand it up to drain; mount as in $\S 3$.

Some sections, especially those of tissues which have been kept long in osmic acid or in chromium compounds, are apt to come away from the glass when treated as above. In such cases a fixative is used as in $b$, and $c$, following.

b. If the sections do not require to be flattened, rub the cover-slip or slide with a mixture of egg-albumin and glycerine (p. 313) in the manner in which collodion was used in $\S 3$. 
c. If the sections require flattening, proceed as in $\S 5, b$, using dilute egg-albumin (2 c.c. filtered white of egg in 100 c.c. water) instead of water.

In either case when the paraffin has been dissolved from the sections, leave them for 5 to 10 minutes in absolute alcohol, then pass through alcohols and stain as in $a$.

In this process the alcohol fixes the sections to the glass by coagulating the film of egg-albumin. The drawback of the process is that the egg-albumin is stained by most reagents.

6. Staining sections still in paraffin. Sections cut in paraffin may be stained, before the paraffin is removed, by floating them on a staining agent.

Sections of tissues which have been hardened in alcohol or in mercuric chloride, stain with 1 p.c. aqueous solution of methylene blue, or with Ehrlich-Biondi fluid-and with other similar stains-in $\frac{1}{2}$ to $\frac{3}{4}$ of an hour ; but they may be left for a day or longer, and decolourized to the proper extent by floating in dilute alcohol. Hæmatoxylin stains in about a day. Eosin stains rapidly and can be used after hæmatoxylin. Picro-carmine and alcohol solutions of methylene blue stain so slowly by this method that they are of little use.

The most convenient method of treatment for most purposes is to interpolate, after the sections are flattened, a stage of staining in the ordinary process of mounting an already stained section. The treatment then is as follows:

a. The sections are flattened on warm water.

b. They are taken up on a broad lifter and transferred to the staining solution, on which they float.

c. When stained, they are placed on water and gently moved to remove excess of staining agent.

d. They are taken up on a cover-slip (or slide) and the water allowed to run from them. 
e. The cover-slip is pressed gently between filter papers to remove as much water as possible.

f. The cover-slip is placed on a warm bath, at $35^{\circ}-40^{\circ} \mathrm{C}$. for about 10 minutes to dry.

g. The paraffin is melted, dissolved in xylol and the specimen mounted in balsam. 


\section{LESSON VII.}

\section{SECTION CUTTING AND IMBEDDING.}

\section{Preparation of Hardened Tissue for Freez-}

ing. If the piece of tissue to be cut has been kept in alcohol, place it in 50 p.c. and then in 30 p.c. alcohol, each for about 10 minutes. Remove the tissue to water for 1 to 3 hours in order to extract the alcohol. The extraction is hastened by placing on the warm bath, at about $38^{\circ} \mathrm{C}$. Place then in dilute gum ${ }^{1}$ for an hour to a day as convenient.

Successful section cutting depends largely upon using a sharp razor, it should not be markedly hollow ground, or it may bend and give sections consisting of bands of unequal thickness. The razor should be placed flat on a microscope stage, and the edge examined with

1 The gum solution is prepared by dissolving gum arabic in sufficient warm water to make a freely flowing solution, and filtering through linen. When it is required to keep the piece of tissue in a given position whilst freezing, it may be transferred to a thick solution of gum a few minutes before placing it in the plate of the microtome; it can then be kept in position by a needle for the short time that elapses before it is frozen. Since gum alone freezes to a hard mass, a little sugar solution may with advantage be added to it. 
a low power; if there are notches in it, it requires re-grinding.

2. Ice and Salt Freezing Microtome. $a$. Ice is broken into fragments about the size of walnuts; salt is sprinkled liberally over the ice; and the mixture packed in the box of the microtome ${ }^{1}$. The plate of the microtome remains below freezing-point for 2 to 3 hours.

Clean the plate of the microtome and the grooves in it. Place the piece of tissue (given you in gum) in the centre of the plate. If there is much gum around the tissue cut it away after it is frozen.

Take the tripod frame which carries the razor, and see that the razor is firmly fixed by the screws. Then adjust the level of the razor by means of the three screws supporting the frame in the following manner:-

Screw up the front screw till $\frac{1}{2}$ to $\frac{2}{3}$ of it is below the frame. Adjust the back right-hand screw so that the right-hand edge of the razor will just cut into the frozen gum over the tissue; adjust similarly the back left-hand screw; repeat these two adjustments, so that whatever part of the razor is used in cutting, sections of nearly the same thickness will be obtained.

Hold the frame firmly, but without unnecessary pressure, and push it straight forward over the tissue; this should cut off a portion of the gum. Lift up the frame-or its anterior end,-carry it back, turn downward the front screw $\frac{1}{6}$ th of a revolution, push the cityi freezing mixture made by pounding together equal parts of ia too great a lowering of temperature, and the frodem tissue if nqgis asy to cut. 
frame straight forward again, and so on. In a short time, sections of the tissue will be obtained. With a small brush moistened with water remove each section, as it is obtained, from the razor, and float it off in a dish of water. A number of sections may be cut, and these removed together from the razor, but the sections are apt to become entangled and they are generally less perfect than the sections which are removed separately as they are cut.

After cutting some sections, of a thickness corresponding to $\frac{1}{6}$ th of a revolution of the front screw, cut others, turning the screw less than $\frac{1}{6}$ th between each section, and note the smallest angle through which the screw can be turned, complete sections still being obtained.

Stain and mount the sections. (See Lesson v.) It must be remembered that the gum unless dissolved out of the sections will form a granular precipitate in them when they are treated with strong alcohol.

After the sections are cut, carefully clean the razor and the plate of the microtome.

The proper rate to carry the razor through the tissue varies with the temperature of the frozen mass; when it is a few degrees only below zero, the movement may be the quickest possible; when it is frozen hard, it should be carried slowly through the tissue, otherwise the sections are apt to curl or break up.

b. In cutting large sections, it is best to place on the razor a number of small drops of water and to cut slowly; the section folds up on the razor. The razor (with the frame) should then be dipped under water and the section floated off; it should be taken out on a glass slide and treated on the slide with $30,50,75$ p.c. alcohol, etc. ; 
care should be taken to remove as much as possible of the clearing agent, otherwise the Canada balsam in which the section is mounted may remain a long time fluid.

3. Ether Freezing Microtome. The fine nozzle of the ether spray apparatus is easily stopped up by fine particles of dust. To avoid this, see that the bottle to contain the ether is clean, and filter into it the ether to be used.

The piece of tissue should not be more than 3 to $4 \mathrm{~mm}$. thick; for the upper surface of pieces thicker than this freezes slowly.

Before beginning the ether spray, adjust the razor (see $\S 2$ ) so that the edge just touches the top of the tissue as it lies on the plate; place a brush and dish of water in readiness. Then set the ether spray going by means of the hand bellows, keeping the second bag of the bellows just pressing against the net surrounding it. The tissue should be frozen in about a minute, the time varying with the temperature of the room. If the freezing does not begin rapidly, look at the spray; if there is not a good jet, the nozzle of the apparatus probably requires cleaning out.

As soon as the tissue is frozen, begin cutting sections as with the ice and salt microtome. Immediately the gum on the plate at the edge of the tissue begins to lose its dense white colour, cease cutting sections, and ply the ether spray to re-freeze. Then cut more sections.

When the sections are cut, clean the razor and the microtome plate.

4. Cutting Fresh Tissues. A piece of tissue fresh from the body may be placed direct on the microtome plate and frozen. It is best to cut it a few degrees only below freezing-point. The ice rapidly blunts the razor, and ice crystals are apt to distort and tear delicate structures. This can be more or less avoided by placing the piece of tissue for $\mathbf{5}$ to $\mathbf{1 5}$ minutes in dilute gum, this however causes some changes in the tissue cells.

a. Cut sections of e.g. a piece of rat's kidney. Transfer the sections to salt solution 0.9 p.c. and with a brush gently unfold them. Dip a slide obliquely under a section, with a needle hold one corner of the section on the slide, lift up the slide, if necessary pull out the edges. of the section so that it lies flat and unfolded, 
drain off the salt solution. Treat another section in the same way.

Place a cover-glass on one of the sections and examine it. drop of dilute methylene blue or Spiller's purple may be added to another section, in 5 minutes the drop drained away, and a cover-glass put on.) Let two or three drops of 95 p.c. alcohol fall on the other. Leave it for a quarter of an hour or longer, then stain e.g. with hæmatoxylin and mount in Canada balsam.

$b$. Cut sections of e.g. a small lymphatic gland. Transfer the sections to 30 p.c. alcohol. With a brush move them about in the alcohol to remove some of the leucocytes. Stain and mount. (Sections after unfolding in 30 p.c. alcohol may be transferred flat on a lifter to any of the usual hardening agents.)

5. Imbedding in Paraffin. Take the piece of tissue given you, which has already been stained in bulk $^{1}$. Place it for $\frac{1}{4}$ hour in 95 p.c. alcohol, and for $\frac{1}{4}$ hour in absolute alcohol. Transfer it to a little turpentine ${ }^{2}$ in a watch-glass, cover up and place on a warm bath at about $45^{\circ} \mathrm{C}$. for 5 to $10 \mathrm{~min}$. Place on the warm bath a pair of forceps and a piece of blottingpaper. Take up the tissue with the warm forceps, drop it on the blotting-paper, and roll it over, wipe the points of the forceps, take up the tissue and drop it into one of the dishes of melted paraffin in the paraffin bath. The paraffin used should have a melting point of $45^{\circ}$ to $52^{\circ} \mathrm{C}$. Leave the tissue in the paraffin for $\frac{1}{2}$ hour to 3 hours according to its size.

1 The piece of tissue should if practicable only be a few millimetres thick. The larger the piece, the longer it should be left in the alcohols. It is stained in bulk by leaving it for 1 to 3 days in acid hæmatoxylin or alum carmine (cp. Less. virr. p. 61).

2 When the student has become accustomed to imbedding, xylol or cedar-wood oil should be used in place of turpentine (cp. Less. VI. p. 43 and Notes at end of this Lesson). 
Rub the inside of a watch-glass with glycerine, removing excess so that the glycerine only remains as a smear. If in the paraffin dish there is more than about half a watch-glassful of paraffin, pour the excess into another dish. Light a Bunsen burner, and have ready a piece of wire or an old scalpel. Pour the paraffin with the tissue into the watch-glass; warm the wire in the Bunsen flame, and with it adjust the tissue so that the face to be cut is towards the edge of the watch-glass; and if air-bubbles are present remove them by means of the heated wire. If the paraffin begins to set round the tissue, when an air-bubble still remains attached to it, heat the wire and melt all the paraffin around the tissue.

Carefully take up the watch-glass and place it in a shallow dish of cold water; when the paraffin has set, immerse the watch-glass cautiously in water; then place the glass surface under a stream of water from a tap. The more quickly the paraffin is cooled, the less chance there is of crystals forming, and the easier it will be to cut.

Cut away the paraffin on each side of the tissue, and remove the block with the imbedded tissue. Cut the paraffin into a rectangular block, cutting away the paraffin close up to the tissue on the face to be cut and on the adjoining faces, but leaving 2 to $3 \mathrm{~mm}$. of paraffin on the face opposite to that to be cut.

A piece of smooth glass is given you with a central mass of paraffin fixed to it. Heat a scalpel in a Bunsen burner and melt the central part of the paraffin, on this place the paraffin end of the block with the imbedded tissue. Pass the heated scalpel once or twice 
along the point of junction of the paraffin mass and the block, to melt it thoroughly and make a good union. With the heated scalpel, heap up a little paraffin about the base of the block. Leave for a minute, then cool under the tap.

6. Cutting sections. a. Take the tripod razor, adjust as in $\S 2$, and cut sections in a similar manner, carrying the razor rapidly through the tissue, and using the same portion of the razor. The successive sections will stick together and form a ribbon. When a ribbon of half-a-dozen sections has been made, place it aside on a piece of paper, and cut a fresh ribbon. The sections are mounted as in Lesson vi. $\$ \S 1,3$, or 4 .

b. The method given above, viz., of pouring paraffin with the tissue into a watch-glass, serves very well for small objects; but as the surface of the watch-glass is curved, it is better when objects more than half a centimetre in length are to be imbedded, to use instead of the watch-glass, either a small card-board or paper box, or two L-shaped imbedding frames. The latter are made of brass or of lead, with sides about a centimetre high; they are placed on a glass slide so that the long limb of each is in contact with the short limb of the other, they thus enclose a space, the size of which can be varied according to the size of the tissue; into the space paraffin with the tissue is poured, and the tissue is adjusted by a hot scalpel.

7. The Rocking Microtome. Note the mechanism of the microtome (Fig. 3). Turn up and down the large screw at the end of the lever, and note the extent of the movement of the anterior end of the lever which carries the paraffin. Turn similarly the milled wheel at the base of the screw. Pull the handle backwards and forwards, note that in pulling it forward, a catch engages with the milled wheel and pushes it round, i.e. pushes the paraffin on the lever towards the razor. Move 
backwards and forwards the guard of the catch, the position of this determines how far the wheel is pushed round by the catch, i.e. the thickness of the section. Pull the handle forward, and then slowly move it back, counting the clicks of the catch as it passes over the teeth of the milling; adjust the guard so that there are 8 to 10 clicks. Eight teeth give sections approximately $5 \mu$ in thickness.

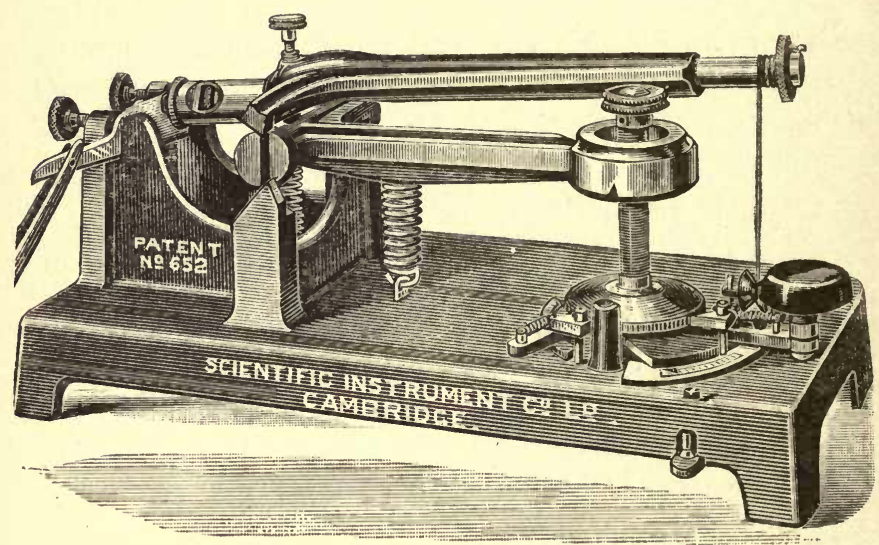

Fig. 3.

Procedure. Imbed the tissue as in $\S 5$, and shape the paraffin into a rectangular block. Take the paraffin carrier from the microtome. On this fix the imbedded tissue, thoroughly melting the adjoining surfaces of the paraffin by means of a heated knife. With a sharp scalpel, carefully shape the part of the block surrounding the tissue so that the surface to be cut is rectangular.

Screw the large screw of the microtome downwards as far as it will go. Fix the carrier to the microtome, adjusting it so that the paraffin reaches nearly up to the position to be taken by the razor. Fix the razor firmly in the frame. Leave the right arm on the end of the lever carrying the paraffin so as to bring the paraffin on a level with the edge of the razor. Adjust the paraffin carrier so that one edge of the block to be cut is parallel to the edge of the razor and about half a millimetre from it; in doing 
this, do not put the left hand over the razor, but adjust the carrier from the right-hand side. Screw up firmly the carrier. Push the guard of the catch back as far as it will go, and move the handle until the first section is obtained, then adjust the guard so that the catch turns the milled wheel 8 to 10 teeth. Each forward movement of the handle now gives a section which is flat and adheres to the preceding section. When 3 or 4 are obtained, lift them up with a forceps, so that the ribbon of sections runs free of the razor.

The chief causes of bad sections are (1) over-hardness of the tissue ; this may be normal to the tissue, or produced by warming in agents such as xylol, or to overheating in the warm bath; (2) imperfect imbedding; this may be due to a lack of sufficient penetration of the paraffin, to crystals of paraffin having been formed, or to the presence of small bubbles of air. The surface of the block to be cut should be examined with a lens after it has been shaped, if patches of crystals or bubbles are visible it is best to re-imbed; (3) bluntness or notches in the razor.

Orienting the imbedded tissue. It is often requisite to cut the tissue in a particular plane. This can be done approximately in the following way:-the paraffin over the tissue is cut in the desired plane, the opposite surface of the paraffin is fused to the holder, and whilst the junction is still soft, the holder is slid along a horizontal groove in wood or metal against a vertical piece of glass at the end of the groove, and gently pressed against it until the paraffin at the junction has become hard. For more delicate adjustment, a special holder should be used, in which the part carrying the paraffin can be fixed in any position.

8. Cutting sections in paraffin melting at $58^{\circ} \mathrm{C}$. Paraffin of high melting point allows thinner sections to be cut than paraffin of low melting point. On this account paraffin melting at $58^{\circ} \mathrm{C}$. is sometimes used. But sections of the paraffin melting at $58^{\circ} \mathrm{C}$. are apt to curl and do not adhere to a ribbon at ordinary room temperatures. They form a ribbon, however, if the block is coated with paraffin of a low melting point.

Imbed a piece of tissue in paraffin melting at $58^{\circ} \mathrm{C}$., shape the block, and fix it in the usual way to the carrier of the microtome. 
Dip the block up to the base in melted paraffin of melting point about $40^{\circ} \mathrm{C}$., leave it there for 2 to 3 seconds, then lift it out, and hold it vertically for about 10 seconds for the paraffin to set. Put it aside for a minute or two to cool (or cool it in water, removing afterwards the adhering water). With a sharp scalpel cut away the soft paraffin from the surface to be cut, and from the sides of the block, leaving it only on the sides which will be parallel to the razor edge in cutting. Examine the junction of the hard and soft paraffin with a lens. If the two do not adhere, the process of re-coating should be repeated.

9. Superficial Imbedding. This can be employed with small firm pieces of tissue. It is often advantageous with portions of the nervous system treated by the Golgi-Ramón method (cp.p. 240). The piece of tissue is placed in 95 p.c. (or absolute) alcohol for 5 to 15 minutes. The imbedding mixture consists of 2 parts of hard paraffin and 1 part of vaseline. Sections of this curl less than sections of hard paraffin, and fold less than soft paraffin.

Take a short oblong or cylindrical block of paraffin-mixture. Scoop out a small hole at an end of it. Take the tissue up with forceps, roll it over on blotting-paper to remove excess of alcohol, but without allowing it to dry, dry the points of the forceps, and place the tissue in the hole in the paraffin. With a warm suction pipette, fill the hole with melted paraffin mixture. Heat a wire or an old scalpel in a Bunsen flame; and with it remove any bubbles that may be present, being careful not to touch the tissue with the wire when it is overheated. Let the paraffin cool a little, then cool it further in water. Pare down the paraffin to the surface of the tissue, and level the edges. Blow strong alcohol on the razor from a wash-bottle and cut sections free-hand, removing the section to 95 p.c. alcohol; the tissue must throughout be kept moistened with alcohol. The sections can be at once transferred to clove oil and mounted, or if the paraffin has penetrated into the outer layers, they may be transferred to absolute alcohol, then to xylol and mounted. If an unstained piece of tissue has been taken the sections may be stained in the usual way. 


\section{NOTES.}

Clearing agents. Cedar-wood oil and clove oil are the essential oils chiefly used for displacing the alcohol before the piece of tissue is placed in paraffin. The former is generally recommended, but different specimens vary more in their power of taking up water than do different specimens of clove oil, so that if tissues are passed direct from 95 p.c. alcohol, it is safer to use clove oil. Clove oil makes the tissues more brittle than does cedar-wood oil, so that it is less good for a large piece of tissue, and it makes a somewhat longer stay in paraftin necessary. (Cp. also p. 305.)

When a piece of tissue is transferred from alcohol to an essential oil, it rises to the surface, and a rapid evaporation of alcohol occurs; to avoid this the tissue with absolute alcohol is placed in a small bottle (or test tube) and the pipette containing the essential oil is passed to the bottom of the bottle and the oil allowed to form a layer under the alcohol. When the tissue has sunk into the oil, the alcoh 1 is sucked off.

Xylol or turpentine are often used in the place of an essential oil, since they allow a more rapid penetration of the paraffin. Tissues warmed in these are very apt to become brittle, so that stay in these fluids should be shortened as much as possible. Turpentine is commonly said to cause more shrinking than the other clearing agents, but $I$ have not found that the particular clearing agent used has any effect upon the appearance of sections of the great majority of tissues, provided the stay of the tissue in it is short.

The larger the spaces in a tissue, and the less it is hardened, the more gradual should be the changes from one fluid to another. For tissues much liable to distortion the following method may be used:

The tissue is transferred from absolute alcohol to chloroform by placing a layer of chloroform under the alcohol (cp. above), paraffin 
in small pieces is added in excess to the chloroform; in half-an-hour the bottle is placed at the melting point of the paraffin, when the paraffin has dissolved, the whole is transferred to an open vessel, more paraffin being added, and warmed for $\frac{1}{2}$ to 1 hour; the tissue is then removed to fresh paraffin, and left for $\frac{1}{2}$ to 1 hour. Chloroform if not driven off, makes the paraffin too soft to cut.

Paraffin cuts less well when mixed with a clearing agent, so that after the tissue has soaked in paraffin for a short time, it may be advisable to transfer it to fresh paraffin. 


\section{LESSON VIII.}

\section{RAPID HARDENING. STAINING IN BULK.}

1. The fixing and hardening of tissues preparatory to cutting sections must be carried out slowly if the best results are to be obtained (cp. p. 295). But it is sometimes desirable to obtain sections on the day on which the tissue is removed from the body. In such cases the freezing method described above (p. 49) may be employed, or the preparatory hardening process may be shortened, as in the methods given below. They give satisfactory results with certain tissues only.

a. Throw a small piece of the tissue into boiling water, and leave it for one to two minutes, just sufficient to coagulate the proteids. (Try tongue of mammal, heart of frog, or muscular tissue.)

b. Place a piece of tissue, not larger than $4 \times 4 \times 2 \mathrm{~mm}$., in 0.5 or 1 p.c. osmic acid for half-an-hour, pass through water and alcohols leaving 5 to 10 minutes in each; leave in absolute alcohol half-an-hour. This will only serve for a small piece of tissue, since the osmic acid penetrates slowly. (Try nerve or ganglion.)

c. Use Flemming's fluid instead of osmic acid. (Try liver of frog.)

d. Place a small piece of tissue in a saturated solution of mercuric chloride in 95 p.c. alcohol. Leave for 1 hour, wash in 95 p.c. spirit. Place for an hour in absolute alcohol coloured brown with iodine dissolved in potassic iodide. (Mammalian liver, kidney or same tissues as in $(\alpha)$.) 
e. Use 4 p.c. formaldehyde in alcohol about 75 p.c. (1 part formol and 9 parts 80 p.c. alcohol) for the mercuric fluid of $d$. (This may be used for any tissue, but the sections stain diffusely, unless well washed.)

If, in methods (b) and (c), the tissue can be left longer in the fixing agent or in the absolute alcohol, this should be done.

The tissue may be passed back through the alcohols, to water, and to gum, then cut frozen and stained; or they may be put for 10 minutes in cedar-wood oil or xylol, imbedded, the sections fixed to a cover-slip and stained.

2. Staining in bulk with homatoxylin. Place a small piece of hardened tissue in Delafield's hæmatoxylin diluted with about three volumes of distilled water (first placing it, if necessary, in 30 p.c. alcohol for a quarter-of-an-hour). Leave for two days unless the piece of tissue is thin, in which case one day may be sufficient. Wash with distilled water, leave half-a-day in tap water, place for half-an-hour, or longer, in each of the several grades of alcohols. Put in cedar-wood oil in the warm for $\frac{1}{4}$ to $\frac{1}{2}$ an hour (cp. Less. vII. $\$ 5$ ); and in melted paraffin for an hour.

The stay in the several fluids should be longer, the larger the piece of tissue. It is advisable but not necessary to use absolute alcohol.

3. Staining in bulk with homatoxylin and eosin. Stain with hæmatoxylin as in $\S 2$, but use acid-hæmatoxylin instead of Delafield's, and leave the tissue in it for three days. After the tissue has been treated with 75 p.c. alcohol, put it in 95 p.c. alcohol containing $\cdot 1$ p.c. cosin for a day ; wash with 95 p.c. of absolute alcohol (10 to 15 minutes); treat with cedar-wood oil and paraffin as in $\S 2$.

\section{NOTES.}

In staining in bulk as given above the outer parts of the tissue are usually stained much deeper than the inner. This may to a certain exteut be avoided by further diluting the stain, and leaving the tissue longer in it. 
The stain with Delafield's hæmatoxylin is less restricted to the nuclei than that with acid-hæmatoxylin, on this account the former is commonly best when one stain only is used. The stain may be further restricted to the nuclei by leaving the tissue when stained in acid alcohol (70 p.c. alcohol containing 1 p.c. hydrochloric acid) for half-a-day to a day.

Hæmalum has been recommended as a hæmatoxylin stain on the ground that it stains more quickly and does not overstain.

After staining with eosin the tissue must not be left long in alcohol, as this removes the eosin stain; the eosin instead of being added to 95 p.c. alcohol, may be added to absolute alcohol, the tissue left in this for a day, and then passed to the clearing agent.

Of the carmine stains, borax carmine is perhaps the best; carmalum, alum carmine, and picrocarmine are also used. These solutions need not be diluted.

Picric acid may be used as a second stain after carmine or hæmatoxylin, the method is the same as that given for eosin in the text. 


\section{LESSON IX.}

\section{HYALINE CARTILAGE.}

1. Snip off a piece of the free edge of any of the thin cartilages projecting from the sternum or shouldergirdle of a freshly killed young newt'. Gently scrape away with a scalpel any tissue attached to it.

a. Mount it in 0.6 or 0.75 p.c. sodium chloride solution $^{2}$ and with a high power note that

The matrix is studded at tolerably regular intervals with cartilage cells or corpuscles.

Each corpuscle consists of a spherical or ovoid mass of cell substance, in which lies a relatively large nucleus. Both of these are fairly clear and transparent. Most of the cells entirely fill up the cavities in which they lie. Along the cut edge some cavities

1 As newts are not always obtainable in sufficient number for the method given here, the fresh cartilage may be cut frozen (Less. vIr. $\S 4$, and the sections given out; or similar sections may be given out of the hyaline cartilage on the head of a long bone of any young animal. In such sections there will be a good many cavities out of which the cells have fallen.

2 See note below. 
from which the cells have fallen out may generally be seen. Except at the free edge, the cells are two or more layers deep.

The matrix is hyaline or faintly granular, and is comparatively (cp. $\$ \S 3,4)$ in small quantity.

If the newts are not quite young there will be considerable amount of matrix and it may have here and there a deposit of lime salts; the cells will be chiefly in groups, many of them will contain fatglobules, and some of them two nuclei (cp. $\$ \S 3,4)$.

b. Irrigate (cp. p. 13) the piece with acetic acid 1 p.c. The following changes will be seen as the irrigation proceeds :

The nucleus becomes much more granular and distinct.

The cell substance becomes granular and more or less hides the nucleus.

The cell substance becomes transparent.

The cell substance shrinks from the matrix, and presents an irregularly serrated border. Note the space thus formed between the cell and the matrix.

Note. Examination of fresh tissues. When a piece of tissue is examined fresh, in order to see as nearly as possible its appearance during life, it must on no account be washed or mounted in water, since water causes rapid and extensive alteration.

The best method, as a rule, is to remove a small piece of fresh tissue as quickly as possible to a slide, and to put on a cover-slip at once without adding any fluid. Drying may be retarded by putting a little moist blotting-paper round the edges of the cover-slip. 
When fluid is added to the tissue, it should be one which causes as little change as possible. A 6 p.c. to $\cdot 75$ p.c. solution of sodium chloride in tap water is used for the tissues of the frog and newt, and a 75 p.c. to 9 p.c. solution for the tissues of the mammal. These are called normal salt solutions. The tissue should not, if it is avoidable, be soaked in the normal salt solution, but only moistened with it. In special cases a 1 to 2 p.c. salt solution is used.

In most cases, fresh aqueous humour, and fresh blood serum, may with advantage be substituted for normal saline.

2. Place a small piece of newt's cartilage in gold chloride solution 5 p.c. for about half-an-hour (until it is of a light yellow colour), then wash well with water, and place it in a vessel containing water just acidulated with acetic acid; leave it exposed to the light. When it has become a red-purple colour, mount it in glycerine containing 1 p.c. formic acid. The reduction takes a few hours only in bright sunlight, and one to two days in cloudy weather.

Observe the cell substance well coloured, and hardly at all shrunken, the nuclei deeply coloured and having a sharp outline, the matrix coloured very slightly.

3. Transverse sections of a cartilaginous rib (picric acid) ${ }^{1}$ of a fully grown, but not old, animal. Stain one section in picrocarmine for $\frac{1}{2}$ hour to 1 hour, and

1 The fixing agent in which the tissue is placed on being removed from the body is here and later given in brackets. The details of treatment are given in App. $\S$ II. 
another in acid hæmatoxylin (diluted as usual) for 5 to $\mathbf{1 0}$ minutes. Mount the former in glycerine, and the latter in balsam.

Observe that the cells are arranged in groups (each group having arisen by division from a single cartilage cell), note the outline of the thin layer of newer cartilage (capsule) around each cell; sometimes the whole of the cells in a group may be seen to be also surrounded by a thin layer just marked off from the rest of the matrix. Towards the outside of the cartilage the cells become flattened in a direction parallel with the surface.

4. Take a piece of costal cartilage from a recently killed oldish animal ; cut thin transverse sections either free-hand or with a freezing microtome and transfer them with a brush to a watch-glass containing normal salt solution. Mount one section in normal salt solution.

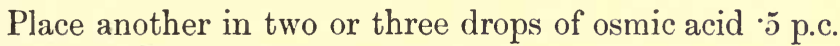
in a watch-glass and cover it up.

a. In the former observe under a high power, that

The cells frequently show signs of partial degeneration, containing fat globules which may be nearly as large as the cell; these are very highly refractive and so have a very distinct outline.

In places the matrix may be fibrillated and towards the centre of the section there may be a nodular semiopaque deposit of lime salts. Irrigate with 1 p.c. hydrochloric acid; the calcareous deposit is dissolved, but the fibrillation is not affected (it differs thus from the fibrillation of white fibrous connective tissue, cp. Lesson $\mathrm{x} . \S 2$ ). 
b. Mount in dilute glycerine, and examine the section which has been treated with osmic acid; the fat globules are stained a deep brown-black, the cell substance, the nuclei and the matrix are but slightly stained. On keeping, the fat globules become black.

5. Sections of cartilage from the head of a cuttle-fish (picric acid) ${ }^{1}$. Stain a section with acid hæmatoxylin, wash it, and mount in glycerine. If it is too deeply stained, place it in a little 1 p.c. acetic acid and when it is sufficiently decolourized, wash out the acid. Observe

a. The groups of cartilage cells.

b. The marked processes proceeding from some of the cells. Sometimes the processes of neighbouring groups may be seen to join.

6. Take a small piece of the ear of a freshly killed mouse or young rat, remove the skin and scrape away the tissue surrounding the ear-cartilage. Mount the cartilage in normal saline solution.

Note the cartilage cells closely packed together, most have one or more refractive fat globules in them. (The fat increases up to a certain limit with the age of the animal.) Unmount, stain the specimens with osmic acid.

1 Picric acid, osmic acid, and mercuric chloride are all good fixing agents for hyaline cartilage. 


\section{DEMONSTRATION.}

Transverse section of ear of adult rat. (Alcohol, acid hæmatoxylin; or gold chloride and formic acid.) Note the parenchymatous cartilage. The cell-spaces, generally polygonal, are separated by very narrow partitions of matrix. The spaces contain very little cell substance. 


\section{LESSON X.}

\section{CONNECTIVE TISSUE.}

1. Elastic Tissue (h. p.). Tease out in salt solution a thin strip of fresh ligamentum nuchæ, e.g. of ox. It is almost entirely made up of rather large, branching, and anastomosing fibres having distinct outlines, and curling at their ends.

Irrigate with acetic acid ( 1 to 5 p.c.); the elastic fibres are unaffected; the small amount of white fibrous tissue present, swells up; a few nuclei only come into view.

2. Network of fine elastic fibres. Stretch a fat-free part of the mesentery of a rat or other mammal', by holding up the intestine, moisten it on both sides with strong alcohol, in a few minutes cut out a piece, place it in 95 p.c. alcohol and brush both sides to remove the surface epithelioid cells. Place it in orcein solution (cp. p. 311) and leave for a day or better for two days, wash with water, look at it with a low power, and if the surface epithelioid cells remain, brush them off, put it in acid alcohol for about a minute, moving it about, then pass through 95 p.c. alcohol, clove oil, and mount in balsam. It is best to

1 The mesentery of a frog will also serve but the blood vessels are a little in the way. 
examine it before putting in clove oil, in order to see that the white fibrous tissue is sufficiently decolourized; if left too long in alcohol the elastic tissue also will be decolourized. Observe (h.p.) the close network of stained elastic fibres.

3. Tendon. Cut off the tip of the tail of a recently killed young rat; cut away the skin for a short distance, break off a vertebra, and pull straight outwards. A bundle of small tendons will be obtained. (A similar bundle can be obtained in the same way from each vertebra.) Gently stretch this over a glass slide from edge to edge, and hold it in this position till the edges are dry, touching the mid portion with a brush moistened with normal saline solution; the fibres are thus kept extended. Cover with a cover-slip. Note the white fibres consisting of parallel bundles of wavy fibrils. Slowly irrigate with acetic acid 1 p.c., watching the while under a high power. Between the bundles of fibrils rows of cells will become visible. Note in each the round or oval nucleus, the rectangular outline of the cell, and the finely granular cell substance. Indications of flange-like lateral processes may be seen as lines running along the cells in the direction of the tendon. After the acetic acid has been added for some little time the cell substance becomes very indistinct, and between the swollen bundles scarcely anything is seen but rows of elongated shrunken nuclei. (Cp. action of acetic acid on cartilage cells, Lesson IX. $§ 1$ b.)

4. Fibrils of tendon. Place a piece of tendon (see $\$ 3$ ) in a saturated aqueous solution of picric acid for a day. Wash with water, renewing it as it becomes coloured, for about a quarter of an hour. Place it in a watch-glass with a 75 p.c. alcoholic solution of acid magenta of such strength that the tendon is easily 
seen. In about a quarter of an hour, wash in 95 p.c. alcohol, tease out one end on a slide with fine needles, transfer to clove oil, tease again, and mount in balsam. Note (h.p.) the very small deeply stained fibrils.

5. Pull out another bundle of tendons : place them in $\cdot 2$ p.c. nitrate of silver for 5 to 10 minutes. Remove to water, move them to and fro once or twice, and gently separate them, renew the water and expose to light, now and then turning them over. In about half-an-hour pass a tendon through alcohols to clove oil. Place on a slide and examine with a low power. The layer of epithelioid cells covering the tendon, will in places be seen (some are often rubbed off in pulling out the tendon from the tail). Cut out the successful pieces, mount in balsam, and examine with a high power. The junctions of the cells are deep black owing to the reduction of silver by the cement substance between them.

6. Transverse sections of a rather large tendon such as that of the digastric muscle of a cat or rabbit. Stain and mount in balsam. Note the connective tissue sheath around the tendon, the septa from the sheath dividing the tendon into bundles, the branching tendon-cells between the fibres of the tendon bundles.

\section{Branched connective tissue cells of cor-}

nea. Take. a pithed frog, cut away the nictitating membrane, squeeze the side of the head to make the eye bulge out, then slice boldly at the edge of the cornea; take up its edge with forceps, and with fine scissors cut through the attached part at its junction with the sclerotic; any blood which may be on the cornea should be removed by placing it in a watchglass containing normal saline solution and very gently brushing it. Put it in gold chloride 5 p.c. solution, 
gently extend it into its normal shape with two finely pointed glass rods, leave it for thirty to forty minutes, wash well with water, transfer to about 20 c.c. of water just acidulated with acetic acid, and expose to light. When the cornea has become of a red- or blue-violet colour $^{1}$, put it on a slide with glycerine, and carefully scrape both surfaces to remove the epithelium, examine it under a low power to see that the epithelium is removed, when it is, mount in formic glycerine and examine it under a high power. If the cornea does not become properly stained in a day, place it in a testtube with a saturated or nearly saturated solution of tartaric acid, and heat for a few minutes to a temperature at which the test-tube can barely be held in the palm of the hand. This will probably complete the reduction.

Note the stained connective tissue corpuscles, with numerous fine branching processes which anastomose with the similar processes of neighbouring cells. This preparation should be preserved for examination of the nerves of the cornea (Lesson xIV. $§ 11$ ).

8. Moist film of areolar tissue. Cut off the hairs from a patch of the skin of the rat used in $\S 3$; wipe off loose hairs with a moist cloth, cut through the skin and turn it back. With fine forceps pull up a small piece of sub-cutaneous tissue, cut it off with scissors, put it on a cover-slip; spread it out with needles, continuing to do this until the edges stick to the glass and it is fully extended. Put a small drop

1 Probably it will not be stained until the following day. 
of salt solution on a cover-slip, and cover; this must be done before the tissue becomes dry. Examine (h. p.).

The tissue is chiefly composed of white fibres having a wavy course, and more or less distinct fibrillation; the bundles are of unequal size and run across one another in all directions. Some small elastic fibres running singly will also be seen, their outlines are more distinct than those of the bundles of white fibres; they branch and anastomose freely with one another. Where the film is well stretched the elastic fibres run for the most part quite straight, elsewhere they are curled at their ends and have a more or less sinuous course. Irrigate with acetic acid (1 to 5 p.c.), the white fibres swell up, and the elastic network becomes distinct.

\section{Moist film fixed with alcohol and stained.}

Prepare a moist film of connective tissue as in $\$ 8$. When it is extended, and before it becomes dry, place the cover-slip with the film in 95 p.c. alcohol. Leave for a quarter of an hour or longer. Hold it for a minute in a saturated solution of methylene blue in $7 \check{\text { p.c. }}$ alcohol, dip it in 75 p.c. alcohol, place it at once on blotting-paper film upwards; and lightly press it two or three times with blotting-paper so as to rapidly remove the alcohol. Leave it for 5 or 10 minutes till it is dry ${ }^{1}$ then add a small drop of balsam and mount. Note (first l.p. then h.p.) the rather large cells, oval or somewhat

1 The tissue in this case is allowed to become dry because the alcohol rapidly removes the stain, in other cases the tissue should be passed through alcohols and a clearing agent in the usual way. 
rectangular, with deeply stained coarse granules. These are the basophil cells or plasma cells. They are scattered irregularly; they are most numerous amongst and in the neighbourhood of fat cells, and often form a row on either side of the small blood vessels.

10. Dry film, stained with eosin and methylene blue. Prepare a film as in $\S 8$, but let it dry. Treat it like a dry blood film (cp. p. 18) but leave it for 30 seconds in eosin, and 60 seconds in methylene blue. Note (h.p.) the oxyphil leucocytes; (these are usually better seen in a dry film than in one fixed in alcohol).

11. Areolar tissue in frog. This may be obtained from the frog instead of from the rat. Cut transversely through the skin of the back of a frog which has been beheaded and held downward till the bleeding has ceased. Turn the lower piece of skin downwards, cutting it through at the sides. Connective tissue will be seen stretching from the skin to the body at the level of the posterior end of the urostyle. Cut out a small piece of this connective tissue, and make a film preparation. If the piece of tissue is covered with blood, dab it on blotting paper; it may be shaken in salt solution and the excess of fluid removed with blotting-paper, but the leucocytes of the tissue are apt to be altered by the salt solution. The basophil cells in the frog are irregular in shape, often elongated, their granules are of medium size.

12. Inter-muscular connective tissue of frog. Make a complete transverse incision of the skin of a pithed frog, in the abdominal region. Tear the skin backwards so as to expose the thigh muscles. With forceps lift up the muscles of the ventral surface of the thigh near the knee, and cut away all the muscles over the femur. Place the muscular mass on cork, deep surface uppermost, and gently pull laterally the muscles on either side of the sartorius, a thin layer of connective tissue on either side of the sartorius will come into view. Pin out the muscles so that the connective tissue layer is stretched, wash it with salt solution 
to rernove adhering blood, pour over it 95 p.c. alcohol and leave for half-an-hour. Then cut out the connective tissue and stain it with hæmatoxylin and eosin.

The connective tissue fibres will be stained with eosin, the nuclei of the cells with hæmatoxylin.

A similar preparation may be made of the connective tissue between the muscles of the rat or rabbit. In this case, the piece of tissue between the muscles may be picked up with forceps, cut out, and spread out to make a moist film in the manner given in $\S 8$. When the edges are dry, the tissue is fixed with alcohol.

13. Make a moist film preparation of the subcutaneous tissue of a fœtal or new-born mammal'.

Then $(a)$ fix with alcohol and stain with hæmatoxylin and eosin, pass through alcohols and clove oil and mount in balsam, or (b) add a drop or two of 1 p.c. aqueous solution of Spiller's purple or methylene blue, leave for a minute or two, wash with water, and mount in water.

Note the cells of various shapes, for the most part with faint outlines, but with distinct and rather large nuclei.

This may also serve to show the development of fat-cells.

14. Note in the section of costal cartilage prepared in Lesson Ix. $\S 6$ the connective tissue layer outside and closely attached to it forming the perichondrium; in places sections of tendons running into the cartilage will probably be seen.

15. Pigment-cells. Pin out on a frog-board one of the webs between the toes of the frog used in $\S 7$, and observe first under a low and then under a high power. There will be seen large corpuscles loaded with dark pigment, and possessing numerous branched

1 An animal just killed serves best, but one preserved in picric acid or Müller's fluid will answer the purpose. 
processes. In some places the pigmented cells will appear as round dots, the processes in this case having been retracted. Every intermediate stage between these two states may be observed by watching from time to time.

Cut off the foot, and pin out on cork the web between two of the toes. Pour a little 95 p.c. alcohol on the foot. In about 5 minutes cut out the web, and put it in 95 p.c. alcohol in a watch-glass. In a quarter of an hour transfer to fresh 95 p.c. alcohol for another quarter of an hour. Then remove excess of alcohol by pressing the web for a moment with dry blotting-paper, and place in oil of cloves. When the web is transparent, mount in balsam; and examine again the pigmentcells.

Pigment-cells will be seen later in preparations of the mesentery, and of the lymphatica cisterna magna (Lesson xviII. $\$ 1,2$ ).

16. Fat-cells. Cut out a small piece of the omentum, from a part containing comparatively little fat. Spread it out on a slide and mount it in normal saline solution. Observe

a. Under a low power, the groups of highly refractive fat-cells.

b. Under a high power, the variable size of the fat-cells, the apparent absence of a nucleus, the connective tissue passing between and over the cells.

17. Place a similar piece of omentum in osmic acid $\circ$ p.c. for about half-an-hour, wash with water, cut in half, mount one half at once in dilute glycerine, and 
the other half, after staining it for an hour in picrocarmine. Observe that the fat-cells are stained a deep brown-black (cp. Lesson Ix. $§ 4, b$ ). If the tissue before being mounted be kept in alcohol (e.g. 70 p.c.) for a day the tint of the fat globules will become deep black.

18. Make a moist film preparation of the sub-cutaneous comnective tissue of a rat containing a small amount of fat, and fix it in alcohol. Stain with hæmatoxylin and eosin. Examine (h.p.); the fat-cells will probably show a distinct sponge-work or network of cell substance.

\section{DEMONSTRATIONS.}

1. Transverse section of ligamentum nuchæ. Note the commonly angular outline of the elastic fibres, and the small amount of white fibrous tissue.

2. Section of a lobule of fat (Müller's fluid, hæmatoxylin, turpentine or xylol, balsam). Note the closely set groups of cells, the small amount of cell substance at the periphery of each cell, and the flattened nucleus.

3. Section of umbilical cord to show mucous connective tissue (formaline, picrocarmine). Note the large amount of homogeneous substance, the scanty fibres, and the branched cells.

\section{NOTES.}

Hardening tendon. A tendon may be hardened by placing it fresh in 30 p.c. alcohol for a few hours, and then in 75 p.c. alcohol; or by placing it in a saturated aqueous solution of corrosive sublimate for a day. 
Tendon. A good preparation of the elastic fibres in tendon may be made by placing a fresh rat's tail tendon in picric acid and in water each for a day, and then staining with orcein. Accompanying nearly every row of tendon cells will be seen one, and sometimes two, fine elastic fibres; here and there an elastic fibre runs across, or sends a branch across to join a neighbouring fibre. In the sheath of the tendon bundle are more numerous elastic fibres, the sheath will be for the most part burst open, but here and there the elastic fibres in it constrict the tendon bundle.

The cells may be stained by placing a swollen bundle in very dilute hæmatoxylin for a day; it should be washed well with water and mounted in glycerine.

Sub-cutaneous tissue. The elastic fibres may be stained with orcein in the manner given in $\$ 2$, either in a dry film, or in a moist film fixed with alcohol. They appear as small threads of different size, here and there anastomosing. In the frog the areolar tissue which, at the sides of the body, separates the dorsal from the ventral lymph sacs has comparatively little elastic tissue; that stretching from the skin to the upper ventral portion of the thigh has much.

The basophil cells vary in appearance in different animals. They are easily preserved and they stain with hæmatoxylin, saffranin and a number of reagents as well as with methylene blue.

Coarsely granular oxyphil leucocytes are often numerous, they are perhaps best seen in dried films.

The cells of connective tissue are fairly well seen in a film fixed in 1 p.c. osmic acid for half-an-hour, overstained with methylene blue, excess of stain removed with alcohol, and mounted in balsam.

Branched connective tissue cells are well seen in the tail of the tadpole (Perenyi's fluid) stained with picrocarmine. The surface epithelium is removed by lorushing or partial teasing. The preparation may also show a stage in the development of capillaries.

Fat tissue. The general characters may be observed in films of sub-cutaneous fat, instead of in the omentum. 
Fat tissue for sections may be taken either from the omentum, or from the mass at the hilus of the kidney.

Quinoline blue dissolved in dilute alcohol is sometimes used for staining fat. The sections are overstained, and decolourized by 35 p.c. potassium hydrate. Sudan III in alcoholic solution is a better stain, the sections are mounted in glycerine.

Sections containing fat which have been treated with osmic acid, are best treated with chloroform and chloroform balsam instead of xylol and xylol balsam, since xylol has a more or less solvent action on the fat.

For action of osmic acid on fat cp. App. p. 325.

Elastic tissues are best stained with orcein (cp. p. 312), but good preparations are also obtained by hardening in chromic acid, and staining in saffranin.

White fibrous tissue is rapidly and deeply stained with acid magenta (acid fuchsin). See Appendix p. 311 for stain with aniline blue.

For removal of pigment cp. App. p. 327. 


\section{LESSON XI.}

FIBRO-CAR'TILAGE. ELASTIC CARTILAGE. BONE. TEETH.

1. Fibro-cartilage. Sections of semi-lunar cartilage of knee joint of dog (picric acid; cut frozen) cut parallel with the mass of the fibres. Stain one section with picrocarmine, and another with hæmatoxylin; mount together in glycerine. Note

The bundles of white fibrous tissue.

The rather large cartilage cells lying here and there between the bundles of fibres, and usually in rows; each is surrounded by a capsule consisting of a small amount of hyaline cartilage.

2. Sections of intervertebral disc with adjoining faces of the vertebræ, cut at right angles to the faces of the disc. Stain with hæmatoxylin or picrocarmine. Note

The intervertebral disc, consisting partly of fibro-cartilage, partly of ligamentous tissue. The bundles cross, chiefly in two directions, at right angles to and parallel to, the faces of the disc.

The fibro-cartilage passing on the faces of the disc either into a thin layer of hyaline cartilage or directly into the decalcified bone, and on its surface into fibrous connective tissue. 
A thin layer of spongy bone, the spaces containing red marrow with a considerable number of fat-cells.

A little farther from the disc, a layer of cartilage, with cells in rows as if ossifying; and a little farther still, spongy bone with red marrow and fat-cells.

\section{Elastic Cartilage and transition to Hyaline} Cartilage. Vertical sections of apex of (e.g.) sheep's arytenoid cartilage ${ }^{1}$ (picric acid).

a. Stain a section with dilute hæmatoxylin (half-

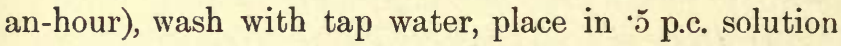
of acid magenta in 75 p.c. alcohol for a few seconds, and then in water or dilute alcohol till the deep red tint of the section is lessened. Dehydrate and put in clove oil.

b. Stain another section in the following way: put it in a small quantity of orcein solution (cp. p. 311) in a watch-glass, place the watch-glass on the warm bath till the solution has nearly evaporated, wash the section with water, put it in acid alcohol for a minute or two till the connective tissue at the edge is nearly decolourized; dehydrate and put in clove oil.

Mount the two sections together in balsam and observe (h. p.)

The hyaline cartilage, showing at its upper border, fine granular fibres-the elastic fibres-in the matrix. These rapidly increase, till the matrix consists

1 The apex of the arytenoid cartilage is cut off and the mucous membrane removed; the two small elastic cartilages at the top (cornicula laryngis) may be left unless they make the section too long. The epiglottis may be taken instead of the arytenoid, but it does not contain hyaline cartilage. 
largely of a close meshwork of fibres, leaving a hyaline portion (stained blue in a) immediately around the cells. In places, the elastic substance may take the form of thick nodular bars.

Externally, areolar tissue; note the transition of the elastic cartilage into this by the elongation of the cells, the disappearance of the capsules, and the substitution of white fibrous tissue for most of the elastic fibres.

The elastic fibres are best shown in $b$, the cells and their hyaline capsules in $a$.

A section may also be stained in picrocarmine for an hour or more, and another in hæmatoxylin and picric acid, and the two mounted in glycerine. In the former the perichondrium is stained red and shows well the passage of this to the cartilage, in the latter hyaline cartilage is stained blue and the elastic fibres deep yellow.

Cartilage is apt to buckle when dehydrated so that it is generally best to mount it in glycerine.

4. Structure of Bone. Transverse section throngh the shaft of an adult long bone. (The bone is dried; thin pieces are cut with a saw, ground down and mounted in balsam.) a. Examine under a low power. Most of the smaller spaces (i.e. Haversian canals, lacunæ, canaliculi) will be filled with air or débris and will therefore appear dark. Observe

The central medullary cavity surrounded by bony substance.

At the circumference, the circumferential lamellæ running parallel with the surface; inside this the Haversian systems, each consisting of a Haversian canal surrounded by concentric lamellæ which are 
chiefly marked off from one another by the lacunæ lying between them.

Between the Haversian systems the intersystemic lamellæ running in various directions.

Next the central cavity either $(a)$ a layer of lamellæ which run parallel with those of the surface, or $(\beta)$ a thin layer of spongy bone having rather large spaces, the Haversian spaces, continuous here and there with the Haversian canals on one side and the medullary cavity on the other. The arrangement as regards $(a)$ and $(\beta)$ varies in different parts of the shaft and in different bones.

In the spongy bone the lamellæ run in the main concentric with the spaces.

\section{b. Examine under a high power. Observe}

'The irregularly fusiform lacunæ giving off numerous wavy branches, the canaliculi, which run across the lamellæ. The canaliculi of any one lacuna either join the similar branches of neighbouring lacunæ or open on the free surface of the lamella.

5. Longitudinal section of the shaft of a long bone. (Prepared as in $\$ 4$.)

a. Examine with a low power. Observe

The Haversian canals running in the main parallel with the surface of the bone, they have connecting branches and open here and there on the surface and into the central spaces.

The lamellæ running for the most part parallel with the Haversian canals. Where a Haversian system is cut obliquely the lamellæ are concentric with the canal. 
b. Examine under a high power. The individual lacunæ are much as in the transverse section, but rather longer; observe the arrangement of the canaliculi (cp. $\S 4, b)$.

6. Transverse sections (in paraffin) through the shaft of a decalcified and stained adult long bone ${ }^{1}$, as femur of rat. Mount in balsam. Note

The periosteum formed of connective tissue closely attached to the bone.

In the bone, each lacuna is occupied by a cell, the bone corpuscle, probably shrunken from the walls of the lacuna. The canaliculi are scarcely visible.

The Haversian canals are chiefly occupied by small blood vessels, the Haversian spaces by blood vessels and leucocytes.

The white marrow, consisting mainly of fat-cells (cp. Less. Ix. §14). Small clumps of marrow cells are seen, most of them are either leucocytes or resemble leucocytes, and here and there giant cells, large cells with irregularly lobed nucleus.

7. Remove the periosteum from a decalcified parietal bone (nitric acid); tear off from the surface thin strips of the bone matrix and mount them with the inner side uppermost in water. Under a high power note the perforating fibres projecting from the surface and the apertures through which similar fibres have passed. Examine carefully the thinnest part of the strip (containing fewest lamellæ) for the fine decussating fibres of the matrix; add acetic acid, both the perforating and decussating fibres swell up and become indistinct or lost to view.

1 For methods of decalcification cp. Notes at end of Lesson. The tissue may be stained in bulk with picrocarmine, but it is better to stain the sections on the slide (Less. vr. § 5). 
8. Homatoblasts. Cut out a rib of a freshly killed rat or other mammal, scrape off the external tissue, cut it open, remove a little of the red marrow to a cover-slip and spread it out making a dry film. Stain with eosin and methylene blue as in the case of a blood film (p. 18), but leave 2 to 3 minutes in the eosin, and $1 \frac{1}{2}$ to 2 minutes in the methylene blue.

Note (h.p.) the hæmatoblasts with cell substance stained orange, and rather small deeply stained nucleus. Numerous coarsely granular leucocytes with granules stained red will be scen, also oxyphil cells with large faintly stained nucleus, basophil cells faintly stained (without distinct granules) and other leucocyte forms.

9. Ossification. Longitudinal sections through the head of the femur of a newly-born (or fotal) cat or rabbit (picric or chromic acid). Stain with hæmatoxylin and eosin, mount in balsam.

Observe (l. p.) passing from the head to the shaft The normal hyaline cartilage.

The longitudinal rows of cartilage cells; many of the cells are triangular in section. The layer of large, probably shrunken, cartilage cells; they are also in rows and have only a small amount of matrix around them.

The irregular spaces (secondary areolæ) of the primary endochondral bone. The bony trabeculæ may show a thin central portion of decalcified cartilage stained with hæmatoxylin'.

Note on the outside of the bone below the head, the periosteum, and the layer of spongy periosteal bone beneath it.

1 The two parts are also distinct in sections stained in the Ehrlich-Biondi mixture. 
Observe (h. p.) the osteoblasts, covering the trabeculæ and in the spaces; they are larger than ordinary leucocytes, with a single ovoid or spherical nucleus, and finely granular cell substance. The spaces also contain blood vessels and some jelly-like connective tissue.

Osteoclasts may be seen here and there in contact with the bone matrix; they are large multinuclear cells, and where they touch the bone are often striated at right angles to the surface.

10. Transverse section of the shaft of the bone used in $\S 9$, stained with hæmatoxylin and eosin. Note

The spongy periosteal bone beneath the periosteum, the osteoblasts especially numerous in the lower layer of the periosteum, and in the peripheral bone spaces. Many of the osteoblasts are elongated and their smaller ends appear to run into the matrix.

The spongy endochondral bone in the centre; there may be the beginning of a central space but no fatcells are present.

11. Structure of Teeth. Longitudinal sections of teeth prepared as bone, $\S 4$. a. Examine under a low power. Observe the dentine surrounding the pulp-cavity, the cement or crusta petrosa covering the dentine of the fangs, and the enamel covering the dentine of the crown. Note the general arrangement of the dentinal tubules.

b. Examine under a high power, and study in detail

The Dentine. In the matrix, apparently homogeneous, are numerous dentinal tubules which run in a 
wavy course from the pulp-cavity outwards. These, dividing as they go, and giving off many anastomosing lateral branches, finally end either in loops or in small irregular cavities, the so-called interglobular spaces, on the surface of the dentine.

In some places the dentinal tubules are cut transversely. Here the central dark spot indicates the space formerly occupied by the dentinal fibre, the ring round this is the dentinal sheath.

The Cement or Crusta Petrosa. This differs little from bone, but Haversian canals are generally absent.

The canaliculi of the lacunæ next to the interglobular spaces, open into these, thus bringing the dentinal fibres into connection with the bone-corpuscles.

Where the cement is massive, wavy 'contour' lines may be seen, indicating the successive deposits.

The Enamel, consisting of striated fibres or prisms, perpendicular to the surface of the dentine.

12. Sections of lower jaw of a fotal mammal (chromic acid 0.2 p.c.). Stain with picrocarmine or as in $\S 9$. Note the stages of the development of the teeth, and also the osteoblasts and osteoclasts of the young sub-maxillary bone.

\section{DEMONSTRATIONS.}

1. Longitudinal section of insertion of round ligament into head of femur (picric acid, hæmatoxylin). Note the transition from the fibrous tissue of the ligament to fibro-cartilage, and from this to hyaline cartilage. 
2. Transverse section of dried parietal bone. Note the surface layer of compact bone and the median layer of spongy bone.

3. Transverse section of rib to show red marrow ${ }^{\mathbf{1}}$. Note the numerous marrow cells, the scattered fat-cells and occasional giant cell.

4. Transverse sections of teeth through the crusta petrosa and through the crown. Compare with the longitudinal sections described in the text.

5. Longitudinal section of decalcified tooth, showing the pulp.

\section{NOTES.}

Intervertebral discs. Remove the spinal cord from (e.g.) a rabbit. Take several successive vertebræ. Saw through them about $3 \mathrm{~mm}$. from the intervertebral dise. Place the discs with the bone attached, in a hardening and decalcifying fluid.

Hormatoblasts. A film may be fixed in the manner given for blood (p. 28) and then stained with hæmatoxylin and pieric acid or hæmatoxylin and eosin. Or a film may be fixed by osmic acid vapour and allowed to dry.

To see the hæmatoblasts in the fresh state the marrow is teased in salt solution tinged with methyl-violet; different strengths of salt solution should be tried.

Red marrow may be fixed in bone by mercuric ehloride, Muiller's fluid, or other agent which fixes hæmoglobin. The bone is decalcified by picric acid.

${ }^{1}$ Short piece of rib of growing animal, fixed in mercuric chloride; decalcified; imbedded; stained on the slide. 
Fat marrow may be obtained by splitting a long bone, it may be fixed in mercuric chloride, formaline, or in any of the usual reagents; or a short piece of bone may be put in the fixing agent for a day or more and the medulla then pushed out with a rod.

Fixing and decalcifying bone and teeth. Tissues containing lime salts may be treated with a hardening agent before decalcification; or treated with a reagent which fixes and decalcifies at the same time. As soon as decalcification is complete the tissue should be washed in running water for one to two days; as a rule it is best not to cut at once but to pass through alcohols, and keep in 75 p.c. to 95 p.c. alcohol for some days.

Fixing. Any fixing agent may be used; if the piece of bone is not too large, those which penetrate best such as alcohol are most generally applicable.

Decalcifying after fixation. The tissue is placed in

(a) 1 to 2 p.c. nitric acid.

(b) 75 p.c. alcohol containing 1 to 2 p.c. nitric acid.

The process may be quickened, if necessary, by using stronger acid up to 5 p.c.

(c) Strong nitric acid with phloroglucin. This is used where rapid decalcification is required; add 1 gram of phloroglucin to 10 c.c. of nitric acid $1 \cdot 4$ sp. gr., warm slowly and carefully, stirring the while; a rather violent solution of the phloroglucin will take place, forming a dark red fluid. To this add 100 c.c. water and 10 c.c. nitric acid. (Haug.) Foetal and young bones are decalcified in about half-an-hour; small pieces of hard adult bones in some hours: large pieces of hard bone and teeth take a day or more.

Simultaneous fixation and decalcification. The decalcification in this case is slow (one to several months). The fluid should be shaken gently every day, and renewed at intervals of a few days.

Picric acid in saturated aqueous solution gives excellent 
results. After a fortnight the decalcification may be quickened by adding nitric acid up to 1 p.c.

Chromic acid. The tissue is placed in $\cdot 2$ p.c. chromic acid for about two days, then in 5 p.c. and this must be renewed several times. The final stages may be hastened by adding to the chromic acid, nitric acid up to 1 to 2 p.c. ; or by using Perenyi's fluid (cp. p. 299). 


\section{LESSON XII.}

\section{CILIATED CELLS. UNSTRIATED AND CARDIAC MUSCLES.}

1. Ciliated Cells. Cut off the head of a recently pithed frog, and cut away the lower jaw. With fine forceps and scissors, cut out on one side a piece of the mucous membrane of the roof of the mouth and place this on a slide, mucous surface uppermost. Pour 2 or 3

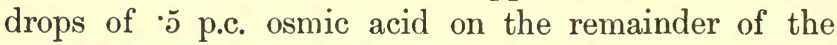
mucous membrane of the roof, cover it with a watchglass for 15 to $20 \mathrm{~min}$. and continue as in $b$.

a. To the piece of membrane on the slide add a drop of 6 p.c. sodium chloride; scrape the epithelium from a portion of the membrane and tease some of the scrapings in the salt solution. Place a fragment of paper at the edge of the drop; and cover. Note

The shimmering appearance caused by the movements of the cilia in the larger portions.

The movements of the cilia in the isolated cells or clumps of cells. Observe carefully the cilia which are moving slowly; it may be seen that the down stroke (contraction) takes place more quickly than the return 
(relaxation); there is no perceptible pause between the two movements.

The results of ciliary action. Granules and bloodcorpuscles are driven along; detached cells may also be seen carried about by the action of their own cilia.

The contracted, almost globular form of the isolated cells.

Note also the movements in a hanging drop. Cp. p. 12.

b. Remove from osmic acid to water; cut out a piece of the mucous membrane, wash it gently with water, place it in picrocarmine for $\frac{1}{2}$ hour to a day, wash, scrape off a little of the epithelium, transfer to a small drop of water faintly coloured with picric acid, tease, cover, and examine (h. p.). Note

The patches of epithelium consisting of ciliated cells and of swollen mucous (goblet) cells. Viewed from the side, adjoining ciliated cells are seen nearly to cover in at the surface the mucous cell between them. Viewed from the surface, numerous, closely set, rather faint dots represent the cilia, here and there are seen the small round openings of the mucous cells, at a lower focus the swollen portions of the mucous cells come into view, surrounded by narrow stained bands, formed of the bodies of the ciliated cells.

The isolated ciliated cells. (If the isolation is not good, tap the cover-slip.) The cilia are densely studded over the whole surface. Beneath the cilia is a hyaline or faintly striated layer, the hyaline border. A little below this, the cell generally tapers, $\mathrm{cp}$. the shape with that seen in $a$. The stained nuclei are conspicuous.

The preparation may be preserved by adding a drop 
of dilute glycerine to the edge of the cover-slip so that it gradually takes the place of the water, but the cilia will then be less obvious.

2. Unstriated muscle. Remove the stomach of the frog used in $\S 1$. Cut it open, and pin it out. Take up the edge of the mucous membrane with forceps, partly tear and partly cut it away from the muscular coat. Place a piece of the muscular coat about $3 \mathrm{~mm}$. square in a watch-glass with 35 p.c. potassium hydrate. In 20 to 30 minutes, tease the piece in the watch-glass into smallish fragments, remove one or two of these to a slide,- - tease further, cover and tap lightly. Note (h. p.)

The isolated muscle cells, long cells tapering at the ends; in some the nucleus-here pale and watery looking-will be seen in the mid and broader region.

The tapering ends of the cells projecting from the less teased fragments of tissue.

3. Cut out one half of the bladder of a pithed frog; put it in normal salt solution and cut it open. Make a moist film preparation, mucous membrane uppermost (Less. x. $\S 8$ ), rubbing it gently with the finger or with a brush to remove the epithelium and to extend the tissue as much as possible. Fix with alcohol. Examine (h. p.) to see that the epithelium is removed. Press with blotting-paper, add hæmatoxylin at once. When it is rather deeply stained, wash, blot again, and add eosin in 75 p.c. alcohol. In about a minute, pour off the eosin, cover with 95 p.c. alcohol until the red colour is not very marked; blot, at once add clove oil. Mount in balsam. 
Note the plexus of unstriated muscle cells ${ }^{1}$.

4. a. Tease out in dilute alcohol a little of the body muscle of a worm (the worm is cut up, washed in 30 p.c. alcohol and kept in fresh 30 p.c. alcohol for one to three days). Note (h. p.) the cells are longer and inuch flatter than in the frog, when seen flat they show a more or less distinct longitudinal fibrillation.

b. Stain a small piece with acid hæmatoxylin, wash, and tease in dilute glycerine. The nuclei are round or oval, and are on the surface of the cells; some will probably have been removed in teasing. (The position of the nucleus varies in different invertebrate muscle cells.) Compare with the muscle cells of vertebrates, $\S 2$.

5. Treat, as in $\S 4 a$, a little of the yellowish anterior part of the posterior adductor muscle of an anodon. Note (h. p.) the double oblique fibrillation of the muscle cells; the angle between the two sets of markings is greater the more contracted the cell.

6. Cardiac muscle. 'Treat a small piece of the ventricle of just killed rat or mouse with 35 p.c. potassium hydrate by the method given in $\S 2$. In the teased specimen, note

The isolated muscle cells; they are short, thin columnar cells, many having a short process coming off obliquely from the body of the cell. At about the centre of each cell is a nucleus. The transverse striation is not very distinct. The cells have no sarcolemma.

7. Isolate the cardiac inuscle cells of the frog by the method given in $\S 2$.

${ }^{1}$ A fine plexus may also be seen in the mesentery of the newt. 
Note that the cells generally resemble unstriated muscle cells in shape, but are much shorter and are transversely striated. By this method the striation is not marked.

Some cells may be seen with branches or with flattened expansions.

\section{DEMONSTRATIONS.}

1. Longitudinal section of the intestine of cat or dog at right angles to the surface. (Alcohol or $\cdot 2$ p.c. chromic acid; hæmatoxylin.) In the longitudinal coat, note the sheet of muscle cells with elongated stained nuclei; in the circular coat, which is cut transversely, note the bundles of muscle cells; the nuclei are only seen in some of the cells; they appear as round, deeply stained central spots.

2. Muscular coats of intestine of frog treated with nitrate of silver. Note the black lines of cement substance between the muscle cells (cp. Less. XviI. §2).

3. Transverse section of worm (osmic acid). Note the band shape of the longitudinal fibres, and their attachment at one edge.

4. Section of ventricle of a small mammal (alcohol; hæmatoxylin). Note the meshwork formed by the junction of the cells, and the hyaline cement substance at the junctions.

\section{NOTES.}

Isolation of unstriated muscle. Potassium hydrate 35 to 40 p.c. affords the readiest means of isolating muscle cells united by cement substance, whether the cells are unstriated or cardiac. The cells when isolate may be preserved by throwing them 
into a considerable excess of 50 p.c. acetic acid, and after a few minutes washing with water, they may be stained in picrocarmine or other carmine fluid and mounted in glycerine or in Farrant's solution. The separation of the cells from the several fluids is best done by a small centrifugal machine.

This method is only good for observing the shape of the cells. The nucleus and the sarcoplasm of the cells are better seen by the following method. A small strip of muscular tissue is stretched and placed in 1 p.c. potassium bichromate or in 30 p.c. alcohol for 2 to 3 days, washed with water, stained with $e g$. picrocarmine by irrigation under the cover-slip and mounted in dilute glycerine. 'The isolation of the cells is however not very good.

Ordinarily it is best to distend the tissue with the isolating agent, when this can be done, as in the case of the bladder and intestine. After leaving in this for one day, it may be cut open and left in an aqueous and dilute alcoholic stain for one or two days before teasing.

When it is desired to isolate a few muscle cells imbedded in much connective tissue the following method may be employed. A small piece of the tissue is placed in 15 to 20 p.c. nitric acid for a day, it is then slightly teased, and shaken up well in a testtube with water, centrifugalized, and the residue examined.

Longitudinal fibrillation. This is much more distinct in invertebrate than in vertebrate unstriated muscle; for vertebrate muscle Ranvier recommends the intestine of the frog (distended with 30 p.c. alcohol for one or two days, and a strip of muscular coat teased). Engelmann recommends the fresh stomach wall of the frog treated as follows: a section of the muscular coat at right angles to the circular fibres is made with a Valentine's knife, it is mounted in 10 p.c. $\mathrm{NaCl}$ and examined at once. Faint dots indicating fibrillæ may be seen in the transverse sections of the muscle cells.

Double oblique fibrillation. According to Schwalbe this is seen best in Solen, well also in the oyster and fresh-water mussel. In anodon cut through the attachments of the posterior 
adductor muscle so that the muscle retracts, and take the anterior yellowish part.

The nucleus in Cœlenterates and Echinoderms is usually on the surface of the muscle cell, it is usually in the muscle substance in Nematodes and Leeches and surrounded by a good deal of sarcoplasm, which may spread out in rays to the periphery.

Purkinje's cells of the heart. These show as transparent lines and patches under the endocardium, they are most readily obtained from the fresh heart of a sheep. For isolation of the cells, the pieces of endocardium are placed in 33 p.c. alcohol for a day or two, stained with picrocarmine and teased in dilute glycerine. The cells are irregular discs, striated at the periphery.

Staining unstriated muscle in sections. Place for 10 minutes in 1 p.c. methylene blue (polychromatic), put in water 15 to 30 secs., then in 1 p.c. ferricyanide of potassium for 10 minutes, transfer to acid alcohol till sufficiently decolourized, wash in alcohol and mount (Unua). 


\section{LESSON XIII.}

\section{STRIATED MUSCLE.}

1. Striated muscle of frog. Cut through the skin of the front of the thigh of the frog, note the band-like sartorius muscle running somewhat obliquely across the thigh from the pelvis to the knee, seize with forceps the connective tissue lying along each border and tear it away from upper to lower end.

Take up with fine forceps a few fibres at one end of the muscle, and gently pull them out to the opposite end. Stretch out the bundle on a dry slide, separate the fibres a little in the centre, place a bristle across them and press gently; remove the bristle and put on a cover-slip.

a. Note (h. p.) the fairly transparent muscular fibres and their varying size.

The transverse striation; alternate dim and light bands, the thick discs and light discs passing through the whole thickness of the fibre.

Longitudinal granular lines or rows of small granules, indicating the sarcoplasm, varying greatly in number and distinctness in different fibres. 
b. Add a drop of normal salt solutiın. 'The longitudinal granular lines will become more distinct. Some of the fibres may show a distinct longitudinal as well as a transverse striation.

Where the bristle was pressed on the fibres, the muscular substance will in some cases be broken, leaving a delicate structureless sheath, the sarcolemma, stretching across the gap; possibly in other places, as where a fibre is bent, the sarcolemma may be seen as a fine bulging line.

c. Irrigate with 1 p.c. acetic acid; after a time the shrunken elongated nuclei of the fibres come into view scattered throughout the muscle substance.

2. Tear off a very small strip of frog's muscle (extended, and then fixed with alcohol), and tease out as finely as possible in dilute glycerine. Note (h. p.; oc. 4)

The transverse striation is more distinct than in $\S 1$. Sometimes a very thin dark line, the thin disc, or end disc may be seen in the middle of the light disc.

A longitudinal striation of the fibres is more or less marked, and some of the fibres have been split up into very fine transversely striated fibrils or bundles of fibrils. Tap the cover-slip; the longitudinal fibrillation will become more distinct, and some fibres may break across, forming discs.

3. Longitudinal sections of striated muscle of frog or mammal (mereuricolobide or alcohol) in paraffin. Stain on a cover-slip islly (\&p dpalif fod by the iron-hæmatoxylin method (cp. p. 287). Mount in balsatig and examine (h. p.) the transverse striation; 
at a certain stage of the decoloration of the fibres this is very distinct.

4. Cut through the skin in the mid ventral line in a small frog, lift up the flap of skin on one side over the middle of the sternum, a thin band of muscle, the sterno-cutaneous muscle (m. cutaneus pectoris), will be seen running from the skin downwards towards the lower part of the sternum. Cut through the skin above and below the muscle, and keeping it well stretched, pour a little 5 p.c. osmic acid over it. In a minute or so the muscle will be fixed (the connective tissue surrounding the muscle may be torn away with fine forceps but in doing this there is considerable danger of injuring the muscle and its nerve) ; cut it out, being careful to cut the upper end as close as possible to the skin; place it in osmic acid for 15 to 30 minutes, wash with water. Divide the muscle transversely near its upper end. Mount in glycerine, the upper end having the outer surface, and the lower end the inner surface uppermost (the latter will be required in Less. xIv. § 10).

Observe at the upper end of the muscle the endings of the muscular fibres; these will probably be covered by a good deal of connective tissue, but the rounded or conical ends of the muscle-substance of the fibres and the continuation of the sarcolemma into the connective tissue (tendon) will be seen.

The muscle, after it has been treated with osmic acid and washed, may be stained with picrocarmine; or the muscle of the opposite side may be fixed with alcohol (Less. x. \$ 9) and stained with picrocarmine; thus the nuclei will be brought out. The nerve fibres stain better if the muscle after osmic acid is placed for a day in 30 p.c. alcohul. 
5. Tease out a piece of the tendinous ending of a muscle from a frog treated as follows. The frog is pithed, placed in water at $50^{\circ}$ to $55^{\circ} \mathrm{C}$. and put aside for about fifteen minutes, the skin removed and the muscles placed in 70 p.c. alcohol. Observe (h. p.) the ending of the sarcolemma in the tendon.

The piece of muscle before teasing may be stained with picrocarmine.

6. Striated muscle of insect. Remove with as little injury as possible one of the thin muscles from the leg of Hydrophilus ${ }^{1}$, tease it out a little without adding fluid, and cover. The fibres will for a brief period be seen in a normal condition. In many, the alternate dim and bright striæ will be very distinct; in others the transverse markings will be more or less obscured by an appearance of longitudinal fibrillation. Occasionally fibres are met with, having only a confused granular aspect. If the preparation has been successfully made, waves of contraction may, at times, be seen to travel along the fibres.

Examine with the highest power available.

Where the transverse striation is distinct and the fibre extended, a longitudinal marking is indistinct or not seen in the light band, but is present in the thick disc-so that it looks like a series of rods-and is indicated in the thin disc by its granular appearance.

Where the fibre is contracted, it is broader, the discs are much closer together, the edge of the fibre is not a straight line but presents a series of small

1 If not obtainable, take the large common water-beetle (Dytiscus marginalis), or failing that a cockroach or a fly. 
bulgings, the bulgings are opposite the thick disc, the depressions are opposite the thin disc (this may be seen by watching a fibre as it contracts on dying); the thick discs are now bright-partly in consequence of the moniliform shape of the fibre-they are separated from one another by rather broad darker discs which represent the bright band and thin disc of the uncontracted fibre.

The nuclei, usually round, are imbedded in a granular mass of protoplasm (sarcoplasm); the whole forms a band or rod running a variable distance in the substance of the fibre. Irrigate with acetic acid 1 p.c. to make the nuclei more distinct.

7. Tease out a little of the wing (thoracic) muscle of an insect, note the small cylindrical striated fibres, the sarcostyles, all of nearly the same size, and the large amount of sarcoplasm. The sarcostyles though small are much larger than the fibrils seen in $\S 2$. Measure one or two.

8. Transverse sections of a piece of wing muscle from an insect (Flemming's fluid). Stain on a cover-slip. Note the round areas of the sarcostyles imbedded in the granular protoplasm.

9. Examination of muscle with polarized light. Place one Nicol's prism under the stage of the microscope in the position of the condenser. Select a specimen of striated muscle, in which the fibres are isolated, and the planes of the discs at right angles to the stage. Using an ordinary ocular, focus the piece of muscle to be observed.

Substitute for the ordinary ocular the frame containing an ocular with a Nicol's prism (the analyser) above it. Put the pointer of the analyser at 0 of the scale on the frame. Turn the frame with the analyser round one complete circle. The field during the complete revolution becomes dark twice and light twice. 
'Turn the frame so that the field is at its maximum brightness, and clamp the frame. Focus the muscle. Turn the analyser slowly through $90^{\circ}$, note that at $45^{\circ}$ the thick discs are light, i.e. they are doubly refractive; whilst the rest of the fibre more or less completely disappears.

Turn the specimen on the stage through an angle of $45^{\circ}$ to see if any other part of the fibre becomes visible. (If the principal plane of a doubly refracting substance is parallel to the principal plane of either prism, no light is transmitted.)

The disposition and amount of the singly and doubly refractive substance vary with the nature of the muscle and with its condition, whether fresh or hardened.

\section{DEMONSTRATIONS.}

1. Transverse sections of mammalian striated muscle (chromic acid 5 p.c.). Observe

The connective tissue around the whole muscle (epimysium) and around the bundles of fibres (perimysium); from this runs a small amount of connective tissue (endomysium) between the muscle fibres.

The cut ends of the fibres are finely dotted, corresponding with the fibrils.

The nuclei lie just beneath the sarcolemma, few or none being imbedded in the muscular substance of the fibres (cp. $\S 1, c)$.

2. Longitudinal section of mammalian striated muscle (alcohol, picrocarmine) to show the nuclei of the fibres.

3. 'leased striated muscle fibres (picric acid) to show the splitting of the fibres into discs.

4. Transverse section of (a) muscle of frog, (b) muscle of insect. Note the greater amount of sarcoplasm in $(b)$ than in $(a)$. Cp. with $§ 1$. 


\section{NOTES.}

Living fibres. Thin muscles may be pinned out whole over a ring of cork; the mylo-hyoid of the frog and the sub-cutaneous muscles of the face and neck of a rabbit may be so treated.

With thick inuscles a few fibres should be torn out and mounted in aqueous humour, fresh serum, or $\mathrm{NaCl} \cdot 75$ p.c. ; the fibres of insects are best mounted in the blood of the animal. According to Nasse, a 1 to 1.5 p.c. NaCl solution is better than a $\cdot 75$ p.c. solution for certain muscular fibres (e.g. of flies). In some fibres contraction waves may be seen; as the fibres die one part of the fibre may be seen to contract, and the contraction to spread from this spot towards the end of the fibres: the behaviour of the various bands should then be carefully noted.

Fixing and isolating agents. To observe the various bands the muscle should be stretched before being placed in the reagent. This may be done conveniently by cutting out the parts to which the muscle is attached, and pinning out the attachments of the muscle over a ring of cork; or by placing the whole animal in the reagent and selecting the extended muscles.

The best reagent to use is different in different cases: the following reagents generally give good results for teased specimens; absolute alcohol; osmic acid $\cdot 5$ p.c. for five to thirty minutes, then alcohol; a concentrated aqueous solution of salicylic acid-this, like alcohol, coagulates the proteids of the muscle, but it also swells up the connective tissue; 30 p.c. alcohol. When a muscle cannot conveniently be extended, a concentrated aqueous solution of boracic acid may be used; this does not coagulate the proteids of the muscle, and causes little or no shrinking (Nasse). For sections, any of the usual hardening agents will serve.

With insects, e.g. cockroach and dytiscus, the reagent may be injected into the body cavity, or the insect, e.g. a caterpillar, may be plunged whole in the reagent. In both of these cases some fibres may usually be found with fixed local contraction waves; a convenient way of obtaining fixed contraction waves is in many cases by tearing out a leg and plunging the protruding 
fibres into osmic acid 0.5 p.c. or into absolute alcohol: good specimens may thus be obtained from the crayfish and the reversal of the bands in contracted muscle seen.

The fibres are readily isolated by placing in 35 p.c. potassium hydrate for 20 minutes and then shaking.

A saturated solution of ammonium carbonate has been recommended to show the sarcolemma (a few minutes), and to cause transverse cleavage (six hours).

Staining. Teased muscle may be stained with hæmatoxylin, treated with acid alcohol and mounted either in dilute glycerine or in balsam. In extended muscle, the thick and thin discs are stained; in dytiscus leg muscle the lines of sarcoplasm will also be distinct. Strips may be stained in very dilute Renaut's hæmatoxylin and eosin for half-a-day to a day; care must be taken not to wash out the eosin in mounting.

Branched muscle fibres may be obtained from the tongue of the frog.

Preparation for polarized light. Stretch the muscles, and pin out, place in 50 p.c. alcohol for half-a-day to a day, pass gradually through the grades of alcohol, tease, clear with clove oil and mount in balsam. 


\section{LESSON XIV.}

\section{NERVE FIBRES.}

1. Spinal Nerves. Cut off $\frac{1}{2}$ to $\frac{3}{4}$ of a centimetre of a small, perfectly fresh nerve (e.g. a branch of the sciatic of a frog), and place it on a glass slide without any fluid. Fixing one end by pressing on it with the blunt end of a scalpel, pass a needle through the other end in the direction of the nerve fibres, and so spread them out into the shape of a fan; add a drop of normal saline solution, and cover with the cover-slip. Observe (h. p.)

The medullated nerve fibres of variable size; about $3 \mu$ to $18 \mu$ in diameter. Measure some (Less. IV.).

In each fibre the double contour, due to the medullary sheath.

The primitive sheath or neurilemma; this is seen with difficulty except at points where the medullary sheath has been displaced in mounting.

The nodes ; these will be seen as short but distinct breaks in the medullary sheath.

Drops and fragments of the medullary sheath, 
extending from the cut ends of the fibres and showing a double contour.

2. Treat a piece of nerve as in $\S 1$, but add a drop of $\cdot 2$ p.c. nitrate of silver instead of salt solution. Note the rapid staining of the cement substance at the nodes. Expose the specimen to light for half-an-hour. Take off the cover-slip. Dip the nerve in distilled water to remove the silver solution. Mount in dilute glycerine, spreading out the fibres of the teased end ${ }^{1}$. Note the small dark crosses formed by the nodal cement substance and the axis cylinder near the nodes. Probably the axis will also be stained at and near the cut ends of the fibres.

3. Take a short piece of nerve, and tease it into small bundles of fibres in a drop of 75 p.c. sodium sulphate. Run off the fluid, keeping the fibres on the slide with a needle. Add another drop of the solution, and run it off. Repeat this. Then add a drop or two of 2 p.c. nitrate of silver, and expose to light for about half-an-hour, avoiding drying. Wash in distilled water in a watch-glass, and mount in dilute glycerine, so that most of the fibres are parallel to one another. The staining will thus be more localized at and near the nodes than by method, § 2.

4. Tease out a piece of nerve as in $\S 1$. Add chloroform instead of salt solution, adding more chloroform as evaporation goes on.

In the middle of the nerve fibre the transparent axis cylinder will be seen running through the swollen medullary sheath.

1 In teasing out tissues which have been treated with silver or gold salts, it is best to use hedgehog quills; a quill is cut in half and the end thrust on the point of a needle. 
5. Take another piece of fresh nerve, and place it in a small quantity of osmic acid 5 p.c. for $\frac{1}{4}$ to $\frac{1}{2}$ an hour, covering it up to prevent evaporation. Wash it in water, place it in dilute glycerine for a minute or two. Pemove to a slide and tcase. Select a small bundle separated from the connective tissue sheath, and put the rest back in glycerine for use if required. 'Tease further the small bundle, and arrange the fibres parallel to one another; place a small drop of dilute glycerine on the centre of a cover-slip, and mount.

Select a nerve fibre which is isolated for a considerable part of its length, and observe

The medullary sheath, stained black with osmic acid.

The nodes; note that the distance between two successive nodes is greater in large than in small nerve fibres.

The numerous oblique breaks in the medulla, dividing it into short overlapping cylinders.

The nuclei of the sheath; there is one to each internode about halfway between the two nodes, it is an inconspicuous transparent elongated body, usually projecting into the medulla.

The nuclei of the sheath may be stained by placing a piece of the nerve, after brief treatment with osmic acid, in picrocarmine or in hæmatoxylin for an hour. In the former preparation, the cells of the fine connective tissue around the nerve fibres will also be well seen.

6. Transverse sections in paraffin of a large nerve stained with picrocarmine (potassium bichromate 2 p.c.). Mount in balsam. Observe

The epineurium surrounding the whole nerve and 
passing between the nerve bundles; it consists of areolar tissue (Less. x.).

The perineurium surrounding the nerve bundles, consisting of two or more concentric nucleated membranes.

The endoneurium between the nerve fibres, consisting of a small quantity of fine fibrous tissue.

The cut ends of the nerve fibres varying in diameter, and in each the section of the stained axis cylinder surrounded by a transparent ring indicating the former position of the medullary sheath, which has been dissolved or made transparent in the process of mounting. The primitive sheath as a limiting circle.

7. Cut through the skin of the frog in mid dorsal line. Cut out one of the small dorsal cutaneous nerves issuing from the muscles of the back and running to the skin. Place it in $\cdot 2$ p.c. nitrate of silver for 5 to 10 minutes. Wash in water and expose to light for about $\frac{1}{2}$ an hour. Dehydrate and mount in balsam. Note the layer of epithelioid cells-shown by the staining of their cement substance-covering the nerve. The nerve will be seen taking a somewhat sinuous course inside the epithelioid sheath.

8. Sympathetic Nerves. Cut out from the fresh spleen of a large animal (e.g. ox) a small piece of one of the large sympathetic nerves running alongside the blood vessels. Remove the connective tissue sheath, and tease out the nerve carefully in normal saline solution. Note

a. The scanty medullated nerve fibres.

$b$. The non-medullated nerve fibres constituting the bulk of the nerves. Add acetic acid to bring out 
more distinctly the elongated nuclei attached to them at short intervals.

9. Tease out in dilute glycerine a small piece of the cervical sympathetic nerve (osmic acid) of a cat or rabbit.

Note the numerous small medullated fibres; some non-medullated fibres may also be seen. Compare the size of the medullated fibres here (most about $3 \mu$ in diameter) and in the sciatic nerve $(\$ 1)$.

10. Peripheral Course of Nerves. In the specimen prepared Less. XıII. $§ 4$ : observe

a. Under a low power, the nerve running across the lower part of the muscle and sending off fibres or bundles of fibres at intervals and so spreading out over it.

$b$. Under a high power, that where the lateral bundles (especially the smaller ones) are given off; one or more of the nerve fibres divide into two fibres, the division taking place at a node. Trace a small bundle of nerve fibres, the nodes are very close together. Each nerve fibre apparently ends abruptly over a muscle fibre; in this specimen it can only be traced as far as the blackened medulla extends.

11. Examine the gold chloride preparation (made in Less. x. $\$ 7$ ) of the cornea. Note

$a$. The small separate bundles of nerve fibres entering the cornea at its periphery; the medullated fibres on account of their medulla are more deeply stained than the non-medullated fibres. 
b. Trace as far as possible the course of one of the nerve bundles; the medulla soon disappears, the fibres, still showing nuclei at intervals, join with the fibres from other bundles to form a coarse plexus; from this proceeds a plexus of smaller bands which have few nuclei; finally from this plexus run very fine varicose non-nucleated nerve fibrils in straight lines across the cornea (these fine fibrils may also be seen forming part of the finer bands of the plexus). The coarse plexus is the primary plexus of the cornea.

12. Neurokeratin network: Tease out in clove oil a piece of nerve which has been extracted with alcohol and ether (cp. Notes). Mount in balsam. Note the distinct network in the region formerly occupied by the outer part of the myelin sheath. The size of the meshes varies in different fibres.

\section{DEMONSTRATIONS.}

1. Transverse sections of sciatic, vagus, and cervical sympathetic nerves. (Cat or rabbit; osmic acid.) Note the relative size of the nerve fibres in the three nerves, and the number of non-medullated fibres in the vagus.

2. Transverse section of non-medullated nerve (splenic nerve of large animal; osmic vapour). Note the oval or circular outlines of the fibres; they vary very little in size, being generally $2 \mu$ in diameter.

3. Teased degenerating nerve fibres ( 5 days after section; osmic acid). Note the myelin broken up into masses and globules of various size; in places a considerable stretch of the nerve may show very little alteration. 
4. Similar nerve fibres in later stage (20 days after section). The myelin has nearly all disappeared, a few fibres still show here and there rows of fat globules.

\section{NOTES.}

\section{Medullated nerve fibres.}

Teasing osmic acid specimens. Nerves, either normal or degenerated, are placed in 1 p.c. osmic acid for 1 to 24 hours, washed in running water, put in 30 p.c alcohol for a day and teased in dilute glycerine. Nerves may be kept for a day or two in dilute glycerine before teasing, but the contrast between the small medullated and the non-medullated fibres becomes less distinct. In strong glycerine the small medullated fibres will be more or less decolourized; in alcohol the non-medullated fibres become dark brown and the whole brittle. If the nerve cannot be teased at once it is perhaps best kept in a saturated aqueous solution of potassic acetate.

In degenerated nerve treated with osmic acid leucocytes crowded in the early stages of degeneration with fatty globules, and in the late stages with yellowish-brown granules (probably from the neurokeratin), are seen. These vary much in number in nerves in different parts of the body and even in different regions of the same nerve. In most stages of degeneration, but especially the later ones, elongated masses of yellowish-brown granules are seen, which appear to be free and not contained in leucocytes. After the medulla has been absorbed the gencral appearance in teased specimens is like that of a non-medullated nerve. The nuclei in a degenerated nerve may be stained with picrocarmine or with a special nuclear stain. An increase of nuclei takes place about the 6th to the 16th day ; two nuclei are commonly seen close together, but dividing nuclei are rarely seen.

The grey rami of the rabbit contain very few medullated fibres, those of the cat and dog may have few or many; the 
anterior rami of the superior cervical ganglion of the cat have many.

Nerve stained with nitrate of silver. In teased fibres treated with silver nitrate, a 'bicone' may be seen at the nodes; this is a stained mass around the axis tapering off on either side away from the nodal region.

On irrigating teased fibres with $0 \cdot 1$ p.c. sodium hydrate, the nerve inside the neurilemma swells up, and the medulla flows out from the cut ends of the fibres; there is no appearance of any special resistance to the flow, such as would be caused by partitions, either at the breaks or at the nodes.

Stuining of axis cylinder. (a) The nerve is stretched and placed in Flemming's fluid for 1 to 6 days ; washed for a day in running water, stained for 1 to 3 days in $\cdot 5$ p.c. aqueous solution of saffranin; excess of stain extracted for a short time with 95 p.c. alcohol; then teased in glycerine containing a little saffranin. (b) The stretched nerve is placed in 10 p.c. aqueous or alcoholic solution of ferric chloride for one or more days, thoroughly washed, placed in a saturated solution of dinitrosoresorcin in 75 p.c. alcohol for 3 or more days, then teased out, or imbedded and cut. Both methods are used for degenerating and regenerating nerves.

Fibrillar structure of axis cylinder. Engelmann recommends irrigating the fresh nerve fibres of a frog with $\cdot 2$ p.c. silver nitrate. The following method is given by Kuppfer; the nerve is stretched, placed in 5 p.c. osmic acid for 4 hours, washed with water, placed in saturated aqueous solution of acid magenta for a day, absolute alcohol 1 to 3 days, imbedded and cut; the transverse sections of the axis cylinders show small deeply stained dots. Neither preparation is very convincing.

Neurokeratin network. Place pieces of nerve in absolute alcohol for a day, boil in the alcohol on a water bath for about 15 minutes and place in ether for a day. Part should be stained with hæmatoxylin, and part with osmic acid. The pieces may be kept in clove oil. 


\section{Non-medullated nerve fibres.}

Non-medullated fibres readily become varicose after death, and when treated with fixing agents. The following method gives good results; a bundle of the splenic nerve of any animal, or a grey ramus of a rabbit, is taken immediately after the death of the animal, pinned out so that the fibres are straight, fixed with osmic vapour (cp. p. 162) for 2 to 3 hours, placed in Flemming's fluid for 2 to 3 hours or till next day, washed in running water, stained with hæmatoxylin (this may be done later, on the slide), imbedded, and transverse sections cut. In such sections the fibres are circular, about $2 \mu$ in diameter, the outer part (sheath) stained deeper than the core; nuclei are seen here and there in the core.

The core of the non-medullated fibres may be stained in the fresh nerve with methylene blue; the nerve is teased out on a slide and before it becomes dry a drop of 06 p.c. methylene blue in 75 p.c. sodium chloride is added, this is left for 15 to 20 minutes, by which time examination with a low power should show fine blue filaments, probably varicose; a cover-slip is then put on, with or without replacing the methylene blue with salt solution, and examined with a high power.

Non-medullated nerves cut off in the body from their nerve cells retain for a long time their ordinary appearance when treated with osmic acid and teased out, they are however smaller owing to the disappearance of the core; the absence of the core may be determined by treating the fresh nerve with methylene blue. 


\section{LESSON XV.}

PERIPHERAL GANGLIA AND NERVE CELTS.

1. Transverse section of spinal ganglion ${ }^{1}$. (Osmic acid; paraffin.) Mount in balsam (cp. Less. vi. § 4).

a. Note with a low power; the sheath of the ganglion; the numerous nerve cells with medullated nerve fibres between them, comparatively few nerve fibres being present between the more peripheral cells; the transversely cut nerve fibres chiefly grouped at one side of the section. (The fibres of the anterior root may form a separate bundle with a distinct sheath.)

b. Note with a high power

The nerve cells of various sizes, the small ones as a rule being stained more deeply than the large ones; the cell substance varying from nearly homogeneous to coarsely granular; the large spherical nucleus, and large nucleolus or nucleoli.

The numerous large nerve fibres; some fibres will be seen coiling amongst the cells in the plane of the section.

${ }^{1}$ In $\$ \S 1$ to 3, the ganglion of a cat or dog may be taken. Specimeus 1 and 4 should be mounted on the same slide. 
The sheath of the ganglion consisting internally of several membranes, and externally of loose connective tissue.

2. Sections of a spinal ganglion (potassium bichromate; cut frozen). Stain a section in hæmatoxylin (or in this and eosin also) and mount in balsam.

Note around each nerve cell the numerous nuclei of the capsule.

3. Sections of spinal ganglion (mercuric chloride) given in paraffin. Take two cover-slips, fix sections to them, and treat them for staining on the eover-slip (Less. vi. § 5) up to the stage of placing them in 50 p.c. alcohol.

a. Place one slip in Nissl's methylene blue (cp. App. p. 310) for about 20 minutes (or warm it with the solution in a watehglass, till the fluid begins to steam). Blot it between folds of blotting-paper to remove excess of fluid; place it before it dries in a mixture of 10 parts aniline oil and 90 parts 95 p.c. alcohol. Gently move it about in this, till the blue colour of the section is rather faint (the proper tint can only be told by trial); then blot, transfer to absolute alcohol for 10 to 30 seconds and blot. Clear in xylol, mount in balsam, taking care that the balsam is added to the eover-slip before the xylol evaporates and the sections become dry.

Note in the nerve eells the basophil masses and granules stained deep blue; they vary in number and size in different cells, and are often absent from the peripheral zone; they are for the most part arranged eoneentrically around the nucleus.

b. Place the other slip for 1 to $1 \frac{1}{2}$ minutes in erythrosin (ep. p. 310) or eosin, blot, and treat as in $a$. The erythrosin stains the parts of the sections left unstained by methylene blue.

Methylene blue in 75 p.c. alcohol or Löffler's methylene blue may be used instead of Nissl's methylene blue; 95 p.c. alcohol may be used instead of aniline oil and alcohol, but this is apt to produce somewhat diffuse staining. 


\section{Transverse section of a sympathetic ganglion} from the sympathetic chain. (Osmic acid; paraffin.) Under both low and high power compare this section with that of the spinal ganglion in $\S 1$. Note

The nerve cells vary in size, but on the whole are not so large as in the spinal ganglion; they are more irregular in shape, and a considerable number of nonmedullated fibres lie between them.

The great majority of the medullated fibres are small $(2 \mu$ to $3 \mu)$.

5. Transverse section of lumbar spinal cord of ox, calf, or dog. (Potassium bichromate; cut frozen, picrocarmine two or more days.)

Note the large multipolar nerve cells of the anterior cornu; the processes are given off in all directions, some are cut short, others will be seen to divide in the section into finer and finer branches (protoplasmic processes or dendrons); here and there a cell may be seen from which a rather large process is given off which runs outwards through the white substance without branching (axis cylinder process or axon).

6. Take a little of the anterior cornu of the spinal cord from a recently killed animal, spread it out on a cover-slip and make a dry film. (The film may be fixed by heating in the manner given for blood Less. III. $\S 4$; this is not necessary, but it helps to prevent diffuse staining.) Stain as in $\S 3 a$.

Observe (h. p.) the isolated nerve cells with their branches and basophil clumps and granules. Where the axon leaves the cell, there is usually a cone of cell substance without basophil material. 
7. Tease out in formic glycerine a small piece of the spinal ganglion of a skate (ganglion in 30 p.c. alcohol for 3 days, one day in picrocarmine, washed; kept in glycerine).

Note the bipolar cells, forming oval to spherical nucleated swellings on the course of a nerve fibre. The connective tissue sheath of the nerve will be seen to run over the cell and form its capsule.

8. Spiral nerve cells of the auricular septum of the frog. Take a pithed frog: expose the heart, cut through the pericardium, lift up the edges and cut it away so far as it is seen. Turn the ventricle forward, tie its ligament and cut peripherally, lift up the heart by the ligament and pass two silk threads under the aortæ. Draw one backwards, and tie, the veins running to the heart; in doing this lift up the ventricle by the ligament and make certain that the auricles are not included in the ligature.

With scissors make an incision into the bulbus just before it branches, being careful not to cut it through. Squeeze the heart a little to empty it, wipe away the blood with a piece of sponge moistened with normal salt solution. Put a fine pointed cannula provided with a short piece of india-rubber tubing into the bulbus, prop up the tubing so that the cannula will not slip out, tie it in the bulbus. By means of a pipette fill the cannula with salt solution, squeeze the tubing and so force the salt solution into the heart. Remove the fluid from the cannula by means of the pipette, fill with fresh salt solution, and so on till the fluid returning to the cannulia from the heart is colourless.

Empty the cannula, fill it with 5 p.c. gold chloride, take a glass rod which fits the tubing, and slowly push it in so that the heart is distended with gold chloride. See that the right auricle is distended for a minute or two; then lift up the heart by means of the cannula and the thread tied round the veins, and cut peripherally of the ligatures. Place the heart in a little gold chloride solution in a watch-glass for half-an-hour. Transfer to water, cut away the bulbus with the cannula, the superfluous 
tissue round the auricles, and two-thirds of the ventricle. Move about in the water, and place in 25 p.c. formic acid in the dark till next day.

Then wash in water, and under a dissecting lens cut through the projecting wall of one auricle, note the position inside of the thin membrane, the septum auricularum, and cut away from it the auricles and the rest of the ventricle. Mount it in formic glycerine. Note $(a)$ the two main strands of nerve fibres running through it; the medullated fibres in these will be stained more deeply than the non-medullated fibres. (b) The septum itself formed of a plexus of cardiac muscle cells in a connective tissue membrane. (c) The numerous nerve cells attached to the nerve-strands. The nerve cells are generally pear-shaped. The spiral process may be seen coiling round the straight process, but it is not usually distinct.

(The heart may of course be injected from the inferior vena cava; the method described above is recommended because it is perhaps easier to insert a cannula into the bulbus than into the vena cava.)

The heart may be injected with alcohol; in this case inject weak before strong alcohol, and colour the strong alcohol with a little eosin, so that the septum may be more easily seen. Pass scissors down the bulbus into the ventricle and cut; cut off three-fourths of the ventricle, pass seissors from the ventricle into one auricle and cut. The septum can then be readily separated under a dissecting leus, and stained with any reagent desired.

9. Nerve cells of Auerbach's plexus. Cut through and reflect the abdominal walls of a recently killed mouse or rat. Cut out about two inches of the small intestine, tie a cannula in one end, and using a syringe wash out the intestine with normal salt solution. Tie the free end. With a pipette fill the cannula with 1 p.c. gold chloride, distend the intestine with this, tie just below the cannula, whilst the intestine is still distended. Place it in a watch-glass in gold chloride solution for $\frac{1}{2}$ to 1 hour. Remove to water; cut open lengthways, and wash well. Place in 25 p.c. formic acid in the dark till next day. 
Scrape off the mucous membrane, and mount in formic glycerine two pieces of the muscular coat, one with the outer, the other with the inner surface uppermost. Note the widemeshed plexus of Auerbach between the muscular coats; the meshes are rectangular and groups of close-set small cells lie at the nodal points, their nuclei staining less than the cell substance. The plexus of Meissner may be seen in places in the sub-mucous layer; it is similar to that of Auerbach but the meshes are irregular in shape, the strands and groups of nerve cells smaller (cp. Less. xxI. $\S 1, b, e$ ).

10. Ganglia of the sympathetic chain in the frog. Lay open the abdomen of a recently killed frog, raise the rectum, and remove the intestine, liver and stomach, cutting through the mesentery just above the kidneys. Lift up the kidneys and cut between them. Lift up each kidney in turn, the peritoneumseparating the abdominal cavity from the lymphatica cisterna magna-will be seen stretching from the lateral edge of the kidney to the body wall. Remove the kidneys with this part of the peritoneum. Sponge up any blood that may be present.

Note on either side of the aorta a longitudinal pigmented strand, the sympathetic chain, and the fine nerves-the rami communicantes-connecting it with the adjacent spinal nerves. With the aid of a lens, the ganglia may be seen as spindle-shaped swellings on the sympathetic chain.

Remove the chain on one side; stretch it out on a slide, cover, and add normal salt solution. Examine with a high power. Note the nearly globular, transparent nerve cells ; much hidden by the pigment cells. The nerve fibres of the rami are chiefly small medullated fibres.

By treating the sympathetic chain with dilute methylene blue as directed in Less. xvi. $\S 1$, a cell will here and there be seen with deep blue spiral fibre and showing the branchings of the spiral fibre (synajses) on the cell. 


\section{DEMONSTRATIONS.}

1. Longitudinal section of spinal ganglion, to show the anterior and posterior roots attached to it, the anterior root running past the nerve cells and joining the fibres of the posterior root at or near the lower end of the ganglion.

2. Section to show basophil granules and masses of sympathetic ganglion cells (cp. §3).

3. Section of spinal cord of mammalian embryo or of chick prepared by Golgi method (cp. p. 240), showing multipolar cells with a single axon, and many dendrons.

4. Section of spinal ganglion of chick prepared by Golgi method, showing unipolar cells with dividing process.

5. Section of spinal ganglion with blood vessels injected.

\section{NOTES.}

Isolation of Cells in Ganglia. The bipolar spinal ganglion cells of the skate are easily isolated, cp. text $\$ 7$. A ganglion may also be placed in 5 p.c. osmic acid for half-an-hour and teased (with or without staining) in dilute glycerine.

The spinal ganglion cells of higher vertebrates, and sympathetic ganglion cells are not easily isolated. The following method is perhaps the best. Place the ganglion in 5 to 1 p.c. 
osmic acid (cut in two longitudinally unless small) for $\frac{1}{2}$ hour to an hour; wash with water. Remove to a mixture of equal parts glycerine and glacial acetic acid for 3 to 4 days (frog) or 4 to 5 days (mammal). Tease out. It is better to take young than adult animals because the connective tissue is less resistant in the former; the rabbit is better than the cat or dog.

The sheath can often be torn off bodily-after treatment as above-from the ganglia on the trunk of the sympathetic, by means of two strong needles. In the frog, the spinal ganglia easiest to get are those on the 7 th, 8 th and 9 th nerves. In many mammals the 2 nd cervical spinal ganglion can be obtained without cutting open the vertebral canal.

Hardening. For most purposes osmic acid 1 p.c. is the most useful hardening agent. It may be noticed that a nerve cell in certain states has a clump (sometimes two) of yellow-brown stained sharp granules. For staining basophil substance the ganglion should be placed in mercuric chloride 1 day; alcohol 2 or more days, and cut in paraffin; alcohol may be used alone but it is apt to cause shrinking of the cells. (Cp. also p. 244.)

In the rabbit and some other animals there are commonly two nuclei in the sympathetic nerve cells.

Changes in ganglion cells are described as occurring on stimulation of the nerves running to them, but it is not easy to satisfy oneself that they occur. For chromatolysis in nerve cells in the central nervous system, cp. p. 242, Demonst. 5.

In the frog peripheral nerve cells not hidden by pigment may be obtained by taking the piece of the bladder which immediately adjoins the cloaca; cutting it open, and spreading it out, onter surface uppermost; it is best to expose the cloaca by cutting through the symphysis pubis.

Auerbach's ganglia may be seen in sections, taken parallel to the outer surface of the intestine. The intestine is cut open, flattened between glass slides and hardened in this position.

For staining nerve cells with methylene blue for synapses, cp. p. 321 ; and for staining them by the Golgi method, cp. p. 240.

The following modification of Golgi's method is recommended by Kolossow for sympathetic ganglia in adults. Place the 
ganglion in a solution containing 3 to 5 p.c. potassium bichromate and 25 p.c. osmic acid for 2 to 3 days (if large up to 6 days). Cut in two with a razor without squeezing, rinse in distilled water, lightly press with blotting-paper to remove all excess of fluid; place in a mixture containing 2 to 3 p.c. silver nitrate and .25 to $\cdot 5$ p.c. osmic acid for 1 to 3 days. Cut free-hand or in celloidin. 


\section{LESSON XVI.}

\section{ENDINGS OF NERVE FIBRES IN MUSCLE.}

1. The End-Brush. Take a pithed frog, and expose the sartorius muscle (cp. Less. XIII. $§ 1)$. Free this at its lower end; raise it by the short tendon and cut through the connective tissue on either side and below it, close to the muscle, being careful not to injure the muscle fibres. Cut through the upper attachment. Place the muscle on a slide, deep side uppermost, add two drops of 0.5 p.c. methylene blue dissolved in 6 p.c. $\mathrm{NaCl}$. Line a watch-glass with moist blotting-paper, and with it cover the specimen. Leave for 15 to 20 minutes; then drain off the methylene blue. Gently pull the ends with needles to extend the muscle, add one drop of normal salt solution, and examine with low objective and high ocular.

Follow the muscle fibres along, until the small rather opaque nerve entering the muscle is seen; trace the course of the nerve across the muscle fibres. Here and there, one or two nerve fibres will be seen leaving 
the nerve, running to the muscle fibres, and ending on them in blue stained nerve-endings.

Selecting a well stained nerve-ending or end-brush, note that in nearly all cases the branches are given off at right angles to the stem, and that they are not very close together. Fine nerve fibrils accompanying the blood vessels will also be seen. When a number of endings have been examined, put on a cover-slip, gently press. With a low power, put a typical ending in the middle of the field, and then examine it with a high power.

Soon after the cover-slip is placed on the muscle, the methylene blue begins to be reduced to a colourless compound, and in consequence the nerve fibres become paler till they are no longer seen.

Note. The success of this preparation depends largely upon not injuring the muscle fibres. Where they are injured, they stain deeply; they should have no stain at a time when the nerve-endings are deep blue.

2. Make a similar preparation of the sterno-cutaneous muscle of the frog (Less. xIII. §4). The nerve-endings resemble those of the sartorius, but in general are not so large or so regular.

3. Reflect the skin from the lower jaw. Observe with a dissecting lens the mylohyoid muscle on either side, attached to the edge of the jaw, and, in the middle line, to its fellow muscle. Cut out the conjoined muscle (or cut off the lower jaw, remove everything but the mylohyoids, pin out). Treat as in $\$ 1$. Note the plexus of fine nerve fibres and fibrils throughout the muscle, and the small and irregular nerve-endings. 
4. Fixing the methylene blue stain. Preserve a specimen in each of the two following ways (cp. also p. 322) using the sartorius for (a) and the mylohyoid for $(b)$.

(a) When the nerve-endings are distinct under a low power, pin out the muscle with hedgehog quills, and place it in a saturated aqueous solution of picrate of ammonia for an hour or more, then tease out and mount in a mixture of equal parts picrate of ammonia solution and glycerine free from acid.

(b) Place in picrate of ammonia solution as in (a), but after 15 minutes

Transfer it, without washing, to the following solution,

$\begin{array}{ll}\text { Ammonium molybdate } 1 \text { gram } \\ \text { Distilled water } & 20 \text { c.c. } \\ \text { Hydrochloric acid } & 1 \text { drop, }\end{array}$

and leave for 1 to several hours. Wash with water, pass through alcohols, and xylol, and mount in balsam.

It is advisable to squeeze as much blood as possible out of the frog inmediately after pithing it. After noting the mylohyoid in position as above, the jaw may be cut off, pinued out on a ring of cork with the tongue uppermost, the tongue removed and the mucous membrane of the mouth removed; the mylohyoid will thus be obtained stretched.

5. End plates. Rat. Expose the intercostal muscles of a rat immediately after death, carefully tear and cut away the external intercostal muscles for a centimetre or two between two costal interspaces. Cut out the ribs with the internal intercostal muscles between them and pin out with hedgehog quills. Flood with 25 p.c. formic acid, leave five to seven minutes, then pour a little 1 p.c. gold chloride over the muscles; in about a quarter of an hour cut out and place in 1 p.c. gold chloride solution, leave for $\frac{1}{2}$ hour. Wash well with water, place for a day in 50 p.c. formic acid in the dark ${ }^{1}$.

Cut the muscles away close to the ribs, put in formic glycerine

1 The muscle may be transferred to undilated formic acid for a day. This will sometimes decolourize the muscles, but leave the nerves stained. 
for a few minutes, transfer to a large slide, put a smaller slide on the muscle to flatten it and examine with a low power. Note the nerves separating and dividing, and forming numerous nerveendings. Cut out a part of the muscle where the nerve-endings are most easily seen, and tease it slightly on a slide and mount in formic glycerine. Note (h.p.) the curved hypolemmal branches of the axis forming the end plate, (the number of branches varies in different endings, there are commonly two main branches, each with a number of side branches); the granular nucleated 'sole.'

The abdominal muscles of the rat or mouse may be similarly treated.

6. End plates. Snake. Take a piece, about an inch and a half long, of a recently pithed snake. Cut through the skin in the mid-ventral line. Cut through on one side the muscle attached to the skin near the mid-ventral line, and pin out the skin. Take the edge of the ribs in forceps, and pull the body gently away from the skin and upwards. A series of small band-like muscles will be seen passing from the body to the skin. Pin back the body so that these muscles are stretched, carefully tear away the tissue on either side of the muscles, isolating them up to their connections at either end. Cut out the muscles and treat them with dilute methylene blue, in the manner given in ¡ 1 .

Isolate similarly the muscles of the opposite side up to their origin and insertion; arrange the pins so that they are well stretched; brush them with 1 p.c. gold chloride. In about 5 minutes, when the muscles have become stiff, cut quickly the attachments, remove with a glass rod to gold chloride for about $\frac{1}{2}$ an hour. During this interval examine the muscles treated with methylene blue, placing on a slide, and moistening them with normal salt solution. Observe in the end plates, the curved branches of the axis cylinder set closely together, the whole end plate forming an oval or round patch.

The muscles which were treated with gold chloride may now be removed to water and washed thoroughly. Place in 25 p.c. formic acid in the dark till next day. Wash and place in formic glycerine, put under a dissecting lens, and tease off as much 
connective tissue as possible. Mount in formic glycerine, press the cover-slip to separate the fibres a little, and examine for end plates, using a lamp for illumination.

\section{Nerve-plexus in unstriated muscle. Cut} out the œsophagus of the frog used in $§ 1$. Cut it open, scrape gently the mucous surface. Pin it out with hedgehog quills over a hole in a piece of cork, muscular coat uppermost. Cut off the quills close to the membrane. On the muscular coat place a couple of drops of 05 p.c. saline methylene blue. Cover up with a watch-glass lined with wet blotting-paper for 20 to 30 minutes. Then wash off the blue with a drop or two of 6 p.c. salt solution. Place the piece of cork on a slide and examine with low objective and high ocular, and without diaphragm.

Note the very close plexus of fine blue-stained nerve fibrils, generally varicose in the muscular coat. Put on a cover-slip and examine with a high power.

8. Make a methylene blue preparation of the nerve plexus in the muscular coats of the rectum of the frog, treating it in the manner given in $\S 6$.

9. Neuro-muscular organs (muscle spindles). Take a piece of mammalian muscle which has been stained by Sihler's hæmatoxylin method (cp. Notes); place it in glycerine on a large slide and cover with an ordinary slide, squeeze the slide, hold up to the light, and look for a dark stained spindle-shaped body (if none is seen examine with a low power of the microscope ; if none is then seen, take a fresh strip of muscle). Cut this out under a dissecting microscope and note

'The swelling of the spindle caused chiefly by several connective tissue membranes. 
The two, three or more small muscle fibres running through the spindle; in the mid-part of the spindle (equatorial region) they have more nuclei than elsewhere.

The one or more large or medium medullated fibres penetrating the membranes of the spindle dividing amongst the muscle fibres, becoming non-medullated and forming nerve-endings on the fibres.

The nerve-endings vary considerably in different mammals and in different muscles, the two chief types are $(a)$ the annulo-spiral, consisting of flat bands partially encircling, or wholly encircling, or surrounding in a spiral, the muscle fibres, and $(\beta)$ the flowered ending, like an end plate, but larger and more irregular, and with many terminal flat expansions. These two often occur in the same spindle. In addition there may be near the end of the spindle, nerve-endings, arising from small medullated fibres, closely resembling small end plates.

In the preparation of snake's muscle (\$ 6) muscle spindles will probably be seen; the spindle consists of a single muscle fibre, the connective tissue membranes are comparatively little developed, so that there is but little swelling in the equatorial region. The sensory nerve-endings stain less readily than the motor nerve-endings; the form is intermediate between the annulo-spiral and flowered ending.

\section{DEMONSTRATIONS.}

1. Transverse section of neuro-muscular spindle.

2. Neuro-tendinous organ of cat or dog.

\section{NOTES.}

The methods of staining nerve-endings in muscle with gold chloride and methylene blue are like those used for nerve-endings in other tissues (cp. App. pp. 318 and 321). The muscle after staining with gold chloride may be soaked in gum and cut with the freezing microtome; when looking for muscle spindles the sections should be rather thick, even then a considerable number of sections may have to be examined before finding one. 
The muscle spindles are perhaps most easily found in the intrinsic muscles of the manus and pes. The characteristic annulo-spiral form is much more marked in dog and cat than in rabbit or rat. In man, a portion of the biceps near the entrance of the nerve may be taken.

In the sterno-cutaneous and other muscles of the frog, muscle spindles also occur, but they are not easy to find. The spindle usually contains two or three muscle fibres; the nerveending consists of fine varicose filaments running for a considerable distance along the fibres.

Homatoxylin method (Sihler). A strip of muscle about $4 \mathrm{~mm}$. thick, or the whole of a small muscle, is placed for $\frac{1}{2}$ to 1 day in a macerating fluid composed of
Ordinary acetic acid 10 c.c.
Glycerine
10 c.c.
1 p.c. chloral hydrate 60 c.c.

The pieces are placed in glycerine for an hour or two, they are then separated into thin strips and placed 3 to 10 days in the staining fluid, which is the same as the macerating fluid except that 10 c.c. of hæmatoxylin takes the place of the acetic acid.

After staining, the strips are placed in glycerine till required, the glycerine being now and then renewed. For investigation the tissue is differentiated in a mixture of equal parts of glycerine and acetic acid, or more rapidly in acetic acid alone. It is then examined as given in the text $\$ 9$.

The muscle may be cut into thick sections with a freezing microtome before being placed in the macerating fluid; in this case teasing out in glycerine is not necessary. The spindles when cut out may be washed in water, hardened in Müller's fluid, imbedded and sections stained on the slide. In investigating degenerated fibres the spindles after hardening with Müller's fluid may be treated by the Marchi method (cp. p. 246).

Neuro-tendinous organs. The nerve-endings of these are stained in the same way as other nerve-endings.

They are most easily found in the tendinous fascia of the back muscles, and in the deep tendon of the gastrocnemius in 
the rabbit (Golgi), and in the tendons of the gastrocnemius, tibialis posticus and extensor longus digitorum of the cat (Huber and de Witt). They usually occur at the junction of muscle and tendon. The number of tendon bundles forming an organ, the distinctness of the sheath, and the spindle forms vary greatly in different cases. In the tendons of the eye nuscle, they are not easily distinguished from the rest of the tendon unless the nerve fibres are stained. In the frog the difference between an ordinary tendon bundle and a tendon bundle of a neuro-tendinous organ is still less. In all cases a large medullated nerve fibre runs to the organ, generally from the muscle, and branches; the branches become non-medullated, and form a spray of fibrils on and partly in the tendon bundle. 


\section{LESSON XVII.}

\section{STRUCTURE OF BLOOD VESSELS. CIRCULATION. INFLAMMATION.}

\section{Large Arteries and Veins. Transverse}

sections of thoracic aorta, carotid artery, and jugular vein of $\operatorname{dog}$ (potassium bichromate 2 p.c.). Stain with hæmatoxylin and eosin (Less. v. $\$ 8$ ), or with hæmatoxylin and picric acid. Mount together.

a. Note in the aorta the inner coat, consisting of an epithelioid lining shown chiefly by the nuclei, and of a thin layer of elastic tissue with a small amount of white fibrous tissue. The elastic tissue shows chiefly as transversely cut fibres.

The thick middle or muscular coat consisting of bundles of smooth muscle and elastic fibres circularly arranged in alternating layers.

The outer coat, much thinner than the middle, consisting of white fibrous tissue and of elastic tissue; most of the fibres of the elastic tissue are cut transversely, they diminish in number in passing outwards. 
b. Note in the carotid artery that the elastic part of the inner coat is chiefly represented by a refractive, and (probably) wavy lamina; and that the elastic tissue is comparatively scanty in the middle coat.

c. Note in the vein that the whole wall is thinner; the inner coat is inconspicuous, except as regards the nuclei of its endothelium; the middle coat is much thinner than the outer.

2. Cut open longitudinally the jugular, or other large vein of a freshly killed rabbit. Pin it out with hedgehog quills, stream it with 75 p.c. sodium sulphate for a moment, add $\cdot 2$ p.c. nitrate of silver and leave for 10 minutes, wash in distilled water, expose to light for half-an-hour, pass through alcohols, clove oil, and mount in balsam.

Observe the rather jagged dark lines of the cement substance between the cells; the cells form a continuous layer, are more or less elongated in a longitudinal direction, and are flat; indications of their nuclei may be seen, and in some places indications also of the fibres of the muscular coat as transverse or longitudinal markings caused by a deposition of silver in the cement substance between the muscle cells. If the vein has been left too long in the silver nitrate solution, or exposed too long to light, silver will be deposited in the substance of the cells also.

3. Tear off a strip from the inner coat of a medium-sized artery (potassium bichromate $\cdot 2$ p.c. for two to six days; it may be kept in dilute glycerine). 
Tease it out in the preserving fluid; it will be found to consist almost entirely of elastic laminæ.

Observe the gradations from an almost homogeneous elastic perforated membrane to a meshwork of elastic fibres.

4. Remove a small portion of pia mater from the brain of a recently killed animal, brush it well in normal salt solution, and wash it in more salt solution, make a moist film of it, fix with alcohol, stain with hæmatoxylin (a trace of picric acid after-stain is advantageous) and mount in balsam. Note

The smallest arteries; no distinct external coat is seen; the middle coat consists of a single layer of muscle cells wound transversely to the tube, the nuclei are deeply stained, the outlines of the cells will be seen on focussing; the inner coat is represented by the elongated nuclei of the epithelioid lining.

The capillaries showing as thin, nucleated, membranous tubes.

The small veins, of larger calibre than the small arteries, with no muscular coat (this is special to the central nervous system), and in general appearance resembling the capillaries.

5. A pithed frog is given you. Take one or two small pieces of cotton-wool and plug the hole in the vertebral canal. Expose the heart, cutting through the sternum in the middle line, and pinning back the two parts.

Cut away the exposed part of the pericardium, pass a thread under the bulbus aortæ, with fine-pointed scissors make a cut in the bulbus near the ventricle. With a sponge, moistened with normal salt solution, wipe away the blood which comes, stroking the abdomen gently upwards to remove as much blood as 
possible. Cut across the inferior vena cava, and sponge up the blood.

Pick up the cut edge of the aortic bulb with fine-pointed forceps, and put into the bulb and up the left aorta a fine nozzled cannula, provided with an inch or so of india-rubber tubing. Tie in the cannula, fill it with 75 p.c. sodium sulphate and pinch the tubing, in order to drive blood out of the nozzle of the cannula, where it would rapidly clot.

Fill the cannula again; take a 5 to 10 c.c. injection syringe, the nozzle of which fits the india-rubber tubing, fill it with $\cdot 75$ p.c. sodium sulphate, and push the nozzle into the tubing, pinching the tubing as the nozzle is inserted, so as to aroid air-bubbles.

Inject the sodium sulphate, sopping up with a sponge the fluid which comes from the cut vessels; and now and then stroking the abdomen upwards. When the fluid is nearly colourless (injection of one syringe-full should be sufficient), inject in the same way a syringe-full of 0.2 p.c. nitrate of silver.

Leave for five minutes. Inject a syringe-full of distilled water. Then put the frog in distilled water. Expose the viscera freely, and cut out the following tissues and expose to light in distilled water. The bladder: lift it up by the ends, cut through the membrane attached to it; remove it and cut it open. The intestine and mesentery: lift up the end of the rectum, cut through the mesentery at its dorsal attachment and remove it with the intestine, cut off the mesentery and take the largest pieces; cut open the intestine, scrape off the mucous membrane, and pin out the muscular coat with quills. (The lungs, pinned out, and the kidneys should also be taken; the latter will show the epithelioid cells of the capsules.). When the tissues show signs of reduction, dehydrate pieces-keeping them stretched out-and mount in balsam.

Note the outlines of the flat elongated epithelioid cells of the arteries, of the capillaries and of the veins; the outlines in the capillaries are more irregular than in the arteries or veins; in the veins the cells are rather broader than in the arteries. In the larger vessels the cement substance between the cells of the 
muscular coat will also show as black transverse lines, these are more numerous in the arteries than in the veins.

6. Circulation of Blood ${ }^{1}$. The frog given you has been deprived of its brain and curarised ( 1 drop 1 p.c. curari). Lay it on its belly on the frog-board, and tie, not too tightly, a piece of soft cotton round the end of the (e.g.) 3rd and 4th digits. Stick two pins into the board a little distance from the hole; by twining the cotton round them the web may be stretched out level above the hole (or the toes may simply be pinned out with hedgehog quills, and the quills cut short). Surround the web, and cover the leg and body of the frog with moist blotting-paper. Put a piece of cover-slip over the toes, and with a small brush press the web from below against the slip. (If the web is not in close contact with the glass it may be outside the focal distance of the high objective; in that case, a triangular piece of cover-slip should be placed on the web between the toes, and excess of fluid sopped up, but by this method the front lens of the objective is apt to be smeared by touching the tissue.)

Examine, first with a low and then with a high power. Note

The course of the blood from the arteries to the veins. A slight pulsation may be observed in the larger arteries and sometimes in the smaller ones.

The greater velocity of the blood in the arteries

1 In the spring it is best to take a male frog for the circulation in the mesentery $(\S 9)$. The male may be recognised by the wart-like projection on the ball of the thumb. 
(owing to their smaller size) than in the veins; probably in neither can the individual corpuscles be made out.

The axial and peripheral zones in the arteries and veins; the peripheral zone is small, and under a low power appears free from corpuscles; under a high power one or two white corpuscles may, if the current is not very fast, be seen in the peripheral zone of the arteries; in that of the veins a few white corpuscles and occasionally a red one will be seen moving along comparatively slowly.

The passage of corpuscles usually in single file through the capillaries.

The elasticity of the red corpuscles; observe the way in which they bend and become deformed, and then regain their normal shape.

7. Inflammation. Remove the cover-slip; compare the circulation in two adjoining webs under a low power. Soak up the fluid on them; on one place a drop of xylol, and examine it, comparing it with the other.

a. The arteries dilate, the veins become larger, and the capillaries much more distinct.

b. At first the circulation is quicker; later it is slower than at first, though the vessels remain dilated.

c. The circulation stops after a time (stagnation), the red vessels being distended with blood (if this is not caused by the xylol, add a drop of turpentine). Where the red corpuscles are pressed together, as in 
the capillaries, their outline is lost. (For other changes in inflammation cp. $§ 9$.

d. The effects are local, they are not seen in the other web.

e. If the injury to the vessels has been slight, the circulation may be seen to be re-established in the stagnated spots, the corpuscles gradually recover their outline and are carried off by the current; this is not seen if stasis has set in, i.e. if the blood has clotted.

8. Observe now the circulation in the tongue; the frog being on its belly, draw forward the tongue over the hole in the stage and pin out the two cornua; the tongue at first pale soon becomes flushed and its vessels full of blood. With a low power the peripheral zone in the arteries and veins will probably be seen better than in the web.

9. Replace the tongue. On the right side make a cut through the skin and body wall, $1 \frac{1}{2}$ to $2 \mathrm{~cm}$. long, midway between the dorsal and ventral surfaces and rather nearer the hind than the fore limbs. Place the frog against the hole in the side of the frog-board, and pull out the coil of the intestine above the rectum, pin it out with hedgehog quills, cut the quills off short, and put small pads of blotting-paper wet with salt solution round the edge of the intestine, cover with a piece of cover-slip, and observe the circulation in the mesentery.

The exposure will probably cause some degree of 
inflammation, and the stages between the early dilation $(\S 7, a)$ and stagnation $(\S 7, c)$ may conveniently be followed. Note under a high power

a. The elongated platelets and the spherical white corpuscles increase in number in the peripheral zone of the arteries and veins, if the current is quick enough to show a peripheral zone; the white corpuscles often roll over along the wall.

$b$. In the veins, and to a less extent in the capillaries, the platelets and white corpuscles cling to the walls, at first for a time only, later permanently. Here and there a mass of adhering corpuscles forms which stretches across the tube; sometimes this is torn away by the current, sometimes it blocks the vessel and causes stagnation. Note in the stagnated vessels the gradual obliteration of the outlines of the corpuscles.

c. If the circulation is fairly rapid, pinch a small vessel with fine pointed forceps and note the way in which the platelets stick to the injured spot.

d. Focus the side of a small vein in which the circulation is slow, and look amongst the white corpuscles adhering to the wall for one which projects a little externally. Draw this at intervals of 15 minutes to note its rate of migration.

10. Circulation of blood in the newt. A newt is given you without brain and curarised. Mesentery. The hole in the stage should be small, about 1 to $1.5 \mathrm{~cm}$. long, and $\cdot 5$ to $\cdot 75 \mathrm{~cm}$. broad. The method is the same as in the frog ( $(9)$.

Pancreas. The skin and abdominal wall are cut through on 
the left side, the cut beginning a little below the fore leg and extending for 1 to $1 \frac{1}{2} \mathrm{~cm}$. The pylorus and the part of the intestine below it are pinned out. The circulation in the mesentery is also seen, but less satisfactorily than in the lower loop of the intestine. The same cut allows the lung to be pulled out, and the circulation in it observed.

11. Preservation of inflamed mesentery. When the circulation has been observed, cover up with a funnel lined with wet blotting-paper till next day. Remove the lower part of the intestine with its mesentery, and wash with salt solution. Fix the mesentery in alcohol, cut it into two parts, stain one with Ehrlich-Biondi fluid, and the other with hæmatoxylin and eosin. Mount in balsam. Note the numerous leucocytes with irregularly shaped or fragmented nuclei outside the capillary walls. A large number of coarsely granular oxyphil cells are usually seen (cp. Less. $x . \S 10$ ).

\section{DEMONSTRATIONS.}

1. Aorta of large animal stained with orcein to show the elastic tissue, longitudinal section.

2. Transverse section stained with orcein of vessels of $\S 1$ to show the elastic tissue.

3. Longitudinal section of vein including valve.

4. Circulation in the lung of the frog or toad (cp. p. 191). 


\section{NOTES.}

In the newt the circulation may be also observed in the stomach (cp. p. 169), intestine, edge of liver, upper third of kidney, and with sufficient care in the spleen.

In the anæsthetized mammal the circulation may be observed in the mesentery and omentum; in the rabbit in the pancreas, the middle lobe of the parotid, in the thin skin muscle of the neck, and in the sterno-hyoid and other thin muscles; warm salt solution 1 p.c. or even stronger is allowed to flow over the tissue ; it is best to use a water immersion lens. In the ocular muscle the circulation may be seen under a low power with reflected light. 


\section{LESSON XVIII.}

\section{THE LYMPHATIC SYSTEM.}

1. Epithelioid cells of serous membranes. Behead a pithed frog, squeeze the body upwards to remove as much blood as possible. Fasten out the lower coil of the intestine with the mesentery (cp. Lesson xVII. $§ 9$ ); wash it with 75 p.c. sodium sulphate; add a drop or two of $\cdot 2$ p.c. silver nitrate, in 5 minutes wash with sodium sulphate. Cut away the intestine, expose the mesentery to light in distilled water. When the outlines of the surface cells show (about $\frac{1}{2}$ hour), place the mesentery on a slide, drain off the water, stretch, drop on it 95 p.c. alcohol to fix it, place in alcohol for 5 or more minutes. Mount in balsam.

Note the epithelioid cells covering the mesentery. They are large and flat; and for the most part polyhedral.

\section{Epithelioid cells of lymphatic ${ }^{1}$ spaces.} Follow the directions given in Lesson $\mathrm{xv}$. $§ 9$, up

1 The dissection is simpler in the male frog, cp. Footnote p. 137. 
to the point at which the peritoneum is seen stretching from the lateral edge of the kidney to the abdominal wall. Keeping the kidney lifted, so that the peritoneum is kept taut, let a drop or two of 75 p.c. sodium sulphate run over both sides of the membrane, then, after sopping up the fluid with a small piece of sponge, repeat the process, but using 2 p.c. silver nitrate. In 3 to 5 minutes cut through the abdominal attachment of the peritoneum, transfer it to sodium sulphate 75 p.c. (or to water), cut off the kidney. Cut the peritoneum into two unequal pieces, so that they may be distinguished, and expose to light in water, one with the abdominal and the other with the lymphatic surface uppermost, and treat in the manner given in $\S 1$. Observe on the external side, (a) the lymphatic epithelium, consisting of large flat cells with very sinuous outline, (b) the stomata, each has a small opening between three or four small cells, more deeply stained than the rest; the outlines of the surrounding epithelioid cells radiate from them.

On the peritoneal side, cells less sinuous in outline than the lymphatic epithelium, but more irregular than the cells covering the mesentery; stomata will also be seen. (The epithelium of both sides can probably be seen in the same preparation, on focussing.)

3. Epithelioid cells of peritoneal surface of diaphragm. Treat with $\cdot 2$ p.c. nitrate of silver (cp. \$ 1) the peritoneal surface of the diaphragm of a guinea-pig and mount, peritoneal surface uppermost. Observe

The tendon bundles of the diaphragm arranged in two layers. The spaces between the bundles mark for the most part the course of the lymphatic capillaries of the tendon (cp. § 4). 
Superficial to the tendon bundles the epithelium of the peritoneum consisting of flat polygonal cells; these are larger over the tendinous bundles than over the intervening spaces. Stomata similar to those of $\S 2$ may be seen, situated over and communicating with the inter-tendinous spaces. Pseudostomata, irregular patches of staining substance at the junctions of the cells, are frequent.

4. In a guinea-pig or rabbit, brush firmly the pleural surface of the diaphragm with a camel-hair brush to remove the surface epithelium and treat with nitrate of silver. Mount with the pleural surface uppermost. Note

The small lymphatic vessels, running a little above the tendinous bundles and lined with somewhat irregular spindleshaped epithelium. In places the curved outline of a valve may be seen.

The superficial lymphatic capillaries with their characteristic sinuous epithelium continuous with the lymphatic capillaries of the inter-tendinous spaces.

The origin of the lymphatics. This is best seen in specimens deeply stained with nitrate of silver, so as to produce the socalled negative image. Note the clear branched spaces, whose sinuous outline resembles that of an epithelium cell of a lymphatic capillary. The clear spaces, cavities containing unstained connective-tissue corpuscles, stand out in strong contrast with the surrounding stained matrix. It may be seen that these spaces here and there apparently form the beginning of a lymphatic capillary.

5. Sections of a small lymphatic gland, including the hilus (one of the upper cervical glands of cat or dog; ammonium bichromate 2 to 5 p.c.; cut frozen). Stain with hæmatoxylin and eosin and mount in balsam.

\section{a. Observe under a low power}

The connective-tissue of the capsule surrounding the gland and sending in

L. 
The trabeculæ, which divide the outer portion of the gland, the cortex, into compartments, the alveoli, and which then in the inner portion, the medulla, of the gland split up into bands, forming a network with rather narrow, elongated meshes.

In the alveoli of the cortex the roundish masses of tissue crowded with leucocytes, the follicles of the cortex; in the intertrabecular spaces of the medulla the elongated masses of similar tissue, the medullary cords. Note that the follicles are continuous with the medullary cords.

Around the follicles and around the medullary cords and separating them from the trabeculæ the lymph-channels comparatively free from leucocytes.

Some of the follicles will probably show a central round area; the germinal area, resernbling somewhat in appearance the Malpighian corpuscles of the spleen (cp. Less. XIX.).

\section{b. Observe under a high power}

The connective-tissue of the capsule and trabeculæ ${ }^{1}$ continuous with

The reticulum of the lymph-channels.

Limiting the follicles and medullary cords may usually be seen a fine line with nuclei at intervals, indicating the flat cells bounding the lymph-channel.

The adenoid tissue of the follicles and cords, continuous with that of the lymph-channels but with finer fibres and smaller meshes; unless the section has been well shaken this will be largely hidden by leucocytes.

1 In some animals, e.g. ox, this contains unstriped muscular fibres. 
6. Shake one or two sections of lymphatic gland with water in a test tube to get rid of most of the leucocytes, stain with picrocarmine and mount in glycerine.

In this section observe (h. p.) the network of fine fibres of the adenoid tissue.

7. Section of lymphatic gland (Flemming's fluid), stain with saffranin (cp. p. 286). Note the leucocytes with deeply stained, dividing nuclei, chiefly in the germinal areas.

\section{DEMONSTRATIONS.}

1. Section of small lymphatic gland ${ }^{1}$ with blood vessels injected. The arteries enter at the hilus surrounded by connective tissue and branch in the trabeculæ of the gland; from the smaller of these branches fine arteries run to the follicles and medullary cords and form in them a capillary network; no capillaries occur in the lymph-channels. The veins have a distribution similar to that of the arteries.

2. Transverse section of thoracic duct. Note the similarity in structure to that of a vein (cp. p. 133).

3. Specimen to show injected lymphatics of tendon of diaphragm.

4. Section of tonsil including the surface epithelium. Note (l. p.) the stratified epithelium dipping down here and there and so forming crypts; the lymphatic tissue, showing roundish germinal areas,

1 For lymphatic follicles and Peyer's patch of intestine, see Less. xxir. 
the outline of an area is often not equally distinct all round; and (h. p.) the leucocytes in places between the epithelium cells.

\section{NOTES.}

Preservation of lymphatic glands. A cat or dog is killed (best by bleeding after chloroform has been given) and warm salt solution is injected into a carotid for a quarter to half-an-hour, the lymphatic glands of the neck are then cut out and placed in ammonium bichromate 5 p.c. for about 3 weeks, sections are cut with a freezing microtome and shaken. In sections so prepared the lymph channels are almost completely free from leucocytes, and by careful and more prolonged shaking they may be removed very largely from the follicles and medullary cords. The leucocytes are more easily removed if sections are cut a few days after the tissue has been placed in ammonium bichromate, but further hardening is desirable.

Injection of lymphatics of lymphatic gland. Take up in a Pravatz syringe about 5 c.c. of a 2 p.c. solution of Prussian blue (Berlin blue), pass the point under the capsule of lymphatic gland of a freshly killed animal and slowly press the fluid in, squeezing the gland slightly with the fingers. Place the gland in 95 p.c. alcohol for a week or more. Place a piece for a day in absolute alcohol faintly tinged with eosin. Imbed in paraffin.

To show the outlines of the lymphatic epithelioid cells the gland is injected first with $\cdot 75$ sodium sulphate solution and then with .2 p.c. nitrate of silver; the gland is cut frozen and the sections gently shaken in water and exposed to light.

Injection of lymphatics. The lymphatics of the sub-cutaneous tissue, of membranes, of the sheath of tendons, may be injected in the same way as the lymphatic glands. If a bulla forms and does not disappear with gentle pressure shift the point of the injection needle, or make another puncture. It requires considerable care and practice to make successful injections.

Natural injection of lymphatics of diaphragm. Ten to fifteen c.c. of a saturated solution of Prussian blue is injected into the abdominal 
cavity of an anæsthetized rabbit. In three to four hours the animal is killed by bleeding, the surface of the diaphragm washed with salt solution, and strong spirit poured over it. In about 5 minutes the abdominal viscera are removed, the thorax opened, the diaphragm pinned out on a piece of cork, removed from the body and placed in strong alcohol. Pieces of the tendon are mounted in balsam.

If the tongue of a frog is drawn out, a lymph sac on its (then) dorsal surface is generally distinct. The sac can readily be distended (a) with the aid of a Pravatz syringe, or glass rod drawn out to a fine point; the skull and upper part of the spinal column being first cut away; (b) by forcing fluid into the dorsal lymph sac. The thin membrane bounding it can be cut out and the epithelium of the outer surface removed by scraping; its inner surface treated with silver nitrate shows large epithelioid cells; it can also be used to show very fine fibrous tissue imbedded in ground substance, and a plexus of branching striated muscle fibres. 


\section{LESSON XIX.}

\section{THE SPLEEN.}

1. Piece of spleen of cat (ammonium bichromate 5 p.c.), cut at right angles to the long axis of the organ including rather more than half of the transverse surface. Note, with and without the aid of a lens, the round whitish Malpighian corpuscles. Prepare sections with the freezing microtome (cp. Less. VIr.). Stain some sections with picrocarmine and mount in glycerine, others with hæmatoxylin and eosin or picric acid and mount in balsam. Observe under a low power

Externally the broad fibrous sheath, the capsule, sending in large and conspicuous trabeculæ; these run throughout the spleen, branching as they go into roundish bundles which are connected with other similar bundles, and so form an irregular trabecular network: the bars of the network cut in all directions are scattered about the section.

In many of the trabeculæ, largish central spaces, 
the veins; they are devoid of any proper muscular and connective tissue coats; in the centre of the section large trabeculæ cut transversely or obliquely will probably be seen containing both arteries and veins; if the section passes through the point of entrance of the vessels these will be seen running towards the centre surrounded by tissue continuous with the capsule.

The splenic pulp occupying the spaces of the trabecular network; it resembles somewhat the follicular substance of the lymphatic glands but has a mottled appearance; in it are roundish masses of tissue, the Malpighian corpuscles, more deeply stained than the splenic pulp: when the corpuscle is cut transversely to the artery which it surrounds, the artery will be seen to be near one side (all the small arteries in the pulp are surrounded by a variable amount of lymphoid tissue).

Examine the splenic pulp under a high power and note that the mottled appearance is due to the presence of red blood corpuscles scattered irregularly in it. (These are stained yellow with picric acid and orange with eosin.)

2. Thin section of a dog's spleen, washed out by injection. Stain as in $\S 1$. Observe (h. p.)

There are no distinct lymph-channels like those in the lymphatic glands.

The reticulum of the splenic pulp varies in appearance; in places it appears as a network of cells having in various directions flange-like projections which taper off and join with the similar processes of neighbouring cells; elsewhere the cells may be nearly or wholly 
absent and a reticulum of fine fibres may be seen. Some leucocytes and red blood corpuscles not washed out of the reticulum will be present.

The reticulum of the Malpighian corpuscles resembles that of the follicles of lymphatic glands, in its meshes are many leucocytes, but no red blood corpuscles.

The small arteries, capillaries and veinlets of the pulp; the veinlets branch out from the trabeculæ and have sharp outlines with nuclei at intervals (they may usually be recognized in the dog by the spiral lines running round them).

The trabeculæ are chiefly composed of unstriated muscle tissue (the amount of this varies in different animals, in some it is very small).

If a section be stained with orcein (cp. p. 82) a network of small elastic fibres will be shown in the trabeculæ.

On the arterial capillaries in the pulp small round clumps of flattened connective tissue cells may in places be seen.

3. Section of spleen injected with Prussian blue from the splenic artery under a low pressure. Mount in balsam. Note (l. p.)

The small arteries having a sheath of lymphoid tissue, which here and there forms a Malpighian corpuscle; the artery lies excentrically in the corpuscle, and gives off a number of capillaries which form a network in it.

Capillaries in the lymphoid sheath of the arteries, but less numerous than in the Malpighian corpuscles.

Small arteries (arterial capillaries) without lymphoid sheath branching in the splenic pulp. 
Small tufts of splenic pulp injected with blue at the ends of the capillaries of the pulp.

Irregular masses of injected splenic pulp outside the Malpighian corpuscles and lymphoid tissue of the arteries where the capillaries open out into the pulp.

If too great a pressure has been used in injecting, instead of the tufts of injected pulp at the end of the capillaries, irregular areas of the pulp or the whole of it will be permeated with the Berlin blue; the Malpighian corpuscles and the lymphoid tissue of the arteries will be free from injection unless the pressure used in injecting has been very great.

\section{DEMONS'IRATIONS.}

1. Section of spleen injected with Prussian blue from the splenic vein under a low pressure. Observe, the veins in the trabeculæ filled with injection material; the veins of the pulp more or less distinctly branching out from the trabeculæ; the irregular masses of injected pulp at the ends of the veins.

2. Section of spleen (dog or cat); nitrate of silver injected into the artery so as just to reach the endings of the artery. 


\section{NOTES.}

Hardening after washing out. As soon as possible after the animal has been killed (best by bleeding under chloroform) all the branches of the cœliac artery except the splenic branches are tied and warm salt solution is injected into the artery until the spleen is quite pale; then 5 p.c. ammonium bichromate is injected until the spleen is yellow, the splenic veins are then ligatured, the spleen a little distended by further injection and the arteries tied. The spleen is removed to 5 p.c. ammonium bichromate; in two days it is cut in pieces and left in bichromate solution for a week or longer. The pieces are then placed in 30 p.c. alcohol, which is renewed until it is no longer coloured; sections may then be made (best with the freezing microtome) or the pieces may be kept in 75 p.c. alcohol.

Injection of blood-vessels. A dog is perhaps the best for injection, but a cat or a rat answer the purpose very well. In a dog the individual arteries and veins which run to the spleen are large enough to be easily injected separately, and since the fluid, with an arterial injection, does not readily spread out beyond the section of the spleen directly supplied by the vessel, a number of injections may be made in the same animal. The whole spleen should be washed out first from the cœliac artery.

In injecting the arteries or veins, the injection should be stopped as soon as spots of injection material are seen on the surface of the spleen; if it be continued, the splenic pulp becomes more and more hidden by the injection.

The most instructive injection material is $\cdot 2$ p.c. solution of silver nitrate; part of the injected spleen should be cut frozen, the sections shaken a little in water and exposed to light, as soon as brown specks appear they should be placed in dilute alcohol, and then each section transferred flat to 75 p.c. alcohol. The rest may be placed in alcohol 75 p.c. for one to two days, then cut frozen and exposed to light. In successful specimens, the disappearance of the epithelium of the capillaries and small veins of the splenic pulp shows in the clearest manner the opening of these into the spaces of the pulp.

For a spleen containing little muscular tissue, that of the rabbit may be taken. The spleen of the tortoise has the capsule and 
trabeculæ very little developed, and a peculiar sheath around the small arteries.

In the frog's spleen, the trabeculæ are very little developed, and -as in other lower vertebrates-the arteries have no lymphoid sheath or Malpighian corpuscles in connection with them.

Iron may be tested for by the ferrocyanide method (cp. p. 184) in sections of spleen which bave been injected with and hardened in alcohol. 


\section{LESSON XX.}

\section{SALIVARY GLANDS.}

1. Serous glands. With fine-pointed scissors cut off a thin piece of the parotid gland of a recently killed mammal, e.g. of a cat or rat; mount without adding fluid, press lightly, and examine under a high power (oc. 4). If the piece is thin, the alveoli will be seen, appearing as roundish masses crowded with small granules. Run 2 p.c. $\mathrm{NaCl}$ solution under the cover-slip, and tap the cover-slip firmly once or twice (first sopping up excess of salt solution, if it moves easily when touched). Observe the numerous granules in the fluid. The outlines of the cells will probably be seen in some of the alveoli.

Salt solution 75 p.c. may be used instead of 2 p.c., but in this the granules swell up somewhat, and soon become indistinct.

2. Prepare a specimen as in $\S 1$, pressing the cover-slip to obtain some separated alveoli or clumps of cells. Irrigate with $\mathrm{HCl} \cdot 2$ to $\cdot 4$ p.c. Note that the granules disappear like bubbles 
bursting, the cells become transparent, their outlines and nuclei come into view. If acetic acid 1 p.c. is used instead of dilute $\mathrm{HCl}$, the nuclei will be more shrunken and the cells less transparent.

3. Section of serous gland. (Parotid of cat, or sub-maxillary gland of rabbit. Alcohol; hæmatoxylin.) Observe

\section{a. Under a low power,}

The lobules of varying size, separated from one another by connective tissue.

The alveoli, appearing as small roundish or short tubular bodies, closely aggregated together; each will be seen to consist of a group of cells surrounded by a small amount of connective tissue. (The terminal branching tubes, the sections of which are here called alveoli, may be so closely pressed together in the process of hardening that at first sight they have the appearance of continuous masses of cells.)

The small lobular ducts, chiefly in the centre of the lobules, cut obliquely and transversely.

The ducts between the lobules; in these the lumen is large, and the epithelium consists of two or more layers of cells. (These will not be seen in sections from the outer part of the gland.)

\section{b. Under a high power,}

The alveoli vary in size; externally the basement membrane shows as a rather sharp outline; the lumina, if visible, are small. In the round alveoli-tubes cut transversely where they do not branch-it will be seen 
that there is only one layer of cells lining the basement membrane.

The cells are more or less polyhedral; they have an irregularly granular appearance, but the cell-granules, seen in the fresh gland, have disappeared. The nuclei are spherical (unless shrunken by the treatment), the nucleus of each cell is placed a little nearer the outer than the inner side of the cell.

The lobular ducts consist of a single layer of slender columnar cells, the inner borders of which form a distinct ring bounding the obvious but small lumen; the outer boundary is not marked by a sharp line. The outer part of the cells is striated (it stains readily with picric acid and with eosin). The nucleus is ovoid and situated at about the inner third of the cell.

4. Section of lachrymal gland of a rabbit. (Mercuric chloride; hæmatoxylin.) Note that the terminal secreting tubes are obviously tubular, they will probably show a distinction between an outer, fairly homogeneous, stained zone, and an inner, irregular granular, unstained zone. (The zones can be readily seen in the fresh gland.)

5. Mucous glands. Tease out in 2 to 5 p.c. $\mathrm{NaCl}$ a piece of the orbital or sub-maxillary gland of a recently killed dogi. Observe the distinct (mucous) granules at the edges of the specimen. Irrigate with $\mathrm{HCl} 1$ p.c.; the granules swell up and disappear; here

1 It is best to take the orbital gland from the body a day after death; isolated mucous cells more or less columnar and full of granules may then be obtained, and the nuclei and nucleoli may also be visible. 
and there a pear-shaped mucous cell will be seen with a nucleus and small amount of protoplasmic cell substance at the narrow end, and a network of cell substance stretching through the swollen, mucous portion.

\section{Section of dog's resting sub-maxillary gland} (alcohol; picro-carmine 1 to 24 hours; hæmatoxylin and eosin; or Ehrlich-Biondi fluid). Mount with it the specimen of active gland $(\S 7)$.

Note under the low power that the general features are the same as those of serous glands, $\S 3(a)$; the alveoli however are more distinct.

Note under a high power that two kinds of cells are present in the alveoli, the mucous cells and the serous or demilune cells (the latter are not present in all mucous glands).

The mucous cells are comparatively large, and often have rounded outlines; most have a disc-shaped nucleus close to the basement membrane; in a few the nucleus is spherical and farther from the basement membrane. Much the greater part of the cell is clear and homogeneous, consisting of mucin (or mucigen) resulting from the running together of the mucous granules (cp. $\S 5$ ). The mucin is unstained in the carmine specimens. The protoplasmic cell substance is arranged much as in the cell swollen by acid (cp. $§ 5$ ).

The demilune cells occur usually in half-moon shaped groups, at the ends of the alveoli; they are more or less overlapped by the swollen mucous cells. The outlines of the several cells are not very distinct. The nuclei are spherical, the cell substance, which 
stains equally throughout, resembles that of the cells of the serous glands.

The ducts are in general features like those of the serous glands (cp. §3).

7. Active mucous gland. Section of dog's submaxillary gland after prolonged secretion ${ }^{1}$. The section should be stained in the same way as that of $\S 6$. Observe, comparing it with the resting gland of $\S 6$; the mucous cells are smaller, owing to a diminution in the mucous part of the cell, and have less rounded outlines; the mucin which remains borders the lumen. The protoplasmic cell substance is more abundant. The nuclei are spherical, have conspicuous nucleoli, and are farther from the basement membrane.

The alveoli are not all changed to the same extent; in some the mucin has almost entirely disappeared, and the demilune cells are more polyhedral, so that the two kinds of cells are not very easy to distinguish; in others the chief change observable is that the nuclei of the mucous cells are spherical. Dividing nuclei are as rare as in the resting gland.

8. Tease in 5 p.c. neutral ammonium chromate a piece of a dog's sub-maxillary gland which has been kept for 3 to 6 days in the fluid ( 2 p.c. chloral hydrate may be used for the ammonium chromate). Observe the isolated mucous and demilune cells. The general appearance of a mucous cell is like that produced by dilute $\mathrm{HCl}$ in $\S 5$, but the basal end of the cell is seen to be prolonged into a process.

1 In a dog under morphia and chloroform, the chorda tympani (or this with the sympathetic) is stimulated at short intervals for three to six hours. 
9. Sections of dog's orbital gland hardened in osmic acid vapour, given out in paraffin.

(a) Stain some sections on a cover-slip with alcoholic methylene blue. Observe the deeply stained mucous granules stretching throughout the cells. The protoplasmic cell substance is stained greenish.

(b) Place a section in xylol to dissolve the paraffin, transfer to absolute alcohol, mount in 95 p.c. alcohol. Observe the brownish mucin granules. Irrigate with 50 p.c. alcohol, watching the cells carefully.

The granules will be seen to swell up till their outlines are lost; the cells swell, their outlines become rounded; an intracellular network becomes visible; thus the general appearance of the hardened gland of $\S 6$ is obtained. Transfer to absolute alcohol and the original appearance will return. (If the tissue has been too short a time in osmic acid vapour the granules as they swell may stick together; in this case absolute alcohol brings back the original appearance imperfectly or not at all.)

\section{DEMONSTRATIONS.}

1. Transverse section of the hilus of the submaxillary gland of a cat or dog. Note; the branching duct with large lumen and one or two layers of cubical or flattened epithelium cells; close to the duct groups of nerve-cells forming part of the sub-maxillary ganglion; the gland artery, and probably a vein.

2. Section of dog's active sub-maxillary gland (osmic acid vapour; methylene blue) to show the inner granular and outer protoplasmic zones. Note the mucous granules, stained deep blue, confined to the inner portions of the cells.

L. 


\section{NOTES.}

Hardening. The best hardening agent for salivary glands is perlhaps alcohol; 75 p.c. for a day, then 95 p.c. for a week to a fortnight (absolute alcohol may be used for the second week). The alveoli can be obtained a little separated from one another by injecting the gland artery first with salt solution, and then with 75 p.c. spirit. When absolute alcohol is used to harden a gland the outside is usually much shrunken, this part should be cut away. Sections of glands hardened in alcohol or in mercuric chloride often become sticky when placed in water, this can be prevented by placing the gland in chromic acid 2 p.c. for 1 to 2 days.

But any of the usual hardening agents may be used-thus, mercuric chloride, chromic acid and alcohol, formol and alcohol, Flemming's fluid.

Staining. The demilunes of the mucous gland are generally best seen in sections of gland hardened in osmio acid 1 p.c. or an osmic acid mixture, stained rather deeply with hæmatoxylin, and left in 1 p.c. acetic acid for a day. This method also shows distinctly the (artificial) network of the mucous cells. The demilunes may also be stained with acid magenta.

Mucin may be stained with methylene blue, toluidin blue, thionin, saffranin, or bismarck brown (cp. p. 326), but where there is much mucin, it is generally best to leave it unstained. Hæmatoxylin does not stain mucin in sections hardened in alcohol, when used in the manner given in the text (p. 35), but does stain deeply mucin granules fixed by osmic acid vapour; the statement that it stains mucin and not mucigen rests on no satisfactory basis.

The granules of the serous glands are in some cases preserved by hardening in a mixture of equal parts of 5 p.c. potassium bichromate and 2 p.c. osmic acid. (Altmann's method.)

Osmic acid vapour for preserving mucous granules. A small bottle is half filled with 2 p.c. osmic acid, corked and left for a day. A hedgehog quill is stuck in another cork. Small pieces-2 to $4 \mathrm{~mm}$. in diameter-of a fresh gland, which have not come in contact with blood or any fluid, are placed on the quill, to which they will adhere. 
This cork replaces the first cork in the bottle, it is left for a day. The pieces of tissue are then placed in absolute alcohol for a day or longer; imbedded in paraffin and cut. The sections are stained for a day in methylene blue in 75 p.c. alcohol, and mounted in balsam.

If the sections are placed in alcohol about 70 p.c. or any lower percentage, the mucous granules swell up, they may then cohere, or they may be only pressed together into an apparently continuous mass, returning to the spherical form when placed once more in strong alcohol; in the latter case they should be stained in aqueous solutions of methylene blue.

They are also more or less preserved by hardening a small piece of gland in absolute alcohol, imbedding in paraffin, and staining the section on the slide in alcoholic stains.

Variations of mucous glands. The orbital gland of the dog is best for showing a typical mucous gland, the sub-maxillary gland of the dog has more serous cells, that of the cat still more. A few mucous alveoli are generally present in the parotid of the dog.

Varieties of serous glands. In some glands more than one kind of secretory cell is present. Thus in a piece of fresh sub-maxillary gland of the rabbit, the ends of the ductules and first cells of the alveoli (transition cells) have distinct granules, whilst the rest of the alveolar cells are only faintly granular. In sections of osmic acid hardened gland, the transition cells are stained darker than the rest. In the serous part of the sub-maxillary gland of the rat, curving tubes with large granules will be seen amongst the mass of faintly granular alveoli; they are easily preserved by reagents and stained.

If $a$ resting and an active serous gland be preserved in 1 p.c. osmic acid, and the sections compared, it will be seen that cells of the active gland stain a darker tint than those of the resting; the granules are not usually preserved by osmic acid so that the distinction of zones in the active gland, readily seen in the fresh state, is not usually seen in the sections.

The sub-lingual gland differs from the typically mucous and from the typically serous glands. It is more obviously tubular, some of the tubes are entirely mucous, some entirely serous, some contain both mucous and serous cells; some have cells with a mucin inner and proteid outer zone.

Glands both serous and mucous not uncommonly contain some 
fat globules in their cells. To observe these the gland should be preserved in osmic acid or in Flemming's fluid, cut frozen, the sections mounted in glycerine.

The cells of the membrana propria (basket cells) will be seen in teased portions of a piece of gland which has been left in water 1 to 2 days.

For isolating serous cells 5 p.c. chloral hydrate may be used. 


\section{LESSON XXI.}

\section{GESOPHAGUS AND STOMACH.}

1. Transverse vertical section of the cardiac end of the stomach ${ }^{1}$ (alcohol or chromic acid $\cdot 2$ p.c.). Stain with hæmatoxylin and eosin; a few seconds in the eosin will probably give a sufficient stain.

a. Observe under a low power,

Externally, the thin connective-tissue layer of the peritoneum.

The muscular coat, consisting of an outer longitudinal and an inner circular coat of unstriped muscle; the former will appear as a cross section of a number of bundles with connective tissue running in between them from the peritoneum; the latter as a continuous layer. On the inner side of the circular coat some small oblique muscular bundles may perhaps be present.

The submucous coat of connective tissue. If the mucous membrane is in folds the submucous but not the muscular coat will be seen to run up in the folds.

The muscularis mucosæ, or thin stratum of

1 Stomach of rabbit, cat, or dog. The muscular layers are thinner in the rabbit than in the cat or dog. 
unstriated muscle fibres a little external to the glands; this is divided more or less distinctly into an outer longitudinal and an inner circular layer.

The mucous coat. Note in this the oxyntic gastric glands with their openings and the ridges between the openings. The bifurcation of some of the glands will probably be made out.

b. Observe under a high power,

The columnar mucous cells, lining the mouths of the glands and covering the free surface of the mucous membrane between them; they are long, slender cells, becoming shorter in passing down the mouths of the glands; the upper third of the cell (containing mucin) is much more transparent than the remaining portion; the nucleus lies at about the lower third. (The stomach must be hardened very soon after death, or these cells will be detached.) An oblique section of the mouths of the glands will cut through two or more of the columnar mucous cells on each side of the lumen, thus a number of small polygonal areas may be seen in the gland mouth, sometimes apparently blocking it up.

The large deeply stained ovoid or oxyntic cells with ovoid nuclei, and the short columnar or polyhedral central or chief cells with spherical nuclei. At the base of the glands the central cells are usually most numerous, the ovoid cells being placed between them and the basement membrane; towards the neck of the glands the ovoid cells increase in number; in the neck, the majority of the cells are ovoid, and abut on the lumen. The ovoid cells usually cause a bulging outwards of the basement membrane; this is especially the case if the animal has been killed soon after it has fed. 
The connective tissue immediately internal to the muscularis mucosæ; it surrounds the bases of the glands, and sends up processes between them. It runs between the glands,-generally with a few muscle-cells from the muscularis mucosæ,- - and is seen as thin bands between the bodies of the glands; the bands spread out near the surface. Leucocytes are present, but not in great numbers.

2. Section of the fundus region of the gastric mucous membrane, through the bodies of the glands parallel to the surface. Observe

The central cells forming a tube with very small lumen.

The comparatively rare ovoid cells on the outer side of the central cells.

If an oblique section is made through the mucous membrane, the mouths of the glands will be seen as cross sections of tubes with distinct lumina; the necks will appear as clumps of cells, most of them ovoid, the lumina being indistinct.

3. Cut with scissors a thin strip of the fundus mucous membrane of a recently killed guinea-pig or rabbit. Mount it without fluid and gently press the cover-slip. Note in the deeper parts of the glands the central mass of granules (granules of the central cells), and the projecting ovoid cells without distinct granules. Add 1 to 2 p.c. salt solution, and press the cover-slip a little more firmly, the bases of some of the glands will probably be obtained isolated, and the disposition of the granules be more distinct. In dilute salt solution or on addition of dilute acid, the granules of the central 
cells disappear more or less quickly, and the ovoid cells become granular. (The central cell granules are not preserved by most hardening agents, cp. $§ 1$.)

4. Vertical section of the pyloric end of the stomach. (Alcohol; hæmatoxylin.) Compare these with the sections made of the cardiac end. Note

The greater thickness of the muscular layers.

The wider and longer mouths to the pyloric gastric glands, their more obvious branching, the absence of ovoid cells (if the section passes through the beginning of the pyloric region a few ovoid cells may be seen), the short columnar cells of the bases of the glands and the usually distinct lumina. (These are more distinct in the dog than in the rabbit.)

5. Examine fresh pyloric glands (cp. § 3). The cells are devoid of the distinct granules seen in the central cells of the fundus.

6. Section of cardiac region of stomach of frog (osmic acid). Observe that the surface cells are in general features like those of the mammalian stomach; the necks of the glands have swollen mucous cells; the bodies of the glands have one kind of cell only, in shape somewhat resembling the ovoid cells, but containing distinct granules. (In lower vertebrates the granules of the fresh gland-cells are preserved by osmic acid.)

7. Transverse vertical section of the lower third of a rabbit's œsophagus (potassium bichromate 1 p.c.). Stain with hæmatoxylin (or Ehrlich-Biondi fluid) and compare it with the corresponding sections of the stomach. Note the following points of contrast:

The muscular coat contains striped as well as unstriped muscular fibres; sections from the upper part of the œsophagus show no unstriped fibres. 
The submucous tissue may contain one or two small serous and mucous glands (cp. Lesson xx.). Each of these consists of a duct, dividing and ending in dilatations, the alveoli.

The muscularis mucosæ, internal to (i.e. on the epithelial side of) the alveoli of the glands.

The papillæ of the mucous membrane.

The stratified epithelium forming a layer several cells deep, the deeper being columnar or spheroidal, the superficial cells flattened (cp. Epidermis, Lesson XXVII.).

\section{NOTES.}

Hardening. The stomach should be taken immediately after death, cut open and the mucous membrane washed in salt solution; the wall, or the mucous membrane only, is pinned out on cork and placed in alcohol or other hardening agent. Or the stomach may be washed out from the œsophagus, and then moderately distended with alcohol.

Osmic acid is excellent for lower vertebrates, but it does not as a rule preserve the cell granules in mammals; it does however in the bat, and sometimes in the mole.

Gastric glands of newt with blood circulating round them. The brain is destroyed; the newt is pinned on its back on the stage, the abdomen just below the fore limb and on the left side being opposite the hole in the stage; the hole in the stage should be about 1 to $11 \mathrm{~cm}$. long and 55 to $75 \mathrm{~cm}$. broad, the cork or india-rubber surrounding the hole being 2 to $3 \mathrm{~mm}$. high. A lateral cut is made through the abdominal skin, the stomach drawn out; this is cut open 2 to $3 \mathrm{~mm}$. from the mesenteric attachment on the lower side; the wall is then pinned out with hedgehog quills, the muscular coat being uppermost-this is best done under a low power to see that no tension is applied to the veins (cp. also Less. xvir. §9). A portion of the muscular wall may be cut away.

The cardiac glands of the newt appear as small round granular 
masses, usually neither the outlines of the cells nor the lumina are seen, the pyloric glands are non-granular and the cell outlines may be visible. The gastric gland-cells in the frog are not so coarsely granular as those of the newt.

Observations in the fresh state after removal from the body. In the newt, frog, small fish, mouse, guinea-pig and other small animals, the mucous membrane is washed or even scraped, the stomach pinned out over a hole in a stage, the muscular coat removed, the pins readjusted so as to stretch the membrane further, a cover-slip is put on, without salt solution unless it is necessary; the ends of the glands can then be examined under a high power. Or the muscular coat may be removed, and the mucous membrane spread out on a slide. When the mucous membrane is thick, small pieces are cut out (cp. § 3). In the guinea-pig and rabbit the granularity of the chief-cells diminishes from the fundus to the pyloric region.

Changes in digestion. If the small newt (Triton tæniatus) is fed with a worm, digestive changes can be observed in $1 \frac{1}{2}$ to 3 hours after feeding, the return to the normal state is rapid, it is usually complete in 5 to 10 hours.

In Triton cristatus the granules rarely disappear sufficiently during digestion to leave an outer homogeneous zone.

In the frog the digestive period is longer, a marked outer nongranular zone is formed in the œsophageal glands in 3 to 6 hours, but the recovery may take 1 to 4 days. The rate of digestion and the rapidity of the change in the cells varies with the condition of the animal and with the time of year.

In mammals the formation of zones occurs in the chief-cells only, it is not infrequently less marked in the fundus than in the greater curvature. In the gastric glands of frog and snake an outer non-granular zone is not formed, but the granules during digestion become smaller and less numerous.

It is to be remembered that if an animal is kept without food longer than the normal digestive period, the granules begin to disappear from the gastric cells, so that in a fasting animal the cells may have an outer non-granular zone and present the other characters of secretory activity.

In observing the changes which take place during digestion the animals taken should be as much as possible alike, and they should 
be fed once or twice at the same time and with the same food before the actual experiment.

Variation in structure in mammalian glands. The mole may be taken to show gastric glands with the upper part composed of oxyntic cells with few or no chief-cells, and with the lower part composed, as a rule, entirely of chief-cells.

Esophageal glands of frog. These may be observed fresh (cp. above), or sections cut after treatment with osmic acid. Alcohol and several other reagents preserve in the active cells the appearance of non-granular and granular zones, but they do not preserve the actual granules. The œsophageal glands are small racemose glands, the cell granules are large; some mucous cells are present; the surface epithelium consists of columnar ciliated cells with some mucous cells.

The mammalian osophagus if hardened in mercuric chloride gives a good triple stain with acid magenta, aniline blue and orange G. Cp. App. p. 311. 


\section{LESSON XXII.}

\section{THE INTESTINE.}

1. Vertical sections of a cat's or dog's small intestine given out in paraffin (chromic acid $\cdot 2$ p.c.; stained in bulk with hæmatoxylin). Mount in balsam (cp. Less. VI. § 4) under the same cover-slip this section and that of $\S 2$.

a. Observe under a low power, the outer longitudinal and the inner, thicker, circular muscular coat; the submucous coat rather thicker than in the stomach (Less. XxI. $\S 1$ ); the mucous membrane consisting of a thin muscularis mucosæ, of tubes closed at their ends, the intestinal glands, or glands of Lieberkühn, with retiform tissue between them; and of villi, projecting from the upper level of the intestinal glands, they may be either extended and long, or contracted and short, with the surface thrown into folds.

In the section there may be present one or more lymph follicles. A lymph follicle if present will appear as a round or oval mass, stained conspicuously, by reason of the nuclei of its numerous leucocytes; its 
deeper part is in the submucous coat, it extends more or less of the way to the upper level of the intestinal glands; if it has been cut through the middle, note that it appears to push aside the intestinal glands, that there are no villi on it, and that its upper surface is only separated from the cavity of the intestine by a single layer of epithelium cells.

b. Observe with a high power (oc. 4)

a. The villi; the epithelium consists of rather long columnar cells, each with a hyaline border striated with vertical lines (the balsam is apt to render this indistinct), and oval nucleus placed at about the lower third of the cell; the hyaline borders of the cells frequently appear to have coalesced into a narrow highly refractive band, which may be traced over the whole villus.

The mucous or goblet cells, irregularly scattered among the former, sometimes abundant, sometimes scanty or absent; they have an upper ovoid portion which is transparent but has sharp outlines, and a lower basal granular portion containing the nucleus (cp. with the mucous cells, Lesson $\mathrm{xx} . \S 6$, and Lesson xII. $\S 1, b)$.

The connective tissue, forming the substance of the villus: this consists of a meshwork of fibres and membranous cells, for the most part hidden by the numerous leucocytes.

The 'lacteal radicle' may be visible in some of the villi as a central space bounded by a fine line formed by the epithelioid cells. 
Unstriped muscular fibres as narrow bands running up the villus from the muscularis mucosæ.

$\beta$. The intestinal glands. Note that

The epithelium consists chiefly of cubical or short columnar cells; observe their gradation into the cells covering the villi, usually they have a small hyaline border similar to that of the columnar cells of the villi. Some goblet cells will be seen; (the number and appearance of the mucous cells vary in different animals).

There is usually a distinct basement membrane immediately beneath the epithelium, formed of connective-tissue cells very much flattened; the outlines of the cells are not seen in the section, but the nuclei are fairly conspicuous.

The lumina of the glands are small, but usually distinct.

$\boldsymbol{\gamma}$. The thin layer of retiform tissue around the bases of the glands of Lieberkühn and between them and the muscularis mucosæ. This, unlike the corresponding tissue in the stomach (Lesson xxI. $\S 1, b$ ), has a large number of leucocytes in its meshes.

$\delta$. The characters of the muscular and submucous coats (cp. Less. xxı. $§ 1$ ); the leucocytes of the follicles, if follicles are present.

$\epsilon$. Between the two muscular coats, here and there nervecells belonging to Auerbach's plexus.

2. Transverse sections of the villi of the small intestine of dog. (Flemming's fluid, stained in bulk in hæmatoxylin, cut in paraffin.) Note, comparing with 
$\S 1$, the cells with hyaline border, the goblet cells, the basement membrane, the connective tissue network with contained leucocytes, the capillaries a little below the basement membrane (these will not be obvious, if they are collapsed), the bundles of muscle-cells. In some sections the central lymphatic space will be seen, bounded by a sharp line probably showing one or more nuclei of its constituent cells.

3. Snip off a few villi from a fresh intestine, and tease in salt solution. Note especially the hyaline border of the columnar cells and its striation.

4. Vertical transverse sections of the large intestine. Observe

The longitudinal and circular muscular coats.

The submucous coat and the muscularis mucosæ both more conspicuous than in the small intestine.

The mucous membrane, probably thrown into longitudinal ridges, the submucous tissue running up into the ridges.

The absence of villi.

The intestinal glands (glands of Lieberkühn); they are broader than in the small intestine, and have more connective tissue (chiefly retiform) between them. The epithelium covering the free intestinal surface or the ridges between the glands consists of long columnar cells; in the glands the cells are shorter. The cells have usually a thin hyaline border. In some animals (e.g. dog) there are many distinct mucous cells.

5. Examine sections of a small intestine in which the blood vessels have been injected, and note the 
capillary network round the glands of Lieberkühn, and the small artery running up each villus and dividing into a capillary network just below the epithelium. The submucous tissue contains rather large vessels which give branches both to the mucous and the muscular coat.

6. Section of frog's intestine after feeding with fat (osmic acid). The columnar cells contain numerous fat globules of various size, the hyaline border is free from fat.

7. Feed a frog with a small piece of bacon; on the next day ${ }^{1}$ kill the frog, remove the stomach and intestine, pin the tube out on cork, cut it open, and gently wash with salt solution.

Note that the mucous membrane of the stomach has a yellowish semi-transparent look, whilst the mucous membrane of the intestine is of an opaque white-this is more marked in the upper than in the lower part of the intestine; the rectum is greyish and semi-transparent. Tease out a small piece of the opaque white mucous membrane in normal salt solution; the epithelium cells are crowded with fat globules, scarcely anything but these being visible. Fat is absorbed by the cells of the small intestine, and is absorbed little or not at all by the cells of the stomach.

8. Pin out pieces of the intestine; place some in 75 p.c. alcohol for an hour, and then in strong spirit; place others in osmic acid 1 p.c. for half-an-hour, wash and place in 75 p.c. alcohol.

In sections of these pieces note that there are no villi and no

1 The difference in the tint of the stomach and intestine is still more obvious if the frog be fed again after two days and killed on the subsequent day. The frog is fed by placing the piece of fat in the upper part of the esophagus, the fat is then usually swallowed at once. 
proper glands of Lieberkiihn. The mucous membrane is however thrown up into considerable folds. In the osmic acid specimens, the cells will probably be so full of deeply stained fat globules that little structure can be seen in them except the hyaline free border; in the submucous connective tissue few or no fat globules are seen.

In the alcohol specimens the cell substance will be seen as a distinct sponge-work or network, the fat globules having been dissolved.

\section{DEMONSTRATIONS.}

1. Vertical longitudinal section through the pylorus and beginning of the duodenum, of cat or dog. Note:the pyloric glands become shorter near the pylorus; at the beginning of the duodenum are Brunner's glands, forming a layer external to the muscularis mucosæ. In places a duct may be seen running down into the submucous tissue, there it divides and subdivides, the endtubes enlarging slightly, and forming alveoli in which as a rule the lumina are obvious.

2. Vertical section of small intestine through a Peyer's patch with blood vessels injected. Note the collection of lymph follicles and compare with the description given in $\S 1, a$. The capillaries in the main radiate from the periphery to the centre of each follicle.

3. Section of Peyer's patch with the lymphatic system injected. Note that the injected material envelops to a greater or less extent each follicle; it occupies the lymph sinus, and does not penetrate into the interior of the follicle. 
4. Transverse section through Lieberkühn's glands of small intestine.

5. Section showing passage of glands of rectum to stratified epithelium at anus; note the continuity of the submucous with the subcutaneous layers.

\section{NOTES.}

Preserving and staining. A short length of the intestine is washed out with salt solution, then distended moderately with chromic acid $\cdot 2$ p.c., the piece still distended placed in chromic acid $\cdot 2$ p.c. for a day. The ligatured ends are then cut off, and it is left in fresh fluid for a week, washed in running water, passed through alcohols up to 70 or 75 p.c. and so kept, best in the dark. Flemming's fluid gives perhaps better results than chromic acid, in this the piece of tissue is only left for a day; sections may be stained on a cover-slip in Ehrlich-Biondi fluid.

Pieces of tissue may be stained in hæmatoxylin and eosin; they are best cut in paraffin; sections of frozen tissue can be cut, and stained separately, but there is some danger of losing the epithelium of the villi. The mucous cells can be deeply stained by aqueous or 50 p.c. alcohol solutions of methylene blue or of thionin. Formol 4 p.c. (one day) and mercuric chloride (one day) are also satisfactory as hardening agents. After hardening in mercuric chloride, excellent results are given by Mallory's triple stain, cp. App. p. 311.

Sections of rectum if hardened in alcohol are apt to be sticky, on account of the mucin of the mucous cells; this can be done away with by placing the tissue for a day or two in 5 p.c. chromic acid.

Peyer's Patches. These are easily recognized as oval patches of the free border of the intestine of a rabbit. In order to show the retiform tissue in them, they may be placed fresh in 5 p.c. ammonium bichromate for three to four weeks (kept in alcohol if necessary), cut frozen and shaken up in a test tube, stained with picrocarmine or hæmatoxylin and mounted in glycerine, or with any of the double stains given in Less. $v$. and mounted in balsam.

The retiform tissue of the follicles will be seen to be continuous with that of the rest of the mucous membrane, but to be rather finer; 
around the follicles may be a zone containing very few leucocytes, and representing the lymph sinus.

The lymphatics of a Peyer's patch can be injected with Prussian blue (cp. Less. xvirr. Notes).

Brunner's glands are massed close to the pylorus in Carnivora and in Rodents; in some animals they are more scattered. The appearance of the gland-cells varies in different animals; in some they are full of distinct granules in the living state. 


\section{LESSON XXIII.}

\section{PANCREAS AND LIVER.}

\section{A. Pancreas.}

1. Section of pancreas of frog $^{1}$ (osmic acid, cut frozen), mount in glycerine or in glycerine jelly. Observe

(a) (l. p.), the lobules with their alveoli and ducts; the arrangement resembling in general features that of the salivary glands: the ducts, however, have a larger lumen, and cubical epithelium (cp. Lesson xx. §3).

(b) (h. p.). The cells contain a number of separate, spherical granules, on the inner or lumen side. How far these stretch towards the outer limit of the cells depends upon the state of digestion at the time the animal was killed, but there will probably be a more or less obvious outer non-granular zone. The outlines of the cells and nuclei, as usual after osmic acid fixation,

1 In mammals the granules are smaller than in the frog; but the pancreas of a mammal may be taken. 
are not very obvious; the nucleolus of each nucleus is generally conspicuous.

2. Section of active pancreas of a dog (alcohol); stain with picrocarmine or hæmatoxylin. The division of the cells into granular and non-granular zones will be seen; the inner zone however appears as a slightly stained confusedly granular mass, and does not show the separate spherical granules of the osmic acid preparation $(\$ 1)$; the outer zone, containing the nucleus, is homogeneous, or nearly so, and stains more deeply than the inner zone.

3. Examine the sections of pancreas for the inter-tubular clumps. In mammals they form roundish clumps of small cells generally of polyhedral outline; they have no obvious granules, and stain very little with carmine or hæmatoxylin. In the frog the cells are elongated, and arranged in indistinct columns.

In some of the lobules of the mammalian pancreas centroacinary cells will be seen; these are small flattened cells occurring in the part of the alveolus close to the ductule and inside the secreting cells.

\section{B. Liver.}

1. Sections of frog's liver (osmic acid). Mount in dilute glycerine. Observe with a low power that the gland apart from the ducts and ductules consists of anastomosing tubes between which the blood capillaries run. Observe (h. p.)

The tubes. In transverse sections they are seen to consist of four to six cells, each containing a large nucleus in its outer portion. 
The bile capillaries; these are the lumina of the tubes; in longitudinal sections of the tubes the bile capillaries are seen to take a zigzag course between the inner ends of the cells.

The cell granules arranged, according to the condition of the liver, either throughout the cells or around the lumen.

The fat globules, stained black with osmic acid; they vary greatly both in number and position according to the condition of the liver.

The glycogen content of the cells, indicated roughly by the extent of the non-granular outer zone. Mount a section in a solution of iodine; the parts of the cell containing glycogen will stain a deep brown-red.

2. Section of mammalian liver, preferably that of a pig, made parallel to the surface of the liver. (Muiller's fluid or potassium bichromate 2 p.c.; hæmatoxylin.)

\section{a. Observe with a low power}

The division into lobules; in the pig, the lobules are completely separated from one another by connective tissue; in the rabbit and in many other mammals, the cell-columns of one lobule are continuous in places with those of the neighbouring lobules.

In the centre of most of the lobules the very thinwalled hepatic or intralobular veinlet; those in which it is not seen have been cut through near the outer end of the lobule.

Between the lobules the thin-walled portal or interlobular veinlets, some of them of considerable 
size; the branches of the hepatic artery, small but with comparatively thick walls; and the small bileducts, with cubical or columnar epithelium and distinct lumina. The three vessels run together.

The hepatic cells radiating more or less obviously from the hepatic veinlet.

b. Observe with a high power, the polygonal hepatic cells with granular cell substance and one or two spheroidal nuclei, and the epithelium of the bile-ducts.

3. Section of liver, injected from the portal vein with Berlin blue or with carmine-gelatine. Mount in balsam. Observe, comparing with the uninjected specimens,

The hepatic veinlet, seen according to the plane in which the lobule is cut, either as a more or less circular section, or as a short veinlet passing from the centre of the lobule to the sub-lobular vein.

The portal veinlet running on the outside of the lobule, and giving branches to more than one lobule.

The radial capillary network between the portal and hepatic veinlets united by numerous cross branches; commonly there is only one row of cells between the radial capillaries.

4. Section of rabbit's liver containing glycogen (alcohol, cut frozen). a. Place in a drop of iodine solution, and mount in glycerine containing a little iodine, observe the red-brown stain of glycogen in the cells.

b. Stain a section with hæmatoxylin and eosin; 
mount in balsam. The cells show a stained outer limit, and a stained network or scattered particles in the cell; the glycogen forming a large part of the cell is unstained. Note the interlobular bile ducts, which commonly are obvious in the rabbit, and the passage of the cell-columns of one lobule with those of the neighbouring lobules (cp. $§ 2)$.

5. Scrape a small portion of fresh liver, and observe the pale, granular, hepatic cells; often containing fat globules.

6. Test for iron. (a) Place sections of liver ${ }^{1}$ in a mixture of equal parts of 2 p.c. hydrochloric acid, and 2 p.c. potassic ferrocyanide, warm for a few minutes, wash and mount in balsam. Particles containing iron or certain simple organic compounds of iron will be stained deep blue. (Prussian blue reaction.) (b) Mount the section in a strong solution of sulphide of ammonium, the particles containing iron will be stained black (ferrous sulphide reaction).

\section{DEMONSTRATIONS.}

1. Section of mammalian liver to show the bile capillaries. (Liver treated by Golgi's potassium bichromate and nitrate of silver method. Cp. p. 240.) Note the black lines indicating the bile capillaries, they form a network passing over the surfaces of the cells.

2. Section of rabbit's liver containing glycogen (osmic acid). The glycogen is represented by the

${ }^{1}$ In a chloroformed animal inject diamine of toluylen into a vein, in 4 or 5 hours eut out the liver and preserve in alcohol. Iron-containing particles will be present in the centre of the cell-columns of the liver. 
clear unstained parts of the cells; small brown stained granules, and possibly some black fat globules, will also be seen (cp. with $\S 4, a$ ).

\section{NOTES.}

\section{Pancreas.}

Mercuric chloride may be used instead of alcohol for hardening.

Resting and Active gland. A mammal is killed 5 to 8 hours after a full meal for the active gland, and one 12 to 16 hours after a full meal for the resting gland. In the frog, the corresponding times are 8 to 10 hours, and 1 to 2 days; the frogs should be fed with worms; in unhealthy frogs and in those which have long fasted, the pancreas cells have usually a distinct outer non-granular zone.

The pancreas of a rabbit may be taken to show in an injected specimen the enlarged and close-set capillaries in the intertubular clumps.

\section{Liver.}

Glycogen in liver. Give a rabbit a full meal of bran and carrots; in about six hours decapitate, and place small pieces of the liver in hardening agents.

Natural injection of bile ducts. . Inject into a blood vessel of an anæsthetized animal a saturated solution of sodium sulphindigotate (about 20 c.c. in a cat); repeat in $\frac{1}{2}$ hour and again in an hour ; in about another hour and a half, kill, harden pieces of the liver in absolute alcohol, stain in bulk in eosin in absolute alcohol, cut in paraffin.

The liver of the frog may be obtained with the tubes separated from one another, by injecting salt solution through its blood vessels (by way of the aorta for 5 to 10 minutes). The liver may 
then be placed in 1 p.c. osmic acid; or alcohol or mercuric chloride may be injected into the blood vessels.

In summer and autumn, the cells are usually granular throughout and have but few fat globules and little glycogen. In winter and spring, the granules are usually confined to the inner zone of the cells, the outer zone being chiefly glycogen; the fat globules may be either in the inner zone, or in the outer zone, the latter is commonly the case in spring especially in unhealthy frogs. Pigment masses, some looking like altered red corpuscles, are present between the tubes. 


\section{LESSON XXIV.}

\section{THE LUNG.}

1. Transverse section of the posterior part of a mammalian trachea (chromic acid $\cdot 2$ p.c., hæmatoxylin), taken so as to include the ends of a tracheal ring, and the membranous part between them. Observe,

Externally the fibrous coat of loose connective tissue, becoming denser internally, and having imbedded in it the two ends of the ring of cartilage.

Stretching between and outside the ends of the cartilage, a transverse band of unstriped muscular fibres; there may also be visible outside this the cut ends of muscular fibres running longitudinally.

The submucous coat (probably much folded) continuous with the fibrous coat, but of finer fibres. In this coat note the small glands consisting chiefly of mucous cells, though some serous cells are usually present; the ducts are not very evident, but they may be seen running towards the surface, and occasionally opening on it.

The mucous coat, consisting from without inwards of (a) longitudinal elastic fibres, becoming finer 
towards the basement membrane (probably the network formed by the elastic fibres will not be seen; some adenoid tissue may be present amongst the inner fibres), (b) the basement membrane, and (c) the epithelium, made up of columnar ciliated cells, and of two or three rows of small cells between the bases of the ciliated cells; some mucous cells also will probably be seen.

2. Longitudinal vertical section of trachea, taken through the tracheal rings. Compare it with the transverse section, noting especially the elastic fibres of the mucous coat.

3. Piece of mammalian lung taken from the more central portion. (Distended with, and hardened in, chromic acid 2 p.c.) Pass through alcohols down to 30 p.c. Place in hæmatoxylin for an hour or two. Imbed in paraffin (Lesson vII. §5) and cut sections. Observe

The larger bronchioles (if present in the section) resemble in general features sections of the trachea and bronchi except that, the cartilages are irregular in form, are irregularly scattered throughout the fibrous coat, the circular muscular fibres form a more or less complete ring at the base of the mucous coat, the epithelial layer, and all the coats are thinner. The fibrous coat is continuous with that of the surrounding lung tissue.

The smaller bronchioles have no cartilage and no glands, the epithelium consists of a single layer of ciliated cells, longitudinal elastic and circular muscular fibres are present. 
The alveoli as roundish areas of various size; in many the central part is simply a space, others show the wall as a thin nucleated membrane; the outlines of the flat cells of the membrane are not very distinct (cp. Demons. 3) but patches of two or more small cells may be seen amongst larger ones.

Irregular spaces larger than alveoli; these are the respiratory bronchioles, the short passages into which these divide, and the infundibula branching from the passages. They all give off alveoli, but the respiratory bronchioles do so from a part only of their periphery.

The epithelium of the atria and the infundibula resembles that of the alveoli except that the groups of small cells are larger; the epithelium of the respiratory bronchioles consists partly of non-ciliated cells either cubical or flat, partly of patches of ciliated cells, muscular fibres may be present in the wall.

4. Section of mammalian lung, the blood vessels of which have been injected; mount in balsam.

Observe the close-set capillary network in the alveolus, and the branching of the large vessels.

5. Cut out a lung from a recently killed newt, open it longitudinally, divide into two parts and spread them out, inner surface uppermost, on separate slides, being careful not to rub off the epithelium.

a. Treat with silver nitrate as in Lesson xvir. § 2, but do not transfer from clove oil to balsam until the outlines of the surface cells are visible.

b. Make a moist film preparation and fix with alcohol. Stain, but not very deeply, with hæmatoxylin and eosin.

Observe-The nuclei of the surface cells of the lung, occurring in groups of two to six. The outline of the cells (silver prepara- 
tion). The close capillary network occupying almost all the space between the nuclear groups. The blood-corpuscles in the capillaries (alcohol specimen), stained orange with eosin; focus up and down and note how near the surface the corpuscles are.

The capillary network may be made obvious and the outlines of its constituent cells shown, by injecting the vessels with silver nitrate (cp. Lesson xvir. $§ 5$ ).

6. Distend the lungs of a pithed newt (or frog) with 30 p.c. alcohol; leave the lung in this fluid for two days, wash, place for a day in Ranvier's picrocarmine ; wash, place in dilute glycerine. Scrape the inner surface, and tease the scrapings in dilute glycerine. Observe

The isolated lining cells of the lung, consisting of a thin hyaline ground plate, having near one border a nucleus with a little granular cell substance around it.

\section{DEMONSTRATIONS.}

1. Longitudinal and transverse sections of trachea (cat), stained with orcein. Note the band of elastic fibres in the mucous coat, and the scattered elastic . fibres in the fibrous coat.

2. Section of lung, stained with orcein. Note the considerable amount of elastic tissue in all the tubes as far as, and including, the openings of the alveoli, and the network of fine fibres in the thin walls of the alveoli.

3. Section of lung of fœtal mammal. Note in the alveoli the absence of large flat cells.

4. Inner surface of frog's lung (distended and fixed with alcohol). Observe with the unaided eye, and with a lens, $(a)$ the large central space, $(b)$ the 
somewhat short primary septa running inwards from the wall of the lung, and forming a number of polygonal chambers open towards the central space, $(c)$ short secondary septa, projecting into the chambers from the primary septa.

5. Section of newt's lung (distended with Flemming's fluid; picrocarmine). Note the epithelium cells, the thicker part between the capillaries containing the nucleus, the thin expansion of the cell lying over an adjoining capillary.

6. Section of mammalian lung treated with nitrate of silver to show the epithelium cells of the alveoli.

7. The circulation in the lung of toad or frog.

NOTES.

Outlines of flat cells of alveoli. Expose the lungs of a decapitated rat. Inject into the trachea a mixture containing .25 p.c. silver nitrate, and $\cdot 5$ p.c. osmic acid; force the fluid repeatedly in and out, so as to remove the air as far as possible from the alveoli. In 15 minutes cut up the lungs, wash with water; place a piece in gum, cut it frozen, expose the sections to light for $\frac{1}{2}$ hour; mount in balsam. The other pieces may be kept in 70 p.c. alcohol.

Sections may be stained on the slide with a nuclear stain. It is generally held that the large flat cells of the alveoli have no nuclei ; owing to the curved form of the alveoli it is difficult to make decisive preparations, but it is on general grounds unlikely that non-nucleated cells should persist for any length of time; nuclei in division are rare in the lung cells.

Circulation in lung of frog or toad. If the lungs collapse, and they usually do in a frog, take a cannula with two necks, about $4 \mathrm{~mm}$. apart, and with a small hole in the glass between 
the necks. Slip over the end of the cannula a piece of the rectum of a frog, and tie it round each neck. Open widely the mouth of frog (brain destroyed, and curarised), put the cannula into the glottis, slightly inflate the lungs by pinching the tubing attached to the cannula, insert into the tubing a glass rod which fits it. The degree of distension of the lung can then be varied at will by pushing the rod in and out. The lung should not be much distended. A special stand is desirable. The lung is less liable to collapse in the toad than in the frog.

Sections of amphibian lung. The septa in the frog's lung enlarge at the ends, which contain a rather large blood vessel and some muscular fibres; the enlarged end is covered with ciliated epithelium containing some mucous cells (respiratory epithelium). Similar epithelium occurs in the lung of the newt over some of the large blood vessels. 


\section{LESSON XXV.}

\section{THE KIDNEY.}

1. Dissection of sheep's kidney. It is advisable, before doing the microscopic work, to revive a knowledge of the points of structure of the kidney which can be seen with the eye.

Cut a fresh kidney in two transversely to the long axis and about one-third from the end; divide the large. piece longitudinally along the convex border as far as the pelvis. Note in the transverse and longitudinal sections, the pale medulla formed by the pyramids ${ }^{1}$ of Malpighi which project into the pelvis, outside this, the intermediate layer, forming a dark red zone not sharply defined, especially on the outer side, and having pale stripes, the medullary rays, extending into it from the pyramids of Malpighi; stretching from this to the surface, the cortex, a brownish-red zone; the pale medullary rays continue outwards in the cortex but do not reach the surface.

Trace out the branches of the renal artery and vein, they enter the kidney substance at the base of

${ }^{1}$ In some animals, e.g. rabbit and rat, there is only one pyramid. 
the pyramids of Malpighi, run to the outer portion of the intermediate layer, and there form a network more complete in the case of the veins than in that of the arteries.

2. Section ${ }^{2}$ of mammalian kidney transverse to its long axis extending from the outer surface to the summit, or nearly to the summit, of a papilla (ammonium bichromate 5 p.c.). Stain with picrocarmine.

\section{a. Observe under a low power}

The medulla, with its straight collecting tubes; some of the numerous divisions of these as they run outwards may be seen, but they are not conspicuous (cp. Demons. 1).

The intermediate layer: the collecting tubes of the Malpighian pyramids separate into bundles the medullary rays; between the bundles are seen numerous small blood vessels and some tubes of Henle (cp. $\S 2, b)$. At its outer limit are one or more large blood vessels.

The cortex: the medullary rays are seen to run out nearly to the free surface, between these are convoluted tubes and glomeruli, the latter arranged as a rule in two rows between each two rays (the symmetrical arrangement of the medullary rays and intervening convoluted tubes will not be obvious if the section is cut obliquely). In the extreme outer part of the cortex convoluted tubes only are seen.

I In cutting out the piece of kidney for sections, the cortical part should not be thicker than the pyramid near its summit, otherwise the medullary portion in some of the sections will be cut too obliquely. 
b. Observe under a high power

a. In the medulla :-

The epithelium of the collecting tubes; in the smaller tubes this is composed of short columnar or cubical cells with spherical or ovoid nuclei; in the larger tubes (outflow tubes) it is composed of longer columnar cells with ovoid nuclei and more transparent cell-substance; the lumina, distinct throughout, become larger as the tubes increase in size.

B. In the intermediate layer:-

The continuation of the collecting tubes outwards in the medullary rays.

The loops of Henle, seen as small straight tubes, chiefly in the medullary rays (the bend of the loop is not easily made out in this specimen). They run also a variable distance into the medulla.

The ascending limbs of the loops; these will probably be deeply stained, the cells have a rather marked striated outer portion.

The descending limbs of the loops; they are about half the diameter of the ascending limbs and have shallow or flat cells.

In some animals the cells of the ascending limb are placed obliquely, and the nuclei (in sections) are oval; the cells of the descending limb may be flat and transparent with nuclei projecting into the lumen, except for the thick basement membrane, they then resemble somewhat blood capillaries. The change in character of the epithelium may take place either in the ascending or in the descending limb of the loop. The lumina may be barely perceptible or about half the diameter of the tube, according to the state of distension.

The numerous blood vessels between the medullary 
rays (cp. $\S 6$ ); in the outer part of the layer, rather large arteries and veins cut transversely or obliquely will be seen (cp. $§ 1)$.

\section{$\gamma$. In the cortex :-}

The capsules, with the nuclei of their epithelium. The glomerulus in each capsule (cp. §6) and the nuclei of its capsular covering and of its capillaries.

The narrow neck of the capsule may perhaps be seen in some capsules in which the section has passed longitudinally through the neck.

The coiled course of the convoluted tubes; the outlines of the individual cells may or may not be distinct, each has a spherical nucleus and is striated in its outer portion. Sometimes the lumen is large, sometimes it can scarcely be made out.

In the medullary rays, the collecting tubes and ascending and descending limbs of loops of Henle.

The basement membrane distinct in all portions of the urinary tubule.

In the cortex are deeply stained short tubules running out from the rays and sometimes seen to be continuous with the ascending loops of Henle; their cells resemble those of the ascending loop except that they are of unequal size, thus giving a very zigzag outline to the tubule; this is the 'irregular' portion of the urinary tubule.

3. Sections at right angles to the collecting tubes (a) through the cortex, (b) through the intermediate layer, (c) through a papilla. (Mercuric chloride; hæmatoxylin.) Mount together.

Note in $(a)$ the medullary rays entirely surrounded by convoluted tubes and glomeruli, in $(b)$ the groups of 
blood vessels and descending limbs of the lonps in the midst of collecting tubes amongst which are also limbs of the loops, in (c) the outflow tubes with large lumina.

4. Cut freehand a thin section of the inner part of the cortex of a fresh kidney, tease it out in normal salt solution and observe the appearance of the fresh cells in the isolated bits of tubules. The convoluted tubes generally appear granular, the ascending limbs striated, the outflow tubes transparent; an opaque deposit is sometimes present in a few of the outflow tubes.

5. Tease a small piece of the cortex of a kidney which has been kept in 5 p.c. neutral ammonium chromate for 3 to 6 days.

Observe the secreting cells of the tubes, isolated or in groups, showing a very distinct striated outer portion; in some cells the outer part may appear as a brush of 'rods.'

6. Section of kidney (taken as in $\S 2$ ) which has been injected from the renal artery. Mount in balsam. Observe

The large arteries and veins in the outer part of the intermediate layer.

The small arteries and veins (arteriæ et venæ rectæ) given off from these, running down between the medullary rays into the medulla; they break up almost immediately into a brush of capillaries which enter the medulla and form a network throughout it; the meshes are elongated in the direction of the tubes, especially near the summit of the papilla.

The interlobular arteries and veins running from the larger vessels outwards in the cortex between the medullary rays; the arteries give off on all sides (two rows will probably be seen in the section) small afferent 
arteries, one to each capsule, where it breaks up into three or four bunches of capillaries to form the glomerulus.

The small efferent vein issuing from each capsule and breaking up into capillaries which form a network in the cortex; the veins from the innermost capsules break up into a brush of capillaries similar to that formed by the arteriæ rectæ and run towards the medulla.

The small veins running from the capillary network of the cortex to the interlobular veins.

Here and there the small artery running to a glomerulus may be seen to send a branch direct to the capillary network of the cortex ; similar direct branches will also be seen in the outer part of the cortex running from the ends of the interlobular arteries.

Small veins at the periphery of the cortex (venæ stellatæ) also arising from the capillaries of the cortex.

7. Examine the frog's kidney injected with nitrate of silver in Less. xuII. p. 136, and mounted in balsam (cp. also Notes, p. 200). Note the polygonal outlines of the cells of the capsules.

8. Section of dog's bladder at right angles to the surface (distended with and hardened in ammonium bichromate 2 p.c.). Stain with hæmatoxylin. Observe

The thin outer fibrous or connective tissue coat.

The muscular coat consisting of an outer generally speaking longitudinal layer, and an inner generally speaking circular layer; (in the lateral parts of the bladder, there is but one coat, formed of a plexus of fibres).

The inner connective tissue coat.

The stratified epithelium, consisting of three or four 
layers of cells, broadly speaking increasing in size from without inwards. The form of the cells naturally varies with the degree of distension of the bladder.

\section{DEMONSTRATIONS.}

1. Radial section of kidney (dog) injected from the ureter. Note the divisions of the outflow and collecting tubes.

2. Nitrate of silver preparation of mammalian kidney to show the outlines of the cells of the tubes. Note especially the irregular outlines of the cells of - the convoluted tubes.

3. Transverse section of kidney of frog; (osmic acid). Note the granules of the cells, and the inner clear or striated border.

4. Transverse sections of ureter (potassium bichromate 2 p.c.; hæmatoxylin) (a) taken near the kidney, (b) taken near the bladder. Note the epithelium similar in general to that of the bladder; the rather thick coat of connective tissue beneath the epithelium; the unstriated muscular coat consists of inner longitudinal and outer circular fibres; the outer fibrous coat; in $(b)$, the longitudinal muscle bundles outside the circular muscle.

\section{NOTES.}

Isolation of kidney tubes. A small radial piece of fresh kidney of a guinea-pig or rat is placed in a mixture of 1 part hydrochloric acid and 2 parts water for 4 hours to a day; it is washed well with water, strips torn off; and the tubes 
partially separated in dilute glycerine on a slide; portions of tubes only are thus obtained. Or the piece is placed in 35 p.c. potassium hydrate for half-an-hour.

Staining outlines of the epithelial cells. (Demons. 2.) A kidney is cut across, washed with sodium sulphate 75 p.c.: 5 p.c. nitrate of silver is poured on it, left for five minutes, the surface is then washed, and exposed to light in water; whon it is brown, sections are made from the superficial layer by the freezing method.

Injection from ureters. A 2 p.c. Prussian blue solution is allowed to run into the ureter of a dog (anæsthetized and bled) at a pressure of 30 to $40 \mathrm{~mm}$. $\mathrm{Hg}$ for a quarter to half an hour. Pieces of the kidney are hardened in alcohol, and cut in paraffin.

Excretion of sodium sulphindigotate. The method is the same as that for obtaining the bile ducts filled with sodium sulphindigotate (cp. p. 185) except that the spinal cord is cut in the upper thoracic region before the injection.

Hcomoglobin menisci in the capsules. The upper thoracic cord is cut in an anæsthetized dog ; 20 to 30 c.c. of blood is allowed to run from the carotid into an equal volume of water; this is defibrinated, filtered, and injected at intervals into a vein. In one to two hours the kidneys are cut up and ( $a$ ) put into boiling water for two or three minutes, $(b)$ preserved in one of the fluids which fixes hæmoglobin.

Glomeruli of frog's kidney injected with silver nitrate. The method of injecting the vessels given on p. 136 may be modified thus. The blood is washed out, the aorta below the kidneys is ligatured and the vena cava inferior clamped; nitrate of silver $\cdot 2$ p.c. is injected until whitish spots appear on the kidney ; in 4 or 5 minutes the vena cava clamp is taken off and distilled water is injected to wash out the silver solution. Then $(a)$ the kidney is mounted whole in balsam; the stain should be almost confined to the afferent and efferent glomerular vessels and the epithelium of the capsules. (b) The vena cava is again clamped and alcohol or formol injected to fix the glomeruli in a 
distended position; in an hour to a day sections are cut and exposed to light.

Kidney of newt. If the anterior part of the kidney of a newt be cut out and examined in salt solution, the cilia of the funnels will be seen in movement. (They open into the neck of the capsule in the newt, into the roots of the vena cava inferior in the frog.)

Good preparations of frog's or newt's kidney may be obtained by hardening in Flemming's fluid and staining with Mallory's triple stain (p. 311).

Kidney of snake. In the kidney of the grass snake (osmic acid), large tubes will be seen, having very large granules throughout. (They occur at the end of the second secretory portion.) 


\section{LESSON XXVI.}

\section{THE DUCTLESS GLANDS.}

1. Section of thyroid of cat or other mammal. (Flemming's fluid, imbedded, stained on the cover-slip with hæmatoxylin and acid magenta.) Note

The separate roundish vesicles forming the gland; they vary much in size, and have very little connective tissue between them.

The epithelium of the vesicles, the cells are of varying height, but usually somewhat flattened.

The homogeneous colloid substance filling the central space of the vesicles (the colloid is probably stained deep red).

In dehydrating the tissue, the colloid substance may shrink irregularly from the cells, giving it a vacuolated appearance at the periphery.

2. Section of parathyroid of cat (treatment as thyroid in $\S 1)$. Note the cells arranged in curved cylinders, or columns, or roundish masses; there are no vesicles like those of the thyroid and no colloid substance.

3. Pituitary body of cat. (Flemming's fluid.) Transverse sections of anterior and of posterior lobe cut separately, frozen (the posterior lobe is apt to break into pieces and is perhaps best imbedded). Stain with Ehrlich-Biondi fluid, or with boraxmethylene blue and eosin.

Note in the anterior lobe the anastomosing cell-tubes, or columns of cells; the two forms of cells, viz. ovoid, deeply 
staining cells, generally peripherally placed, and smaller cubical or columnar cells ; here and there, especially at the outer portion, stained secretion may be seen in the lumina of the tubes.

Note in the posterior lobe $(a)$ the central rather fibrous mass with scattered nuclei and some angular cells, forming the nervous or infundibular portion, (b) the glandular investment, consisting of polyhedral or cubical cells arranged in clumps, or anastomosing columns, or forming tubes.

4. Section of supra-renal body of cat ${ }^{1}$, cut transversely to its long axis. (Flemming's fluid, cut frozen.) Stain with hæmatoxylin (better with Ehrlich-Biondi fluid). Note

The thin connective tissue capsule.

- The cortex, consisting of bands of cells stretching inwards from the capsule. The medulla fairly sharply marked off from the cortex; it consists of a network of rather tubular-looking cell-masses, and generally shows some conspicuous, thin-walled veins.

If stained with Ehrlich-Biondi fluid, the cortex will be a darker red than the medulla ; if the gland is hardened in mercuric chloride and stained with picrocarmine the cortex will be yellowish, and the medulla red.

5. Distinguish the zones of the cortex, viz. (1) an outer narrow zone, the zona glomerulosa, consisting of cylinders of cells; at right angles to the surface there are usually two elongated. cells from side to side of the cylinder, and the nuclei are nearer the centre than the basement membrane; (2) a broad zone, zona fasciculata, consisting of cell-columns continuing the line of the cylinders but for the most part having a single row of polyhedral cells. (The arrangement resembles somewhat that of the liver cells.) The columns here and there communicate ; (3) a narrow zone, the zona reticulata, consisting of a cell-plexus, generally two cells from side to side of a strand; the cells are polyhedral and smaller than those of the preceding zone.

1 The appearance varies somewhat in different mammals. 
The cells of the cortex, especially those of the outer part of the cell-columns, contain usually a number of small fat globules; in the section they may have been dissolved; if so the cells under a high power will appear to have a very distinct network.

6. Tease out a piece of fresh supra-renal ( $a$ ) from the cortex, (b) from the medulla. Note that the cells of the cortex are granular or contain fat globules, those of the medulla are transparent ; irrigate with potassium bichromate 1 to 2 p.c., the cortex cells become yellow, the medulla cells become reddish-brown.

7. Section of a lobule of the thymus of a newborn animal (cat). (Mercuric chloride; picrocarmine.)

a. Note under a low power

The connective tissue sending in trabeculæ and dividing the cortex into alveoli. The alveoli are crowded with leucocytes.

The central mass or medulla of the lobule staining less than the cortex. 'In it are some small bodies concentrically striated, the corpuscles of Hassall.

b. Note under a high power

In the alveoli of the cortex there is no indication of a lymph channel (cp. p. 146).

In the medulla, small leucocytes are relatively less frequent than in the cortex; connective tissue cells with membranous processes and giant-cells may be seen; the striation of the corpuscles of Hassall is due to layers of flattened cells.

\section{DEMONSTRATION.}

Section of thymus with blood vessels injected. Note that in the cortex the capillaries run, broadly speaking, in loops between the periphery and the centre of the alveoli. (Cp. with lymphatic gland, p. 147.) 


\section{NOTES.}

\section{Thyroid and Parathyroid.}

The cells of the thyroid are more columnar and the vesicles smaller in young than in adult animals. To show columnar cells the thyroid of a rabbit two to three weeks old may be taken. Flat cells and large vesicles will be seen in the thyroid of an adult dog; and occasionally colloid substance between the vesicles. In sections hardened in Flemming's fluid the colloid substance stains with acid fuchsin, saffranin, picric acid and a number of other reagents; at times some cells (so-called colloid cells) stain more deeply than others.

In the fresh state, the cells are faintly granular, with some tistinct small globules. In the cat there are a number of these small globules, forming more or less of an inner zone; they may be stained in specimens hardened in Flemming's fluid. In the calf there are similar granules or globules, said to be pigment.

The parathyroid lies on the trachea below the thyroid in the rabbit; it is more or less imbedded in the thyroid in the cat, dog, and monkey.

\section{Pituitary Body.}

The pituitary body may be stained in bulk with hæmatoxylin and eosin. In serial sections (cat), the glandular outer coat of the posterior lobe will be seen to be continuous with the anterior lobe ; in the dorsal part of this coat are distinct tubes often filled with a homogeneous material; near the surface of the anterior lobe a ciliated tube may be seen.

\section{Supra-renal Body.}

The cells of the medulla take a red-brown or brown tint with chromic acid and chromic salts.

The fat globules of the cortex, after treatment with osmic acid, are readily soluble in xylol, soluble also though less readily in chloroform and in bergamot oil (cp. p. 326). They become however insoluble if the tissue is kept in alcohol for some time. 
In the dog the cell-cylinders of the outer zone of the cortex join in curves at the surface; the cells are flattened with their long axis across the axis of the cylinder.

In the supra-renal gland of birds, hardened in chromic acid $\cdot 2$ p.c. and cut frozen, the cells between the anastomosing epithelial cords are stained brown somewhat like those of the medulla of the mammal ; the cells of the epithelial cords may contain fat globules.

\section{Thymus.}

The corpuscles of Hassall are fairly numerous in the thymus of man and cat, fewer in the rabbit and guinea-pig, and still fewer in the rat. In the adult, the thymus is chiefly formed of fibrous connective tissue and fat.

A small piece of thymus tissue is present in the thyroid of the cat, generally close to the parathyroid. 


\section{LESSON XXVII.}

\section{SKIN. ENDINGS OF SENSORY NERVES ${ }^{1}$.}

- 1. Vertical section of human scalp. (Alcohol; picrocarmine.) Observe

a. The epidermis formed of :

The horny layer, consisting of much flattened cells, without visible nuclei; possibly the inner part only of this will remain.

The stratum lucidum, a thin layer of transparent cells (stained yellow by picric acid).

The granular layer, one or two cells deep, probably stained deeply with carmine. Examine under a high power for the eleidin granules of the cells.

The Malpighian layer, consisting of $(a)$ polyhedral cells (prickle cells), and of (b) a row of columnar or elongated cells (the germinal layer).

$b$. The dermis, consisting of white, fibrous, and elastic tissue, which becomes coarser and has larger spaces in passing inwards. Note the papillæ, conical

1 For sensory endings in Muscle and Tendon, see Lesson xvi. 
projections of the dermis surrounded by epidermis. A thin, fairly homogeneous basement membrane may be seen beneath the epidermis; it is not always distinct.

c. The sub-cutaneous connective tissue continuous with and indistinguishable from the deep layer of the dermis. It consists of loose connective tissue, with, usually, masses of fat-cells.

d. The hairs. Before examining these in the section, take a hair from the head, cut off a small piece, place it in 95 p.c. alcohol containing picric acid, leave a few minutes, wash in strong alcohol, clear and mount. Note in this the outer hyaline cuticle of the hair (here and there yellow stained scales will probably be seen partly detached from it), and the core with longitudinally arranged pigment grains; possibly also with a central portion, the pith. Turn now to the section, and follow a hair cut longitudinally in its lower part, it expands at the end forming the hair bulb. Note

The dermis sends the papilla, a bulbous mass with a narrow neck, into the hair bulb. In the epidermis the hair is surrounded by a continuation of the horny layer; this ceases to be distinct a short way from the surface (a little above the duct of the sebaceous gland). The continuation of the Malpighian layer of the skin outside the hair, the root sheath, stretching down to the hair bulb.

The cuticle consists of two layers, one attached to the hair, the other to the root sheath. Outside the cuticle, the root sheath consists of two parts, the inner and the outer root sheath.

The dermic coat of the hair follicle (the depression in the skin in which the hair lies), formed externally of 
dense connective tissue, internally of a hyaline membrane (the hyaline membrane varies in distinctness).

Note under a high power that the hair bulb consists of an outer row of columnar or cubical cells and of inner polyhedral cells, and that the cells are continuous laterally with the root sheath and centrally with the hair.

$e$. The sebaceous gland (or glands) attached to each hair: It consists of a duct, and of a variable number of alveoli. The duct opens into the upper part of the hair follicle, its epithelium is continuous with that of the root sheath. The alveoli consist of roundish -masses of polyhedral cells in which the cell substance appears as a network owing to the solution of the fatty globules it contained.

$f$. The erector muscle of the hair. The erector stretches as a band of unstriated muscle from the upper part of the dermis obliquely inwards to the dermic sheath of the hair, a little below the sebaceous gland.

g. One or two sweat glands may be present, but they will be better seen in $\S 2$.

2. Section of the tip of the finger; stain with hæmatoxylin. Note in the sweat glands the gland duct, a small tube showing in the dermis numerous nuclei; it consists of two or three layers of cells continuous with those of the Malpighian layer of the epidermis. In the epidermis the lumen of the duct is continuous with a tubular and more or less spiral channel between the cells.

The terminal secreting tube in the sub-cutaneous 
tissue. This forms a coil, and hence will be seen as a clump of tubes cut in various directions. The secreting portion is larger in diameter than the duct, it is lined by a single layer of cubical or columnar cells (a layer of longitudinal fibres may be present between the cells and the basement membrane).

\section{Sensory nerve-endings in stratified epi-} thelium. Vertical section of cornea of cat or rabbit. (Gold chloride; cp. Lesson x. § 7; alcohol; cut in paraffin.) Observe

The bars of the primary plexus (cp. Lesson xIv. $\S 11$ ) cut across; from this plexus small bundles of fibrils run through the anterior membrane and separate into a brush of fine varicose fibrils which spread out immediately underneath the epithelial cells, forming the sub-epithelial plexus. Probably the section in some part will be a trifle oblique; here a fragment of the small meshed sub-epithelial plexus will be seen, elsewhere fine fibrils will be seen running a longer or shorter course underneath the cells ${ }^{1}$.

The inter-epithelial nerve-fibrils seen in places to arise from the sub-epithelial plexus; they are fine varicose fibrils running at first nearly straight outwards, their branches are best seen near the surface.

The peripheral course of the nerve fibres in the parts of the skin where there are no special terminal organs is in the main like that described above for the cornea.

1 The sub-epithelial plexus is only seen satisfactorily in sections, cut from the surface of the cornea, which include the anterior surface of the basement membrane. 
4. Examine again the skin of the tip of a finger $(\S 2)$. Observe the touch corpuscles.

They are oval in form, and are found in the axes of the papillæ; many papillæ are without them, in which case a capillary may generally be seen running up into the papilla.

They appear to consist of a mass of connective tissue in which nuclei are disposed transversely. (For the nerve fibre cp. Demonstration 2.)

Pacinian bodies (cp. $§ 5$ ) may sometimes be seen in the sub-cutaneous tissue.

5. Examine the mesentery in a recently killed cat; in it will be seen a considerable number of oval transparent bodies, the Pacinian bodies. (Some are always present in the mesentery just above the inferior mesenteric artery.) Select one which is not surrounded by fat, cut it out and mount it in normal saline solution. With a little care the mesentery covering it may be removed with needles. Observe

The medullated nerve fibre and the thickening of its connective-tissue sheath as it approaches the Pacinian body.

The division of the connective-tissue sheath to form the numerous concentric capsules, which become closer together towards the centre of the body. At intervals on the capsules elongated nuclei will be seen.

The loss of medulla as the sheath splits up.

The hyaline core inside the innermost capsule.

The axis cylinder penetrating the core, and ending in it in a slight enlargement.

6. Treat a piece of skin of the face of a rat or kitten (containing the whiskers) with gold chloride and formic acid 
(Lesson xvi. § 5). Harden in alcohol, imbed, cut sections. Note the nerve plexus in the sub-cutaneous tissue and the bundles of nerve fibres which proceed from it to the large hairs (sinus or tactile hairs).

Note further the superficial nerve plexus in the upper part of the dermis, and the small bundle of nerve fibres sent downwards to the smaller hairs ; the nerve fibres form a ring around the hair just below the duct of the sebaceous gland.

In successful preparations (and better in successful methylene blue preparations) the non-medullated branches of the deep nerve fibres may be followed forming spatula-like endings, partly outside the hyaline membrane, partly amongst the cells of the outer layer of the root sheath; and in the region of the 'ring' a close plexus of fine varicose fibrils may be seen.

7. Section of the beak of a young duckling (Flemming's fluid, picrocarmine). Note

The simple form of touch corpuscles (Grandry's corpuscles) just below the epidermis, consisting of two or three disc-shaped cells to which a medullated fibre runs, ending in a non-medullated expansion between each two cells.

The simple forms of Pacinian corpuscles (Herbst corpuscles); they are smaller than Pacinian bodies and have fewer capsules; a row of nuclei is seen in the core on either side of the axis cylinder.

8. Special nerve endings in the epidermis. Cut out the hairless skin of the snout of a freshly killed mole, and treat it with gold chloride (25 p.c. formic acid 10 minutes, gold chloride $\frac{1}{2}$ to $\frac{3}{4}$ hour, wash in water, 25 p.c. formic acid in the dark for a day, wash, pass through alcohols). Cut sections of one piece at right angles to the surface and another parallel to the surface.

(a) Note in the vertical section (h.p.)

The downward projections of the epithelium. The medullated nerves running to each projection, there losing medulla, and continuing on, in the middle of the projection between the epithelial cells, as a bundle of varicose fibres ; in the outer part 
of the epidermis the fibrils will probably be represented by a series of small globules corresponding to the varicosities; in the centre of the bundle are two or three larger fibrils having a zigzag course.

The slightly conical mass of modified epithelium cells extending from the surface, around and in which the nerve fibrils run.

A few fibrils run to the surrounding ordinary epidermic cells.

A small end-bulb may be present immediately beneath the epidermis where the nerves lose their medulla.

(b) Note in the transverse section

The circular areas of the columns of modified epithelium cells ; the ring of nerve fibrils around each, and the two or three fibres in the centre.

DEMONSTRATIONS.

1. Vertical section of scalp, or other skin containing hairs (osmic acid). Note the fatty globules in the sebaceous glands.

2. Vertical section of tip of finger (osmic acid). Note the medullated fibre entering a touch corpuscle.

3. Section stained with orcein to show the elastic fibres.

4. Section of skin of face of rat or cat cut nearly in the plane of the surface, but a little obliquely (alcohol, picrocarmine). Observe one of the large tactile hairs with its cuticle, and the sheaths of its follicle (cp. $\S 1, d)$. In the sections of the roots, note the ring of transversely cut nerve fibres outside the hyaline membrane. 
5. Piece of mesentery of cat containing Pacinian bodies treated with osmic acid and mounted in water (or dilute glycerine). Note the bundle of nerve fibres separating to the several Pacinian bodies. Some of the fibres may divide and supply more than one Pacinian body.

6. Pacinian body after removal of the mesentery treated with silver nitrate. Note the outlines of the epithelioid cells of the outer capsules.

7. Longitudinal and transverse sections of bed of nail (picric acid; picrocarmine). Note the upper clear portion of the nail (corresponding to the stratum lucidum of the skin), the Malpighian layer, and the longitudinal ridges of the dermis.

8. Skin of mammal with blood vessels injected.

\section{NOTES.}

\section{Skin.}

Hardening. Mercuric chloride, picric acid and formol, chromic acid, may also be used for hardening skin. Calleja's stain (p. 311) gives good results. Thin sections of tissue hardened in mercuric chloride may be stained with Mallory's fluid (p. 311).

In imbedding, the tissue should be left but a short time in xylol and in melted paraffin, as in these it is apt to become hard.

For prickle cells, sections of the Malpighian layer parallel to the surface may be cut from skin fixed in osmic acid, and mounted in glycerine-jelly.

The horny layer will swell up and the cells show as vesicles with sharply outlined walls, if a piece be cut off with a razor, placed in 35 p.c. potassium hydrate for 10 to 15 minutes, and then slightly teased in a drop of water on a slide. 


\section{Sensory nerve endings.}

The endings in mucous membranes, and in tactile corpuscles are best seen in preparations made by the methylene blue injection method. Cp. p. 321.

For other gold chloride methods cp. p. 318. The lateral line of a fish may be taken for nerve eminences.

In birds, Grandry's corpuscles and other forms of sensory nerve endings are numerous in the waxy skin at the edge of the beak, in the palate and in the tongue (best perhaps in the back of the tongue). In the duckling, a transverse section of the posterior part of the beak including the palate may be made. 


\section{LESSON XXVIII.}

\section{ORGANS OF TASTE AND SMELL.}

\section{A. Taste Organs. The Tongue.}

1. Longitudinal section of a papilla foliata of the tongue of a rabbit (chromic acid 2 p.c. or potassium bichromate 2 p.c.). Stain with hæmatoxylin and eosin. Observe

The transverse section of the ridges with the intervening fossæ.

In each ridge three papilliform processes of the dermis, one median, two lateral.

The horny epidermis, consisting of cells very flattened but still showing nuclei, covering the ridges and lining the fossæ.

The Malpighian layer of the epidermis. In the fossæ both layers of the epidermis are thinner and less marked off from one another than on the surface.

On the outside of each lateral papilla, and therefore lining each side of the fossa, the flask-shaped taste-buds. There are usually four nearly in contact, one above the other. Each bud is in contact by its deeper part with the dermis of the papilla, and has a 
short neck running to the free surface of the epidermis of the fossa, where its circular open mouth may often be seen. The epidermic cells are flattened around its median portion, forming a nest for it.

The external or cover-cells of the taste-bud, curved and flattened, with conspicuous oval nuclei.

The internal taste-cells, each with spherical or ovoid nucleus, thin peripheral and still thinner central process.

Nerve fibres running along the dermis of the papillæ, and branching off to the buds.

2. Longitudinal section of tip of tongue of kitten (Flemming's fluid). Stain with picrocarmine. Observe

The filiform papillæ of the dorsal surface. If fungiform papillæ are also present, note the taste-buds in them.

The absence of papillæ from the ventral surface of the tongue.

The bundles of striated muscular fibres, vertical, horizontal and transverse.

The small racemose glands.

\section{B. Nasai Mucous Membrane.}

1. Transverse section of nose of newt (Flemming's fluid ; picrocarmine). Observe (l. p.)

The nasal chamber on either side surrounded by bony and cartilaginous plates and lined by an epithelial layer, thick, except in its lateral part.

The glands and the cut bundles of nerve fibres below the mucous membrane. 


\section{Observe (h. p.)}

The outer layer of the olfactory epithelium, without nuclei, and appearing as very closely packed thin cell bodies or processes (the outer portions of the columnar and of the olfactory cells).

The inner layer, in which little is seen but closely packed nuclei; the outermost layer of nuclei (belonging to the columnar cells) are elongated; the rest are round or nearly so (nuclei of the olfactory cells).

The delicate processes of the olfactory cells projecting on the surface.

The bundles of non-medullated fibres of the olfactory nerve, and the small serous glands in the submucous tissue. Here and there a duct may be seen running through the epithelium, as a fine tube consisting of basement membrane and flattened cells.

The respiratory epithelium, consisting of columnar ciliated cells and mucous cells. (This will probably be seen in the lateral part of the nasal cavity. It is the sole epithelium at the nasal openings.)

2. Take a pithed frog or newt, cut off the upper part of the head just in front of the eyes, from this cut off the tip a little behind the nostrils. Examine the piece with a lens and observe the nasal cavities, cut away the roof of one nasal cavity, place in osmic acid 5 p.c. for about $\frac{1}{2}$ an hour, wash well with water, place in picrocarmine for 1 to 24 hours (better the longer time), wash, scrape off a little of the olfactory mucous membrane, tease and mount in dilute glycerine. Observe

The columnar or supporting cell; it has a 
cylindrical outer portion, and a much thinner and sometimes branched inner portion.

The olfactory cell; it has a projecting spherical nucleus, a slender, smooth, outer portion, and a still more slender, rather irregular inner portion.

The columnar cells surrounded and partially hidden by three, four, or more olfactory cells.

Probably the granules of the serous glands beneath the epithelium (corresponding to Bowman's glands in the mammal) will be preserved and be very obvious.

\section{DEMONSTRATIONS.}

1. Vertical section of tongue (rabbit or cat) with blood vessels injected.

-2. Section of the respiratory part of the nasal mucous membrane of a mammal (osmic acid 1 hour, well washed; hæmatoxylin). Note the ciliated cells, the mucous cells, and the glands.

3. Section of mammalian olfactory mucous membrane (upper part of septum of nose of dog; Flemming's fluid; Ehrlich-Biondi stain). Compare with B $§ 1$; note that the processes of the olfactory cells project very little beyond the columnar cells.

\section{NOTES.}

What has been said in the Notes to Lesson xxvir. with regard to hardening and staining the skin holds also for the tongue.

For circumrallate papillæ the back of the tongue of the calf may be taken.

Organs similar to taste-buds will be seen in the skin of many fish (piece of punctated skin of head; Flemming's fluid). 
Nose of newt. The upper jaw of a pithed newt is cut off in front of the eyes, the anterior part is cut away, the cut passing a little behind the nostrils. The nasal portion is hardened in Flemming's fluid, decalcified, stained in bulk with picrocarmine or with alum carmine, cut in paraffin. A similar preparation showing all the nasal chambers may be made in any small mammal.

The isolation method given in $\mathrm{B} \oint 2$ serves also for mammals; the olfactory mucous membrane may be placed for an hour in 33 p.c. alcohol before being placed in the osmic acid.

The nerve endings in the taste cells and the sensory nerve endings in the olfactory mucous membrane may be brought out by the methylene-blue injection method (20 to 30 minutes after injection, sections of a papilla foliata may be cut free-hand, and exposed to the air in a drop of salt solution). For the olfactory cells the Golgi method is used (cp. p. 240).

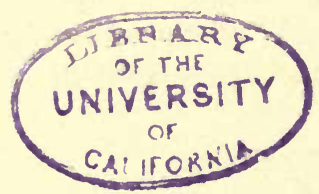




\section{LESSON XXIX.}

\section{THE EYE.}

1. Section of the anterior part of the eye of cat or dog (Flemming's fluid). Observe

The irregular connective-tissue of the sclerotic passing into the lamellæ of the cornea. The fan-like bundles of fibres spreading from the junction of the cornea and sclerotic, to the iris (ligamentum pectinatum), and to the choroid. Amongst the latter bundles are some bands of unstriped muscle, the ciliary muscle.

The ciliary processes, forming a much folded membrane. Note the two layers of cells, columnar to cubical cells and pigment cells, continuous respectively with the inner coat and with the pigment cells of the retina.

The hyaline suspensory ligament attached to and projecting from the ciliary processes, and running to the capsule of the lens.

The passage of the layers $\mathrm{i}$ to ix of the retina $(\$ 7)$ to columnar epithelium at the ora serrata.

The iris, consisting of, $(a)$ a layer of pigment cells (uvea) continuous with the pigment of the ciliary processes, and so of the retina; $(b)$ a thin fibrous-looking layer, forming the dilatator pupillæ; $(c)$ a thick layer 
of connective tissue with pigment cells, and with numerous blood vessels (note the transversely cut vessels in the peripheral part of the iris) and nerve bundles; $(d)$ a wedge-shaped bundle of transversely cut muscle fibres near the pupillary margin, the sphincter pupillæ; (e) a rather indistinct anterior limiting membrane.

The cornea, consisting of, (a) the anterior epithelium continuous with that of the conjunctiva; note, the external layer of flattened but nucleated cells, the middle layer of two or three polyhedral cells, and the inner layer of a single row of columnar cells; $(b)$ the connective tissue arranged in laminæ, with flattened cells between them, it forms an inconspicuous anterior basement membrane; (c) the posterior elastic membrane (membrane of Descemet), thick and hyaline, with very sharp outlines; $(d)$ the posterior epithelium of flattened cells.

2. Lens. Take an ox's or sheep's lens which has been in potassium bichromate 2 p.c. for a week. The junctional lines of the lens fibres will be seen as a star; the fibres readily peel off in laminæ.

3. Antero-posterior section of lens (Müller's fluid, cut frozen); stain with picrocarmine, mount in glycerine: Note

The hyaline capsule.

The columnar epithelium of the anterior surface of the lens; at the sides these rapidly but gradually elongate into fibres.

At the sides, the nuclei of the fibres forming an irregular band. 
4. Section through the centre of a lens at right angles to its short axis. Observe the cross sections of the fibres, and their junctional lines.

5. Place the lens of a rabbit or rat in osmic acid 25 p.c. for about three hours; it will swell up somewhat, and the outer coat becomes jelly-like and easily torn; to obviate this, place it in gold chloride $\cdot 25$ p.c. for a minute or less; then tear off as long a strip as possible of the outer coat, and tease out in water. Observe the long band-like fibres with serrated edges usually adhering together in layers but in some cases isolated.

In some of the fibres a nucleus will be seen; when the fibres form a layer, the nuclei appear as an irregular band running across it.

6. Make a moist film preparation of, and fix with alcohol, the iris of a white rat with the posterior surface of the iris uppermost; stain with hæmatoxylin. Observe the arrangement of the sphincter muscle.

7. Retina. Section through posterior part of the eye of a mammal (Flemming's fluid or potassium bichromate 2 p.c.; stained in bulk, cut in paraffin). Observe

(i) The inner limiting membrane showing as a thin line.

(ii) The layer of optic nerve fibres, thin, and inconspicuous; the fibres are without medulla, a small bundle of fibres may be seen here and there, dipping towards the next layer.

(iii) The ganglionic layer, consisting of a single layer of nerve-cells with conspicuous nuclei.

(iv) The inner molecular layer, appearing as very close plexus of fine fibrils.

(v) The inner nuclear layer, showing two to 
four rows of round or oval nuclei. The cell substance is inconspicuous.

(vi) The outer molecular layer, a thin layer much like the inner molecular layer (iv).

(vii) The outer nuclear layer; the nuclei are smaller and more numerous than in the inner nuclear. layer (v).

(viii) The outer limiting membrane, a well defined line.

(ix) The layer of rods and cones, probably the outer and inner limbs of the rods can be distinguished. Note the cones, shorter or less numerous than the rods.

(x) The layer of pigment cells enveloping the free ends of the rods.

Observe also the supporting fibres (fibres of Müller), seen as lines stretching a greater or less distance between the inner and the outer limiting membrane.

8. Section of posterior part of eye of newt (osmic acid vapour; Flemming's fluid; Ehrlich-Biondi stain). Note

The supporting fibres, having an expanded membranous base at the inner limiting membrane, an elongated nucleus in the inner molecular layer, and stretching to the outer limiting membrane.

The large outer limbs of the rods, and the processes from the pigment cells running between them.

9. Examine in detail the retina of the newt $(\S 8)$, and compare it with the mammalian retina (§ 7). Note 
The ganglionic layer is represented by two rows of cells, the nuclei are conspicuous, but with very little cell substance.

The outer molecular layer is a mere line.

The nuclei of the outer nuclear layer are elongated.

The rods and cones are much larger and more easily scon than in the mammal. The outer limbs of the rods will be more deeply stained with osmic acid (if this has penetrated) than the inner limbs ; the longitudinal fluting of the outer limbs will be seen, and probably the transverse breaking into discs.

The distinct pigment cells and their processes.

10. Cut out the eye from a freshly killed frog; holding it up by the optic nerve cut off a small part 5 to $1 \mathrm{~mm}$. of the coats of the eye around the optic nerve. Insert the point of the scissors into the hole thus made and make two radial cuts including about a third of the eye between them, cut off the anterior part, place the posterior part inner surface downwards on a slide, between two strips of thickish paper, take off the sclerotic, fixing the pigment layer at one edge and the rest of the retina at the other; pull them apart. If this is done quickly, the retina will be seen to be a purplish-red, due to the visual purple in the rods. Cover with a cover-slip having on it a small drop of salt solution, and examine at once. 'The mosaic formed by the ends of the rods and cones of the retina should be seen ; most of the rods are purplish-red, but a few green ones are present. The colours soon fade; when they have faded, remove the strips of paper and tease out the piece of retina. Note the large outer limb of the rods, its longitudinal fluting, and transverse breaking into discs, the lenticular piece following this, the refractive globule in the concs, and the pigment granules and cells.

11. Make a similar preparation of the retina of a mammal. Note the small diameter of the rods and cones.

12. Tear off a small piece of the retina from a sheep's eye preserved in Muiller's fluid, probably the pigment-layer of the retina will be left adhering to the choroid. Take a small piece of this pigment-layer, and 
mount it in glycerine (or take a fresh eye, and mount the cells in salt solution). Observe the single layer of hexagonal cells with large pigment granules.

\section{DEMONSTRATIONS.}

1. Ciliary processes and iris of rabbit (or of a smaller mammal) with vessels injected, mounted flat with ciliary processes uppermost.

2. Radial section of anterior part of eye of man. Note the well-developed bundles of the ciliary muscle, passing from the region of the inner anterior part of the sclerotic to the choroid. At the inner and anterior part of the muscle, some transversely cut fibres may be seen (circular muscle).

3. Vertical section of blind spot; note the fibres of the optic nerve passing through the layers of the retina to reach the inner surface.

4. Vertical section through the fovea centralis of man: note the elongation of the cones and the thinning of the other layers.

5. Sections of retina by Golgi method.

\section{NOTES.}

Anterior part of the eye. The eye is placed in Flemming's fluid for half-an-hour to an hour, the posterior half is then cut away: the anterior half placed again in Flemming's fluid. When hardened, a cut is made in the suspensory ligament and the lens removed; the rest is cut in radial pieces, these are stained in bulk, cut in paraffin, the sections approximately parallel with the ciliary processes alone being mounted.

Lens. The eye of a rabbit or cat, with the cornea and sclerotic cut through, is placed in Müller's fluid for three weeks 
or longer; then the lens is cut out with its capsule, and vertical sections made through its centre with a freezing microtome; neither the lens nor the sections should be touched with spirit.

The lens fibres may be to a certain extent isolated by placing for a day in 33 p.c. alcohol.

Posterior part of eye of newt or other small animal. The eye is suspended in osmic acid vapour for 10 minutes, placed in Flemming's fluid for about 2 hours, the anterior part removed, the posterior part passed slowly through alcohols, and imbedded. Sections stained on the slide with Ehrlich-Biondi fluid.

Retina. The treatment by the Golgi method is chiefly due to Ramón y Cajal. The retina is removed, then

(a) rolled up, dipped for a second in dilute celloidin solution, and exposed to the air for a second to allow the solution to acquire a little consistency,

or (b) the vitreous humour side is covered with a thin layer of gelatine,

or (c) the retina is simply removed from the eye.

It is then placed for

1-2 days in Golgi's mixture (p. 247); then the fluid adhering to it removed with blotting-paper.

1-2 days in $\cdot 75$ p.c. silver nitrate ; the excess of fluid removed as before.

$1-2$ days in Golgi's mixture, but containing only $\frac{1}{2}$ to $\frac{1}{3}$ the amount of osmic acid.

1-2 days in $\cdot 75$ p.c. silver nitrate.

It is then treated as other Golgi preparations, cp. p. 240.

The celloidin or gelatine is used to avoid the precipitate of silver salts which is apt to form in the outer part of thin tissue. According to Ramón y Cajal it is best to take the retina of a large animal.

The methylene-blue method is chiefly due to Dogiel. It is similar to that given above for nerve-endings (Less. xvI.). The retina is placed on a slide, vitreous humour surface uppermost, 
with some vitreous humour still attached to it. A drop or two of 06 p.c. methylene blue in salt solution is added, and it is left for 20 to 40 minutes covered up; when examination with a low power shows that staining has occurred, the methylene blue is washed off with a little salt solution, and half-a-dozen drops of a saturated solution of ammonium picrate added; in 3 to 4 hours a drop or two of glycerine and ammonium picrate is added, in 18 to 20 hours the fluid is poured off, and the retina mounted in glycerine and ammonium picrate.

A little ammonia may be added to the ammonium picrate, and gum and sugar used as mounting agent.

The retina may be hardened in mercuric chloride for observing the effect of light on the retinal elements. 


\title{
LESSON XXX.
}

\author{
THE INTERNAL EAR.
}

1. Semicircular canals of skate. Transverse section in paraffin of crista acustica. (Flemming's fluid ; picrocarmine.) Observe

The projection (conical in section) of the crista, composed mainly of homogeneous-looking connective tissue.

The numerous large medullated fibres running up the projection.

The cap of epithelium thicker than elsewhere. In this note the superficial columnar cells, and two or more rows of deeper lying nuclei belonging to the fibre cells; here and there the slender inner and outer process of a fibre cell will be seen.

Hair-like processes projecting from the cap of epithelium.

On either side of the crista, the thinner connective tissue wall, and the single layer of short columnar or even flattened cells. 
2. Place a fresh ampulla in osmic acid $\cdot 5$ p.c. for about half-an-hour (or longer), treat it in the manner given in Less. XII. $\S 1, b$, observe the nerve fibres with blackened medulla in the wall of the tube and the shape of the isolated cells.

3. The cochlea. Section of the cochlea ${ }^{1}$ of a guinea-pig or other mammal cut parallel with the axis of the modiolus. Observe

The division of each turn of the cochlea into three canals by the basilar membrane running across from the end of the lamina spiralis, and by the membrane of Reissner starting from the lamina farther back; the latter may have been torn through.

The following modifications of the epithelium cells of the scala media, starting from the inner side of the basilar membrane.

a. Cells passing from cubical to columnar.

b. The single inner hair cell, columnar with short hair-like processes, the so-called hairs arising from its free surface; its deep pointed end is more or less hidden by small cells with large nuclei.

\section{c. The inner and the outer rod of Corti.}

d. The three or four outer hair cells, long

${ }^{1}$ Cochlea in Flemming's fluid 8 to 24 hours (expose in one place the cochlear canal), water 1 day, decalcify in 75 p.c. alcohol containing 1 p.c. nitric acid, water 1 day. Stain in bulk with acid hæmatoxylin, or alum carmine, or stain the sections on a cover-slip with Renaut's eosin-hæmatoxylin. 
irregular cells, not perpendicular to the membrane, but bending inwards, with short hair-like processes projecting from the surface, and deeply seated nucleus; occasionally two nuclei are seen in a cell.

e. The supporting cells between the basilar part of the outer hair cells, each sending a thin process up to the reticular membrane.

$f$. The rings of the reticular membrane surrounding the tops of the outer and inner hair cells.

g. Cells passing from columnar to cubical, inclining inwards, like the outer hair cells.

The membrana tectoria proceeding from a projection of tissue on the lamina spiralis, thence enlarging and forming a more or less distinct pad above the organ of Corti; in the preparation it will probably be considerably shrunken.

The nerves running along the lamina spiralis towards the basilar membrane, and (if the section passes through the modiolus) the group of nerve-cells-cochlear ganglion-at the base of the lamina spiralis.

4. Break the cochlea of a mammal in two, place the pieces in 5 p.c. osmic acid for two hours; break up the cochlea into smaller pieces, wash with water for an hour or two; place in picrocarmine for an hour; under a dissecting lens, separate portions of the membranous tube and tease them out in dilute glycerine; observe the isolated fragments and cells of the organ of Corti. 


\section{DEMONSTRATION.}

Section of cochlea through modiolus showing the cochlear ganglion. 


\section{LESSON XXXI.}

\section{THE SPINAL CORD.}

1. Transverse sections of human spinal cord through the cervical swelling, the mid-thoracic region and the lumbar swelling (e.g. 6th C., 6 Th., 4th L.) (potassium bichromate, cut frozen, picrocarmine). Mount in balsam. Comparison of the sections will be easier if they are mounted on the same slide. Observe the following general features of the spinal cord, first under a low and then so far as is necessary under a high power.

The pia mater, of connective tissue surrounding the cord; it sends into the cord numerous septa. Note the blood vessels running from the pia mater into the cord along the septa.

The anterior and posterior fissures; the pia mater folds down into the anterior fissure; it sends a septum only into the posterior fissure.

The exit from the cord of the anterior roots of the spinal nerves; they are seen as several small inconspicuous bundles running longitudinally through the white substance.

The entrance into the cord of the posterior roots of the spinal nerves in a compact mass. 
The white substance, consisting chiefly of medullated nerve fibres, forming the outer part of the cord and divided on each side by the entrance of the nerve roots into anterior, lateral and posterior columns; since the fibres of the anterior root do not enter the cord in one bundle there is no definite line of division between the anterior and lateral columns.

The grey matter projecting on each side into an anterior and a posterior cornu, but with no distinct separating line between them. The posterior cornu is divided into the neck, the head, and the apex, the latter pointing to the surface along the line of entrance of the nerve roots.

The large multipolar cells of the anterior cornu.

The central canal; it may be plugged up with epithelial cells.

A ring of deeply stained neuroglia around the central canal.

On either side of the central canal the posterior or grey commissure deeply stained.

The anterior or white commissure consisting of fairly large decussating nerve fibres in front of the anterior grey commissure; some måy perhaps be traced from the anterior cornu of one side to the anterior column of the opposite side.

A deeply stained area, the substantia gelatinosa, just internal to the apex of the posterior cornu. It will be better seen in the specimen $\S 6$.

The reticular area in the lateral part of the posterior cornu, a little in front of the substantia gelatinosa, consisting of bundles of fibres surrounded by a small amount of grey substance. 
The area of small nerve fibres at the apex of the posterior cornu, and extending a little laterally of the head is Lissauer's tract.

2. Compare the three sections and note

a. General differences in the cord and the white substance.

The transverse area of the cord is largest in the cervical swelling, and is larger in the lumbar region than in the thoracic region.

The transverse area of the white substance, i.e. the number of nerve fibres, is greater in the cervical than in the thoracic region, and greater in the thoracic than in the lumbar region. (The latter difference may not be easily appreciable by the eye.)

Outline. The side to side diameter is larger than the antero-posterior in the cervical swelling; this is much less the case in the lumbar swelling, and the diameters are nearly equal in the thoracic region.

The central canal is nearer the ventral than the dorsal surface (rather more than $\frac{1}{3}$ rd way from the ventral surface) in the cervical swelling and thoracic region; it is about the middle of the section in the lumbar swelling.

Division of posterior column. In the cervical region the posterior column is divided into two parts, Goll's column (funiculus gracilis, median posterior column) near the posterior fissure, and Burdach's column (funiculus cuneatus, postero-lateral column) near the posterior cornu and posterior roots.

In the mid-thoracic region the division is still seen, though not always distinctly; it is not present in the lumbar region. The two columns may be made 
out by the eye by a difference of tint, when no proper septum is present.

(Goll's column begins about the lower third of the thoracic region, and increases in passing upwards.)

In the lumbar region there is an oval area of small nerve fibres about the centre of the combined posterior columns, the posterior septum running through its long axis.

In the sacral region there is a triangular area of small fibres in the combined posterior columns, the base of the triangle being on this surface, and the posterior septum dividing it into two equal halves.

These areas must not be confused with Goll's columns.

b. Differences in the grey substance.

Relative amount of grey substance. The grey substance is much larger in amount in the cervical and lumbar swellings than in the thoracic region.

Shape of anterior cornu. In the cervical and lumbar swellings the anterior cornu has a large lateral projection, in the thoracic region it forms a narrow band with nearly parallel sides. The median border is approximately parallel with the anterior fissure in the cervical and thoracic regions, but curves away from it in the lumbar region.

The lateral cornu. In the thoracic region there is a small lateral projection of the grey substance, the lateral cornu, about midway between the anterior and posterior cornu. (It is less distinct in the lowel thoracic region and varies in different sections.)

Shape of posterior cornu. The neck of the posterior cornu is narrow in the thoracic region, and the apex is some distance from the surface of the cord 
(especially in the lower thoracic region); in the cervical region it is broader, and is broken up by bundles of transversely cut fibres, and is nearer the surface than in the thoracic region; in the lumbar region the neck is broad; the apex is near the surface, and the head forms a rather large, roundish mass.

Nerve-cells of anterior cornu. In the cervical and lumbar regions distinct groups of large nerve-cells are seen; in the thoracic region the nerve-cells are fewer, smaller, and less obviously in groups.

Clarke's nucleus. This is seen in the thoracic region as an oval area near the neck of the posterior cornu, a littie behind the level of the central canal. The cells in it are fairly large, but less obviously multipolar than those of the anterior cornu. Clarke's nucleus is not seen in the cervical and lumbar swellings.

Cells of lateral cornu. These are only obvious in the thoracic region, they are medium to small cells elongated in the direction of the lateral cornu.

3. Sections of 2nd or 3rd cervical, lower part of 1st thoracic, and 1st or 2nd lumbar segments of man. Note in these that the anterior cornu has no considerable lateral bulging as it has in the cervical and lumbar swellings, but is larger than in the mid-thoracic region. Note also

In the 2 nd or $3 r d$ cervical segment ; Goll's column is distinct ; the central canal is about $\frac{1}{3}$ way from the ventral surface ; a few medium-sized cells, the cervical nucleus, are present in the region of Clarke's thoracic nucleus; one or two small bundles of large nerve fibres of the spinal accessory are present either in the grey substance close to the reticular area or running obliquely outwards and dorsally from it (these may be seen in the first 5 or 6 cervical segments); the reticular area increases rapidly in passing upwards in this region. 
In the 1st thoracic segment; Goll's column is present, but runs more to a point than in the upper cervical region, and is smaller ; Clarke's nucleus is distinct, the neck of the posterior cornu is rather long. (The anterior cornu has a considerable lateral bulging in the upper part of this segment.)

In the 1st or 2nd lumbar segment ; Clarke's nucleus is probably present (it disappears in the lower part of the 2nd segment); Goll's column is absent; the oval area seen in the lumbar swelling is represented by fibres near the surface in the 1st lumbar, rising to the oval area in the 2nd lumbar; the neck of the posterior cornu is thick and the apex short.

4. Section in sacral region (man). Note that the area of this grey matter exceeds that of the white; the neck of the posterior cornu is very thick; the anterior cornu is large, its outline rounded, it contains marked groups of large nerve-cells with large nerve fibres between and amongst them; scattered large cells, forming the sacral nucleus, are present in the base of the posterior cornu.

5. Sections of cord of $\operatorname{dog}$ (3rd C. ; 7th C.; 1st Th. ; lower Th. ; 6th L. ; 2nd S.). Note the following differences from the human cord :

In the cervical region the cord is only slightly flattened in outline, and the central canal is only slightly nearer the ventral than the dorsal surface. The outer boundary of Goll's column is concave. The neck of the posterior cornu is rather broad, and its apex is fairly close to the surface. The fibres of the spinal accessory-1st to 5th or 6th cervical segments-are generally more obvious than in man. The cervical swelling is more like the lumbar swelling than it is in man.

In the greater part of the region between the cervical and lumbar swellings, Clarke's nuclei touch the posterior fissure, thus giving an appearance of a very broad grey commissure behind the central canal. In the two or three segments near the swellings, they are less developed and farther from the p. f. ; they cease about the 4th L. in dog, and 5th L. in cat. Goll's 
column forms in the upper and middle region an area with its long axis at right angles to the posterior column.

In the lumbar swelling a sharp angle-almost a right angleis presented by the head of the posterior cornu towards the posterior column (this is not very different from some sections of the human cord).

6. Section of human cord (lumbar) with the medulla of the fibres stained (cp. § 7). Note

The great number of small medullated nerve fibres in the grey substance, except in the substantia gelatinosa of the head of the posterior cornu, and around the central canal; the crossing small medullated fibres in the grey commissure; the large medullated fibres crossing in the white commissure (from the anterior cornu of one side to the anterior column of the opposite); the fibres of the posterior root partly curving into Burdach's column, partly running in small bundles through the substantia gelatinosa; the bundles of fibres from the deep part of Burdach's column curving into the grey substance.

7. Sections of lumbar region of spinal cord (chrome alum mixture, cut frozen). Place the sections :

in 1 p.c. osmic acid for about half an hour, and wash with water;

in 5 p.c. pyrogallic acid for about half an hour, and wash with water;

in $\cdot 25$ p.c. permanganate of potash for a few seconds to a minute or two, according to the rate of decolourization, and wash with water;

in 1 p.c. oxalic acid for one or two minutes and wash with water.

Dehydrate and mount in balsam. Note the large number of medullated fibres in the grey matter. The grey substance apart from its medullated fibres should be of a light grey tint. 
8. Section of spinal cord (alcohol) in paraffin. Fix to a cover-slip and stain the basophil granules and masses in the cells as in Lesson xv. $\S 3, a$.

9. Golgi's chromate of silver method modified by Ramón y Cajal. Place some small pieces of the spinal cord of a chick (about 12 days after hatching) or of a fœtal mammal in about 20 volumes of Golgi's osmic-bichromate mixture (p. 247) and leave in the dark. After 2, 3, and 4 days rinse a piece for an instant with distilled water, and put at once in 75 p.c. silver nitrate, and leave for a day or more in the dark. Rinse as before, and repeat from the beginning.

Place the piece in 95 p.c. alcohol for 10 to 15 minutes, imbed superficially in paraffin (p. 58), and cut at once, moistening the razor with 95 p.c. alcohol, place the sections on a thin coverslip, sop up excess of fluid, press lightly with smooth tissue paper, add a drop of xylol or bergamot oil, sop this up and blot, cover with xylol or balsam, place at about $40^{\circ} \mathrm{C}$. to dry. Fix two pieces of thick cover-slip to a slide a little distance apart, and on these fix the slip with the specimens downward.

The pieces may also be cut frozen, washed quickly in water, dehydrated rapidly with absolute alcohol, cleared and mounted in xylol balsam ; but they are more apt to become decolourized than by the former method.

\section{Beginning of decussation of pyramids.} Section of upper part of 1st cervical segment. Note

The numerous bundles of fibres surrounded by grey substance about the level of the central canal; decussating bundles cut obliquely at the base of the anterior fissure, which may be very shallow; a wedge-shaped bundle of fibres more or less obliquely cut on the median side of each anterior column. (Fibres of the pyramid crossing to the lateral pyramidal tract of the spinal cord.) 
Note also the increase in grey substance dorsally of the central canal ; the caput of the posterior cornu forming a roundish mass near the surface of the cord; a thin cap of small fibres on the caput (descending fibres from Gasserian ganglion), the superficial group of large fibres ventrally of the caput (the direct cerebellar tract).

\section{DEMONSTRATIONS.}

1. Section of cord of dog or cat (Marchi's method, cp. Notes) above a region of transverse section. Note the black globules of medulla showing degeneration :in Goll's column; in the posterior and external part of the lateral column (direct cerebellar tract); and (more diffusely) in the antero-lateral columns, chiefly near the surface (ascending antero-lateral tract).

2. Section similar to $\S 1$, but below the point of injury. Note

The degeneration in the centre of the posterior part of the lateral column (the crossed pyramidal tract).

The diffuse degeneration in the antero-lateral columns, chiefly at the surface of the anterior column (descending antero-lateral tract).

A few degenerated fibres may also be present in the posterior columns (descending root fibres and endogenous fibres).

3. Three sections of cord of dog or cat (Marchi's method) above, below and through a segment of which the posterior roots of one side are in a state of degeneration. Note in the segment, the degeneration of the 
entering nerve-roots and of the outer portion of the column of Burdach, and of numerous fibres throughout the grey substance. On the opposite side of the cord no degeneration is seen.

Above the segment, the degeneration in a median portion of Goll's column on the side of the injury.

Below the segment, either no degeneration or a scattered degeneration in the median part of Burdach's column.

4. Section of fœtal cord treated by Golgi's method (cp. §9). Note the wide-spreading processes of the nerve-cells of the grey substance.

5. Section of cord, to show chromatolysis in anterior horn cells (nerves of cord segment cut about 3 weeks, mercuric chloride, methylene blue). Note the excentric position of the nucleus, and the decrease in basophil substance.

NOTES.

Spinal Cord.

The spinal cord and lower part of the brain should be taken out with the dura mater attached, a light weight tied to the cauda equina, a thread passed through the upper part of the dura mater on either side, and the cord suspended by the threads in a tall cylindrical vessel containing the hardening fluid.

In the cat and dog, if the brain is not required for microscopical examination, it is convenient to take out the brain with the cord, and suspend by means of a glass rod passed transversely through the cerebral hemispheres.

To show the general features of the spinal cord, it is placed in 2 p.c. potassium bichromate for 3 to 4 weeks, washed for a 
day in ruming water, placed for a day in the dark in 30 p.c., 50 p.c., 75 p.c. alcohol, then for a week in 95 p.c. alcohol. It is kept till required in 75 p.c. alcohol. (For the treatment when medullated nerve-fibres or neuroglia fibres have to be stained cp. below.)

On the 2nd or 3rd day after placing in potassium bichromate, the dura mater may be cut open over the anterior and posterior fissures.

Müller's fluid may be used instead of potassium bichromate ; and the potassium bichromate may be 3 to 5 p.c. instead of 2 p.c.

The dura mater should be removed, and the cord cut into segments, the segments being determined by the place of exit of the roots; in the lower lumbar and sacral region the roots must be carefully followed to their place of exit. The segments are placed in separate bottles.

The piece to be cut is placed in water for half a day to a day, and the same time in gum; sections are cut frozen, and left in picrocarmine-best perhaps Ranvier's-for two or more days in the warm.

\section{Methods for the Central Nervous System.}

Hardening. Potassium bichromate as given above may be used for all parts of the central nervous system. Erlicki's fluid (p. 300) hardens more quickly, and Müller's fluid with formol (p. 300) still more quickly.

The hardening should be carried out in the cold till the fluid has thoroughly penetrated; it may then be carried out in the warm and thereby much hastened.

These hardening agents do not allow a staining of the basophil substance; when this is required in addition to other stains, Marina's fluid (cp. p. 301) or formol alone may be used. Formol penetrates quickly, but the staining after it is not entirely satisfactory.

Staining. Picrocarmine as given above for the spinal cord is for general purposes the most useful stain. A 25 p.c. aqueous 
solution of aniline blue-black may also be used; to avoid overstaining a section should be examined now and then.

Thin pieces may be stained in bulk with Bourne's picrocarmine or with borax carmine (p. 308), for one or more weeks, but the result is not very satisfactory.

Staining basophil cell-substance. Sections of the brain or spinal cord may be treated in the way already described for sections of spinal ganglia (Lesson xv. $§ 3$ ).

As hardening agents are used :

(a) Alcohol about 95 p.c. ; this however causes considerable shrinking. If the cord is cut into thin pieces about half-anhour after being placed whole in the alcohol, the pieces will be hardened in about a day.

(b) A saturated solution of mercuric chloride in salt solution; it is best to place small pieces in this for a day, then transfer to alcohol (cp. p. 297).

(c) Formol 10 p.c. for 2 to 4 days, then alcohol 2 to 4 days.

The piece of tissue may be imbedded in celloidin or paraffin. Or it may be cut without imbedding, thus : one surface is partially . dried with blotting-paper, fixed to a piece of cork with fish-glue or'gum, left for half an hour in alcohol, then cut moistened with 95 p.c. alcohol.

Instead of methylene blue, a saturated aqueous solution of thionin or toluidin blue may be used, the sections are differentiated in aniline oil and alcohol (p. 117), passed quickly through absolute alcohol to xylol and balstam. Or they may be stained with a saturated aqueous solution of acid magenta, differentiated for 1 to 2 minutes in absolute alcohol, passed through clove oil to balsam.

Sections stained with methylene blue, and differentiated with aniline oil and alcohol, may be again stained and again differentiated, then blotted, cleared quickly with cajeput oil, blotted, cleared with benzin, and mounted in benzin solution of colophonium. 
Staining medullated fibres. The method given in the text $\S 7$ is the Heller-Robertson modification of the Weigert-Pal method; it is on the whole the simplest and best.

If the tissue has been hardened in Müller's fluid or potassium bichromate, the medullated fibres may be stained by one of the methods given below.

After hardening in formol, sections may be placed in chromic acid 5 p.c. for half-a-day, for about an hour in 80 p.c. alcohol, then stained by Weigert's hæmatoxylin method.

Weigert's method. The tissue is imbedded in celloidin, the block placed for a day in the warm in a mixture of equal parts of cold saturated acetate of copper and 10 p.c. aqueous solution of the double tartrate of potassium and sodium;

and for a day in the warm in sat. neutral acetate of copper solution diluted one half;

it is rinsed in water, placed in 10 p.c. alcohol for $\frac{1}{2}$ hour, and cut;

the sections are placed for 4 to 24 hours in the hæmatoxylin sol. (below) ;

differentiated in a few c.c. of a mixture of 2 grams borax; 2.5 grams potassium ferricyanide, 100 c.c. water;

and thoroughly washed with water.

Modification by Pal. Müller's fluid is said to give better results than potassium bichromate.

The following mixtures are required :

Staining fluid-Hæmatoxylin 1 gram. Absolute alcohol 10 c.c.

Lithium carbonate 1 gram.

Distilled water 90 c.c.

The first two and the last two are perhaps best made separately and mixed when required.

Decolourizing fluid-Oxalic acid 1 gram. Potassium sulphite 1 gram.

Distilled water 100 c.c. 
The piece of tissue is cut, either superficially imbedded in paraffin (p. 58), or imbedded in celloidin, or frozen.

The sections are placed in a few c.c. of the hæmatoxylin solution for 5 hours to a day at the room temperature, and for about an hour in the warm.

If the tissue has been kept in alcohol, and the chromic salts extracted, the sections are placed for a day in 2 p.c. potassium bichromate, and washed in water before being stained.

The sections are washed in water containing a little lithium carbonate and placed

(a) in 25 p.c. permanganate of potash for 20 secs. to 1 minute according to the rate of decolourization, washed and placed in

(b) a few c.c. of the oxalic decolourizing fluid for a few seconds to a minute till the grey substance is of a light grey tint; the same fluid should not be used for more than a few sections.

The sections are then well washed in running water, best till next day, dehydrated and mounted; before dehydrating they may if desired be stained with alum carmine or picrocarmine.

\section{Modification by Kutschitzky and Wolters.}

The following mixture is required : 1 gram hæmatoxylin dissolved in abs. alcohol; 100 c.c., 2 p.c. acetic acid.

The sections (in celloidin) are placed in the warm $\left(45^{\circ} \mathrm{C}\right.$.) for a day in the hæmatoxylin fluid, put for a second or two in Müller's fluid, and differentiated as in Pal's method.

Staining degenerating fibres. (Marchi's method.) The piece of central nervous system is placed in Muiller's fluid or in 2 p.c. potassium bichromate for 10 days to three weeks, the fluid in this case not being changed; slices a few millimetres thick are then cut and placed for one to two weeks in a mixture of equal parts of Muiller's fluid and 1 p.c. osmic acid. The pieces may be cut frozen, but they are apt to be brittle. 
They are perhaps best imbedded in celloidin, but they may be imbedded in paraffin; to prevent the xylol or other clearing agent dissolving the osmic acid stained medulla it is advisable after treatment with osmic acid to keep the pieces for some time in alcohol.

The method may be modified in the following way: the tissue hardened in Muiller's fluid or potassium bichromate is soaked in the same fluid saturated with gum, then cut frozen, and the sections placed in the chromic-osmic mixture. Some of the sections may be stained with picrocarmine.

Golgi's chromate of silver method. See p. 240. The mixture consists of 1 vol. of 1 p.c. osmic acid, and 4 vols. of 3 p.c. potassium bichromate.

In order to obtain successful preparations it is generally necessary to place a number of pieces in the osmic-bichromate mixture, and to transfer them to silver on successive days. After a day in the silver, a section is prepared from each free-hand, if the preparations are not successful they are passed once more through the fluids. Some pieces may also be left 2 or 3 days in the nitrate of silver instead of 1 day, but as a rule repeating the treatment with the fluids is more successful.

According to Lenhossek, 2 or 3 days in the osmic-bichromate mixture is best for neuroglia cells, 3 to 5 days for nerve-cells, and

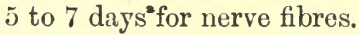

Neuroglia stain. (Weigert; for human nervous system.) Small pieces of the spinal cord are placed for 8 days or longer in the chrome alum and acetate of copper mixture (p. 301), they are then washed, imbedded in celloidin and cut.

The following solutions are required :

(1) $\cdot 25$ p.c. potassium permanganate.

(2) (a) 5 grams chromogen.

5 c.c. formic acid.

60 c.c. water.

The solution is filtered.

(b) 10 p.c. sodium sulphite. 
Before use 1 c.c. of $(b)$ is added to each 9 c.c. of $(a)$.

(3) 5 p.c. aqueous chromogen solution.

(4) Methyl-violet solution in 75 p.c. alcohol, saturated in the warm, allowed to cool and decanted 100 c.c. Oxalic acid 5 p.c. 5 c.c.

(5) A saturated solution of iodine in 5 p.c. potassium iodide.

(6) Mixture of equal parts aniline oil and xylol.

The sections are placed :

(a) in the potassium permanganate solution for about 10 minutes; and washed in water ;

(b) in the chromogen mixture for a $\frac{1}{4}$ hour to 4 hours ;

(c) in the aqueous chromogen solution for a day or more. (This stage may be omitted; if it is, the stain is more restricted to neuroglia, but is less complete.) They are then fixed to the slide ; blotted ;

(d) the methyl-violet mixture is poured over them and run off ; blotted ;

(e) the iodine solution is poured over them and run off; blotted ;

(f) they are washed well in aniline oil and xylol, then in sylol, and mounted.

Neuroglia stain. (Mallory.)

Pieces of nervous tissue 2 to $5 \mathrm{~mm}$. thick are placed for 4 or more days in the following fluids in succession :

(a) 10 p.c. formol ;

(b) saturated aqueous picric acid;

(c) 5 p.c. ammonium bichromate in the warm, renewing the fluid at the end of the first day. 
The tissue is cut in celloidin, and the sections placed in

1 p.c. aqueous acid magenta for 2 to 5 minutes and washed quickly

1 p.c. aqueous phospho-molybdic acid for 1 to 2 minutes, and washed well

aniline blue and orange G (cp. p. 311) for 1 to 3 minutes, washed in water ; and mounted in xylol-balsam.

The neuroglia fibres should be stained deep red, the connective tissue blue, the nerve cells and axons light red.

Neither method of staining neuroglia is very satisfactory. 


\section{LESSON XXXII.}

\section{THE SPINAL BULB.}

The sections described unless otherwise mentioned are of man. The axis of the bulb is fixed in a straight line with the axis of the cord, and sections made approximately at right angles to it. The sections are stained with picrocarmine, so that the grey substance stains deeper than the white substance.

The sections are to be examined with $1 \frac{1}{2}$ to 2 inch objective. In addition they should be observed without magnification, holding them up to the light, or against a white background; the larger masses of grey and white substance can thus be distinguished. The groups of nerve cells should be examined with a ${ }_{3}^{2}$ rd inch, and in special cases with a $\frac{1}{6}$ th inch objective.

In the description of the sections of the spinal bulb of the dog, the chief points in which they differ from the sections of the bulb of man are noted; the description given for man is sufficient for the recognition of most of the corresponding structures in the dog.

1. Section through the lower part of the pyramidal decussation. Note:--

The central canal, slightly on the ventral side of the middle of the section.

The thickened grey mass dorsally of the central canal.

The funiculus gracilis (Goll's column), with elongated patches of grey substance in it-the beginning of its nucleus. 
The funiculus cuneatus (Burdach's column), with a small triangular or rounded mass of grey substance projecting into it - the beginning of its nucleus.

The caput of the posterior horn, a round deeply stained mass near the surface; this is now the nucleus of the bulbar or descending root of the 5th nerve; between the substantia gelatinosa and the surface are many small nerve fibres-bulbar or descending root of the 5th nerve-but they are not very obvious in this region in carmine preparations; amongst them are a few bundles of large fibres.

Ventro-laterally of the caput and on the surface a patch of large fibres-the dorsal cerebellar tract.

In the median ventral region extending nearly up to the central canal, the bundles of fibres of the pyramidal decussation; in the lateral region these bundles are separated by grey substance forming the reticular area; ventrally of this is seen the anterior cornu cut off by decussating fibres from the grey substance round the central canal.

Dog. The decussation of the pyramids is much more regular, the fibres crossing in smaller bundles, so that the double crossing is more obvious; the fun. gr. is thin, and its nucleus is fairly developed; the anterior cornu is less cut off from the caput and the reticular area is more marked; the layer of fibres covering the caput is distinct.

2. Section through the upper part of the pyramidal decussation. Note :-

The central canal is now on the dorsal side of the middle of the section.

The nucleus of the funiculus gracilis spreads throughout all the central parts of the funiculus.

The nucleus of the funiculus cuneatus is larger than in $\S 1$ and forms a rounded stained mass ; the funiculus is broader and less deep.

The lower part of the bulbar root of the 5th and its nucleus is on a level with the central canal.

The central grey substance is a round mass; its lateral boundary being formed by a number of small bundles of fibresthe beginning of the sensory decussation. 
In the lateral area of the cord grey and white substance is much intermixed, there is no separate mass representing the anterior cornu, but the cerebellar tract is obvious.

Ventrally of the bundles of the pyramidal decussation, a somewhat oval mass on either side-the pyramid, now nearly complete.

3. Section just above the pyramidal decussation and below the lower olive. The nucleus of the funiculus gracilis and that of the funiculus cuneatus are larger; the fibres of the funiculus cuneatus form a shallow horseshoe-shaped mass; the bulbar root of the 5th is larger. Note:-

Small patches of grey substance with rather large cells stretching into the funiculus cuneatus-the accessory nucleus of the funiculus cuneatus ; examine the cells with $\frac{2}{3}$ rd objective. (The nucleus may be absent immediately above the decussation.)

The very marked sensory decussation; bundles of fibres curve from the base of the nuclei of the posterior columns, round the central grey substance, and decussate dorsally of the pyramids.

The pyramids forming two rather large masses in the ventral region.

External arcuate fibres; large fibres taking an oblique course on the surface of the pyramids and the lateral region of the cord, covering the bulbar root of the 5th nerve, and part of the funiculus cuneatus; fibres may be seen spreading over the bulbar root from the dorsal cerebellar tract.

On the course of the fibres in the pyramids are small masses of grey substance with fairly conspicuous cells, the nuclei of the external arcuate fibres.

The accessory lower olive, an elongated mass of grey substance, dorsally of the pyramid, and stretching a short way laterally of the sensory decussation.

The antero-lateral nucleus, a large group of scattered nerve cells, dorsal to the lateral edge of the accessory olive; it is not marked immediately above the pyramidal decussation. 
Dog. Sections 2 and 3. The bulbar root of the 5th nerve and its nucleus are relatively larger than in man; the sensory decussation is less obvious; the antero-lateral nucleus is formed earlier and is probably present in (2); the oblique fibres of the pyramid are better marked off from the continuation of the anterior column (2); the pyramid is relatively smaller (3).

4. Section about $2 \mathrm{~mm}$. above the lower end of the lower olive and just below the 4th ventricle.

The central grey substance is larger and stretches in a point with the elongated central canal nearly to the dorsal surface, the accessory nucleus of the funiculus cuneatus is larger and in several bundles, the external arcuate fibres are throughout more numerous, a thin bundle of them nearly covers up the funiculus cuneatus; the bulbar 5 th is a half-moon shaped mass.

Note :-

The raphe, a thin band in the median line below the central canal, here chiefly composed of fibres running dorso-ventrally and obliquely.

The white reticular area on either side of the raphe, composed almost entirely of nerve fibres, and the grey reticular area laterally of the white, composed of nerve fibres intermixed with grey substance (the distinction is more obvious in the next section). The dorsal part of the white reticular area is the anterior column tract; the ventral part is the fillet, here the continuation of the fibres of the sensory decussation.

The fillet between the accessory and lower olives is sometimes called the inter-olivary tract.

Ventrally and laterally in the central grey substance a group of large angular cells, the nucleus of the 12th nerve (hypoglossal); bundles of fibres of the nerve may be seen at the junction of the white and grey reticular areas and between the olive and pyramid.

Dorsally and laterally in the central grey substance, a somewhat oval group of moderate sized elongated cells, the dorsal 
nucleus of the 9th and 10th nerves (vago-glossopharyngeal nucleus).

Dorsally of the preceding a somewhat oval mass of grey substance without obvious nerve cells - the sensory nucleus of the 9 th and 10th nerves.

The solitary bundle (descending vago-glossopharyngeal root) a round bundle of small fibres; it will be seen laterally of the dorsal nucleus, more or less covered dorsally and at the sides by curving bundles of fibres, it is not very obvious in this region, and it may perhaps be better seen with oblique than with directly transmitted light.

The motor nucleus of the 9th and 10th nerves (nucleus ambiguus), a small group of angular cells a little medially and ventrally of the bulbar root of the 5th nerve. Fibres run from it in the direction of the dorsal nucleus and of the solitary bundle. It is not seen in every section.

Root fibres passing from the region of the solitary bundle to make their exit below or through the ventral edge of the bulbar root of the 5th; they are not seen in every section. The whole of the 9 th and 10th system is better seen in the next section.

The solitary bundle and vago-glossopharyngeal nuclei are present in the preceding section but are inconspicuous.

The lower olive, a large folded lamina of grey substance, with rather large elongated cells, dorso-laterally of the pyramid.

The internal arcuate fibres, running chiefly from the base of the posterior column nuclei, and extending through nearly the whole of the lateral area; many are seen to decussate.

In the lateral part of the grey reticular area, two large groups of cells occur, the dorsal and ventral antero-lateral nuclei.

The accessory olive is present as a band dorsally of the pyramid and stretching a short way up on the lateral edge of the white reticular area.

If a section is taken close to the extremity of the olive, the 12th and 10th nuclei will be inconspicuous, and more fibres will be seen passing on the medial side of the solitary bundle and decussating in the anterior column tract. 
Dog. The lower olive is much less conspicuous in lower animals than in man; in most sections it appears as a double lamina placed obliquely. The 12th $\mathrm{n}$. fibres run laterally of the lower olive. The bulbar root of the 5 th forms a half-moon shaped bundle, more distinct and more compact than in man.

\section{Section through the lower part of the 4 th ventricle.}

The central canal has now opened into the 4 th ventricle; the nucleus of the hypoglossal forms a conspicuous round mass near the raphe and close under the floor of the ventricle, dorsolaterally, is the dorsal nucleus, and then the sensory nucleus of the 9 th and 10 th nerves.

Ventro-laterally of the nucleus of the funiculus gracilis is the nucleus of the funiculus cuneatus, distinct from the nucleus of the funiculus gracilis by its larger cells; the fibres of these are now mixed up with the grey substance.

Laterally of and on a level with the lower part of the dorsal 9 th-10th nucleus is the solitary bundle.

Note:-

On the dorsal surface of the nucleus of the funiculus gracilis, the attachment of the thin membrane-the ligula,--forming the roof of the ventricle (probably torn).

Laterally of the nucleus of the funiculus cuneatus the rather large mass of nerve fibres-the restiform body (formed from cerebellar tract, external and internal arcuate fibres).

Laterally of the solitary bundle and stretching dorsally on the medial side of the nucleus of the funiculus gracilis are a number of small bundles of nerve fibres, the bundle formation (descending fibres of the vestibular nerve [8 v.]), (cp. $\S 6$ ).

Dorsally and medially of the bundle formation, i.e. chiefly between the nuc. f. gr. and the 9th and 10th n. nuclei, a small amount of grey substance without nerve cells-the lower end of the median nucleus of the vestibular nerve.

The internal arcuate fibres are very numerous.

The internal arcuate fibres starting dorsally and just laterally of the solitary bundle chiefly cross in the dorsal part of the raphe; those starting more laterally, apparently from the n. fun. cun., run 
chiefly to and through the olive. Note the bundles running between the bulbar root of the 5th and its nucleus, apparently from all parts of the olive, to the restiform body. Note also the fibres curving round the outer border of the olive, and the numerous bundles running across the raphe between the olives.

6. Section a little below the pons and through the lower region of the cochlear division of the 8 th nerve.

In this region of the medulla the appearance of the dorsal part of adjoining sections varies very considerably.

In the more caudal region, the 12 th nucleus and fibres from it will be seen.

A little more anteriorly, there are no 12 th $\mathrm{n}$. fibres; the grey matter in the position of the 12th nucleus has moderate sized cells ; in it near the middle line is a round mass of deeper stained grey matter, the nucleus of the funiculus teres. Ventrolaterally of this is a small elongated mass of cells, the dorsal nucleus of the 9 th $\mathrm{n}$.; probably a thin bundle of fibres run from it to the surface through the middle of the bulbar 5th $\mathrm{n}$. The solitary bundle is fairly large and fibres may run from it to the surface through the dorsal part of the bulbar 5th $\mathrm{n}$. The nucleus ambiguus and lateral nucleus will probably be seen.

A little more anteriorly still, the only part of the 9th system present is a small solitary bundle with a little grey substance medially of it, and 9 th $\mathrm{n}$. fibres running from it through the dorsal limit of the bulbar 5th. The dorsal nucleus of $8 \mathrm{v}$. stretches to the raphe.

The nucleus funiculus gracilis and nucleus funiculus cuneatus are not present or are not recognizable as separate masses. The internal arcuate fibres are much fewer in the dorsal region, though there are many transverse fibres.

Numerous internal arcuate fibres are still seen running through the descending 5 th root connecting the restiform body and the olives.

Note :-

The mass of grey substance with scattered, but not very obvious, cells forming a large part of the floor of the 4 th ventricle-the median nucleus of the vestibular nerve ( $8 \mathrm{v}$.); laterally 
of nucleus $8 \mathrm{v}$., numerous small bundles of fibres with scattered, lather large nerve cells-the inner division of the restiform body containing the descending root of the vestibular division of the 8th nerve (bundle formation).

The bundle of fibres on the lateral surface of the restiform body-fibres of $8 \mathrm{c}$. In this bundle in the ventral part of its course an oval mass of oval cells, the accessory nucleus of $8 \mathrm{c}$, and in its further course chiefly on its outer surface deeply stained grey matter with small nerve cells-the lateral nucleus of $8 \mathrm{c}$.

Dog. Section just below the trapezium. There is no lower olive. The 12th, the 9th and 10th nuclei will probably be absent. The accessory nucleus is more on the medial side of $8 \mathrm{c}$. Medially and dorsally of the bulbar 5th is a large group of large cells-the nucleus of the $7 \mathrm{th}$; from this fibres will be seen to run dorsally and a little medially. The anterior column tract is separated from the fillet by diffuse grey substance, the fillet is the layer immediately dorsal to the projection formed by the pyramid, the boundaries of the two are not distinguishable.

7. Section through the lower edge of the pons and upper extremity of the lower olive.

Note :-

The superficial fibres of the pons (middle peduncle of cerebellum) running ventrally to the pyramids, and between these fibres, grey substance with numerous nerve cells-the nucleus of the pons.

The lower olive, probably not open towards the raphe.

The nucleus of $8 \mathrm{v}$. stretching nearly to the middle line; laterally continuous with a little grey substance stretching over the restiform body; on the dorsal surface there may be a band of fibres (stria acustica). The accessory nucleus of $8 \mathrm{c}$. ventrolaterally of the restiform body, its size varies much in different sections in this region; it may be completely covered by the white substance of the cerebellum: large bundles of the 8 tl nerve may be seen medially and ventrally of the accessory 
nucleus; between the restiform body and the bulbar 5th root there may be some fibres of the vestibular nerve.

Fibres of the trapezium; these are better seen in $\S 8$.

8. Section through the pons and the lower part of the 6 th nucleus. The pons fibres and their nuclei surround the pyramids and occupy a half or more of the dorso-ventral diameter. The fibres of the restiform body are more or less oblique, curving dorsally into the cerebellum. Note :-

In the dorsal part of the inner division of the restiform body, some large angular cells-Deiter's nucleus.

A little below the floor of the 4 th ventricle a little distance from the raphe, a round mass of angular cells-the nucleus of the 6th nerve.

Medially of the lower part of the descending 5th, a mass of grey substance with angular cells-the nucleus of the 7 th nerve; in it are some large nerve fibres, and others run from its dorsal border dorsally and medially; similar fibres are seen curving dorsally of the nucleus of the 6th nerve; medially of the 6 th nucleus is a small bundle of fibres-the ascending fibres of the 7th. (The 7th nucleus is more conspicuous in a section a little below the 6 th $\mathrm{n}$. nucleus, it begins at the upper end of the lower olive.)

Ventrally of the nucleus of the 7th nerve a round mass, not showing nerve cells very distinctly-the upper olive.

Immediately dorsally of the pons fibres and its nucleus a somewhat elongated mass of transversely cut fibres-the fillet, now fairly distinct from the surrounding tissue.

The change of form from the inter-olivary tract may be seen with the eye if two or three sections are made between $\$ \S 7$ and 8 . It first becomes somewhat comma-shaped on either side of the raphe and then extends laterally.

In the white matter of the cerebellum near the lateral angle of the 4 th ventricle, a folded lamina of grey substance-the nucleus dentatus (this is present in $\$ \S 6$ and 7 but more dorsally). 
Numerous transverse bundles of fibres between the pyramids and the fillet, and through the fillet itself-the trapezium fibres, sometimes called the deep fibres of the pons.

Running from the 6 th nerve may be seen obliquely cut root fibres, running ventrally and a little laterally (they run backwards in the dorsal part of the pons fibres).

9. Section through the outgoing fibres of the 7th nerve and the anterior part of the 6 th nucleus. The ascending bundle of the 7 th nerve near the raphe is large, fibres proceed from it and curve dorsally over the 6th nucleus; more laterally a large bundle of the outgoing 7 th is seen and perhaps running out between the descending 5th and the upper olive.

Medially of the outgoing root is the 7th nucleus with fibres running dorsally (they pass through the 6th nucleus to the ascending 7 th).

From the medial border of the 6 th nucleus run fibres of the 6th nerve.

The dorsal part of inner division of the restiform body is at the side of 4 th ventricle and has large nerve cells in itBechterew's nucleus.

Fillet, trapezium, pons, bulbar 5th, nucleus dentatus, are much as in $\S 8$.

In a section taken a little farther forward the nuclei of the 6 th and 7 th nerves will be' absent, but the ascending fibres of the 7 th will be seen curving out; forming the genu.

Dog. $\S \S 7,8,9$. Owing to the comparatively small development of the middle peduncle of the cerebellum in lower animals, the arrangement in this region is more easily followed than in man.

Section through the trapezium. There are no superficial pons fibres. The upper olive is present; it is seen in the ventro-lateral region as a rod and an S-shaped piece of grey substance.

The accessory nucleus of $8 \mathrm{c}$. and Deiter's nucleus are distinct. Between the acc. nuc. of the two sides are numerous bundles of fibres, the trapezium, running between the fibres of the fillets and dorsally of the pyramids. 
The anterior column tracts, now called the posterior longitudinal bundles, are almost immediately beneath the floor of the ventricle; laterally of the p. l. b. is a marked round bundle, the root of the 7 th nerve; ventro-laterally of this is the nucleus of the 6th nerve. Some root fibres of the 6th may be seen a little medially of the upper olive.

In a section taken a little more anteriorly the fibres of the 7 th $n$. will be seen running out between the bulbar 5th and the upper olive.

10. Section through the motor nucleus of the 5 th nerve. The pons is large-occupying $\frac{1}{2}$ to $\frac{2}{3}$ of the dorso-ventral diameter. The fillet is more elongated, is farther from the raphe, and stretches a little up the lateral surface of the reticular area; there may be a small piece of the upper olive; trapezium fibres are present in the lower sections ; on the dorso-lateral boundary of the ventricle is a large comma-shaped mass of fibres (seen with the eye)-the superior cerebellar peduncle (it arises chiefly from the dentate nucleus). The large lateral masses of white substance are part of the middle peduncles of the pons.

Note :-

The bulbar 5th fibres running obliquely outwards but not yet at the surface. A band of fibres (chiefly of the motor and mid-brain roots) extending dorsally and medially of the bulbar 5 th.

Medially of this a group of large nerve cells-the motor nucleus of the 5th nerve, and laterally of it, one or more clumps of grey substance without obvious nerve cells-the sensory nucleus of the 5th nerve.

In the ventral part of the grey substance of the 4 th ventricle, curving fibres running to the band between the sensory and motor nucleus.

Just beneath the grey substance of the floor of the 4th ventricle, on either side of the raphe, a triangular bundle of large fibres - the posterior longitudinal bundle. A bundle in this position more or less marked off from the rest can be seen in several of the sections already examined. 


\section{Section through the locus cœruleus.}

The general features are much as in the previous section, except as regards the 5th nerve and its nuclei; there may be large bundles of 5th nerve near the surface, and small portions of the motor and sensory nuclei. Note :-

In the grey substance at the lateral angle of the ventricle about half-a-dozen large round cells-the lower part of the mid-brain nucleus of the 5 th nerve, and just outside these a bundle of large nerve fibres-the mid-brain root of the nerve.

Just beneath the grey substance of the floor of the ventricle at its lateral angle a marked group of oval nerve cells-the cells of the locus cœruleus; with a higher power most of them are seen to be pigmented.

Dog. In $\S 10$ the pyramids are in the midst of the pons fibres and their nuclei; the bulbar root turns out rather abruptly, in a section at this point the sensory nucleus is large, the motor small; the upper olive is probably present.

In a section made a little more anteriorly, the motor nucleus is large and the sensory small; olive and trapezium fibres are absent, the comma-shaped sup. cer. ped. is obvious at the side of the ventricle.

In $\S 11$ the cells of the locus cœruleus are unpigmented; the sup. cer. ped. is a little more ventral than in $\S 10$; the division of the fillet into median and lateral can be seen.

\section{DEMONSTRATION.}

Series of sections of spinal bulb after section of the cord. (Marchi's method.) Follow the dorsal cerebellar tract running in the middle of the restiform body, and the ventral cerebellar tract running with the superior cerebellar peduncle; both ending in the middle lobe of the cerebellum. 


\section{NOTES.}

For methods of treatment see Notes to the previous Lesson. The groups of nerve cells, the course of the nerve roots and most of the nerve tracts of the medulla can be made out much more conveniently in the medulla of the cat or dog than in that of man. 


\section{LESSON XXXIII.}

\section{THE MID-BRAIN AND INTER-BRAIN.}

1. Section through the anterior part of the 4 th ventricle (man). The parts are the same as in $\S 11$, Lesson xxxiI. Note:-

The median fillet, an elongated mass of fibres dorsally of the pons fibres.

The lateral fillet (posterior mid-brain fillet), a triangular mass of fibres, running obliquely dorsally, at the lateral edge of the median fillet; it has grey substance on its surface and a little also amongst its fibres. The sup. cér. ped. extending ventrally nearly to the median fillet; its ventral part is medial to the lateral fillet.

2. Section just behind the exit of the 4 th nerve (man). The parts are the same as in $§ 1$. The ventral fibres of the sup. cer. ped. stretch to, or nearly to, the middle line. The lateral fillet lies as an oval mass over its outer surface with grey substance on both sides of it. The post. long. bundle stretches laterally nearly to the mid-brain root of the 5 th $\mathrm{n}$. 
3. Section through the exit of the 4 th nerve (man). The ventral fibres of the sup. cer. peduncles decussate in the middle line; the lateral fillet forms an oval bundle on the dorso-lateral angle of the section; the median fillet is much elongated and its lateral part has a dorsal curve; the cells of the locus cœruleus are scattered and comparatively few. Note:-

The bundle of the 4th nerve issuing on each side from the dorso-lateral angle of the grey substance, and crossing over the aqueduct in the velum.

4. Section through the exit of 4 th nerve and anterior part of pons (dog). The 4th nerve bundles arise laterally of the mid-brain 5 th root; on the dorso-lateral angle of the section is a piece of the p. c. q.; ventrally of this the large lateral fillet with grey substance of the lateral fillet; the sup. cer. peduncle consists of bundles of oblique fibres, it is in this region much less conspicuous than in man. The pes will probably be seen as an oval bundle immediately ventral to the median fillet, and nearly free from pons fibres.

5. Section through the posterior corpora quadrigemina (man). The pons fibres are now comparatively few and probably are only present with some grey substance in the middle region. On the lateral surface of the central grey substance are the large round cells of the mid-brain root of the 5 th $\mathrm{n}$. and the slender half-moon shaped group of the large fibres forming the root. (These will be seen in all sections up to the anterior part of the a. c. q.)

Note:- the large mass of fibres of the pes or crusta fairly distinct on the ventral surface on either side.

Dorsally of the crusta and stretching nearly up to 
the p. c. q. the elongated medial fillet; this forms the ventral boundary of the tegmentum.

The decussating sup. cer. peds. forming a large round whitish mass in the mid-region of the tegmentum.

The central grey mass of the p. c. q., and with a band of white fibres in its ventro-lateral region (fibres of the lateral fillet), spreading into it and over it laterally (cp. Demons. 1), and in a thin line medially.

The nucleus of the 4th nerve, a group of large nerve cells in the grey substance dorsally of, and in the post. long. bundle.

6. Section at posterior third of the p.c.q. and anterior part of pons (dog). Note:-

The post. corp. quadrigemina do not meet in the middle line; a thin membrane attached about half-way up the p. e. q. covers in the aqueduct.

The interpeduncular ganglion, a round mass situated in the middle line between the pedes, dorsal to the pons fibres; grey substance corresponding to this will also be seen in the corresponding sections in $\operatorname{man}(\S 3$ and $\S 5)$.

7. Section at the anterior third of the p.c.q. and just in front of the pons (dog). The membrane of the roof of the aqueduct starts nearly from the dorsal limit of the p. c. q. ; the lateral fillet is no longer seen; the dorso-lateral surface of the p. c. q. has a cap of fibres; the 4th nerve nucleus stretehes ventrally between the strands of the p. l. b. ; the lateral edge of the median fillet extends a little dorsally; the decussation of the s. c. ped. is only seen in the ventral part of the section; the interpeduncular ganglion is free on the medial ventral surface. Note:-

The pes, ventrally and a little laterally; it is much smaller than in man, cp. $\$ 9$.

Between the pes and the fillet, the rather thin line of grey substance with distinct nerve-cells, the substantia nigra. 
8. Section through the commissure of the p. c. q. (dog). The substantia nigra is in larger amount; the medial fillet is more lateral and its dorso-lateral part consists of oblique fibres separated by a little grey substance (anterior mid-brain fillet). Note :-

The commissure of the p. c. q., consisting of numerous nerve bundles above the aqueduct; (the similar fibres in man are less distinct since they are much scattered in grey substance).

9. Section through the posterior part of the anterior corpus quadrigeminum and above the pons (man). Note:-Dorsally of the large pes, now free from pons fibres, a deeply stained mass, the substantia nigra.

In the tegmentum a large round mass, the decussated sup. cer. ped. with some grey substance amongst the bundles.

The medial fillet divided into two portions, one between the sb. n. and the lateral part of the sup. cer. ped., the other more dorsal with oblique fibres directed towards the a. c. q. (anterior mid-brain fillet). On the surface just ventral to the a. c. q. an elongated oval mass of fibres, the brachium of the p. c. q.

The nucleus of the 3rd nerve, dorsally and a little laterally of the p. 1. b.: fibres of the 3 rd nerve run from the nucleus, and others issue near or through the medial part of the pes.

The deep white layer of the a. c. q. consisting of bundles of fibres forming a white line to the eye in the ventral part of the a. c. $q$.

10. Section through the posterior part of the a. c. q. (dog).

The interpeduncular ganglion is not present, the fillet is much broken up into small bundles. 
The nucleus of the 3rd nerve is nearer the middle line than in $\operatorname{man}$.

The br. of p. c. q. is on the surface about midway between the pes and the a. c. q.

\section{Note:-}

The large cells in part of the crossed sup. cer. ped.-the beginning of the red nucleus; fibres of the 3rd nerve are seen running through its medial portion. The dorsal tegmental decussation (Meynert's) just ventral to the p.l. b.; and the ventral tegmental decussation (Forel's) in the ventral part of the raphe. All of these are more marked a little farther up.

In the a. c. q. the blood vessels take a direction in general at right angles to the surface; some rather large pyramidal cells will probably be seen in the deep grey substance of the a. c. q.

11. Section through the a. c.q. and internal corpus geniculatum $(\operatorname{dog})$. The pes is farther from the middle line. Note:-

The internal corpus geniculatum, a round mass of grey substance on the lateral surface; on its medial or medial and ventral border are bundles of nerve fibres-(brachia of i. c. g. and of p. c. q.).

A small bundle of fibres near the ventral surface and the raphe,Meynert's bundle.

12. Section through a. c. q., the external corpus geniculatum and the corpora mammillaria (dog). The 3rd nucleus (chief nucleus), 3rd n. fibres, and red nucleus are not present, bundles of fibres (passing to the optic thalamus) are seen in the place of the red nucleus. 
In the lateral region, about half-way from dorsal to ventral surface, the largish stained mass of the internal corpus gen.

Laterally of the i. c. g., a band of oblique fibres, fibres of the optic tract; bundles of fibres issue from the medio-ventral side of the i. c. g. forming its brachium.

Dorsally of the i. c. g. and optic tract, the external corpus geniculatum; fibres from the optic tract run into and over it.

The corpus mammillare on each side of the mid-ventral line; according to the position of the section, the anterior pillar of the fornix may be seen on its dorso-lateral side, and the mammillothalamus bundle on its dorso-medial side.

A small part of the a. c. q. is seen; in it laterally are bundles of fibres-its anterior brachium; in the middle line over the aqueduct are a number of transverse fibres (deep white and posterior cerebral commissure fibres). Meynert's bundle will be seen laterally of the lower part of the ventral grey substance.

13. Section through the anterior part of the anterior corpus quadrigeminum and geniculate bodies (man). Note:-

The red nucleus, consisting of large nerve cells in the region of the crossed s. c. ped.; fibres of the 3rd nerve run through its medial part.

The deep white substance of the a. c. q. spreading out laterally into the tegmentum; some fibres of the fillet (anterior mid-brain fillet) may be seen running dorsally of the deep white, but they are not very distinct.

The pulvinar of the optic thalamus, laterally of the a. c. q.

Between the pulvinar of the optic thalamus and the pes an oval grey mass, the internal corpus geniculatum.

Fibres of the optic tract attached to the lateral surface of the pes, and running over and into a roundish body, the external geniculate body. 
14. Section through the brain just in front of the posterior commissure and through the tuber cinereum (cat). Note.-

The 3rd ventricle above and below the soft commissure.

The inner capsule, a thick band of fibres, for the most part obliquely cut, lying on the lateral side of the optic thalamus; its ventral part is continuous with the pes. The anterior end of the e. c. g. may be imbedded in it.

Numerous bundles of fibres connecting the optic thalamus and the inner capsule. The lateral and the median nuclei of the thalamus are separated from one another by a thin layer of white fibres, the internal stria medullaris.

In the curve of the inner capsule, dorsally of the thalamus a small patch of grey substance, the tail of the nucleus caudatus.

Ventro-laterally of the pes a little grey substance with nerve fibres, the ansa lenticularis, and outside this on the surface, the optic tract.

The triangular lenticular nucleus, continuous with the ansa lent. and bounded laterally by the outer capsule.

On the inner side of the pes a layer of grey substance, the corpus subthalamicum, occupying approximately the position formerly occupied by the substantia nigra.

Dorsally of the corp. subth. a little grey substance with nerve fibres, the zona incerta: bounded dorsally by a line of white substance-the external stria medullaris-running from the inner capsule and extending nearly to the mid-line. This forms the dorsal boundary of the subthalamic region.

Near the ventral surface and near the mid-line, a transversely cut bundle of fibres, the anterior pillar of the fornix; dorsally of this obliquely cut fibres, the mammillo-thalamus bundle or bundle of Vieq d'Azyr. 
On the dorsal surface of the thalamus near the mid-line a small mass consisting medially of nerve-cells, the habenular ganglion, and laterally of nerve fibres, the stria pinealis. Meynert's bundle will be seen a little ventrally of it.

Dorsally of the thalamus, a fold of the brain cortex, the hippocampal convolution, and on the lateral edge of this a band of fibres, the fimbria (continued anteriorly into the anterior pillars of the fornix).

15. Section through the anterior part of the optic thalamus.

The habenular ganglion and corpus subthalamicum are not present. The lenticular nucleus and its ansa are larger.

The nucleus caudatus is obvious. The anterior and lateral nuclei of the thalamus are fairly distinct from one another. Note the fornix attached to the under surface of the corpus callosum.

16. Section a little in front of the anterior commissure and optic chiasma. Note the large nucleus caudatus projecting into the anterior cornu of the lateral ventricle; the anterior commissure a little ventrally of the inner capsule; the small lenticular nucleus; the transversely cut olfactory fibres on the ventral surface of the cortex.

\section{DEMONSTRATIONS.}

1. Frontal section through the posterior part of the posterior corpus quadrigeminum with medullated fibres stained. Note the radiating bundles of fibres from the lateral fillet spreading out in the p. c. q. 
2. Frontal section through the anterior corpus quadrigeminum with medullated fibres stained. Note the fibres spreading outwards from the middle and the deep white layer (optic tract fibres, fibres to cerebrum and fibres from fillet), and the thin layer of superficial fibres (optic tract fibres). 


\section{LESSON XXXIV.}

\section{THE CEREBRUM AND CEREBELLUM.}

1. Section of cerebral hemisphere of rabbit (ammonium bichromate 2 p.c.; picrocarmine), mount in balsam. Observe

$a$. The inner layer of horizontal nerve fibres (medullated) forming the white substance; (between the fibres a considerable number of leucocytes will be seen;) from this bundles of fibres at fairly regular intervals run out into the grey substance, usually ceasing to be distinct in the third layer.

$b$. At the outer limit of $(a)$ a layer of fusiform nerve cells lying amongst nerve fibres and forming the 5th layer of the grey substance of the cortex.

c. Outside this, a layer of small cells of various shapes, cells with three or more obvious though small processes predominating (angular cells); these form the 4th layer of the cortex.

d. Outside (c) are large pyramidal cells, the process from the apex of the cell tapering off from it and often being traceable upwards for a considerable distance; from the base three, four, or more processes may be seen to proceed. The district of the large pyramidal cells forms the 3rd layer of the cortex; it will be seen that it is much thicker than any of the rest, and that generally 
speaking its cells diminish in size from within outwards. Small angular cells may be seen in its deepest part.

e. Outside the preceding layer is a thin layer with numerous small pyramidal cells, the peripheral process being usually distinct; this is the 2nd layer.

The 1st layer of the cortex, consisting of a fine network of fibrils showing a few very small cells.

Blood vessels may be made out in all portions of the cortex; they are usually most conspicuous in the outer layers of the cortex, running into it from the pia mater.

2. Section of cortex of cat or dog (chrome-alum mixture; medulla stain). Note the radiating bundles of fibres from the white substance into the grey.

3. Section of a lobule of the cerebellum extending from the surface to the inner white substance and at right angles to the direction of the folds. Observe

The inner strand of medullated nerve fibres spreading into

The nuclear layer, formed mainly of small cells closely packed together; these cells have a very small amount of cell substance, so that probably their deeply stained nuclei only will be seen.

A single layer of large, somewhat globular cells (Purkinje's cells); each has a large peripheral process which will be seen to branch, and the branches to branch again and so on, eventually extending as fine branching fibrils nearly to the surface of the cortex; close to the surface the fibrils become lost to view. Since the branches, especially the larger ones, run to some extent laterally, the processes from neighbouring 
cells will be seen to cross one another. In a good specimen a small process may be seen to run from the deep portion of the cells towards the nuclear layer.

The outer layer of the cortex contains, besides the fibres from the cells of Purkinje, some scattered small angular cells with relatively large nuclei; from these cells one or more small branching processes may be seen to proceed, the fibres and cells being imbedded in a close fibrillar network; in this layer numerous capillaries will be seen.

4. Section of cerebellum (chrome-alum mixture, medulla stain). Note the fine medullated fibres in the nuclear layer and just outside the cells of Purkinje.

\section{DEMONSTRATIONS.}

1. Section of cortex of cerebral hemisphere treated by the Golgi method (Less. xxxI. §9). (Fœtal or young mammal.) Note:-

The pyramidal cells with a large apical dendron, smaller lateral dendrons, and a single axon which runs towards the white matter. 'Thorns' will probably be seen on the main dendritic branches.

2. A similar section, to show neuroglia cells.

3. Section of the sigmoid gyrus and one of the occipital lobe (dog; potassium bichromate, picrocarmine), for comparison of cell layers.

4. Section of cerebellum treated by Golgi method. (Fœtal or young mammal.) (a) cut parallel with the laminæ, (b) cut transversely to the laminæ. 


\section{NOTES.}

The fresh brain is taken without the dura mater or with it frcely opened, and placed in 2 p.c. ammonium or potassium bichromate; on the following day it is cut into pieces and placed in fresh potassium bichromate for 1 to 3 months; then treated in the manner given for the spinal cord, p. 242.

Instead of a rabbit's brain the brain of a cat or dog may be taken; a solution of the chromium salt may advantageously be injected into the basilar artery, but even then it is not easy to preserve the natural form of the cells of the 3rd and 4th layers of the cortex; the structure of the cortex in the cat and dog differs also at different points more than in the rabbit, the chief points of difference being the occurrence of very large cells in groups or singly in the lower part of the third layer, and the variation in number and extent of the angular cells, which may spread into the third layer or may be inconspicuous.

In staining with picrocarmine, it is perhaps best to cut sections by the freezing method as soon as the tissue is hardened in potassium bichromate, and before placing in alcohol.

For other methods cp. p. 243. 


\section{LESSON XXXV.}

\section{TISSUES OF REPRODUCTION.}

1. Ovary. Longitudinal section of ovary of a mammal, e.g. cat, passing through the hilus (mercuric chloride, stained in bulk, cut in paraffin).

Observe first with a low and then with a high power

The germinal epithelium, consisting of a single layer of short columnar cells covering the surface of the ovary except at the hilus.

The connective tissue radiating from the hilus throughout the ovary to form the stroma; in this many blood vessels are seen; towards the periphery the fibrous tissue largely disappears; immediately underneath the epithelium the stroma forms a denser layer.

Small Graafian follicles forming a zone a short distance below the germinal epithelium.

Deeper (older) Graafian follicles of various sizes scattered throughout the rest of the stroma; in each of these there is a more or less considerable, clear space.

One or more corpora lutea (unless the ovary has 
been taken from a young animal). The corpora lutea vary greatly in size and appearance according to their age; at their maximal development they consist of narrow radiating threads of stroma, between which are a number of large polygonal cells; if the corpus luteum is younger there will be pigment (from effused blood) in its centre; and at a still younger stage the larger central part will contain blood, and the peripheral zone consist of a fine network of branched cells with polygonal cells in their meshes. (This is better seen in the ovary of the rabbit.)

2. Observe with a high power

a. The peripheral parts of the stroma consist chiefly of elongated spindle-shaped cells.

b. The small Graafian follicles. Note in these

The ovum, large and spherical; within it lies a comparatively large spherical nucleus, the germinal vesicle, in which may be seen a nucleolus, the germinal spot.

The membrana granulosa, a layer of flattened epithelium cells.immediately surrounding the ovum.

The thin membrana propria enclosing the membrana granulosa.

In the smallest Graafian follicles the membrana propria will not be seen, in the larger ones the cells of the membrana granulosa become cubical or short columnar and the ovum has a membrane (cp.c).

c. The large Graafian follicles. Note in these

The stroma investment of the follicles, consisting chiefly of spindle-shaped cells, partly of fine fibrous tissue; inside this is the membrana propria. 
The membrana granulosa, several cells deep, those next the membrana propria being short columnar cells, the rest flattened polyhedral cells.

The central space of the follicle.

The cumulus proligerus projecting into the space; it consists of a mass of cells much like those of the membrana granulosa and continuous with them, and it encloses

The ovum, like the ovum of the small Graafian follicles but with all its parts larger and its cell substance (beginning vitellus) more granular; it has further a distinct investing membrane which in some is much thickened so as to form a zona pellucida; from this the cell substance frequently shrinks in the process of hardening. The cells of the cumulus which lie next the zona pellucida are frequently arranged in a radiating manner.

Probably most of the stages between the smallest and the largest follicles will be seen in the specimen.

d. Large polyhedral cells in the stroma, something like those that occur in the interstitial tissue of the testis. (These are much less numerous in the ovary of the rabbit.)

In some of the sections taken near the hilus there may be seen lying in the stroma groups of tubules, lined with a short cubical or flattened epithelium, and cut at various angles. These are the tubules of the parovarium.

3. Take the fresh ovary of a mammal (preferably a large one); observe the bulgings due to the more or less ripe Graafian follicles. Holding the ovary on a glass slide, carefully prick the most prominent follicle and receive the contents on the slide. Examine without a 
cover-slip, with simple lens or low objective. If the ovum is present it will at once be recognized. (The whole procedure is best performed under a dissecting microscope.) When one is obtained carefully cover with a cover-slip, inserting a thickish ring of paper in order to avoid pressure, and examine with a high power. Observe

The thick zona pellucida, with double contour (and radiating striation).

The granular cell substance (vitellus).

The transparent germinal vesicle, with its germinal spot. If the follicle be quite ripe these may have disappeared.

The cells of the cumulus proligerus attached all round the zona pellucida.

4. Uterus. Transverse section of cornu of uterus of cat (chromic acid and spirit, cut frozen); stain with hæmatoxylin and (slightly) with eosin. Observe

\section{The thin external peritoneal coat.}

The muscular coat, consisting broadly of an external longitudinal and an internal circular coat. separated by copnective tissue containing largish blood vessels. The size and arrangement of the coats vary in the different parts of the uterus and in different animals.

In most parts of the uterus the external muscular coat consists of two parts, an outer longitudinal coat, and an inner coat with fibres in various directions. The main circular coat, called above the internal, is taken to correspond with the muscularis mucosæ.

The mucous membrane, consisting of connective tissue covered with columnar epithelium, and containing long tubular glands, sometimes branched at their ends. 
The surface cells, and most of the gland cells are ciliated, but possibly the cilia will not be seen, as they readily disintegrate.

5. Transverse section of Fallopian tube. Note the outer longitudinal and the inner circular muscular coat; the much folded sub-mucous and mucous membrane with glands, the surface ciliated epithelium.

6. Mammary Glands. Section of a portion of mammary gland (adult but not old, non-pregnant cat or rabbit; Flemming's fluid, cut frozen); stain with picrocarmine.

Observe the groups of lobules forming alveoli; the commonly large lumina of the alveoli, and their frequent connection with one another.

Under a high power, note the epithelium, flattened, cubical, or columnar in different alveoli; the cells commonly contain fat globules, and some have more than one nucleus. Where the contents of the alveoli have not tumbled out, note that they form a granular mass crowded with fat globules.

7. Section of mammary gland (alcohol, stained in bulk, cut in paraffin). Compare with $\S 6$; the fat will have been dissolved out, the alveolar contents will be granular.

8. Testis. Transverse section of testis, and head of epididymis of cat or dog (Müller's fluid or alcohol); stain with picrocarmine (or better with Ehrlich-Biondi fluid).

a. Observe under a low power

The tunica vaginalis, a thin membrane covering 
the greater part of the testis and firmly attached to the underlying tunica albuginea.

The tunica albuginea, the thick connective tissue coat of the testis.

The mediastinum (corpus Highmori), a patch of connective tissue seen near the centre of the section; bands of connective tissue radiate from it towards the tunica albuginea, but most become thin or branch on their way, so that the division of the testis into lobules is very imperfect.

The tubuli seminiferi, contorted tubes, surrounded by a little fibrous tissue and a considerable number of polygonal cells, the interstitial cells. (The interstitial cells are absent in some animals, as the rat; cp. $\S 2, d$.)

The convoluted tubes unite near the mediastinum, forming the straight tubes.

The rete testis, into which the straight tubes open; note the irregular and anastomosing spaces.

The efferent tubules (vasa efferentia), rather large tubes arising from the rete (not present in every section).

The conspicuous tubes of the epididymis with large lumina.

b. Observe under a high power

The connective tissue structures and the interstitial cells mentioned under $a$.

The tubuli seminiferi, consisting of basement membrane and several layers of cells. (The characters of the cells will be better seen in $§ 9$.)

The straight tubes, lined by a single layer of cubical or flattened cells. 
The rete testis, without special basement membrane, and lined by much flattened epithelium.

The efferent tubules and canal of the epididymis. Note the fibrous and unstriated muscle coats, both thin; the epithelium consisting of columnar ciliated cells, with some small cells near the basement membrane.

In the canal of the epididymis the cells are long and slender, but there is some variation in different animals; in the efferent tubules and in the coni vasculosi the cells are shorter and broader.

To see the masses of spermatozoa in the tubes, a section of the epididymis of the rat treated as the testis in $\$ 9$ should be made.

9. Section of testis of rat (mercuric chloride, stain deeply in bulk with hæmatoxylin, cut in paraffin). Note the slight amount of connective tissue and the absence of interstitial cells.

The epithelium varies in arrangement in different tubes. Observe the following forms.

a. An outer single layer of small cells, lining cells with deeply stained nuclei; next to this a single layer of larger cells, the nuclei being in some stage of division, most probably in the tangle stage, the spermatogenic cells; a layer consisting of four or five small cells, spermatoblasts, with less stained nuclei; lastly spermatozoa, the deeply stained heads of some lying close to and between the outermost layer of the spermatoblasts.

$b$. The lining cells are of two kinds, neither staining deeply; one kind, the supporting cells, have a flattened base, they narrow on the inner side, and from them pass bands of faint lines to the lumen, thus dividing the 
remaining cells into columns. The spermatogenic cells are smaller and form an irregular double row.

c. Tubes with the heads of the spermatozoa in groups at various levels from that of the spermatogenic cells outwards.

10. Transverse section of the vas deferens. Note

The thick outer longitudinal and inner circular muscular coat.

The mucous coat, slightly folded, without glands; the epithelium cells are columnar and have no cilia.

11. Spermatozoa. Cut in half the fresh testis of a rat or mouse, and gently press the cut surface on a glass slide. Observe the spermatozoa, each consisting of

A head or body.

A long tapering tail or process.

A short intermediate part.

Note that the spermatozoa move by a whip-like movement of their tails.

12. Observe in like manner the spermatozoa of a frog or newt in the spring. The head is long and pointed, the intermediate part small and not very distinct; from the intermediate part starts a filament which runs in a spiral around the long tail; the filament is at the edge of a thin spiral membrane, but this is difficult to make out. .

\section{DEMONSTRATIONS.}

1. Section of young ovary. Note the germinal epithelium dipping down from the surface to form the ovarial tubes.

2. Section of vagina (dog or cat; potassium bichromate). Note the epithelium consisting of several 
layers of cells; the connective tissue layer of the mucous coat containing numerous elastic fibres and blood vessels; the muscular coat, chiefly longitudinal; the fibrous coat.

3. Transverse section of testis and head of epididymis, of young pig (formol, cut frozen, EhrlichBiondi stain). Note the general features described in the text, $\S 8$; the connective tissue and the interstitial cells are in relatively greater amount.

4. Section of prostate gland (dog; alcohol or mercuric chloride; eosin and hæmatoxylin). Note the irregularly shaped alveoli lined by one or two layers of cubical to columnar cells; and between the alveoli, the considerable amount of fibrous tissue with elastic fibres and unstriated muscle.

5. Section of erectile tissue (dog; potassium bichromate, eosin and hæmatoxylin). Note the spongework of connective tissue containing bands of unstriated muscle, and covered with flat epithelium; the spaces are the venous sinuses.

\section{NOTES.}

The ovary may be hardened in mercuric chloride, chromic acid and alcohol, or Flemming's fluid, and stained with any of the usual stains.

The Fallopian tubes, uterus, vagina, vas deferens are perhaps best hardened in potassium bichromate, but alcohol, mercuric chloride, or one of the formol mixtures may be used. The testis may be hardened in mercuric chloride or a formol mixture to show the general features: and in Flemming's or Hermann's fluid to show spermatogenesis. 
Sections of the testis on the cover-slip may be stained in saffranin and then by Hermann's gentian violet method (cp. p. 289); the sections are left in the gentian violet for 2 to 3 hours.

Film preparations may be made of spermatozoa, and these may be (a) dried or (b) fixed in formol and alcohol (cp. p. 28) or in mercuric chloride or in 1 p.c. osmic acid.

The films may be stained by the iron-hæmatoxylin method (cp. p. 287) or with gentian violet (p. 289), or with acid magenta. 


\section{LESSON XXXVI.}

\section{CELL-DIVISION.}

\section{Sections of salamander. (Flemming's fluid.)}

Place some sections in alcoholic saffranin for 1 to 2 days; pass through alcohols and leave in absolute alcohol until the excess of colouring matter is extracted, clear with cedar-wood oil and mount.

Stain other sections with hæmatoxylin, treating afterwards with acid alcohol.

Note the following stages of nuclear division :

The tangle, consisting of one or more filaments.

The star in which the division of the filaments into chromosomes is complete, and the bent portion of the chromosomes is directed approximately to the centre of the nuclear space.

The stage of meta-kinesis, in which most or all of the primary chromosomes have divided longitudinally, forming the secondary chromosomes. The secondary chromosomes are arranged in two groups with the bent portions in each group pointing away from the centre of the nuclear space. (Each set is directed towards the region to be occupied subsequently by the daughter nuclei.) 
The double star, in which the secondary chromosomes have separated from one another, and have moved towards the poles.

The secondary tangle, in which the secondary chromosomes have united more or less completely by their ends, and by transverse connecting threads; the cell-substance may show a slight constriction.

The secondary nuclei, having the character of resting nuclei, and with the cell-substance between them more or less constricted.

In the salamander a thin-fibred tangle precedes the thick-fibred tangle.

Indications of the cell-spindle may be seen, but this structure will not be very distinct.

2. Stain sections of salamander (mercuric chloride ; cut 3 to $6 \mu$ thick in paraffin) by the iron-hæmatoxylin method.

Prepare the sections for staining on the cover-slip (cp. p. 46).

Place in 25 p.c. aqueous solution of violet crystals of ironalum for 4 to 8 hours, wash well with water, place in Weigert's hæmatoxylin (see p. 289), diluted with an equal volume of distilled water.

Wash in 1-2 litres of water; place in a little 2.5 p.c. ironalum, moving the cover-slip about; when the sections are sufficiently decolourized, put back in the water to wash.

Dehydrate, clear with xylol, mount in balsam.

Note the two small particles, the centrosomes, on one side of some of the resting nuclei, and on opposite sides in the star and later stages of the dividing nuclei. Indications of spindle fibres will probably also be seen.

3. Stain, as in $\S 2$, sections of red medulla of bone hardened in mercuric chloride. Some of the leucocytes may show two centrosomes and a centrosphere. 
4. Sections of rootlets of Pinus. (Alcohol, or mercuric chloride, frozen, cut longitudinally, stained with hæmatoxylin.) Note:-

The cell-spindles in various stages of development. The chromosomes are generally bent at a right angle near one end.

The cell-plate, seen as a thin granular band running across the middle of the cell-spindle in the cells which are dividing.

\section{DEMONSTRATIONS.}

1. Section of salivary gland of larva of Chironomus (Flemming's fluid; Ehrlich-Biondi stain). Note the very large nucleus; the long filament in it, consisting of stained discs (chromatin) and of unstained substance (hyaloplasm); the large nucleolus.

2. Embryo-sac of Fritillaria imperialis (Hermann's fluid; hæmatoxylin). Note the different stages of nuclear-division in the cell.

\section{NOTES.}

The larvæ of salamanders, newts, or frogs may be taken for cell-division. The larvæ of the salamander may be cut out in the spring, or taken soon after birth. The animals should be well fed for some time before death, the adult salamanders on worms, their larvæ on Tubifex riv.

When hardened, the body of the larva is cut into pieces, imbedded in paraffin and cut transversely. The tail is cut flat, either imbedded or frozen. 
Numerous dividing nuclei but with small nuclear fibres will be seen in transverse sections of a limb of a young chick ( 2 to $3 \mathrm{~cm}$. in length) or in any young fotal mammal.

Hardening. The tissue should be placed in the hardening agent in as fresh a condition as possible.

Flemming's fluid and Hermann's fluid preserve the figures with least alteration and allow a sharply defined stain. Hermann's fluid is said to be better for the spindle fibres.

The staining is as good, if not better, after hardening in mercuric chloride, chromic acid 2 p.c., or saturated aqueous picric acid, but the nuclear figures are less perfectly preserved. Glacial acetic acid up to $\cdot 1$ p.c. may be added to the chromic acid in order to make the spindle fibres more distinct.

Potassium bichromate and other solutions of chromic salts do not give good results.

Staining. After staining in saffranin (cp. p. 286), sections may be stained with gentian violet, thus

The sections are placed for a few minutes in a gentian violet solution, prepared as follows:

4 c.c. of aniline oil are added to 100 c.c. water, well shaken and filtered; to the filtrate are added 5 c.c. of a saturated solution of gentian violet in absolute alcohol.

The sections are rinsed in water, placed in iodine and iodide of potassium till they are black, then decolourized to the proper extent with alcohol (Hermann).

Weigert's homatoxylin solution. Dissolve' 1 gram of hæmatoxylin in 10 c.c. of absolute alcohol, and add 90 c.c. of water. Leave for a month before use ; when used, filter and add to the stock. If it is necessary to use a fresh solution, add iron-alum to it drop by drop till it has a dark tint.

In many cases 5 p.c. aqueous hæmatoxylin gives a stain which is not appreciably different from that given by Weigert's hæmatoxylin.

Larva of Chironomus. If the head be torn off, the salivary glands remain attached to it as two small transparent masses; these can be examined fresh in the blood of the larva; and then 
irrigated with methyl-green in 1 p.c. acetic acid. The same stain may be used for other fresh tissue cells, or for fresh ova.

Plant tissues. The rootlets of pine may be obtained from the young plants which grow under fir trees; it is best to dig them up on a warm day, and preserve at once. Rootlets serving the same purpose may be obtained by placing onions in water, and keeping at about $25^{\circ} \mathrm{C}$. The tips of the rootlets are cut off and hardened in any of the ways given above, or in absolute alcohol.

The anthers of a lily may be taken to show division in nuclei containing a considerable amount of chromatin ; the anthers of Fritillaria persica to show division in nuclei with comparatively little chromatin. 


\section{APPENDIX.}

\section{Observation of Fresh Tissues. Dissociation. Teasing.}

A. Observation of fresh tissues. All tissues should so far as possible be examined in the living state.

In the frog, and other small cold-blooded animals, the gastric glands (cf. p. 169), pancreas, edge of the liver, tongue, and mylo-hyoid muscle can be seen with the circulation continuing. In the newt the kidney and spleen can also be observed. In the rabbit the pancreas, the middle lobe of the parotid gland, the thin platysma muscles of the skin can be seen with the circulation. The tissues in the mammal should be irrigated with 1 p.c. salt solution at about $39^{\circ} \mathrm{C}$.

The living appearance is preserved for a time after the tissue is removed from the body. A small piece of the tissue should be taken and examined as quickly as possible, without the addition of fluid.

Small pieces may be obtained,

a. by cutting free-hand with a razor; this method may be used if the tissue is fairly firm; 
b. by cutting a section with a Valentine's knife, i.e., a double-bladed knife, in which the distance of the blades from one another can be varied;

c. by cutting off a thin piece with fine-pointed scissors ;

d. by tearing off a small strip with fine-pointed forceps if the tissue is fibrous.

After examining the piece of tissue, normal salt solution should be allowed to run under the cover-slip, the cover-slip pressed, an examination made, the coverslip tapped smartly two or three times to break up the tissue, and examined again. Other pieces should be similarly treated with fresh aqueous humour, fresh serum, 1 p.c., 2 p.c., 5 p.c. sodium chloride, and with dilute acids and alkalis.

Membranous structures may be pinned out over a hole in a stage.

Motile cells should be examined in a hanging drop as well as on the slide.

Freezing a tissue alters more or less markedly the living appearance; the alteration appears to be chiefly due to the formation of ice crystals. To avoid this the piece of tissue may be soaked for a quarter of an hour in fresh white of egg or in a dilute solution of gum in salt solution, but this of itself causes considerable changes. For the method of cutting frozen sections cp. Lesson vir.

B. Dissociating fluids. These are fluids which, whilst preserving certain parts of a tissue, dissolve or partially dissolve others, principally the cementing or ground substances, so that the former can be isolated by teasing or shaking. As a rule the 
piece of tissue so treated should be not more than 1 to $2 \mathrm{~mm}$. square.

Osmic acid, 1 to 1 p.c., and dilute alcohol, 30 to 35 p.c., are dissociating fluids of general application. After staying a short time in osmic acid, or a day or two in dilute alcohol, the pieces may be placed in picrocarmine for a day or two and teased in dilute glycerine (cp. pp. 93, 218).

The following agents are mentioned in the text; picric acid (tendon) p. 71 ; 35 to 40 p.c. caustic potash (muscle) pp. 94, 96, 106, (horny layer of skin) p. $214 ; 20$ p.c. nitric acid, 1 p.c. potassium bichromate (muscle) p. 97 ; 5 p.c. neutral ammonium chromate (mucous glands) p. 160, (kidney) p. 197; hydrochloric acid (kidney) p. 199 ; 5 p.c. chloral hydrate (serous cells) p. 164 ; water (basket cells) p. 164.

Besides these may be used, 02 p.c. potassium bichromate and - 02 p.c. chromic acid (nerve-cells of central nervous system). A mixture consisting of 5 c.c. "of a saturated solution of each of the following: neutral ammonium chromate, phosphate of potash, sulphate of soda with 100 c.c. of water (Landois). After 1 to 3 days in this the piece of tissue is placed for a day in dilute picrocarmine. It has been chiefly recommended for the central nervous system.

C. Teasing. A small piece of tissue only should be taken.

As a rule it is best to tease in the fluid in which the tissue has been preserved, but it may generally be teased in dilute glycerine or in glycerine.

The teasing is as a rule easier if no more fluid is taken than that which clings to the piece of tissue; when the teasing is complete, a small drop of fluid is placed on the centre of the cover-slip, and this is lowered on the specimen.

It is important to place the slide on an appropriate ground; if the object is of a light tint, the slide 
should be placed on a piece of black paper; if it is of a dark tint, or stained, the slide should be placed on a piece of white paper.

Fine needles, e.g. No. 12, should be used.

The teasing is best done under a dissecting microscope, and the parts which are not required should be thrown away.

In teasing bundles of fibres, the fibres are best separated completely from one another and then arranged close together-parallel to one another, in a row.

Teased tissues mounted in water or in aqueous solutions can be temporarily preserved by surrounding the edges of the cover-slip with olive oil. 


\section{Methods of Hardening and Preserving Tissues.}

a. The tissues should be removed from the body to the hardening agent as soon as possible after the death of the animal.

The tissues should not be allowed to soak, either in or out of the body, in blood, serum, lymph or normal salt solution.

In many cases the tissues may be left in the body for a day after death, provided they are not surrounded by any excess of fluid. It is in fact easier to obtain the peripheral nerves (osmic acid) and the central nervous system (Marchi's method) without injury a day after death than in the fresh state.

If any blood or fluid is on the tissue, it should be removed by placing the tissue on blotting-paper.

The tissue should be divided with a sharp razor, into as small pieces as is consistent with obtaining all the parts required for examination. As a rule the pieces should be only 2 to $4 \mathrm{~mm}$. in thickness. But very soft tissues-such as the brain-are generally placed whole in the hardening agent; they may be sliced as soon as the surface is sufficiently hardened, but such slices of the brain are apt to buckle.

The volume of the fluid should be 15 to 20 times that of the tissue. When a piece of tissue is kept days or weeks in a hardening agent, such as Muiller's fluid, the fluid should be renewed in 1 day, and once or more later.

The tissues should be placed in a flat short bottle rather than in a narrow high one, unless they are suspended in fluid; they should be kept cool for the first day or two, then they may be warmed if it is desired to hasten the process of hardening.

b. Treatment after the primary hardening agent. After treatment with the primary fixing or hardening agent, the excess of the agent is in nearly all cases removed from the tissue. 
As a rule this is done by placing the tissue in a basin of water and allowing a slow stream of water from a tap to fall into the basin. It is left so for three hours to a day or two. This washing in running water should be carried out with tissues hardened in osmic acid, Flemming's fluid, chromic acid.

It may also be carried out with tissues hardened in chromium salts, mercuric chloride, formol, or Perenyi's fluid, but súch tissues may be passed direct to alcohol, which should be renewed two or three times.

Water should be used as little as possible with portions of the nervous system in which the basophil substance of the cells is to be stained. Prolonged treatment with water deteriorates also the medullary staining of nerve fibres by Weigert's method.

After washing out, the tissue is left for a day in each strength of alcohol 30 p.c., 50 p.c., 75 p.c. It may be further hardened in 95 p.c. or in absolute alcohol for a week or more. It is kept in 70 or 75 p.c. alcohol.

Since chromic acid, potassium bichromate and other chromium salts are precipitated by alcohol in the light, tissues hardened in fluids containing these reagents, when transferred to alcohol, should be kept in the dark, until the alcohol on renewal no longer becomes yellow.

c. Preparation of Solutions. It is generally advisable to make of any given substance a solution of the maximum strength likely to be required, and to dilute this when weaker solutions are needed. If the stronger solution contains $x$ p.c. of the substance and it is required to make a weaker solution of $y$ p.c., add $\frac{x}{y}-1$ c.c. of water to each c.c. of the stronger solution.

It is rather better to use distilled water in making up the solutions, but in most cases this is not of much importance.

\section{Simple Hardening Agents.}

Alcohol. Alcohol is especially used for glands and for preserving the brain and spinal cord for staining nerve-cells by Nissl's method (cp. p. 117). Strong alcohol (95 p.c. or absolute) is 
generally used, but it causes great shrinking, especially of the outer parts of the tissue.

The shrinking is less if the tissue is placed in 70 to 75 p.c. alcohol for some hours to a day; transferred to 90 or 95 p.c. for a day or two, and then to absolute alcohol. When well hardened, the tissue may be kept in 75 p.c. alcohol.

Chromic acid. Make a 1 p.c. solution; from this make $\cdot 2$ p.c. and other solutions. Tissues to be hardened in chromic acid $\cdot 2$ p.c. are left in it about a week. (Cp. p. 91.) If sections of tissues hardened in chromic acid or in chromic salts do not stain well, place them for about 3 hours in acid alcohol, and wash with alcohol before staining.

Formol or formaline is a 40 p.c. aqueous solution of formaldehyde. A solution containing 10 p.c. of formol, i.e. 4 p.c. of formaldehyde, is the most generally useful. It has great penetrating power and fixes rapidly, and without external shrinking.

It is perhaps best to leave a piece of tissue of moderate size not more than a day, to wash thoroughly and pass through alcohols as given above. Otherwise the staining is apt to be diffuse.

The vapour of formol may be used, as the vapour of osmic acid, to fix films, or small fragments of tissue.

Mercuric chloride. A saturated solution in water or in $\cdot 75$ p.c. salt solution is used. It is a good hardening agent for glands, and epithelium of skin and cornea. Tissues should not as a rule be left in it more than one to two days. They are then washed in running water (cp.p. 296) and passed through alcohols, kept for a week or more in 95 p.c. alcohol, then transferred to 75 p.c. alcohol till required.

Unless the piece of tissue is small, the mercuric salt will not be wholly removed by this process; to facilitate its removal, a drop or two of iodine dissolved in potassic iodide is added to the stronger alcohols, until the fluid is no longer decolourized. Then the alcohol is renewed.

The salt is similarly removed from the tissues when any of the fluids given below which contain mercuric chloride are used. 
The iodine solution is made as follows:-Dissolve 2 grams of potassic iodide in 100 c.c. of water, and add iodine to slight excess.

Since mercuric chloride is soluble in alcohol (in fact more soluble than in water), the tissue may be transferred direct to alcohol ; this sometimes gives a better preservation of the tissue, but it demands repeated renewal of the alcohol.

Further hardening in alcohol is generally advisable.

If the sections show a mercuric precipitate, they should be treated with alcohol containing the iodine solution.

Osmic acid. The bottle to contain it should be washed with strong sodium hydrate or soft soap, then with sulphuric acid, and finally with distilled water. The tube containing the osmic acid should also be washed. Put the tube in the bottle, add water sufficient to make a 2 p.c. osmic acid solution, break the tube, and shake occasionally till the acid is dissolved. From the 2 p.c. solution make $1, \cdot 5$ and $\cdot 2$ p.c. solutions.

Osmic acid does not penetrate well, so that a small piece only of the tissue should be taken.

If the tissue is to be stained, it should be left an hour or two only in osmic acid, washed in running water, passed through alcohols-a few hours to half-a-day for each-and cut without delay. Some tissues are sufficiently hardened by a short stay in osmic acid to be cut frozen without having been treated with alcohol. If the tissue is not to be stained, it may be left in osmic acid for a day. In the sections the nuclei are generally spherical and indistinct, whilst the nucleoli are obvious.

Tissues treated with osmic acid become darker in alcohol, and deteriorate. Sections of glandular tissues are as a rule best prepared by the freezing method and best mounted in glycerine.

Picric acid. Make a cold saturated solution in water.

Leave the tissue in the fluid for one to two weeks. Harden in alcohol. Pass back through alcohols and wash out the picric acid in running water. Picric acid alone usually gives less satisfactory results than a mixture containing picric acid (cp. below). 
Potassium bichromate. Make a 2 p.c. solution. This is, on the whole, the best reagent for the brain and spinal cord. The cord takes four to six weeks to harden, and the brain two to three months, unless it is cut into slices.

A 3 p.c. solution is preferred by some observers; to obtain a sharper nuclear stain acetic acid up to 5 p.c. may be added; glandular tissues are fixed in this in 1 to 3 days.

\section{Compound Hardening Agents.}

Chromic acid and alcohol. Mix equal parts of chromic acid 3 p.c. and alcohol 75 p.c. Various other mixtures are used. Make as required and filter. Tissues placed in the mixture should be kept in the dark. After four to six days, wash in running water.

Chromic and nitric acids (Perenyi's fluid).

$\begin{array}{ll}10 \text { p.c. nitric acid } & 40 \text { c.c. } \\ 95 \text { p.c. alcohol } & 30 \text { c.c. } \\ 0.5 \text { p.c. chromic acid } & 30 \text { c.c. }\end{array}$

The tissue is left in the fluid three to six days.

Chromic and osmic acids (Flemming's mixture).

1 p.c. chromic acid 15 c.c.

2 p.c. osmic acid 4 c.c.

Glacial acetic acid $\quad 5$ to 1 c.c.

This is a good hardening reagent for small pieces of tissue; and it is especially used to preserve dividing nuclei. The penetration of the osmic acid is slow.

The tissue is placed in the fluid for a few hours to a day (cp. $b$ above). If it is desired to see fat globules after hardening in Flemming's fluid, the tissue should be washed with water and cut frozen, or kept in 70 to 80 p.c. alcohol for some time before imbedding.

The fluid is sometimes modified by taking only 5 to 1 c.c. of osmic acid.

Chromic acid and platinum chloride (Merkel).

$\begin{array}{lr}1 \text { p.c. chromic acid } & 25 \text { c.c. } \\ 1 \text { p.c. platinic chloride } & 25 \text { c.c. } \\ \text { Water } & 150 \text { c.c. }\end{array}$


Tissues are left in this 2 to 6 days, and the hardening completed with alcohol.

Potassium bichromate and cupric sulphate (Erlicki's fluid).

$\begin{array}{lr}\text { Potassium bichromate } & 2.5 \mathrm{grms} . \\ \text { Cupric sulphate } & 5 \mathrm{grm} . \\ \text { Water } & 100 \text { c.c. }\end{array}$

This is sometimes used for the brain and cord, when a quicker hardening agent than potassium bichromate is required. After two days the tissue with the fluid may be kept at $38^{\circ}$ to $40^{\circ} \mathrm{C}$. ; it will then be ready in 3 or 4 more days.

If the sections have a precipitate on them they should be placed in warm water acidulated with hydrochloric acid.

Potassium bichromate and mercuric chloride.

$\begin{array}{lr}\text { l p.c. acetic acid } & 500 \text { c.c. } \\ \text { Potassium bichromate } & 20 \text { grams. } \\ \text { Mercuric chloride } & 5 \text { grams. }\end{array}$

The tissue is left 2 to 3 days in the mixture, and 2 days to a week in strong alcohol.

This hardening has been recommended for the central nervous system, preliminary to the Weigert medullary stain (acetate of copper, hæmatoxylin, etc., cp. p. 245).

Potassium bichromate and sodium sulphate (Müller's fluid).

$\begin{array}{lr}\text { Potassium bichromate } & 25 \text { grams. } \\ \text { Sodium sulphate } & 10 \text { grams. } \\ \text { Water } & 1 \text { litre. }\end{array}$

Müller's fluid and formol. To Müller's fluid as above add 50 to 100 c.c. of formol. The formol should not be added until the fluid is required for use. This mixture may be used to harden organs or large pieces of tissue ; it fixes small pieces of tissue in about a day.

Müller's fluid and mercuric chloride (Zenker).

$\begin{array}{lr}\text { Müller's fluid } & 100 \text { c.c. } \\ \text { Mercuric chloride } & 5 \text { grams. }\end{array}$

When required for use add 5 c.c. of acetic acid. 
Pieces of the nervous system are hardened in this fluid in about a fortnight; they are then washed with water, placed in alcohol and iodine solution, and then in alcohol.

Mercuric chloride and alcohol. A saturated solution of mercuric chloride in 75 to 95 p.c. alcohol.

\section{Formol, alcohol and chromic acid (Marina).}

$\begin{array}{lr}90 \text { p.c. alcohol } & 100 \text { c.c. } \\ \text { Chromic acid } & 5 \text { c.c. }\end{array}$

Shake now and then till the chromic acid is dissolved, add 5 c.c. of formol when required for use.

This has been recommended when it is desired to stain sections of the central nervous system by different methods.

Small pieces of tissue are hardened in 1 to 2 days. If large pieces are taken, they are cut into slices after a day, the fluid renewed in this and the following day; hardening will be complete in about a week.

The pieces may be fixed to a block and cut unimbedded, the razor being moistened with 90 p.c. alcohol. Sections may then (a) be stained by Nissl's and similar methods, $(b)$ placed in 3 p.c. potassium bichromate for a day, and $(a)$ treated by Weigert's method, or (b) stained with picrocarmine etc., (c) placed in chromogen solution (cp. p. 247) and stained by Weigert's neuroglia method.

Chrome alum and acetate of copper (Weigert's fluid).

$\begin{array}{lr}\text { Chrome alum } & 2.5 \mathrm{grm} . \\ \text { Acetate of copper } & 5.0 \mathrm{grm} . \\ \text { Ordinary acetic acid } & 5.0 \mathrm{grm} . \\ \text { Formol } & 10 \mathrm{c.c} . \\ \text { Water } & 77.5 \mathrm{c.c} .\end{array}$

Boil the chrome alum in water; when it is dissolved remove from the flame, add the copper acetate in fine powder and the acetic acid, stir well, let cool, and filter. Add then the formol.

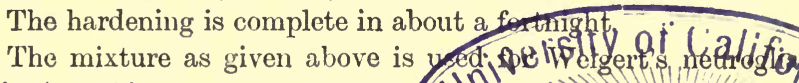
stain (p. 247). 
When used for staining medullated fibres (p. 239, § 7), 2 to 5 c.c. of formol is added instead of 10 c.c.

Picric acid and nitric acid.

Make a cold saturated solution of picric acid in water. To 100 c.c. of this add 2 c.c. of concentrated nitric acid.

Picric acid and sulphuric acid (Kleinenberg). Sulphuric acid is used instead of nitric acid in the preceding mixture.

Picric acid and mercuric chloride. Equal parts of saturated solutions of the two substances (for spinal ganglion cells); other proportions are used in special cases.

\section{Alcohol and chloroform. (Carnoy, v. Gehuchten.)}

$\begin{array}{ll}\text { Absolute alcohol } & 60 \text { c.c. } \\ \text { Chloroform } & 30 \text { c.c. } \\ \text { Glacial acetic acid } & 10 \text { c.c. }\end{array}$

The mixture penetrates well. It has been modified as follows: absolute alcohol 80 c.c. ; chloroform 15 c.c. ; acetic acid 5 c.c. ; mercuric chloride 20 grams. The hardening is rapid. 


\section{Imbedding and Cutting Tissues in Celloidin.}

Tissues are imbedded in celloidin chiefly to avoid the shrinking which in some cases occurs when they are heated in melted paraffin. The disadvantages of the method as compared with parafin imbedding are that it takes longer, does not allow such thin sections to be cut, and is less adapted for serial sections.

Celloidin solutions. Two solutions are used. 1.2 grams of thin dry shavings of celloidin are dissolved in 10 c.c. of ether and 10 c.c. of absolute alcohol. This gives the thin solution; the thick one contains about twice as much celloidin.

5 c.c. of cedar-wood oil are sometimes added to the celloidin solution.

Dehydration. The tissue is in all cases dehydrated. This is usually done with absolute alcohol ; the tissue being left in it for several hours to a day or more according to the size of the object.

Large objects may be left in absolute alcohol and ether for a day to increase the rate of penetration of the celloidin.

Imbedding in celloidin. The dehydrated tissue is transferred to celloidin, being left for two or more days in the thin solution and for two or more days in the thick solution.

If the piece of tissue is small the hardening of the celloidin may be conveniently carried out as follows. A little thick celloidin is dropped on a piece of cork, and exposed to the air for about 5 minutes; on this the object with some thick celloidin is placed, and when a film has formed on the surface the whole is placed either

$a$. in chloroform (free from water) for an hour to a day;

or $b$. in a desiccator and exposed to the vapour of chloroform for an hour to a day;

or c. in 85 p.c. alcohol for a day or more. 
When the tissue is to be cut as soon as imbedded, the carrier of the microtome may be used instead of the piece of cork. And instead of fixing the tissue to cork, it may be placed in a paper case, celloidin poured over it, and the case after a short time put in chloroform or 85 p.c. alcohol; as soon as the outer part is firm, the paper should be removed.

If the object is large, it is placed in a small dish covered up but so as to allow a very gradual evaporation of the solvents; when the celloidin is fairly firm a fresh coat is added, and the process repeated until there is sufficient firm celloidin around the object. A block with the object is then cut out and the hardening completed with chloroform.

If the block is not sufficiently transparent it may be cleared by placing it in a mixture of equal parts of cedar-wood oil and chloroform.

Fixing to the carrier of the microtome. The imbedded tissue is either fixed directly to the carrier of the microtome, or to a piece of wood which can be attached to it, or take its place.

A layer of thick celloidin is spread over the wood and allowed to dry; the imbedded tissue is cut away from the cork, so as to give a clean surface of celloidin, this surface is moistened with absolute alcohol and ether; the dry celloidin on the wood is similarly moistened; a drop of thick celloidin is placed on it, and the tissue-block is lightly pressed into the drop. In a minute or two the whole is dipped into chloroform for a quarter of an hour or more.

Cutting. The razor is fixed obliquely so that it passes from heel to point through the tissue. The razor and the tissue are moistened with 80 to 95 p.c. alcohol, and the sections as soon as cut are placed in this fluid. If the celloidin has been cleared with cedar-wood oil and chloroform, cedar-wood oil with a little chloroform should be used in place of alcohol.

In the case of a large piece of tissue it is sometimes advisable to brush over the exposed surface with a dilute celloidin solution before cutting each section.

Staining sections. The sections still permeated by celloidin may be stained with any reagent. But most aniline dyes stain the celloidin also. For such dyes the celloidin should be dissolved 
before staining if the sections hold together well ; if they do not the celloidin should be dissolved after staining and fixing to the slide.

Mounting. Sections in which the celloidin is not stained may be mounted in glycerine or in balsam without removing the celloidin.

In mounting in balsam, when the celloidin is not to be dissolved, the sections are placed in 95 p.c. alcohol to remove most of the water; then in origanum oil or cajeput oil (neither of these dissolves aniline colours).

It aids the clearing process to blot the sections on the slide, add a drop or two of the clearing agent, pour it off after a minute or two, blot again and repeat the process.

The following clearing agents are also used: bergamot oil; 3 parts white oil of thyme and 1 part of clove oil ; 3 parts of xylol and 1 part of carbolic acid; to this calcined copper sulphate may be added to dehydrate it (it discolours certain aniline stains, and for such Weigert substitutes aniline oil for the carbolic acid).

Some specimens of origanum oil and of cajeput oil are said to have a slight solvent action on celloidin.

Equal parts of chloroform and absolute alcohol may be used instead of 95 p.c. alcohol to dehydrate.

Solvents for celloidin. A mixture of equal parts of ether and absolute alcohol ; or either alone; the former has a much greater solvent power than the latter.

Carvol (Ol. carvi).

Clove oil and cedar-wood oil also dissolve celloidin, though slowly. Clove oil should not be used for aniline dyes which are soluble in it.

Fixing sections to the slide. Of the various methods the following may be mentioned. A thin layer of egg-albumin and glycerine is spread upon the slide, which is then placed at $100^{\circ} \mathrm{C}$. for a few minutes to coagulate the albumin. The celloidin sections from 70 p.c. alcohol are arranged on this. The alcohol is then soaked up with blotting-paper, and the sections pressed firmly with a pad of blotting-pajer. 
Rapid method (Gilson). The dehydrated tissue is placed in ether for an hour or more, then in thin celloidin in a short testtube, and this is placed on a bath in melted paraffin until the solution is reduced to about 2 rds in bulk.

It is then poured into a watch-glass placed with some of the thickened celloidin on a small block of hardened celloidin; after a few minutes the block is placed in a mixture of equal parts of chloroform and cedar-wood oil for an hour or more, fixed to a block and cut, moistening the razor and the tissue with cedar-wood oil. Lee recommends gradually increasing the amount of cedar-wood oil and cutting without moistening the razor.

Cutting in celloidin with the freezing microtome. The celloidin around the specimen is pared away, and the block placed in water for an hour or two, then transferred to gum for any longer time.

Or, though less satisfactorily, the block after soaking in water may be simply dipped in gum to make it stick to the microtome.

The sections are placed in water to remove the gum ; this is done more quickly if warm water is used.

If it is desired not to soak the tissue with water, the block may be passed through 95 p.c. alcohol (1 day); xylol (1 to 2 hrs.), and anethol (melting point $20^{\circ} \mathrm{C}$., 6 to $8 \mathrm{hrs}$.); the cooled block can then be frozen and cut.

Celloidin and paraffin. (a) The tissue is soaked in thin celloidin for 1 to 3 days and hardened. The block is placed for an hour in origanum oil, then in origanum oil and paraffin at about $38^{\circ} \mathrm{C}$. for several hours, and finally in melted paraffin (of melting point about $50^{\circ} \mathrm{C}$.) for two or more hours.

(b) The tissue is soaked in a mixture of 4 parts of 2 to 3 p.c. celloidin solution and 1 part cedar-wood oil; hardened in a mixture of 4 parts chloroform and 1 part cedar-wood oil; put in xylol at $30^{\circ} \mathrm{C}$., to which paraffin is added to saturation. Then in paraffin at $50^{\circ} \mathrm{C}$., which is changed once or twice.

In these cases it is not necessary to moisten the razor, and if a paraffin mantel is left serial sections can be cut. 


\section{Staining Fluids.}

Preservation of staining fluids from fungi. A fragment of camphor or thymol should be added to all aqueous solutions of stains.

\section{Ehrlich's acid hæmatoxylin.}

Hæmatoxylin 2 grms.

Absolute alcohol 100 c.c.

Water 100 c.c.

Glycerine $\quad 100$ c.c.

Glacial acetic acid 10 c.c.

Alum to saturation.

\section{Delaffeld's hæmatoxylin.}

4 c.c. of a saturated solution of hæmatoxylin in absolute alcohol.

150 c.c. of a solution of ammonia alum saturated in the cold.

Leave for a week, filter, and add

$$
\begin{aligned}
& 25 \text { c.c. methyl-alcohol. } \\
& 25 \text { c.c. glycerine. }
\end{aligned}
$$

Hæmalum (Mayer). Add

$$
\begin{aligned}
& 1 \text { gram hæmatein, to } \\
& 50 \text { c.c. of } 90 \text { p.c. alcohol, } \\
& \text { and dissolve by warming, pour into } \\
& 1 \text { litre of a } 5 \text { p.c. solution of alum. }
\end{aligned}
$$

Leave two or three days, and filter.

Time of maximum staining power. Delafield's hæmatoxylin becomes darker and increases in staining power for several months after it has been prepared; the acid hæmatoxylin increases in staining power for a month or two; the hæmalum is at its maximum or nearly so, when first prepared.

Dilution of homatoxylin. It is best to dilute the several fluids, when they stain too quickly, with a mixture of the constituents of the fluid minus the hæmatoxylin, but when 
the dilute solution is only required for staining at the moment, and not for diluting the fluid in the bottles, a 1 p.c. solution of alum or distilled water may be used.

Comparison of the homatoxylin fluids. Delafield's hæmatoxylin gives perhaps the best preparations for the student, but it is apt to overstain and it requires freqnent filtering; these disadvantages are much less marked in the case of acidhæmatoxylin; the latter if used should be diluted so as to stain in 15 to 30 minutes (see also p. 63).

Iron-hæmatoxylin (Heidenhain), cp. p. 287. The chief use of the method is for staining the centrosome; it stains also for the chromatin of nuclei, striated muscle (cp. p. 100), the granules of the pancreas and of various other cells.

Alum carmine.

$\begin{array}{ll}\text { Carmine } & 1 \text { gram } \\ 2 \cdot 5 \text { p.c. ammonia alum } & 100 \text { c.c. }\end{array}$

Boil for 15 minutes. Let cool and filter.

Carmalum (Mayer).

$\begin{array}{ll}\text { Carminic acid } 1 \text { grm. } & \text { Alum } 10 \text { grm. } \\ \text { Water } & 200 \text { c.c. }\end{array}$

Warm and filter.

Carminic acid 1 grm.

Picrocarmine (Bourne). Add 5 c.c. of ammonia to 2 grams carmine in a bottle capable of containing about 250 c.c. Stopper, shake and put aside till next day. Add slowly, shaking the while, 200 c.c. of a saturated solution of picric acid in distilled water. Put aside till next day. Add slowly, constantly stirring, 11 c.c. of 5 p.c. acetic acid. Put aside till next day. Filter; to the filtrate add four drops of ammonia, put back in the stoppered bottle.

Picrocarmine (Ranvier). To a saturated solution of picric acid add a saturated ammoniacal solution of carmine till a precipitate occurs. Evaporate in a water bath till the volume is reduced by four-fifths. Filter, and evaporate the filtrate to dryness. A crystalline mass is thus obtained. Make a 1 p.c. solution in distilled water, diluting before use as required. 
Borax carmine (Grenacher). To 100 c.c. of a 4 p.c. aqueous borax solution add 2.5 grams carmine. Shake at intervals for 2 to 3 days. Add 100 c.c. 70 p.c. alcohol and, after 1 to 2 days, filter.

Pieces of tissue, or sections stained with this, are treated with acid alcohol.

Comparison of carmine stains. Bourne's picrocarmine is the most generally useful for students; and perhaps borax carmine for staining in bulk.

Methylene blue, toluidin blue, thionin, saffranin, Spiller's purple.

a. An aqueous solution is made of such strength that a section when placed in two or three drops in a watch-glass can just be seen. This stains in a minute or two, the section is mounted in water; if overstained, the excess is taken out by 30 p.c. alcohol. The section may be mounted in glycerine tinged with the staining agent, but in a varying time the stain becomes diffuse.

$b$. The section is stained in a 5 to 1 p.c. aqueous solution for half-an-hour to a day, passed through alcohols and mounted in balsam; if the period of staining has been short, the stay in alcohol requires careful attention in order to obtain the proper degree of decolourization.

c. A solution is made in 75 p.c. alcohol, the strength being tested as above. The sections are left in this for a day, then decolourized to the required extent with 75 p.c. and stronger alcohols. A saturated solution of the substance in absolute alcohol plus an equal volume of water is used by some observers, but the advantage hardly seems sufficient to make up for the expense.

With these stains, cedar-wood oil or xylol should be used to clear the sections, and not clove oil or turpentine.

For the method of using methylene blue cp. p. 18 (basophil granules of leucocytes); p. 74 (connective tissue cells); p. 117 (basophil granules of nerve-cells); pp. 125, 321 (nerve-endings). Thionin is especially used to stain the mucous cells of the 
intestinal canal (cp. p. 326); and saffranin for staining dividing nuclei (cp. p. 286).

Nissl's methylene blue.

$\begin{array}{ll}\text { Methylene blue } & 3.75 \text { grms. } \\ \text { Venetian soap } & 1.75 \text { l" } \\ \text { Water } & 1 \text { litre. }\end{array}$

For method of using cp. Lesson xv. p. 117.

Löffler's methylene blue. 30 c.c. of a saturated solution of methylene blue in absolute alcohol, and 100 c.c. of 01 p.c. caustic potash.

Eosin. The solution is made as in p. $309, \S c$; cp. p. 17 (oxyphil granules); pp. 40, 117 as diffuse plasma stain; p. 41 orange stain for red blood corpuscles; p. 67, staining in bulk.

Erythrosin (Held).

$\begin{array}{ll}\text { Erythrosin } & 1.0 \text { grm. } \\ \text { Distilled water } & 150.0 \text { c.c. } \\ \text { Glacial acetic acid } & 2 \text { drops. }\end{array}$

Ehrlich-Biondi stain. (Cp. p. 42.) It is best to get from Grubler of Leipzig a mixture of solid methyl-green and orange G, and make up as he directs.

It is perhaps best used with tissues hardened in mercuric chloride or alcohol, or for a short time in Flemming's fluid.

Acid magenta and picric acid (van Gieson).

$\begin{array}{lr}95 \text { p.c. alcohol } & 200 \text { c.c. } \\ \text { Picric acid } & 2 \text { grms. } \\ \text { Acid magenta (Rubin S) } & 0 \cdot 2 \text { grm. }\end{array}$

It is best used after rather deep staining with hacmatoxylin (cp. p. 41). Sections after staining with hæmatoxylin are left in this fluid for half a minute to 2 or 3 minutes; if left too long the acid magenta overstains, and the hæmatoxylin tint is apt to be destroyed. The sections are washed with water (15 to 30 seconds), dehydrated, and cleared with cedar-wood or origanum oil. To avoid too great a loss of colour, the water and the alcohols may be made a faint red by adding a drop of the staining mixture 


\section{Aniline blue and orange G (Mallory).}

$\begin{array}{lr}\text { Aniline blue soluble in water } & 0.5 \text { gram. } \\ \text { Orange G } & 2.0 " \\ \text { Oxalic acid } & 2.0 ", \\ \text { Water } & 100.0 \text { c.c. }\end{array}$

The tissue is fixed in mercuric chloride, sections may be imbedded and stained on the cover-slip, or cut frozen and stained. Place in

(a) 1 p.c. aqueous phosphomolybdic acid for 1 or more minutes, and wash well in water.

(b) Aniline blue mixture for 2 to 20 minutes. Dehydrate in alcohol (best rather quickly), clear in xylol.

Connective tissue fibres are stained deep blue, mucin and amyloid substance a light blue; blood corpuscles, keratin and to a certain extent nuclei and muscle are stained yellow. The staining is very sharp and very effective.

Triple stain. The section may be stained for 1 to 3 minutes in $\cdot 1$ to $\cdot 5$ p.c. acid magenta, and washed in water before being treated as above.

Carmine, picric acid and indigo carmine (Calleja).
(1) Carmine
2 grams.
Sat. aqueous lithium carbonate
100 c.c.
(2) Indigo carmine
$0 \cdot 25 \mathrm{gr}$.
Sat. aqueous picric acid
100 c.c.

Sections are placed in fluid (1) for 5 to 10 minutes, in acid alcohol for 20 to 30 seconds (till pale red); and washed well with water. They are then placed in fluid (2) for 5 to 10 minutes, in acetic acid $\cdot 25$ to 5 p.c. for a few seconds and washed well in water. They are finally placed in alcohol to dehydrate and take out excess of picric acid; aud cleared with xylol.

The method gives good results with connective tissue and epithelial cells.

Orcein (Unna's method).

100 c.c. absolute or 95 p.c. alcohol.

1 gram orcein.

1 c.c. hydrochloric acid 
Sections are placed in a watch-glass with a little of the solution, warmed at about $20^{\circ}$ to $25^{\circ} \mathrm{C}$. till the fluid has nearly evaporated. The sections are then placed in alcohol and moved about, this rather rapidly removes the stain but much less rapidly from the elastic tissue and the nuclei than from the rest of the section; the sections after dehydration are mounted in balsam. If it is not convenient to mount at once, the sections are washed with water and left in this.

Films (cp. p. 74) which are only imperfectly hardened shrink when warmed. They are best left for about two days in a few c.c. of the following :

$$
\begin{aligned}
& 80 \text { c.c., } 95 \text { p.c. alcohol, } \\
& 20 \text { c.c. water, } \\
& 1 \text { gram orcein, } \\
& 1 \text { c.c. hydrochloric acid, }
\end{aligned}
$$

washed with water and differentiated with acid alcohol.

Sections may also be stained in this way. The optimum quantity of hydrochloric acid varies with the hardening agent. 


\section{Transferring Sections. Fixatives. Fluids For Mounting.}

\section{A. Transferring a number of sections from one fluid} to another. In preparing a number of sections for class work, it is convenient to transfer them from fluid to fluid by means of a horse-hair filter. A piece of horse-hair tissue, such as is used by wig-makers, is sewn over a ring, provided with a handle. The fluid with the sections is poured on this; the sections remain, and float off readily when the filter is placed in fluid, with the surface downwards on which lie the sections.

For large sections it is best to use flat perforated porcelain dishes; in transferring from one fluid to another excess of fluid is allowed to run off, and the dish with the sections is then placed on thick blotting-paper to drain. When the sections are staining they should be moved now and then with a brush.

\section{B. Albumin fixative for sections.}

$\begin{array}{lr}\text { White of egg } & 50 \text { c.c. } \\ \text { Glycerine } & 50 \text { c.c. } \\ \text { Salicylate of soda } & 1 \text { grm. }\end{array}$

Shake up well and filter. The fluid filters very slowly.

Shellac. Dissolve pieces in creosote in the warm; if necessary filter warm.

Collodion. Make a thin solution of collodion or celloidin in clove oil.

C. The distinctness of the different constituents of a section depends in part upon the refractive index of the substance in which the section is mounted. Generally speaking fluids of low reiractive index are advantageous when the parts to be seen are not deeply stained. The following are arranged in order of increasing refractive index;

(1) water, (2) 2 p.c. sodium chloride, (3) 90 p.c. alcohol. 
4. A saturated solution of potassium acetate. This is sometimes used as a permanent mount for nerve fibres stained with osmic acid. The edges of the cover-slip may be surrounded with soluble glass.

5. Dilute Glycerine. 1 part of glycerine, 2 parts of water and a drop or two of camphor water or salicylic acid. Or equal parts of glycerine and water. Or alcohol in place of the water.

\section{Glycerine-jelly.}

$\begin{array}{ll}\text { Glycerine } & 70 \text { c.c. } \\ \text { Water } & 60 \text { c.c. } \\ \text { Gelatine } & 10 \text { grms. }\end{array}$

Place the gelatine with the water in a porcelain capsule, heat the mixture in a small water-bath over a Bunsen burner until the gelatine is dissolved, stirring the while and taking care that the gelatine does not stick to the capsule. The water should not be allowed to boil, or at any rate for a short time only. To the hot solution add the glycerine and a drop or two of a strong alcoholic solution of thymol. If necessary, cool the mixture to about $40^{\circ} \mathrm{C}$., add the beaten-up white of an egg and well mix. Then heat as before to about $90^{\circ}$ C., stirring continuously. Filter through a hot-water filter.

The gelatine may be left for a day in the cold water to swell up, then dissolved by warming to about $40^{\circ} \mathrm{C}$. The glycerine, warmed to about the same temperature, is added. Then proceed as above.

7. Glycerine. Should be neutral, acidity may commonly be detected by the taste. It is apt to become dilute by taking up water from the air. Delicate sections should be soaked in dilute glycerine before being placed in strong glycerine.

Many gold chloride and carmine stained sections are advantageously mounted in glycerine containing 1 p.c. of formic acid $1 \cdot 16$ sp. gr.

When sections are mounted in dilute glycerine or in glycerine, the edges of the cover-slip are perhaps best cemented to the slide with gold size; they may first be surrounded with a thin film of hot glycerine-jelly, and this allowed to dry (cp. p. 40, $\$ 6,7$ ). 
In mounting in glycerine-jelly (cp. p. 40) the excess of the jelly should be squeezed out in the warm chamber; this may be done by placing a small bottle containing a little mercury on the cover-slip, or by the use of a special clamp squeezing cover-slip and slide, or by the use of a compressorium.

\section{Glycerine and Gum. (Farrant's solution.) It is} simplest to buy this.

It may be made thus :- Take lumps of gum arabic which are nearly free from colour, weigh out 40 grams, grind to powder, place in about 150 c.c. water, warm or boil to dissolve. Add 1 gram of carbolic acid dissolved in a little water. Filter through a hot filter, changing the filter when clogged. Evaporate the filtrate until it is about 80 c.c., then add 20 c.c. of glycerine. The mixture is best kept in a bottle with a glass cap.

When mounting in it, let a section soak for a minute in glycerine, then in a drop of Farrant's solution on the slide. Before cementing, the solution should be allowed to become firm at the edges.

9. Colophonium (rosin). Dissolve in benzine or in chloroform. It does not turn yellow on keeping as Canada balsam is apt to do.

10. Dammar : this may be dissolved in a mixture of equal quantities of turpentine and benzine.

11. Canada Balsam. Put some Canada balsam into a capsule, and place it in the warm chamber at about $65^{\circ} \mathrm{C}$. for twenty-four hours to drive off all water. Let it cool, and dissolve it in a sufficient quantity of xylol to make a fairly fluid solution; it should be kept in a bottle with a ground-glass cap fitting over the neck of the bottle, instead of a stopper, as the stopper is apt to become fixed in the bottle; if any balsam is allowed to get on the neck of the bottle wet it with xylol and rub it off with a cloth.

\section{Monobromide of naphthalene.}




\section{Treatment with Silver Nitrate and Gold ChLORIDE.}

\section{Silver Nitrate.}

Nitrate of silver is chiefly used (1) to make evident the limits of cells especially of flat cells arranged in a single layer, (2) to show cell-spaces and by staining all the elements of a tissue except its cells (negative image).

Since proteids and sodium chloride give rise to a precipitate with nitrate of silver, these as a rule should be washed away before the tissue is placed in the silver solution. This is perhaps best done with a $\cdot 75$ p.c. solution of sodium sulphate or potassium nitrate. The washing should in all cases be carried out quickly. If distilled water is used it should be applied for a few seconds only, since it causes rapid swelling and disintegration. In some cases good results can be obtained by treating the tissue straightway with silver nitrate (cp. p. 72 , tendon; p. 108 § 2, nerve fibres).

To bring out the outlines of superficial epithelioid cells a very brief treatment- $\frac{1}{2}$ to 2 minutes-with $\cdot 2$ to $\cdot 5$ p.c. solution of nitrate of silver is sufficient. When it is required to bring out such cells on one side of a membrane only, the membrane should be pinned out with hedgehog quills, or stretched between two rings of gutta-percha, and the surface gently brushed with the silver solution. When it is required to show the lymphatics of a tissue which is covered with epithelioid cells, such as the diaphragm, it is best to brush or scrape away the surface cells before or whilst it is placed in nitrate of silver.

After treatment with silver nitrate the tissue should be washed with distilled water; it may then be left for $\mathbf{5}$ minutes in a gentle stream of water from a tap.

When the excess of nitrate of silver has been washed away the tissue is exposed to sunlight or to light as bright as possible in either (1) water, (2) acetic acid 1 p.c.; when much white 
fibrous tissue is present, as in tendons, this is not advantageous, since it causes too great a swelling of the fibres. (3) 30 to 50 p.c. alcohol. This is used when it is feared that the fluids (1) and (2) may cause too much alteration in some constituents of the tissue (e.g. in the kidney).

The reduction of the silver can in all cases be hastened by warming the tissue to about $40^{\circ} \mathrm{C}$. whilst it is exposed to light. In bright sunlight the outlines of surface epithelioid cells of a membrane such as the cisterna lymphatica magna of a frog will be evident in 5 to 10 minutes. In most cases, however, little or no harm is done by leaving the tissue exposed for a day. On dull cloudy days this time at least will be necessary, but on such days it is best to expose the tissues to the electric light. A preliminary examination in water should be made as soon as the first tinge of brown appears, to see if the reduction is sufficient. A brown tinge in the fluid indicates that the tissue has not been properly washed after treatment with the nitrate of silver. Until the reduction of silver is complete the tissue should not be touched with metal forceps, scissors, \&c.

As soon as the tissue is sufficiently stained it should be mounted. It is usually best to treat the tissue with alcohol, with clove oil, and to mount it in Canada balsam, since the further reduction of silver is much slower in Canada balsam than in glycerine. This further reduction is greatly retarded by gently shaking the tissue for a few minutes in 2 to 10 p.c. solution of sodium hyposulphite; the sodium hyposulphite must be thoroughly washed out with water before mounting.

A specimen which has become too dark may be decolourized to any extent desired by a 5 to 10 p.c. solution of potassium cyanide, or more slowly by sodium hyposulphite.

In order to preserve the elements of a tissue in a more normal manner than is done by nitrate of silver alone, the action of osmic acid may be combined with that of nitrate of silver (cp. p. 191, lung). The tissue is placed in 5 p.c. osmic acid for 5 to 10 minutes, well washed with water, and then treated with nitrate of silver; or a mixture of equal volumes of 1 p.c. osmic acid and 1 p.c. silver nitrate is at once applied. Further, the tissue after treatment with silver nitrate may be placed 
for 5 to 10 minutes in osmic acid, well washed, and exposed to light.

Instead of silver nitrate, the following are sometimes used : (a) silver lactate, acetate and citrate ; 1 drop of 1 p.c. solution of the acid being added to 1 c.c. of the 5 p.c. solution of the salt; (b) ammonia is added drop by drop to 1 p.c. silver nitrate until the first formed precipitate is re-dissolved; distilled water is then added to make a 5 or 25 p.c. solution of silver nitrate; (c) 1 p.c. largin or other organic silver compound.

The nuclei of a tissue which has been treated with nitrate of silver, provided the treatment has not been too long, may be stained with any nuclear stain.

Nitrate of silver is sometimes applied in the solid, as lunar caustic, but their results are not very satisfactory.

References to the use of nitrate of silver in the text, besides those mentioned above, are : epithelium of vein, p. 134 ; injection of blood vessels generally, p. 136, of spleen, p. 154, of kidney, p. 200 ; serous membrane, lymphatics, and diaphragm, pp. 143-145.

\section{Gold Chloride.}

The tissue is usually treated with gold chloride immediately after the death of the animal, but according to Drasch it is best to leave the animal for 12 to 24 hours after death at about $3^{\circ} \mathrm{C}$. (method i. $b$, Auerbach's plexus, papilla foliata).

The piece of tissue should not be larger than necessary, since gold chloride does not penetrate well; it should be transferred from one fluid to another with a small brush or a glass rod.

i. The tissue is placed in 5 to 1 p.c. gold chloride for 20 minutes to an hour and washed well in water. It is then placed in

a. water acidulated with acetic acid (about 1 drop of acetic acid to 50 c.c. of water), and exposed to light.

The success of this and of other methods in which the tissue is exposed to the light depends upon exposure to bright sunlight. On cloudy days, the electric light should be used. The method gives good results with the cornea (cp. pp. 72, 210). 
or b. 25 p.c. formic acid in the dark, i.e. 25 c.c. formic acid, of sp. gr. 1.12 and 75 c.c. water (cp. p. 119, septum auricularum; p. 120, Auerbach's plexus ; p. 128, end-plates of snake)

or c. in distilled water for 6 to 20 hours until it is of a steelgrey colour. It is then warmed at $40^{\circ}$ to $50^{\circ} \mathrm{C}$. in a strong solution of tartaric acid until it becomes dark; this may take five or ten minutes only, or an hour or two (cp. p. 73)

or $d$. an aqueous solution containing 1 p.c. formic acid and 1 p.c. alcohol (used for the cochlea).

ii. The tissue is placed in a mixture of 4 parts of 1 p.c. gold chloride, and 1 part of formic acid, which has been boiled and cooled.

The tissue is either exposed to light in dilute acetic acid, or in 20 p.c. formic acid (Ranvier).

iii. The tissue is placed for about 5 minutes in fresh lemon juice which has been filtered through flannel. It is rinsed with water, treated with gold chloride as in i., washed with water, and either exposed to light in acidulated water, or kept in the dark in 20 p.c. formic acid (Ranvier).

iv. $a$. The tissue is placed in 50 p.c. or undiluted formic acid for a few minutes until it is fairly transparent; then in 1 p.c. gold chloride for 20 to 30 minutes ; it is washed well with water, placed for a day in 50 p.c. formic acid in the dark-the acid being renewed at the end of the first hour-and in undiluted formic acid for a day, to decolourize it (Löwit). The strength of the formic acid before and immediately after gold chloride does not appear to be of much consequence (cp. p. 127, endplates, rat).

b. In the preceding method, 25 p.c. formic may be used before and after this gold chloride; the tissue is then left for a day in 50 p.c. formic acid, and for two to three weeks in glycerine containing 20 p.c. formic acid.

v. The tissue is placed in 5 p.c. arsenic acid for about 15 minutes ; in 5 p.c. chloride of gold and potassium for half-anhour, washed and exposed to light in 1 p.c. arsenic acid for a day, 
changing the fluid if it becomes violet. (Golgi. Nerve-endings in muscle and tendon.) The specimen is perhaps best mounted in 1 p.c. arsenic acid, but it may be mounted in glycerine.

Gold chloride is chiefly used for nerve-endings in the cornea, in muscle and in skin.

Cornea : strong acid should not be used; methods i. $\alpha$, i. $c$, iii. give good results; the cornea may be either mounted at once in formic glycerine, or hardened in alcohol and cut.

Muscle. Methods iv. and v. give the most constant results. If the muscle is to be teased, it is perhaps best to cut out a small piece with scissors, and to tease it with glass or platinum needles whilst it is in the gold chloride. Whole muscles treated by the formic acid method can be squeezed between slides in formic glycerine, and teased out in this, or sections may be cut with the freezing microtome. It is not as a rule advisable to pass the muscle through alcohol or to mount in balsam, since this causes too much shrinking.

Skin is generally best treated by the formic acid method; using 25 p.c. formic acid after the gold chloride, thoroughly washing, hardening in alcohol and cutting sections (cp. p. 212, nose of mole). If the epidermis is not too thick, methods i. $b$ and iii. may be used.

Gold chloride is also used to colour cells (cp. p. 66, cartilage ; p. 72 , cornea). 


\section{Treatment of Living Tissues with Methylene Blue.}

A dilute solution of methylene blue applied to a living tissue, exposed to the air, stains for a time nerve-endings and nervefibrils without staining other structures (except some connectivetissue cells, leucocytes and nuclei). The maximum stain is in about half-an-hour, but it varies in different tissues and in different circumstances. Then the nerve-endings begin to decolourize, and the medullated nerve fibres and other structures begin to stain.

For the tissues of cold-blooded animals, if sufficiently thin to be observed without cutting sections, the method given in the text, p. 125, is perhaps the best. The same method may be employed for sections of tissues which are sufficiently firm to be cut free-hand in the fresh state.

When the tissue is not exposed to air, the nerve-endings still take up methylene blue, but decolourize it ; the colour returning on exposure to air. Thus the fluid may be injected into the body, and this is generally the best method in the warm-blooded animal. The injection may be made in either of the following ways in an anæsthetized animal :-

(a) A 1 p.c. solution of methylene blue in normal salt solution is injected into a blood vessel until the skin in an exposed part, such as the ear, is light blue. The animal is then left for half-an-hour to an hour, bled, the tissue to be investigated cut out, moistened with a normal fluid, and exposed to air.

(b) Injections of methylene blue are made at intervals of 15 minutes until the animal dies.

(c) The animal is bled to death, 1 p.c. methylene blue injected into an artery supplying the part to be investigated.

The specimen when covered with a cover-slip rapidly loses its tint, so that for examination with a high power it is generally

L. 
necessary to fix the stain. None of the fixing agents however are entirely satisfactory. The time of stay of the tissue in the reagents varies with its size, and to some extent with the kind of tissue.

The two principal methods are given in the text (p. 127).

With regard to these methods :-

(a) is used for tissues which it is not necessary to cut; the tissue is left in the picrate of ammonia for 1 hour to half-a-day, and usually for some hours in the mixture of picrate of ammonia and glycerine before mounting in this fluid;

(b) is used both for fixing thin tissues and sections, and for fixing tissues to be cut. The molybdate of ammonia is dissolved by warming in water ; a precipitate forms on adding the hydrochloric acid, but it dissolves on shaking.

The tissue is left in the ammonium picrate for $\frac{1}{4}$ to 1 hour (until the nerve-endings become violet); in the ammonium molybdate solution for one to several hours. If the tissue is to be cut, it is not advantageous to leave it long in the ammonium molybdate solution, since this has a macerating action; the tissue is washed with water (about half-an-hour), placed in 75 p.c. and in 90 p.c. alcohol for 10 minutes, in absolute alcohol for half-anhour ; in xylol for 10 minutes and in paraffin for $\frac{1}{2}$ to 1 hour.

The sections may be stained with alum carmine.

In place of 20 c.c. of water in the molybdate solution, 10 c.c. of water and 10 c.c. of osmic acid, 5 p.c., may be taken. The stay of the tissue in this fluid may be 4 to 12 hours.

The picrate of ammonia method was introduced by Dogiel, the molybdate of ammonia method by Bethe. There are numerous slight modifications of the principal methods. Thus

(a) The ammonium molybdate mixture is made up with 10 c.c. instead of 20 c.c. of water. This is cooled to about $0^{\circ} \mathrm{C}$., and in it the tissue is placed as soon as it is stained, and left for 4 to 6 hours. It is then washed with distilled water, dehydrated with absolute alcohol, imbedded and cut;

$(\beta)$ The ammonium molybdate mixture is made as above, except that the hydrochloric acid is omitted, and $\cdot 5$ c.c. of peroxide 
of hydrogen added just before use. This has been recommended for invertebrate tissues.

Dogiel recommends for the nerve-endings in Herbst corpuscles the following methods: (i) Sections of the waxy edge of the beak or palate of a young duck are cut free-hand; they are moistened with $\frac{2}{15}$ to $\frac{1}{8}$ p.c. methylene blue in salt solution; covered up and warmed at $35^{\circ} \mathrm{C}$. for 5 to 10 minutes; then examined; if the nerve-endings in the Herbst corpuscles are not stained, a drop of methylene blue is added, and the preparation warmed for a few minutes more. If the sections are not then stained, others are made. (ii) Warm $\cdot 25$ to $\cdot 5$ p.c. methylene blue is injected into the circulation, in 20 to 30 minutes the pieces of tissue are exposed to air, placed in ammonium picrate solution for $\frac{1}{2}$ to 1 hour, in 5 to 10 p.c. ammonium molybdate in water for 12 to 18 hours, then washed, dehydrated and cut.

Neutral red can be used like methylene blue (except for fixation), i.e. for injection into blood vessels or adding a tissue exposed to air ; in the latter case it must be very dilute to avoid staining the nucleus; granules only should be stained.

Most granules in mammals are stained orange red. neutral water, rod; in weak alkali, yellow orange.) 


\section{Methods with REgard to some Special Chemical Constituents.}

\section{IRON.}

The reactions mentioned below are given by inorganic salts of iron, and probably by certain simple organic iron compounds.

The tissue to be examined is best hardened in alcohol, but various other hardening agents may be used. The sections after treatment are washed with water, passed through alcohol, clove oil, and mounted in balsam.

a. Prussian blue method. A section is placed in a mixture containing 1 p.c. hydrochloric acid and 1 p.c. potassic ferrocyanide for 5 to 10 minutes.

Another section is warmed to about $50^{\circ} \mathrm{C}$. in the same fluid for a few minutes (cp. p. 184, liver).

The presence of iron will be shown by blue particles, or by a diffuse blue stain.

b. Hæmatoxylin method. A section is placed for a few minutes in a 5 p.c. solution of hæmatoxylin in distilled water (a brownish-yellow solution). The parts containing inorganic iron salts stain blue-black or blue-violet; elsewhere the colour is reddish brown, and this tends to hide the iron stain; it is removed by placing the sections for $\frac{1}{2}$ to 1 hour in a mixture of equal parts of absolute alcohol and ether. According to Macallum inorganic iron salts only are stained by this method.

Ammonium sulphide in dilute glycerine is also used, and the sections mounted in dilute glycerine, but methods $a$ and $b$ are preferable.

The more complex iron compounds do not give the iron reactions; in order to detect the presence of these, the compound must be split up. This may be done by treating sections with a 95 p.c. alcohol containing 4 p.c. sulphuric acid in the warm, and taking a section from time to time ( 1 to 24 hours), washing the 
acid out with alcohol, and testing for iron. If left too long, the iron salts set free are dissolved.

The organic iron compounds are slowly decomposed by ammonium hydrogen sulphide (hydrogen sulphide in ammonia sp. gr. 96). Sections or small teased pieces are treated on a slide with a drop of dilute glycerine and two drops of ammonium sulphide solution, covered, kept in a moist chamber at about $55^{\circ} \mathrm{C}$. for two days to a fortnight (Macallum).

Inorganic iron salts may be extracted by warming sections for $\frac{1}{2}$ to 1 hour at $50^{\circ}$ to $60^{\circ} \mathrm{C}$. in 95 p.c. alcohol containing 10 p.c. of strong hydrochloric acid (25 p.c. solution). Some splitting up of organic iron compounds no doubt occurs at the same time.

\section{Phosphorus.}

1 gram of molybdic acid is dissolved in 4 grams of strong ammonia; to this solution 15 grams of nitric acid sp. gr. 1·12 are slowly added. The fluid is allowed to stand, and decanted.

The tissue is hardened in alcohol. Sections are placed in the nitric-molybdate solution, and best at about $34^{\circ} \mathrm{C}$. After 10 minutes, a section is rinsed in water, placed in 2 p.c. phenylhydrazin hydrochloride for a minute or two, washed with distilled water, dehydrated, cleared and mounted in balsam. Other sections are taken from the nitric-molybdate solution at late periods up to a day and similarly treated. Inorganic phosphates are first affected, then lecithin, then organic phosphorus compounds. The presence of phosphorus (orthophosphates) is shown by a dark green coloration (Macallum).

Most of the inorganic phosphates may be extracted by treating with 20 p.c. acetic acid; lecithin by repeated extraction with boiling ethyl alcohol.

Fat.

Fat in a tissue is best stained by placing the tissue fresh in osmic acid for a day, some fatty granules are only stained yellow-brown by osmic acid; this may perhaps be due to their containing very little olein or oleic acid, for osmic acid is said not to be reduced by palmitin and stearin. Fat after treatment 
with osmic acid is not soluble in alcohol (oleic acid may be to a slight extent), and as the yellow-brown granules spoken of above become black in alcohol, the tissue may be kept in alcohol, best 75 to 80 p.c., for some days before being cut. It is safest to cut the tissue frozen; but it may be imbedded in paraffin and cut, provided it has been kept some time in alcohol. Fat treated with osmic acid is soluble in turpentine, less soluble in xylol, still less in benzin, clove oil, chloroform : the solubility in these reagents decreases as the tissue is kept in alcohol.

Fat globules in sections of tissues which have been hardened in Müller's fluid, formol or other aqueous solution, and which have not been treated with alcohol, may be stained by placing them in 1 p.c. osmic acid for some hours to a day, or in Marchi's fluid in the warm. For staining with Sudan IIr, and quinoline blue, cp. p. 80.

\section{MUCIN.}

Whether mucin stains or not depends upon the hardening agent used, and upon the way in which the stain is applied; speaking generally mucin is not stained by acid coal-tar colours, and is stained by basic coal-tar colours (cp. p. 162), but none of these is a specific stain for mucin.

The following methods may be used :

Tissue hardened in alcohol. Sections are fixed on the coverslip, passed down to water, placed for about a minute in polychromatic methylene blue, washed in acidified water, placed for about 30 secs. in 10 p.c. potassium bichromate, passed quickly through absolute alcohol to bergamot oil, then mounted (Unna).

Tissue hardened in mercuric chloride. Sections are fixed to the slide, passed down to water, left 3 to 5 minutes in 5 p.c. aqueous mercuric chloride, placed in weak thionin solution 10 to 15 minutes, passed through alcohols, and cedar-wood oil, to balsam (Hoyer). 


\section{Pigment.}

Destruction of pigment. Put the hardened piece of tissue in a mixture of

$\begin{array}{lr}1 \text { p.c. chromic acid } & 70 \text { c.c. } \\ \text { Nitric acid } & 3 \text { c.c. } \\ \text { Water } & 200 \text { c.c. }\end{array}$

for $\frac{1}{2}$ a day to 2 days, and wash out well with water (both best done in dark). Sections to be similarly treated should be stuck to the slide with albumin.

Glycogen, cp. p. 182. In tissues hardened in osmic acid, glycogen is not extracted by water, or very incompletely; it may be extracted by treating the sections with a diastatic ferment.

Fibris. The tissue is hardened in alcohol. A section is placed for about 10 minutes in a strong solution of gentian-violet in aniline, washed in water and transferred to a slide. Here it is gently pressed with blotting-paper, covered with iodine in potassic iodide (p. 298) for two or three minutes; blotted; decolourized with aniline 2 pts. and xylol 1 pt.; blotted, the aniline xylol washed out with xylol; mounted in balsam.

Chitin in tissues becomes hard in the process of imbedding in paraffin; in order to soften it place the tissue $\frac{1}{2}$ to 1 day in the following mixture :

$\begin{array}{ll}\text { Nitric acid } & 16 \text { parts. } \\ 5 \text { p.c. chromic acid } & 16 ", \\ \mathrm{HgCl}_{2} \text { sat. sol. in } 60 \text { p.c. alcohol } & 24 ", \\ \text { Sat. aq. sol. picric acid } & 12 ", \\ \text { Absolute alcohol } & 42 ",\end{array}$

Amyloid substance. The tissue is best hardened in alcohol. Amongst other methods, the sections may be stained with methyl-violet, washed in dilute hydrochloric acid and mounted in glycerine. The amyloid substance stains a reddish tint. 


\section{InJECTION Mass.}

$\alpha$. Place 20 grms. of gelatine in cold water until it is well swollen, then pour off the water, and place the gelatine in a water bath at about $40^{\circ} \mathrm{C}$. (covering it up to prevent evaporation) until it forms a fluid mass.

Rub 8 grms. of carmine into a paste with water, add about 10 grms. of strong ammonia and mix well, then add about 100 c.c. of water (or 2 p.c. chloral hydrate if the mass is to be kept), shake well and filter; if a suction-pump is not used it will probably take 10 to 20 hours to filter. Warm the filtrate to about $40^{\circ} \mathrm{C}$. Pour it then slowly into the gelatine kept warm over a water bath, stirring continuously; when the fluids are well mixed, add gradually first strong acetic acid and then acetic acid diluted 10 times, stirring as before, until the smell of ammonia gives way to a faint smell of acetic acid. Strain through new flannel washed with warm water.

b. Prepare gelatine as in $(a)$. Take 100 c.c. of a 2 p.c. solution of Berlin blue warmed to $40^{\circ} \mathrm{C}$. and pour it slowly into the gelatine kept warm on a water bath, stirring continuously.

c. 10 grams of gelatine are placed in 40 c.c. of water, allowed to swell, then warmed to solution; to this 10 c.c. of a solution of bichromate of potash, saturated in the cold, are added. The mixture is warmed to about $90^{\circ} \mathrm{C}$; ; and to it is added slowly, stirring the while, 10 c.c. of a neutral lead acetate saturated in the cold and also at about $90^{\circ} \mathrm{C}$. This should be made as required.

The gelatine mixtures must of course be injected warm; the blood should be washed out of the organ to be injected with warm salt solution; during the injection warm salt solution should be poured over the organ or the whole animal should be immersed in warm salt solution. 
Just before the end of the injection, the vein or veins should be tied, and the pressure of injection kept up for a few minutes, the arteries tied, and the injected organs placed in cooled alcohol (about 80 p.c.); the vessel is kept cool either by surrounding with ice, or putting under a stream of water, for half-an-hour.

Injections are best made by using a pressure apparatus, in which the pressure is kept constant and the fluids warm, but very good injections can be made by hand with an injection syringe.

d. Injections which require a small amount of fluid only may be made with the following mixture; this ean be injected cold.

The white of an egg is cut up and beaten, small pieces of camphor are added, and it is filtered through a dry filter ( $\frac{1}{2}$ to 1 day). A stick of Indian-or Japanese or Chinese-ink is rubbed up with a few drops of the egg-white on a ground glass plate, till a drop on a thin filter paper does not make a grey ring round a central black mass. This is put aside and more prepared and added to it, and so on till sufficient of the mixture has been obtained; it should not be too thick. In the preparation care must be taken not to let the egg-white dry on the Indian ink.

The tissues ean be preserved in most hardening agents ; but formol by itself is said not to give good results.

e. A 2 p.c. aqueous solution of soluble Prussian blue may be used for the injection of lymphaties, or injection of blood vessels when it is only required to determine their general distribution. The tissue is preserved in alcohol. 


\section{Destruction of Brain or of Brain and Spinal Cord (Pithing) in the Frog.}

When killing a frog for physiological or microscopical purposes it is sometimes advisable to remove as much blood as possible from the body and sometimes to lose as little blood as possible.

1. Pithing and bleeding. a. Cut off the head or the upper jaw with the skull with one stroke of strong scissors, thrust a seeker down the spinal canal; squeeze the body upward gently to get rid of the blood.

b. Have ready a nearly straight seeker. Hold the frog in a cloth, with the legs between the third and fourth fingers; and depress the head with the fore-finger. Thrust the point of a scalpel into the depression immediately behind the skull and so cut across the medulla. At once push the seeker into the brain and destroy it; and destroy similarly the spinal cord. Blood will flow copiously from the cut. Place the frog in a stream of water from a tap, and gently squeeze the body upwards, till the bleeding ceuses.

2. Pithing without bleeding. Have ready some small fragments of cotton-wool, and fine-pointed forceps. Proceed as in $\S 1, b$, but as soon as the brain and cord are destroyed, thrust one or more of the pledgets of wool into the cut to stop the bleeding.

3. Destruction of the brain only. Proceed as in $\S 2$, but destroy the brain only.

Before killing the frog in any of the preceding ways it may be anæsthetized with ether or chloroform. Take 100 c.c. of water, add 2 c.c. of ether or 2 c.c. of chloroform, shake well ; in this place the frog; the limbs will gradually relax, and it will 
become completely insensible. The skin may then be cut through at the junction of the skull and spinal column; the muscles behind the occipital bone cut through, the medulla exposed, before the brain or the brain and spinal cord is destroyed.

A frog, after the brain has been destroyed, may be curarized by injecting one drop of a 5 p.c. solution of curari under the skin of the back. More than is necessary should not be given if the circulation is to be observed. In the case of a newt, after the brain has been destroyed, two drops of 1 p.c. curari may be injected in the abdominal cavity with a Pravatz syringe.

The following rough table may be useful to the student.

1 litre

1 minim

1 pint

1 gallon

1 fluid ounce

1 sq. inch

1 cubic inch

1 gram

1 kilogram

1 grain

1 drachm

$1 \mathrm{oz}$. Troy

$1 \mathrm{oz}$. Avoird.

$1 \mathrm{lb}$. Avoird.

1 centimetre

1 metre

1 inch

1 foot

1 yard

$\frac{1}{1000}$ inch

$\frac{1}{200}$ inch

$\frac{1}{200}$ inch
$=1$ cubic decimetre $=1 \frac{4}{5}$ pints nearly.

$=\cdot 059$ cubic centimetre.

$=0.57$ litre.

$=4.54$ litres.

$=\frac{1}{20}$ pint.

$=6.45 \mathrm{sq}$. centimetres.

$=16.39$ cubic centimetres.

$=15 \cdot 43$ grains.

$=35 \cdot 27 \mathrm{oz}$. Avoird. $=2 \cdot 2 \mathrm{lbss}$.

$=65$ milligrams.

$=3.88$ grams.

$=31 \cdot 1$ grams.

$=28.35$ grams.

$=0.45$ kilogram.

$=\frac{2}{5}$ inch.

$=1$ yard $3 \frac{1}{3}$ inches.

$=2.54$ centimetres.

$=3.05$ decimetres.

$=0.91$ metre.

$=\frac{1}{\frac{1}{40}}$ millimetre about.

$=12 \cdot 7 \mu$.

$=10 \cdot 16 \mu$. 

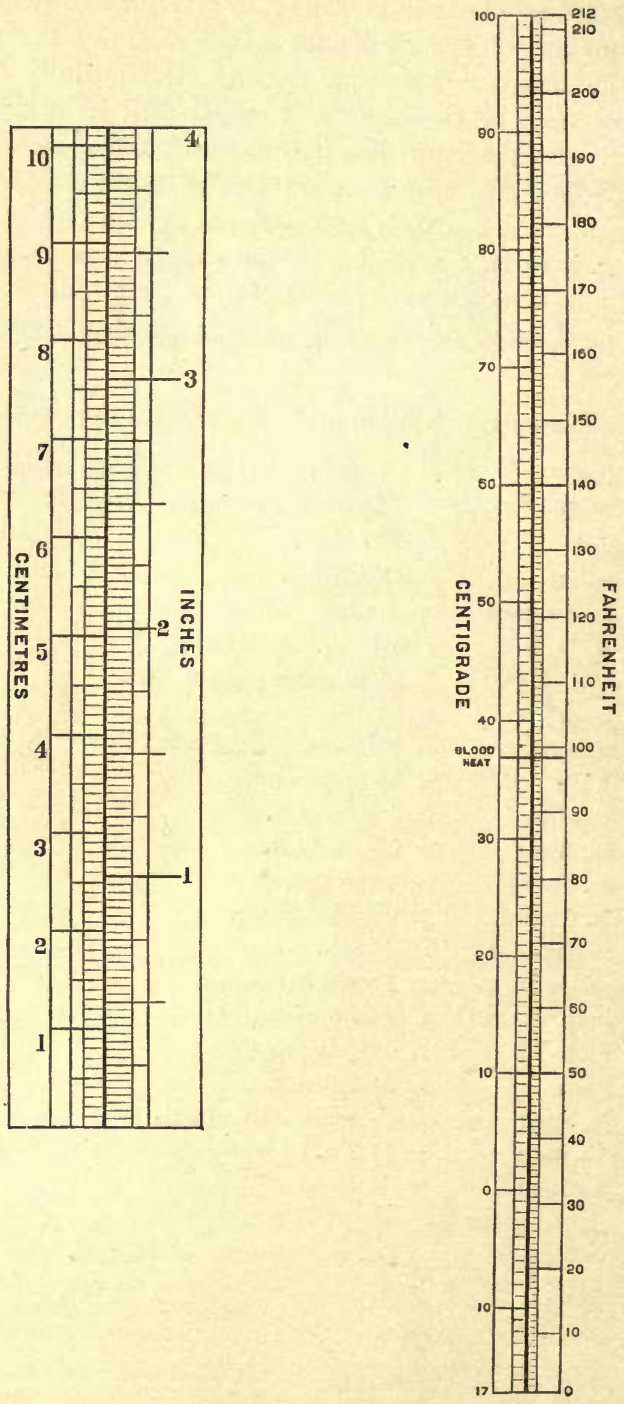


\section{INDEX.}

Abbe's drawing camera, 34 Achromatic objectives, 8 Acid magenta (acid fuchsin) and picric acid, for staining, 310

Albumin fixative, 313

Alcohol, as dissociating fluid, 293; as a hardening agent, 296; in combination with, chromic acid, 299; mercuric chloride, 301 ; chromic acid and formol, 301 ; chloroform, 302

Alum carmine, 308

Amœboid movements of blood corpuscles, 12

Amyloid substance in tissue, treatment of, 327

Anethol, 306

Angle of aperture, 8

Aniline blue and orange $G$, for staining, 311

Anterior commissure, 270

Apochromatic objectives, 8

Apparatus : camera lucida, Zeiss', 30 ; Schröder's compound, 30 ; ocular micrometer, 33 ; Abbe's drawing camera, 34; Edinger's projection, 34 ; microtome, ice and salt freezing, 50 ; ether freezing, 52; rocking, 55

Areolar tissue, moist film of, 73 ; basophil cells of, 75 ; in the frog, 75

Arteries, structure of, 133-5

Auerbach's plexus, nerve cells of, 120

Basilar membrane, 230

Basophil cells, in blood, 18; connective tissue, 75; frog's areolar tissue, 75 ; substance, methods of staining in nerve cells, 117, 244

Bechterew's nucleus, 259
Bladder (frog), 94 ; (dog), 198-9

Blind spot, section of, 226

Blood, preparation of a dry film, 16 ; circulation of (frog), 137-8; (newt), 140-1; in lung (toad), 191

Blood corpuscles: frog's, structure of colourless corpuscles, 11 ; red corpuscles, 11 ; amœboid movements, 12 ; staining with eosin and methylene blue, 18; man's, structure, 21 ; fixing by beat before staining (method), 24 ; counting, 25, 26, 29; fixing wet films, 28; staining after fixing, 28

Blood platelets, amphibian, 18; human, 24

Blood vessels, 197-8; structure, 133-7; injection with silver nitrate in frog, 135-6; of spleen, injection, 154

Bone, structure of, 83-5; ossification, 86 ; decalcification and fixing (method), 90

Borax carmine (Grenacher), 309

Bourne, picrocarmine, 308

Brain, cortex, 272-4 ; preparation of, 275

Bronchioles, 188

Brunner's glands, 177, 179

Burdach's column, 235

Calleja's staining fluid, 311

Camera lucida, Schröder's compound, 30 ; Zeiss', 30

Canada balsam, mounting in, 37, 315

Cardiac muscle, 95

Carmalum (Mayer), 308

Carmine stain, 63, 311

Cartilage, hyaline, 64; fibrocartilage, 81 ; elastic, 82

Cedar-wood oil, for clearing, $53 \mathrm{n}$., 
59 ; in imbedding in celloidin, 306

Cell-division, 286-8

Celloidin, imbedding and cutting tissues in, 303-6

Central nervous system, hardening and staining, 243-4

Centrosomes, 209

Cerebellum, 273, 274

Cerebrum, 272

Chenzinski's eosin and methylene blue, 28

Chironomus, larva of, preparation of section, $289-90$

Chitin, in tissues, treatment, 327

Chloroform and alcohol, for hardening tissues, 302

Chromatolysis, 242

Chrome alum and acetate of copper, for hardening tissues, 301

Chromic acid, as a hardening agent, 297; in combination with alcohol, 299 ; nitric acid, 299 ; osmic acids, 299 ; platinum chloride, 299; alcohol and formol, 301

Ciliary muscle, 221

Ciliated cells, 92, 93

Circulation of blood, frog, 137-8; newt, 140-1, 142; in lung (frog or toad), 191

Clarke's nucleus, 237

Clearing agents, 37, 59 ; cedarwood oil, $53 \mathrm{n}$., 59 ; turpentine, 53, 59 ; xylol, 53 n., 59 ; clove oil, 59 ; aniline oil, 117 ; cajeput oil, 244 ; for specimens in celloidin, 305

Cochlea, 230-2

Collodion, for fixing, 313-4

Colophonium, for mounting, 315

Colourless corpuscles, of frog, 11 ; of $\operatorname{man}, 22$

Compensating eyepieces, 8

Connective tissue, structure of, 70 ; fixing moist film, 74 ; dry film, 75

Copper salts for hardening tissues, sulphate of, and potassium bichromate, 300 ; acetate of, and chrome alum, 301
Cornea, staining with gold chloride, 72,320 ; cells, 72 ; nerves, 111,210 ; structure, 222

Corpora lutea, 276-7

" quadrigemina, 264-8

" mammillaria, 267-8

" geniculata, 267-8

Corti, organ of, 230,231

Costal cartilage, $67,68,76$

Cover-slip, thickness, 6 ; measure, 7,10 ; cleaning, $16 \mathrm{n}$.

Crusta petrosa, 88

Cumulus proligerus, 278

Dammar, for mounting, 315

Deiter's nucleus, 258

Delafield's hæmatoxylin, $36 \mathrm{n}$., $62,63,307$

Demilune cells, 159

Dentine, 87-8

Dermis, 207-8

Diaphragm, injection of lymphatics, 148-9

Dissociating fluids, 292-3

Dogiel, methylene-blue method for retina, 227-8; for Herbst corpuscles, 323

Ear, of mouse, cartilage, 68,69 ; internal, 229-31

Egg-albumin (for fixing sections), 46

Ehrlich's acid hæmatoxylin, $36 \mathrm{n}$., 307; 'triacid' staining fluid, 28

Ehrlich-Biondi stain, 42, 310

Elastic tissue, in the mesentery, 70 ; structure, 70 ; in tendon and in connective tissue, 79 ; staining, 80, 312; elastic cartilage, 82; in blood vessels, 135 ; in lung, 188, 190

Enamel of teeth, 88

End-brush, 125; -plates, 127, 128 Eosin, staining blood with, 17, 18,28 ; and methylene blue, $18,28,117$; and hematoxylin, 40 ; staining sections with, 40 , 117 ; staining tissue in bulk, 62,63

Epidermis, 307; nerve endings in, 212 
Epididymis, 280, 281

Epithelioid cells, of tendon, 72 ; of nerve (frog), 110; of veins, 134 ; of serous membranes and lymphatic spaces, 143-5; of capsule of kidney, 200

Erectile tissue (dog), 204

Erlicki's fluid, 300

Erythrosin (Held), 310

Eye, mammal, 221-4-6; newt, 224-5, 227; frog's, 225

Fallopian tubes, 280, 284

Farrant's solution, for mounting, 315

Fat-cells, from omentum, 77 ; subcutaneous tissue, 78; staining of fat, 325-6

Fat tissue, prep. and staining, 79-80

Fibrin, treatment of, in tissue, 327

Fibro-cartilage, 81

Fillet, 253

Films, dry film of blood, 16; staining with eosin, 17; and methylene blue, 18; fixing wet films of blood and staining, 28 ; moist film of tissue, 73 , fixing and staining, 74; dry film of tissue, 75

Fixatives, 313

Flattening, folded sections, 45

Flemming's mixture, for hardening, 299

Formol, for hardening tissues, 297 ; in combination with alcohol and chromic acid, 301; Müller's fluid, 330

Fovea centralis, section of, 226

Freezing mixture, 50

Fresh tissues, method of examining, 65, 291

Frog, destruction of brain, pithing, anæsthetics, curari, 330-1

Funiculus cuneatus, 251

Funiculus gracilis, 250

Ganglia, 116-21; isolation of cells, 122 ; methods of hardening, 123
Gastric glands, 166-171

Gentian violet, 285, 289

Glycerine, mounting in, 39, 314; and gum, 315; -jelly, mounting in, 40,314

Glycogen, appearance and staining in liver, 182-3; feeding rabbit for, 185; extraction from tissues, 327

Gold chloride, treatment of tissues (methods), 318-20

Golgi's chromate of silver method (spinal cord) modified by $\mathrm{Ra}$ món y Cajal, 240, 247; modified by Kolossow for sympathetic ganglia in adults, 123-4

Goll's column, 235

Gower's hæmacytometer, 27

Graafian follicles, 276, 277-8

Grenacher, borax carmine, 309

Gum solution, for freezing microtome, 49

Gum and glycerine, for mounting, 315

Hæmalum, staining with, 63, 307 ; preparation, 307

Hæmatoblasts, 86, 89

Hæmatoxylin, staining sections with, 35-7; and eosin, staining blood corpuscles, 28; staining sections, 40 ; staining in bulk, 62,63 ; rubin $\mathrm{S}$ staining and picric acid, 41 ; iron hæmatoxylin, 287, 308; Ehrlich's acid, Delafield's, hæmalum, 307

Hairs, 208-9; tactile, 212-3

Hanging drop, 12

Hardening of tissues, directions for rapid, 61

Hayem's fluid, 25

Heller-Robertson, method of staining medullated fibres, 239,247

Homogeneous oil-immersion objectives, 8

Huyghenian eyepieces, 8

Hyaline cartilage, 64-69; fixing agents for, $68 \mathrm{n}$.; transition to, 81,82 
Hyaline corpuscles (frog's blood), 11

Imbedding in paraffin, 53, 55; orienting, 57 ; superficial, 58 ; method for delicate tissues, 59

Inflamed mesentery, preservation of, 141

Inflammation, changes in, 13840

Injection mass, 328-9

Internal corpus geniculatum, 267

Interpeduncular ganglion, 265

Intervertebral discs, 81,89

Intestine, cement substance of muscular coats (frog), 96; small, 172 ; large, 175 ; preserving and staining, 178

Intestine and stomach (frog), after feeding with fat, 176

Iodine, solution in potassic iodide, 298

Iris, 221-2

Iron, method of detection of, $155,184,324$

Iron-hæmatoxylin (Heidenhain), 287,308

Irrigation of mounted specimen, 13

Kidney, structure, 193-8 ; isolation of tubes, 199-200; glomeruli injected with silver nitrate, 200 ; hæmoglobin menisci in the capsules, 200; ciliated funnels in the newt, 201 ; of snake, 201

Lachrymal glands, rabbit, 158

Lens, 222-3, 226-7

Lieberkühn's glands, 172, 175-6

Ligamentum nuchæ, 70; transverse section of, 78

Ligula, 255

Liver, structure, 181-4; glycogen in, 182, 184, 185; test for iron, 184 ; bile ducts, natural injection of, 185

Locus cœruleus, 261

Löffler's methylene blue, 117, 310
Lower olive, 254

Lung, 187-192 ; amphibian, 1902; circulation, 191

Lymph corpuscles, method of obtaining (frog), 12-13; sac, injection of sub-lingual (frog), 149; follicles, small intestine, 172-3

Lymphatic gland, 145-8; injection, 148; preservation, 148; spaces, treatment of epithelioid cells with nitrate of silver, 143-4

Lymphatics, origin of, 145

Lymphocytes (human), 23

Mallory, staining fluid, 248-9, 311

Malpighian corpuscles, 151

Malpighian layer, of skin, 207; of epidermis, tongue of rabbit, 216

Mammary glands, 280

Mammillo-thalamus bundle, 269

Marchi's method of staining degenerating fibres, 246

Marina's fluid for hardening tissue, 301

Marrow, white, 85, 90 ; red, 86, 89

Mayer's carmalum, 36 n., 308; hæmalum, 307

Measurement, of objects under microscope, 30

Medulla oblongata (see Spinal bulb)

Medullated fibres, staining, 245

Meissner, plexus of, 121

Mercuric chloride, as a hardening agent, 297; in combination with, Müller's fluid, 300; potassium bichromate, 300 ; alcohol, 301; picric acid, 302

Merkel's mixture, for hardening, 299

Methylene blue, staining blood corpuscles, 18; staining sections, 38, 309; staining unstriated muscle, 98 ; staining basophil substance in nervecells, 117; fixing in nerve 
endings, 127; Löfller's, 310; Nissl's, 310 ; treatment of living tissues, 321

Meynert's bundle, 270

Microscope, use of, 1-9

Microtome, ice and salt freezing, 50 ; ether freezing, 52; rocking, 55

Mid-brain, structure of, 263

Monobromide of naphthalene for mounting, 315

Mounting, in Canada balsam, 37,315 ; in glycerine, 39,314 ; in glycerine jelly, 40, 314; sections imbedded in paraffin, 44; serial stained sections, 44 ; fluids for, 313-15

Mucin, staining of, 326

Mucous cells, 159; of gastric glands, 166; of intestine, 173

Mucous glands, 158-61; variations of, 163

Mucous granules, preservation in osmic acid vapour, 162-3

Müller's fluid for hardening tissue, 300 ; in combination with formol, 300 , with mercuric chloride, 300

Muscle, cardiac, 95 ; ciliary, 221 ; nerve endings in, 125-6-7-9; spindles, 129 ; treatment with gold chloride, 320

Striated, frog's, 99-102; insect's, 102-4; examination with polarized light, 103, 106; fixing and isolating agents, 105; living fibres, 105 ; branched muscle fibres, 106; staining, 106; end plates, $127-8$

Unstriated, 94 ; isolation of, 96-7; variations in invertebrates, $97-8$; staining in sections, 98 ; nerve plexus in, 129 ; erector, of hair, 209

Mylohyoid muscle (frog), fixing methylene blue stain, 129; preparation of nerve-fibres in, 126
Nail, section of bed of, 214

Nerves, peripheral, course of, 111

Nerves-origin of cranial, 12th, 253,255 ; 10th, 9th, 254-5; 8th, 256-7, 259; 7th, 257-9; 6 th, 258-9; 5th, 200, 251264 ; 4th, 263-4; 3rd, 266-7

Nerve cells, spinal ganglia, 116-7, 123; basophil granules and masses, 117; spinal cord, in, 118,119 ; spiral, auricular septum (frog), 119 ; Auerbach's plexus, 120, 123; Meissner's plexus, 121; sympathetic ganglia, 121, 123; bipolar, isolation of, 122 ; cerebrum, in, 272

Nerve endings, in muscle, striated and unstriated, 125-8; in muscle spindles, 129 ; staining of, 130-2; in tendons, 131; in stratified epithelium, 210 ; in touch corpuscles and Pacinian bodies, 211; in hairs, 212 ; in nose of mole, 212; in Grandry's and Herbst corpuscles, 212, 215, 323

Nerve-fibres:

Medullated, 107, 111; fibrillar structure, 114; neurokeratin network, 112, 114 ; regeneration, 112,113; teasing osmic acid specimens, 113 ; staining of axis cylinder, 114; the bicone in silver nitrate specimens, 114; staining medullary sheath, 239, 245; in cerebral hemisphere, 272 Non-medullated, 110, 112 ; fixing and staining, 115; treatment with methylene blue, 115

Nerve-plexus, unstriated muscle, 129

Neuro-muscular organs, 129-30

Neuro-tendinous organs, staining of nerve-endings, 131

Neuroglia stain, 247-9

Neurokeratin, 112, 114

Neutral red, methods of treating tissue with, 323 
Nissl's methylene blue, 117, 310

Nitric and chromic acids, for hardening tissue, 299

Nitric and picric acids, for hardening tissue, 302

Normal salt solutions, 66

Nose, newt, 217-19-20

Nuclear division, stages of, 286-7

Nucleus dentatus, 258

Numerical aperture, 8

Objectives, achromatic, 8 ; angle of aperture, 8 ; apochromatic, 8 ; equivalent focal distance, 8 ; homogeneous oil-immersion, 8; initial magnifying power, 8 ; numerical aperture, 8; working distance, 9

Ocular micrometer, 33

Oesophageal glands (frog's), 171

Oesophagus, structure, 168 ; hardening and staining, 171

Oil-immersion lenses, 7,9

Olfactory mucous membrane, 218-9

Optic chiasma, 270 ; tract, 268; thalamus, 270

Orange $\mathrm{G}$ and aniline blue, 310 Orbital gland (dog), 161

Orcein (for staining elastic fibres), 311 (see also Elastic tissue)

Osmic acid, as dissociating fluid, 293 ; for hardening, 289; with chromic acid, 299

Ossification, 86

Osteoblasts, 87

Osteoclasts, 87

Ovary, mammal, 276-9 ; hardening of, 284

Ovum, 277

Oxyphil granules, 17, 23, 79

Pacinian bodies, 211, 212, 214

Pal, method of staining medullated fibres, 245-6

Pancreas, 180 ; resting and active, 185

Paraffin, dissolving, from sections, 43 ; staining and mounting sections imbedded in, 43-8; imbedding in, 53,55 ; influence of melting point on section cutting, 57

Parathyroid, 205

Parenchymatous cartilage, 69

Parotid gland, 156-8

Perenyi's fluid, 299

Peritoneal surface of diaphragm, epithelioid cells, 144-5

Peyer's patch, 177, 178-9

Phosphorus, method of detecting, 325

Pia mater, 135, 233

Picric acid, staining with, after staining, 41,63 ; in combination with hæmatoxylin and rubin S, 41; with acid magenta, 310: hardening with, 298; combined with mercuric chloride, 302 ; nitric acid, 302 ; sulphuric acid, 302

Picro-carmine, staining sections with, 35-7; staining isolated cells with, 93,190 ; preparation of solutions, 308

Pigment, destruction of, 327 ; cells, frog's web, 76-7

Pithing, 330

Pituitary body, 202, 205

Platelets, frog's, 18; human, 24

Platinum chloride and chromic acid for hardening, 299

Polarized light, examination of striated muscle by, 103, 106

Pons varolii, 257-8

Potassium bichromate, for hardening, 299; and cupric sulphate, mercuric chloride, sodium sulphate, 300

Potassium hydrate for isolating cells, 94, 95, 106

Prostate gland (dog), 284

Purkinje's cells, of heart, 98 ; of cerebellum, 273, 274

Pyramids, decussation of, 240

Quinoline blue for staining fat, 80

Ramón y Cajal, treatment of retina, 227; modification of 
Golgi's chromate of silver method, 240

Red corpuscles, frog's structure, 14-15; man's structure, 21; enumeration, 25; mixing fluid, 29

Restiform body, 235

Retina, structure, 223-4 ; treatment, 227-8

Rocking microtome, 55

Saffranin, staining with, 38, 309 Salamander, cell-division in, 286-8

Salivary glands, structure, 156161 ; hardening and staining, 162

Sarcolemma, muscle, 100, 106

Sarcoplasm, muscle, 99

Sarcostyles of insect muscle, 103

Sartorius muscle (frog), 125-7

Sebaceous glands, 209

Section cutting, 55; preparation of hardened tissue for freezing, 49 ; frozen tissue, 50 ; fresh tissue, 52 ; cause of bad sections, 57; in paraffin melting at $58^{\circ} \mathrm{C} ., 57$

Semicircular canals (skate), 229 Serial sections, mounting, 44; staining on cover-slip, 46

Serous glands, structure, 156 ; varieties, 163 ; appearance on treatment with osmic acid, 163

Serous membranes, epithelioid cells, 143

Shellac, for fixing, 313

Sihler's hæmatoxylin method, 129,131

Silver nitrate, for treating tissues (method), 316-18

Skin, structure, 207-15; harden. ing, 214 ; treatment with gold chloride, 320

Sodium sulphate and potassium bichromate, for hardening tissues, 300

Sodium sulphindigotate, injection of bile ducts, 185; excretion by kidney, 200
Spermatozoa, 283, 285

Spiller's purple, 309 ; for staining fibrin, 15

Spinal bulb, structure (dog's), 253, 259,261; (man's), 250-62 : cord, structure, 233-242 ; multipolar nerve cells, 118; Golgi's treatment modified by Ramón, 240; degenerations, 241-2; demonstration of chromatolysis, 242 ; hardening and staining, 242 -3; medullated fibres, staining of, $245-6$; degenerating fibres, staining of, 246

Spinal ganglion, 116-7, 122-3 ; fixing, 123 ; nerves, roots of, 233

Spindle of dividing cells, 288

Spleen, structure, 150-3; hardening after washing out, 154; injection of, 154 ; variation in structure, 155

Staining, double staining, eosin and methylene blue, 16,75 ; fluids, 28-9, 35-8, 41, 42, 30712 ; unimbedded sections, 35 ; hæmatoxylin and eosin, 40, 62; after-staining with picric acid, 41 ; triple atain, $41,42,311$; sections imbedded in paraffin, 43 ; in bulk, 62

Sterno-outaneous muscle (frog), preparation of nerve fibres in, 126

Stomach, cardiac end, 165-8; pyloric end, 168; circulation in newt, 169; hardening, 169; changes in digestion, 170

Stomach and intestine (frog), after feeding with fat, 176

Stria pinealis, 270

Subcutaneous tissue, fœtal or new-born mammal, 76 ; rat, 78 ; preparation of elastic fibres, 79

Sub-lingual gland, 163

Sub-maxillary gland (rabbit), 157-8 ; (dog), 159-61

Substantia nigra, 265, 266

Sudan III., for staining fat globules, 80 
Sulphuric acid and picric acid for hardening tissue, 302

Superior cerebellar peduncle, 260 Supra-renal body, 203, 205-6

Sweat glands, 209-10

Sympathetic nerves, 110-12 ; ganglia, 118, 121

Taste-buds, 216

Teasing, 293-4

Teeth, structure, 87-8 ; decalcification and fixing, 90

Tendon, structure, 71-2; hardening of, 78; preparation of elastic fibres, 79

Testis, structure, 280-3 ; hardening, 284 ; staining, 285

Thionin, 309

Thoma hæmacytometer, 25

Thoracic duct, section of, 147

Thymus, 204, 206

Thyroid gland, 202, 205

Tissues, observation of fresh, 65, 291-4; hardening and preserving, 295; simple $h$. agents, 296-9 : compound, 299-302; imbedding and cutting in celloidin, 303 ; transferring of sections, 313 ; treatment of living, with methylene blue, 321

Toluidin blue, 309

Tongue (frog), lymph sac, 149 ; mammal, 216-17; hardening and staining, 219

Tonsil, 147

Touch corpuscles, 211, 212

Trachea (mammal) 187,190

Trapezium fibres, 259

Turpentine, for clearing, 53, 59

Umbilical cord, 78
Unna's method of staining with orcein, 311

Unstriated muscle, 94-5; double oblique fibrillation, 95,97 ; isolation, 96-7; longitudinal fibrillation, 97; Unna's method of staining, 98

Ureter, 199, 200

Uterus (cat), 279-80; hardening, 284

Vagina (dog or cat), 283-4; hardening, 284

Vagus, section of, 112

Van Gieson, staining fluid, 310

Vas deferens, 283; hardening, 284

Veins, structure of, 134

Ventricle of heart, section, 96

Visual purple, 235

Weigert's hæmatoxylin solution, 289 ; fluid for hardening tissues, 301

Stain for medullated fibres, 215; modification by Pal, 245 ; modification by Kulschitzky and Wolters, 246

Stain for neuroglia, 247-8

White corpuscles (frog), 11-13, 17,18 ; $(\operatorname{man}), 22$; enumeration, 26

White fibrous tissue, staining of, 80

Worm, transverse section of, 96

Xylol, for clearing, 53 n., 59 ; mounting, 43

Zeiss, drawing prism, 30

Zenker's fluid for hardening tissue, 300 
By Sir MICHAEL FOSTER, K.C.B., AND Dr J. N. LANGLEY.

\section{A COURSE OF ELEMENTARY PRACTICAL} PHYSIOLOGY AND HISTOLOGY. By Sir M. Foster, K.C.B., and J. N. Langley, D.Sc. Seventh Edition, edited by J. N. Langley, D.Sc., F.R.S., and L. E. Shore, M.D. Crown 8vo. 7s. $6 d$.

By Sir MICHAEL FOSTER, K.C.B.

TEXT-BOOK OF PHYSIOLOGY. By Sir Michael Foster, K.C.B., M.D. With Illustrations. Sixth Edition, largely revised. In Four Parts.

Part I. Blood-The Tissues of Movement, the Vascular Mechanism. 10s. $6 d$.

Part II. The Tissues of Chemical Action, with their Respective Mechanisms-Nutrition. 10s. 6d.

Part III. The Central Nervous System. 10s. $6 d$.

Part IV. The Senses. 10s. $6 d$.

Appendix. The Chemical Basis of the Animal Body. By A. S. Lea, 7s. 6d.

PHYSIOLOGY FOR BEGINNERS. By Sir M. Foster, K.C.B., M.D., and Lewis E. Shore, M.A., M.D., Fellow of St John's College, Cambridge, and Senior Demonstrator of Physiology in the University of Cambridge. Globe 8 vo. 2s. $6 d$.

PhySIOLOGY. By Sir Michael Foster, K.C.B., M.D., Professor of Physiology in the University of Cambridge. With Illustrations. Pott 8vo. $1 s$.

[Science Primers.

\section{THE ELEMENTS OF EMBRYOLOGY. By Sir}

Michael Foster, M.A., M.D., LL.D., F.R.S., and the late F. M. Balfour, F.R.S., Professor of Animal Morphology in the University of Cambridge. Edited by A. SEDGwICK, and Walter Heape. Illustrated. Third Edition, revised and enlarged. Cr. 8vo. 10s. $6 d$. 


\section{WORKS ON PHYSIOLOGY AND ANATOMY.}

LESSONS IN ELEMENTARY PHYSIOLOGX. By Thos. H. HuxLex, F.R.S. Illustrated. Revised and Enlarged Edition. 4s. 6d. Questions, 1s. 6d.

ANATOMY AND PHYSIOLOGY FOR NURSES. By D. C. Kimber. 8vo. 10s. net.

GENERAL PHYSIOLOGY. An Outline of the Science of Life. By Max Verworn, M.D., Ph.D., A.O. Professor of Physiology in the Medical Faculty of the University of Jena. Translated from the Second German Edition, and Edited by Frederic S. LeE, Ph.D. With 285 Illustrations. Medium 8vo. 15s. net.

A TEXT-BOOK OF THE PHYSIOLOGICAL CHEMISTRY OF THE ANIMAL BODY, including an Account of the Chemical Changes occurring in Disease, By Arthur Gamaee, M.D., F.R.S. Vol. II., $18 s$.

ELECTRO-PHYSIOLOGY. By Prof. W. Biedermann. Translated by F. A. Welby. In 2 Vols. 17s, net each.

LESSONS IN ELEMENTARY ANATOMY. By St Ggorge Mivart, F.R.S., etc., late Lecturer on Comparative Anatomy at St Mary's Hospital. Fcap. 8vo. 6s. 6d, THE STRUCTURE OF MAN. By ROBERT WIEDER SHEIm, Professor of Anatomy in the University of Freiburg in Baden. Translated by H. M. Bernard. Revised by G. B. Howes. 8 vo. 8s. net.

ELEMENTS OF THE COMPARATIVE ANATOMY OF VERTEBRATES. Adapted from the German of Robert Wiedersheim by W. N. Parker. Med. 8vo. 12s. $6 d$. net.

THE PHYSICAL NATURE OF THE CHILD, AND HOW to STUDY IT. By Stuart H. Rowe, Ph.D. Ex. cr. 8 vo. 4 s. $6 d$. 


\section{WORKS ON BIOLOGY, etc.}

INTRODUCTORY PRIMER OF SCIENCE. By Prof. T. H. Hoxlewy, F.R.S. Pott 8vo. $1 s$.

[Science Primers. LESSONS IN ELEMENTARY BIOLOGY. By Prof. T. Jefrenry PARKer, B.Sc., F.R.S. Illustrated. Third Edition, revised. 10s. 6d.

ELEMENTARY BIOLOGY. By T. H. Huxley, F.R.S., and H. N. Martin, F.R.S. New Edition. Revised by G. B. Howes and D. H. Scotr. 10s. $6 d$.

THE LIVING ORGANISI. An Introduction to the Problems of Biology. By Alfred Eari, M.A. Crown 8 vo. $6 s$.

AN ATLAS OF PRACTICAL ELEMENTARY ZOOTOMY. Being a revised edition of the Zoological portion of the Atlas of Practical Elementary Biology. By G. B. Howes, LL.D., F.R.S. With a Preface to the First Edition by the Right Hon. T. H. HuxìeY, F.R.S.

[In the press.

ORGANIC EVOLUTION AS THE RESULT OF THE INHERITANCE OF ACQUIRED CHARACTERS ACCORDING TO THE LAWS OF ORGANIC GROWTH. By Dr G. H. T. Eimer. Translated by J. T. Cunningham, F.R.S.E. $8 \mathrm{vo}$. 12s. $6 d$.

Works by ALFRED RUSSEL WALLACE, F.R.S., LL.D.

DARWINISM : An Exposition of the Theory of Natural Selection. Crown 8vo. 9s.

NATURAL SELECTION: AND TROPICAL NATURE. New Edition. Crown 8vo. 6s.

ISLAND LIFE. New Edition. Crown 8vo. 6s. STUDIES SCIENTIFIC AND SOCIAL. 2 Vols. Extra Crown 8vo. 188. LONDON: MACMILLAN AND CO. LTD. 


\section{WORKS ON BIOLOGY, etc. (cont.).}

ON BRITISH WILD FLOWERS CONSIDERED IN RELATION TO INSECTS. By Lord AvEBURY, F.R.S. Illustrated. Crown 8vo. 4s. $6 d$. [Nature Series.

THE DEVELOPMEN'T OF THE FROG'S EGG. By T. H. Morgan, Ph.D. 8vo. 7s. net.

THEORY OF DEVELOPMENT AND HEREDITY. By H. B. OrR, Ph.D. Crown 8vo. 6s. net.

AMPHIOXUS, AND THE ANCESTRY OF THE VERTEBRATES. By A. Willey, B.Sc. 8vo. 10s. $6 d$. net.

THE CELL IN DEVELOPMENT AND INHERITANCE. By E. B. Wilson, Ph.D. 8vo. 14s. net.

THE SURVIVAL OF THE UNLIKE. By L. H. BaILey. Crown 8vo. 8s. $6 d$.

ARE THE EFFECTS OF USE AND DISUSE INHERITED? By W. Platt Ball. Crown 8vo. 3s. $6 d$. MATERIALS FOR THE STUDY OF VARIATION. By W. Bateson, M.A. Illustrated. 8vo. 21s. net.

EVOLUTION AND MAN'S PLACE IN NATURE. By Prof. H. Calderwood, Ll.D. Second Edition. 8vo. 10s. net.

EXPERIMENTAL MORPHOLOGY. By C. D. Davenport, Ph.D. Parts I. and II. 8vo. 9s. net each.

HUMAN EMBRYOLOGY. By Prof. G. S. Minot. 8 vo. 25s. net.

LONDON: MACMILLAN AND CO. LTD. 



\section{UNIVERSITY OF CALIFORNIA LIBRARY}

BERKELEY

Return to desk from which borrowed.

This book if DUE on the last date stamped below.

MAY 311950 


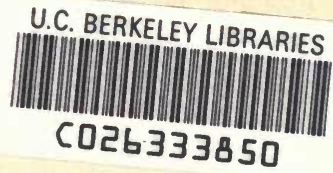


